

\author{
Antonio Gilson Barbosa de Lima \\ Maria Fátima David Dantas \\ Nívea Mabel de Medeiros \\ Júlia Medeiros Bezerra \\ José Jorge da Silva Júnior \\ Paulo César Sales da Silva \\ Sanduel Oliveira de Andrade \\ Samara Raquel Souza Ribeiro Andrade \\ (organizadores)
}

\title{
O Empoderamento Científico e seus Aspectos Inovadores Na interface do I SIMPEP
}

EDIC̃̃̃): I SIMPEP (SIMPÓSIO DE PÓS-GRADUAÇÃO EM ENGENHARIA DE PROCESSOS)

1a Edição

Belo Horizonte

Poisson

2020 
Editor Chefe: Dr. Darly Fernando Andrade

Conselho Editorial

Dr. Antônio Artur de Souza - Universidade Federal de Minas Gerais

Ms. Davilson Eduardo Andrade

Dra. Elizângela de Jesus Oliveira - Universidade Federal do Amazonas

Msc. Fabiane dos Santos

Dr. José Eduardo Ferreira Lopes - Universidade Federal de Uberlândia

Dr. Otaviano Francisco Neves - Pontifícia Universidade Católica de Minas Gerais

Dr. Luiz Cláudio de Lima - Universidade FUMEC

Dr. Nelson Ferreira Filho - Faculdades Kennedy

Ms. Valdiney Alves de Oliveira - Universidade Federal de Uberlândia

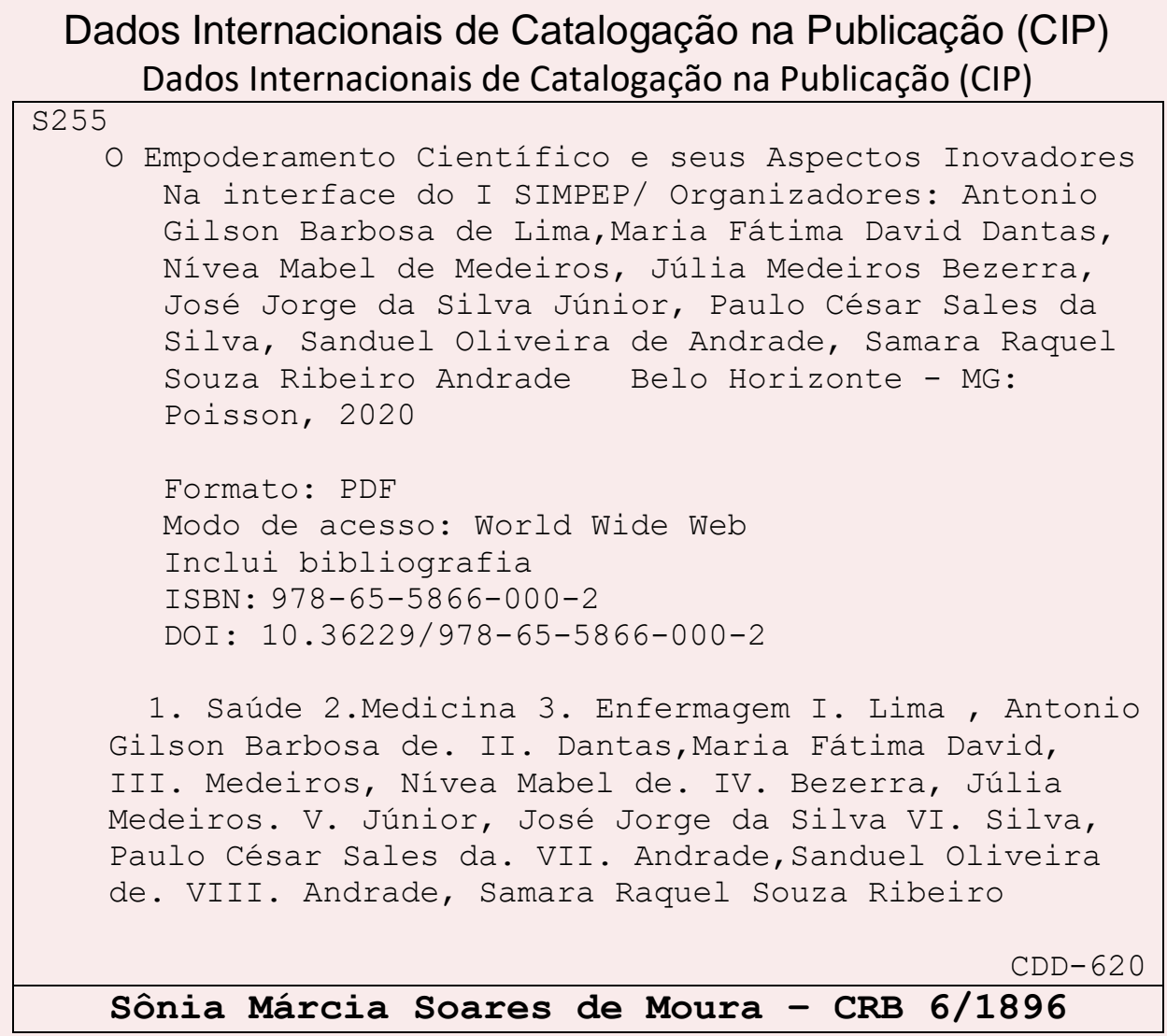

O conteúdo dos artigos e seus dados em sua forma, correção e confiabilidade são de responsabilidade exclusiva dos seus respectivos autores.

Baixe outros títulos gratuitamente em

www.poisson.com.br

contato@poisson.com.br 


\section{APRESENTAÇÃO}

O Primeiro Simpósio de Pós-Graduação em Engenharia de Processos (SIMPEP) intitulado: O Empoderamento Científico e seus aspectos inovadores, teve como objetivo articular um evento cientifico com aspectos multidisciplinar, transversal, e incentivar a publicação científica e o desenvolvimento de estudos inovadores. A realização do mesmo disseminou o conhecimento sobre o fenômeno do desenvolvimento de processos, bem como estimulou os participantes a externar a ciência, tecnologia e inovação com métodos científicos.

É possível através desses eventos garantir maior intercâmbio científico entre pesquisadores de áreas distintas que sejam detentores do saber científico relacionado aos processos. Para a comunidade científica foi possível oportunizar saberes voltados à diversas áreas, fomentar divulgação de tal discussão e debater propostas que visem a produção de conhecimento na perspectiva da interdisciplinaridade.

O Livro o Empoderamento científico e seus aspectos inovadores, expõem as linhas de pesquisas discutida no evento, na qual encontram se dentre as três unidades expressadas no sumário. Os capítulos foram sistematizados a partir da unidade pertencente, bem como sobre o olhar da área de pesquisa dos autores. É perceptível que por se ponderar de interdisciplinaridade a engenharia de processos, os conteúdos nos capítulos expandem abordagem multidisciplinar, permitindo aos leitores uma diversidade na leitura, assim como propondo discussão cientifica em áreas distintas.

Esperamos que você leitor aplique os seus aspectos inovadores ponderando se de acervos científicos que lhe desperte para uma interdisciplinaridade versus multidisciplinaridade. 


\section{PREFÁCIO}

Este e-book coloca em evidência os trabalhos completos apresentados no I Simpósio de Pós- Graduação em Engenharia de Processos, que teve como tema "O Empoderamento Científico e seus Aspectos Inovadores". Organizado pelo Programa de Pós-Graduação em Engenharia de Processos (PPGEP) da Universidade Federal de Campina Grande (UFCG), o Simpósio apresentou um caráter multidisciplinar transversal, incluindo as áreas de Engenharia, Ciências da Saúde, Exatas e da Terra e Ciências Agrárias, e como objetivo, divulgar o estágio de desenvolvimento de estudos inovadores nas áreas citadas.

A presente publicação conta com 18 capítulos divididos em três Unidades, a saber, Processos Térmicos e de Separação, Desenvolvimento e Tecnologia de Materiais e Bioprodutos. Estes capítulos tratam de temas tais como o desenvolvimento de um secador solar de exposição indireta, caracterização reológica e térmica de blendas de pet reciclado, secagem de sementes de sorgo e de banana nanica, obtenção de corante natural do pimentão vermelho, compostos bioativos do pimentão amarelo, compostos bioativos do alho, gargalos do processo produtivo de mel, avaliação do ruído ocupacional em determinada empresa, avaliação de parâmetros respiratórios em operários de empresa de produção de brita e incidência de anemia ferropriva em crianças de uma creche municipal. Estes temas são uma prova da multidisciplinaridade do evento.

Os trabalhos científicos foram apenas uma parte das atividades desenvolvidas no Simpósio. Ocorreram também palestras, tais como "O empoderamento científico e seus aspectos inovadores para a ciência e sua interdisciplinaridade" e "Discutindo a modelagem atual da turbulência"; mesas-redondas como "A inovação e seus impactos no desenvolvimento de novos produtos e processos" e minicursos como "Microencapsulação por spray drying: teoria e prática", "Programação aplicada à pesquisa usando software Wolfram Mathematica", "Fermentação em estado sólido: fundamentação e estudo de caso", "Escoamento multifásico nas engenharias" e "Uso de OpenFoam para análise em CFD".

Todas estas atividades, incluindo o presente e-book, mostram a relevância desta primeira edição do Simpósio de Pós-Graduação em Engenharia de Processos e você, leitor, se deseja se informar sobre os desenvolvimentos inovadores em Engenharia de Processos e áreas correlatas, não deve perder as próximas edições desse Simpósio.

Ricardo A. Medronho Professor Emérito da UFRJ

Coordenador de Avaliação Institucional da UFRJ Presidente do Conselho Superior da ABEQ 


\section{ORGANIZADORES}

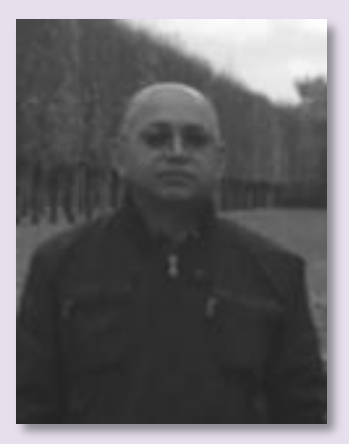

ANTONIO GILSON BARBOSA DE LIMA - Coordenador do Programa de Pós Graduação em Engenharia de ProcessosPPGEP

Graduado em Engenharia Mecânica pela Universidade Federal da Paraíba (1991). Graduado em Licenciatura Plena em Física pela Universidade Estadual da Paraíba (1990). Mestre em Engenharia Mecânica pela Universidade Federal da Paraíba (1995) e Doutor em Engenharia Mecânica pela Universidade Estadual de Campinas (1999). Atualmente é Professor Titular do Departamento de Engenharia Mecânica, do Centro de Ciências e Tecnologia, da Universidade Federal de Campina Grande. Tem experiência na área de Engenharia Mecânica, com ênfase em Transferência de calor e massa, Escoamento fluido, Matemática aplicada, Princípios Variacionais e Métodos Numéricos, atuando principalmente nos seguintes temas: volumes finitos, secagem e desenvolvimento de secadores, escoamento multifásico e meios porosos. Tem publicado um número expressivo de artigos em periódicos de relevância, livros e capítulos de livros em editoras de reconhecida competência internacional e formado recursos humanos de alto nível (Graduação, mestrado e doutorado).

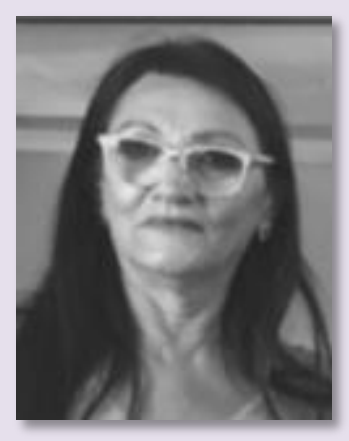

MARIA FÁTIMA DAVID DANTAS- Secretária do Programa de Pós Graduação em Engenharia de Processos- PPGEP

Graduada em Recursos Humanos pela UNIP. Mestre em Sistemas Agroindustriais pela UFCG. Servidora pública da Universidade Federal de Campina Grande-UFCG, exercendo o cargo de assistente em administração, com função de secretaria do Programa de Pós Graduação em Engenharia de Processos-PPGEP.

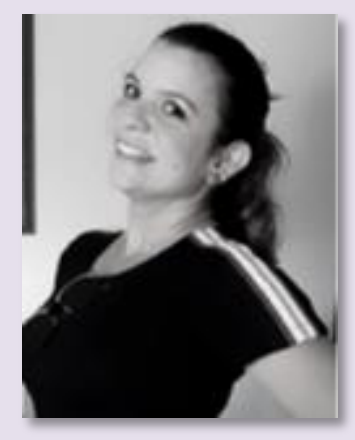

\section{NÍVEA MABEL DE MEDEIROS- Presidente do SIMPEP}

Doutoranda no Programa de Pós Graduação em Engenharia de Processos -PPGEP pela UFCG/CCT (Atual). Mestre em Sistemas Agroindustriais pela UFCG/CCTA (2017) Especialista em Saúde da Família pela Faculdade Integradas de Patos - FIP (2014). Bacharel em Enfermagem pela Faculdade Integrada de Patos- FIP (2012). Membro do Grupo de Pesquisa Violência e Saúde -UFCG/CNPq. Atua em pesquisas nos eixos temáticos das áreas da Ciência da Saúde Humana. 


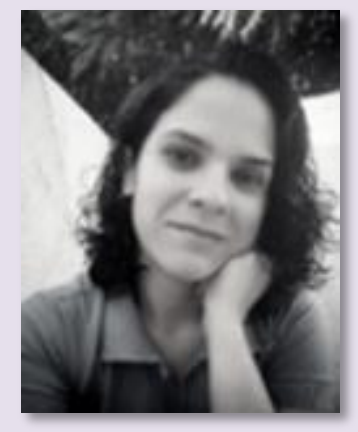

JÚLIA MEDEIROS BEZERRA- VICE-PRESIDENTE SIMPEP

Graduada em Engenharia de Alimentos (2012) pela Universidade Federal de Campina Grande, Mestre em Sistemas Agroindustriais (2015) pela mesma instituição. Doutoranda em Engenharia de Processos também pela Universidade Federal de Campina GrandeUFCG. Atua em pesquisas das áreas de: ciência e tecnologia de alimentos, com ênfase em tecnologia de produtos de origem vegetal, fisiologia e pós-colheita, transformações bioquímicas, compostos bioativos e antioxidantes assim como também na elaboração de novos produtos.

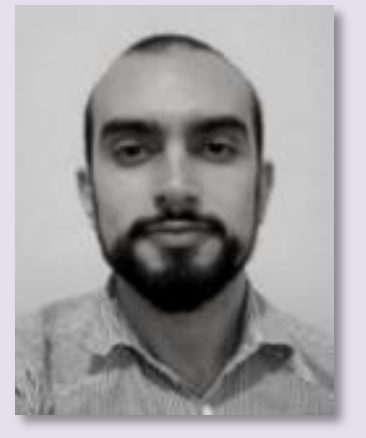

\section{JOSÉ JORGE DA SILVA JÚNIOR- PRODUTOR DE MARKTING SIMPEP}

Graduado em Engenharia Mecânica pela Universidade Federal de Campina Grande (2014), atuando principalmente nos seguintes temas: energia solar e secagem de frutas. Mestre em Engenharia Mecânica pela Universidade Federal de Campina Grande (2017), atuando na linha de pesquisa: Projeto e Análise de Sistemas Termomecânicos com ênfase em Termografia aplicada à análise de óleos em ensaios de atrito cisalhante. Doutorando do Programa de Pós-graduação em Engenharia de Processos da Universidade Federal de Campina Grande - UFCG, atuando na linha de pesquisa de Processos Térmicos e de Separação.

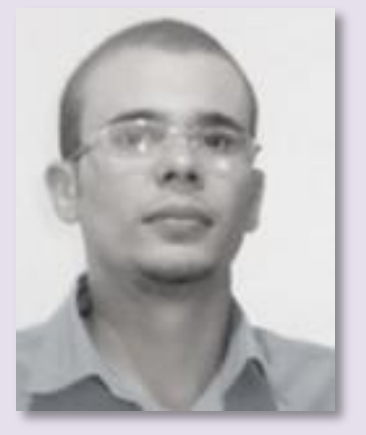

\section{PAULO CÉSAR SALES DA SILVA}

Graduado em Engenharia Mecânica pela UFCG (2016). Mestre em Engenharia Mecânica pela UFCG (2018). Doutorando do Programa de Pós-graduação em Engenharia de Processos da Universidade Federal de Campina Grande - UFCG. Atua na área de mecânica dos sólidos e simulação computacional. 


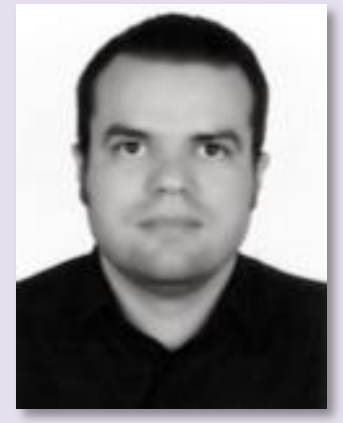

\section{SANDUEL OLIVEIRA DE ANDRADE}

Engenheiro Agrônomo pela Universidade Federal de Campina Grande (UFCG) / Licenciado em Ciências Biológicas pela Universidade Pitágoras Unopar/ Especialista em Geoprocessamento pelas Universidades Integradas de Patos (FIP) e em Educação Ambiental e Geografia do Semiárido pelo Instituto Federal do Rio Grande do Norte (IFRN)/ Mestre em Sistemas Agroindustriais pela Universidade Federal de Campina Grande (UFCG)/ Doutorando em Engenharia de Processos também pela Universidade Federal de Campina Grande (UFCG). Professor efetivo da rede municipal de Ensino de Patos-PB. Pesquisador do Núcleo de Saneamento e Economia Ambiental (NUSEA) vinculado à Universidade Federal de Campina Grande (UFCG).

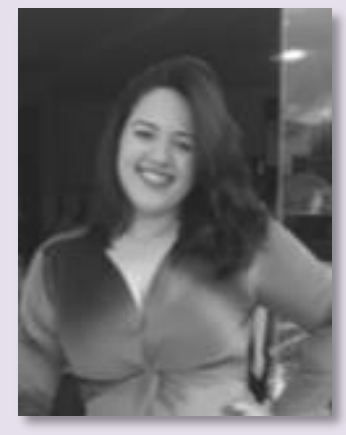

\section{SAMARA RAQUEL SOUZA RIBEIRO ANDRADE}

Licenciada em Química - IFPB/ Mestre em Sistemas Agroindustriais - UFCG/ Doutoranda em Engenharia de Processos - UFCG/ Atualmente professora substituta no IFPB campus Picuí-PB

\section{COLABORADORES}

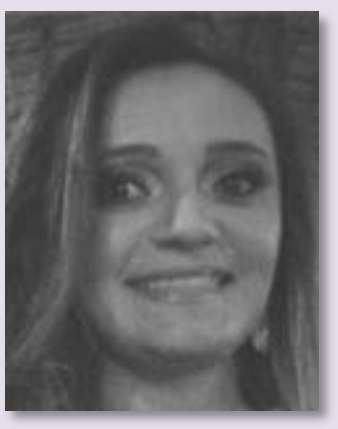

\section{AMANDA SILVA DA COSTA}

Graduação em Engenharia Floresta pela UFCG. Mestrado em Ciências Florestais pela UFCG. Doutoranda em Engenharia de Processos - UFCG.

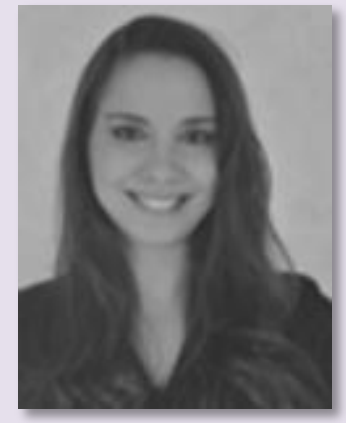

\section{ANA CAROLINA NÓBREGA LEITE}

Graduada em Química Industrial (2016) pela Universidade Federal da Paraíba, Mestre em Engenharia Química (2018) - Processos de Separação pela mesma instituição e Doutoranda em Engenharia de Processos - Processos Térmicos e de Separação pela Universidade Federal de Campina Grande. 


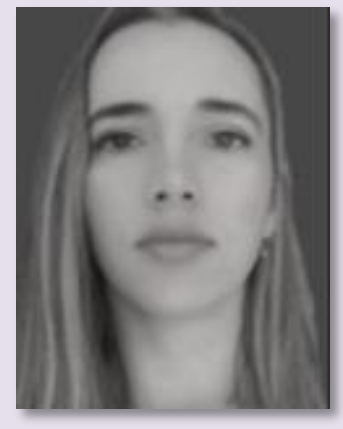

\section{ANA MARINHO DO NASCIMENTO}

Engenheira de Alimentos pelo Centro de Ciências e Tecnologia Agroalimentar (UFCG). Mestre pelo Programa de Pós-Graduação em Sistemas Agroindustriais (UFCG). Doutoranda em Engenharia de processos (UFCG).

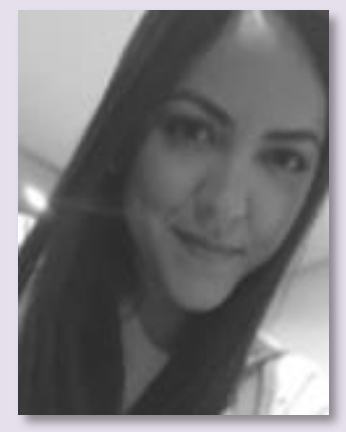

\section{ISIS DA SILVA RODRIGUES}

Engenheira de Petróleo e Engenheira de Segurança do Trabalho. Mestre em Exploração Petrolífera e Mineral. Especialista em Docência do Ensino superior. Doutoranda em Engenharia de Processos (UFCG). Atualmente é revisora da Revista Verde de Agroecologia e Desenvolvimento Sustentável.

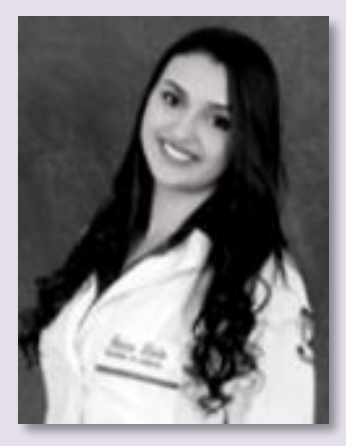

\section{JÉSSICA LEITE DA SILVA}

Engenheira de Alimentos pela Universidade Federal de Campina Grande (UFCG/2010-2015), Mestre em Sistemas Agroindustriais (UFCG/2015-2017) e Doutoranda em Engenharia de Processos (UFCG/2017-atual).

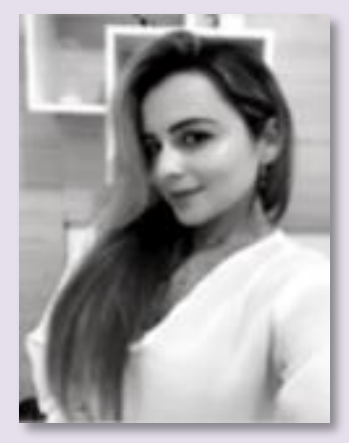

\section{JORDANY RAMALHO SILVEIRA FARIAS}

Graduação em Farmácia pela Faculdade Santa Maria de Cajazeiras. Especialização em Análises Clínicas pela Faculdade Leão Sampaio. Especialização em Gestão Pública Municipal pela Universidade Federal da Paraíba, UFPB. Especialização em Farmacologia Clínica pela Regional do Cariri, URCA. Especialização em Farmácia Estética pelas Faculdades Integradas de Patos. Mestrado Profissional em Sistemas Agroindustriais pela UFCG. Doutoranda em Engenharia de Processos pela UFCG. 


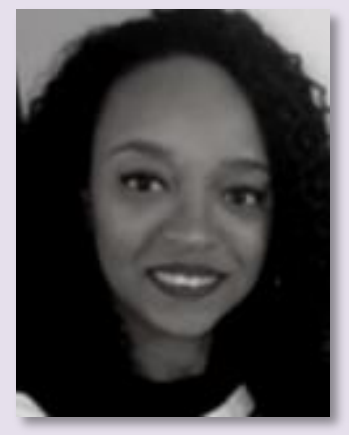

\section{NANCY LIMA COSTA}

Graduada em Matemática e Mestre em Matemática. Licenciada em Matemática (UEFS); Mestre em Matemática (UFCG); Doutoranda em Engenharia de Processos (UFCG). Professora Assistente da Universidade de Pernambuco Campus Petrolina.

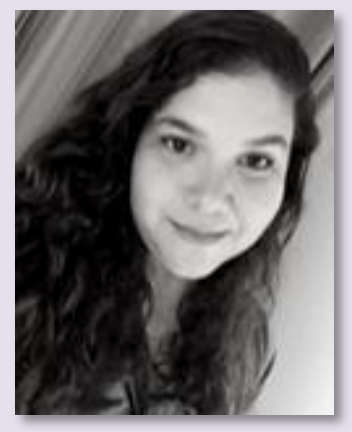

\section{YAROSLÁVIA FERREIRA PAIVA}

Engenheira de Alimentos e Mestre em Sistemas Agroindustriais pela Universidade Federal de Campina Grande-UFCG, possui MBA em Gestão e Engenharia de Produção, Doutoranda em Engenharia de Processos (UFCG).

\section{CORPO DOCENTE COLABORADOR}

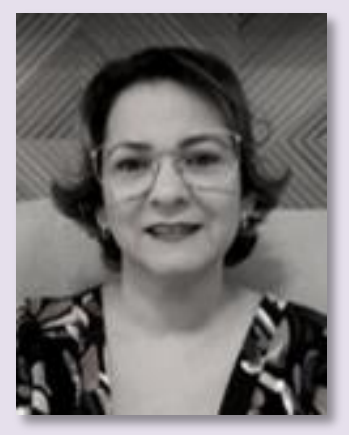

\section{ANA PAULA TRINDADE ROCHA}

Doutora em Engenharia de Processos pela UFCG, Pós-Doutorado na Newcastle University-UK. Mestre em Engenharia de Química (UFCG). Graduada em Engenharia Química (UFCG).

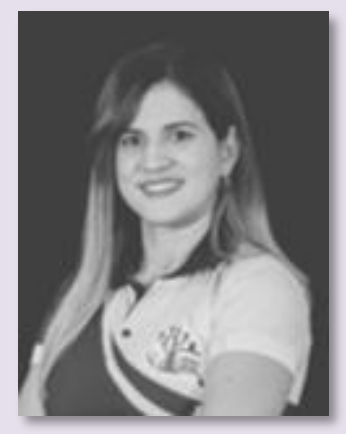

\section{MARIA BERENICE GOMES NASCIMENTO}

Bacharel em Enfermagem pela UFPB. Mestre em Saúde Coletiva. Doutoranda em Ciências da Saúde pela Faculdade de Medicina do ABC. Membro do Grupo de Pesquisa LATICS/UFCG. Professora da Universidade Federal de Campina Grande UFCG campus de Cajazeiras. 


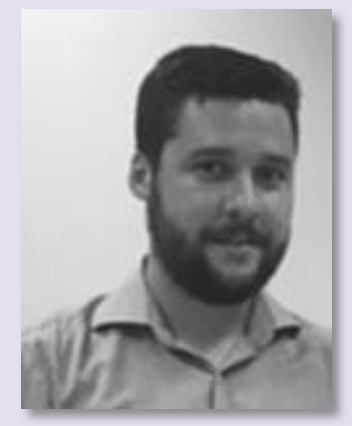

\section{BONIEK EVANGELISTA LEITE}

Graduado em Química Industrial pela Universidade Estadual da Paraíba. Mestre em Engenharia Mecânica. Doutor em Engenharia de Processos pela Universidade Federal de Campina Grande (UFCG). Atualmente é pesquisador do Doutorado do Programa de PósGraduação em Engenharia de Processos da UFCG, atuando na área de simulação computacional de escoamentos multifásicos, fenômenos de combustão de biocombustíveis e rendimento térmico de motores de combustão interna.

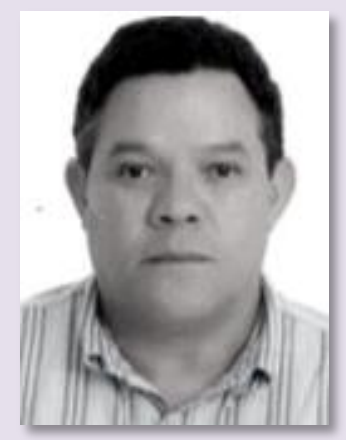

\section{JOSÉ JEFFERSON DA SILVA NASCIMENTO}

Graduado em Engenharia Mecânica pela Universidade Federal da Paraíba (1988); Mestre em Engenharia Mecânica pela Universidade Federal da Paraíba (1995) e Doutor em Engenharia Mecânica pela Universidade Federal da Paraíba (2002). Formação em geração solar fotovoltaica: projeto, legislação e instalação. Atualmente é Professor titular da Universidade Federal de Campina Grande. Docente e orientador no Programa de Pós Graduação em Engenharia de Processos. Tem experiência na área de Engenharia de Materiais e Metalúrgica, com ênfase em Cerâmicos, atuando principalmente nos seguintes temas: secagem, experimental, cerâmica, simulação, fluidodinâmica

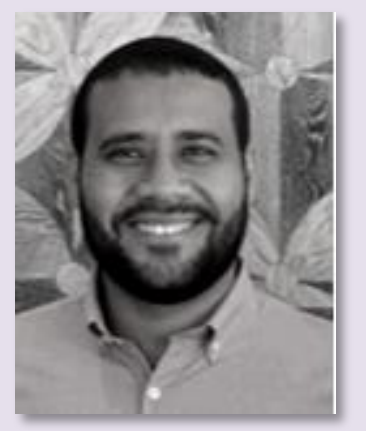

\section{VALDECIR ALVES DOS SANTOS JÚNIOR}

Graduado em Matemática pela Universidade Federal do Maranhão UFMA (2009), Mestre em Matemática pela Universidade Federal da Paraíba - UFPB (2011) e Doutor em Engenharia de Processos pela Universidade Federal de Campina Grande - UFCG (2018), trabalha com transporte de fluido com ênfase no Método Integral baseado em Galerkin; Modelagem numérica; Meio poroso. Professor da Universidade Estadual da Paraíba-UEPB no Centro de Ciências, Tecnologia e Saúde - Campus VIII, Araruna-PB. 


\section{Sumário}

\section{UNIDADE I - PROCESSOS TÉRMICOS E DE SEPARAÇÃO}

Capítulo 1: Análise da distribuição do tamanho de particula por diferentes métodos........16

Ligia Mara Gonzaga, Severino Rodrigues de Farias Neto, Elias Nunes Filho, Manuel José Andrade Romero DOI: $10.36229 / 978-65-5866-000-2 . C A P .01$

Capítulo 2: Evolução do desenvolvimento do secador solar de exposição indireta na UFCG .23

Nancy Lima Costa, Jonas Fernando de Souza Fernandes, Ítalo de Andrade Gomes, Maria de Sousa Leite Filha, João Marcos Domingues Botelho, Marcelo Bezerra Grilo

DOI: $10.36229 / 978-65-5866-000-2 . C A P .02$

Capítulo 3: Caracterização reológica e térmica de blendas de pet reciclado com pead compatibilizadas com Anidrido Maleico

Raquel Marques dos Santos, Antonio Gilson Barbosa de Lima

DOI: $10.36229 / 978-65-5866-000-2 . C A P .03$

Capítulo 4: Gradientes de temperatura e pressão: Um risco de dano industrial em tubulações industriais .48

Adriano de Sousa Cabral, Fabiany Bento da Silva, Herllange Chaves de Brito, José Jefferson da Silva Nascimento, Rubenia de Oliveira Costa DOI: $10.36229 / 978-65-5866-000-2 . C A P .04$

Capítulo 5: Cinética de secagem de sementes de Sorgo (Sorghum Bicolor 1. Moench) e avaliação física e química da farinha.

Antonio Daniel Buriti de Macedo, Ana Paula Moisés de Sousa, Renato Alexandre Costa de Santana, Ana Regina Nascimento Campos, Josivanda Palmeira Gomes

DOI: $10.36229 / 978-65-5866-000-2 . C A P .05$

Capítulo 6: Comportamento fluidodinâmico da interface água- ar: Modelagem e simulação . .67

Marcella Mayara Costa Araújo Aragão, Severino Rodrigues Farias Neto, Boniek Evangelista Leite DOI: $10.36229 / 978-65-5866-000-2 . C A P .06$

Capítulo 7: Cinética de secagem de banana nanica utilizando modelos empíricos .80

Emmanuel Fabiano Marques da Silva, Arnaldo Bezerra Lopes de Almeida, Fagno Dallino Rolim, José Jefferson da Silva Nascimento

DOI: $10.36229 / 978-65-5866-000-2 . C A P .07$ 
Capítulo 8: Composição centesimal e compostos bioativos do alho refrigerado ..... .92

Charlene Maria Alcântara, Ana Marinho do Nascimento, Jéssica Leite da Silva, Tatiana Marinho Gadelha, Larissa Félix Macêdo, Franciscleudo Bezerra da Costa

DOI: $10.36229 / 978-65-5866-000-2 . C A P .08$

\section{UNIDADE II - DESENVOLVIMENTO E TECNOLOGIA DE MATERIAIS}

Capítulo 9: Avaliação do ruído ocupacional em uma empresa localizada em Campina Grande, Paraíba

Isis da Silva Rodrigues, Yaroslávia Ferreira Paiva, Herusca Hellyca Souza de Medeiros, Plínio Tércio Medeiros de Azevedo

DOI: 10.36229/978-65-5866-000-2.CAP.09

Capítulo 10: Principais gargalos do processo produtivo de mel no estado da Paraíba utilizando o método AHP

Alan Dél Carlos Gomes Chaves, Aline Costa Ferreira, Herllange Chaves de Brito, José Jefferson da Silva Nascimento, Rubenia de Oliveira Costa, Wilson Luiz dos Santos Filho

DOI: $10.36229 / 978-65-5866-000-2 . C A P .10$

Capítulo 11: Avaliação de parâmetros respiratórios em operários de empresas de produção de brita na cidade de Cajazeiras - PB 112

Jordany Ramalho Silveira Farias, Ana Carolina Nóbrega Leite, Pablo Antônio Maia de Farias

DOI: 10.36229/978-65-5866-000-2.CAP.11

Capítulo 12: Incidência de anemia ferropriva em crianças de uma creche municipal na cidade de Piancó - PB 120

Victor Vinícius Lins Nunes, Alanna Michely Batista de Morais, Heloisa Farias Gonzaga DOI: 10.36229/978-65-5866-000-2.CAP.12

Capítulo 13: Corante natural do pimentão vermelho: Obtenção e caracterização 127

Plínio Tércio Medeiros de Azevedo, Yaroslávia Ferreira Paiva, Agda Malany Forte de Oliveira, Dayanne Kelly Pereira Abreu, Alfredina dos Santos Araújo

DOI: $10.36229 / 978-65-5866-000-2 . C A P .13$

\section{UNIDADE III - BIOPRODUTO}

Capítulo 14: Qualidade físico-química e compostos bioativos no pimentão vermelho 133

Tatiana Marinho Gadelha, Ana Marinho do Nascimento, Jéssica Leite da Silva,, Charlene Maria Alcântara, Larissa Félix Macêdo, Franciscleudo Bezerra da Costa DOI: 10.36229/978-65-5866-000-2.CAP.14 
Capítulo 15: Características físico-químicas e compostos bioativos do pimentão amarelo

Ana Marinho do Nascimento, Jéssica Leite da Silva, Tatiana Marinho Gadelha, Charlene Maria Alcântara, Larissa Félix Macêdo, Franciscleudo Bezerra da Costa

DOI: $10.36229 / 978-65-5866-000-2 . C A P .15$

Capítulo 16: Qualidade físico-química de Cladódios jovens de palma minimamente processados 150

Larissa Félix Macêdo, Ana Marinho do Nascimento, Jéssica Leite da Silva, Tatiana Marinho Gadelha, Charlene Maria Alcântara, Franciscleudo Bezerra da Costa

DOI: $10.36229 / 978-65-5866-000-2 . C A P .16$

Capítulo 17: Corante natural do pimentão vermelho aplicado em gelados comestíveis....158 Yaroslávia Ferreira Paiva, Plínio Tércio Medeiros de Azevedo, Dayanne Kelly Pereira Abreu, Agda Malany Forte de Oliveira, Alfredina dos Santos Araújo

DOI: $10.36229 / 978-65-5866-000-2 . C A P .17$

Capítulo 18: Coloração de frutos de Juazeiro armazenados sob temperatura controlada ..165 Jéssica Leite da Silva, Ana Marinho do Nascimento, Tatiana Marinho Gadelha, Larissa Félix Macêdo, Charlene Maria de Alcântara, Franciscleudo Bezerra da Costa

DOI: $10.36229 / 978-65-5866-000-2 . C A P .18$

Autores: 


\section{Unidade I}

Processos Térmicos e de Separação 


\section{Capítulo 1}

Análise da distribuição do tamanho de particula por diferentes métodos

\section{Ligia Mara Gonzaga \\ Severino Rodrigues de Farias Neto \\ Elias Nunes Filho \\ Manuel José Andrade Romero}

Resumo: A distribuição de tamanhos de partículas é uma das variáveis mais importantes em processamento mineral, e existem diversos métodos diretos e indiretos para a sua determinação. Contudo, quando uma partícula se distancia de uma esfera os resultados gerados por diferentes métodos necessariamente divergem quando comparados ou quando há um cruzamento dos dados, sendo necessário a aplicação de fatores de correção. Neste trabalho foram medidas as distribuições de tamanho de partículas, obtidas utilizando o cicloclassificador, a pipeta de Andreasen o granulômetro a laser e o peneiramento convencional, para análise de uma amostra de fosfato.

Palavras Chave: Fosfato; Partícula; Granulometria. 


\section{INTRODUÇÃO}

A avaliação das características das partículas é de vital importância no tratamento de minérios. Em alguns casos torna-se simples quando se visa apenas uma adequação de tamanho. Em outros, casos torna-se mais complexa quando representa uma variável de controle nos processos de cominuição, classificação e concentração [1].

Para obtenção da distribuição de tamanhos de partículas existem diversos métodos diretos e indiretos para a sua determinação. Contudo, os resultados gerados por diferentes métodos necessariamente divergem quando comparados ou quando há um cruzamento dos dados.

0 método de determinação da distribuição de tamanhos de partículas mais utilizado na área de tecnologia mineral é o tamanho de peneira, que é obtido por peneiramento em uma malha quadrada. 0 limite prático para o peneiramento em laboratório é de $37 \mu \mathrm{m}$. A determinação da distribuição de tamanhos por peneiramento de partículas finas, menores que $37 \mu \mathrm{m}$ é, no entanto, considerada pouco eficiente, as peneiras mais finas são relativamente frágeis, susceptíveis a perfurações e deformações, além disso, a malha mais fina comercialmente disponível no mercado é a de $20 \mu \mathrm{m}$, tornando-se impraticável a aplicação do peneiramento [2]. Nesse contexto, outras metodologias de distribuição de tamanho de partículas, utilizando equipamentos que medem outras grandezas físicas e as recalculam para distribuições de diâmetros de esferas equivalentes.

As partículas de interesse no processamento mineral não apresentam formatos regulares como esferas e cubos o que proporcionaria uma melhor analogia. Nesse contexto, uma medida indireta de tamanho é normalmente empregada em tecnologia mineral [3].

Nesse contexto, esse trabalho tem como objetivo descrever as diferentes técnicas de medida de distribuição de tamanho de partículas, a fim de obter a distribuição granulométrica do material analisado e fazer comparações entre os diferentes métodos aplicados.

\section{TÉCNICAS DE ANÁLISE DE TAMANHO DE PARTÍCULA}

\subsection{PENEIRAMENTO}

0 peneiramento é um dos métodos mais antigos na área de processamento mineral, é normalmente realizado com o auxílio de máquinas vibratórias, que utilizam oscilações e vibrações. Em termos técnicos, o peneiramento é compreendido como um processo de classificação de partículas por tamanho, que corresponde ao fracionamento de partículas usando uma série de peneiras com aberturas decrescentes [4].

Essa técnica permiti a separação da amostra em frações de tamanhos de partículas conhecidas, as quais podem ser analisadas quanto à composição química, mineralógica ou densimétrica.

O limite inferior prático para o peneiramento em laboratório é, compreende a faixa granulométrica, de 37 $\mu \mathrm{m}$ [2]. Embora peneiras com aberturas ainda menores encontrem-se disponíveis, a obtenção de resultados confiáveis é considerada pouco eficientes.

\subsection{SEDIMENTAÇÃO E ELUTRIAÇÃO}

As técnicas de elutriação e sedimentação são as mais frequentemente usadas na análise de tamanhos de partículas abaixo do intervalo normalmente empregado no peneiramento. Dentre as técnicas mais usadas estão a elutriação centrífuga (usando o aparelho conhecido como cicloclassificador, ou Cyclosizer $囚$ ) e a sedimentação gravitacional usando a pipeta de Andreasen ou o Sedígrafo (Sedigraph®) [5].

\subsubsection{CICLOCLASSIFICADOR}

A classificação de minérios pode ser feita por elutriação centrífuga utilizando um conjunto de hidrociclones ligados em série. 0 cicloclassificador foi desenvolvido como uma ferramenta para a análise granulométrica de materiais abaixo do intervalo normalmente empregado no peneiramento, na faixa de, aproximadamente, 10 a $50 \mu \mathrm{m}$, para materiais com densidade similar à do quartzo $\left(2,65 \mathrm{~g} / \mathrm{cm}^{3}\right)[6]$.

0 cicloclassificador apresenta uma sequência de cinco hidrociclones invertidos de $75 \mathrm{~mm}$ de diâmetro com diâmetros de vortex finder decrescentes, sendo que o produto de cada vortex finder é a alimentação do 
ciclone seguinte. Entre 10 e 20 g de sólidos são empolpados em água e alimentados lentamente através do conjunto de ciclones a partir de um recipiente. Cada ciclone "corta" a um dado tamanho de partícula, sendo as dimensões limite de separação para o cicloclassificado, nas condições padrão para os ciclones de 1 a 5 são 44, 33, 23, 15 e $11 \mu \mathrm{m}$, respectivamente, sendo os valores padrão: Vazão da água 696 l/h, Temperatura da água $20^{\circ} \mathrm{C}$, Massa específica $2,65 \mathrm{~g} / \mathrm{cm}^{3}$ e Tempo de elutriação equivalente ao infinito.

O tamanho real de corte em cada ciclone é, então, modificado por uma série de fatores de correção. A correção das variáveis é feita por meio de gráficos ou equações dos quais se obtém um fator de correção para cada variável, dentro da faixa operacional especificada. Nesta etapa utilizam-se os fatores de correção das quatro variáveis, multiplicando-os pela dimensão limite de separação de cada hidrociclone [7]. Para cada hidrociclone, a relação entre as dimensões limite e a efetiva de separação das partículas é dada pela Equação 1:

$$
d_{e=d_{i} * f_{1} * f_{2} * f_{3} * f_{4}}
$$

Onde:

$\mathrm{d}_{\mathrm{e}}$ - dimensão efetiva de separação das partículas;

$\mathrm{d}_{\mathrm{i}}$ - dimensão limite de separação do hidrociclone;

$\mathrm{f}_{1}$ - fator de correção da temperatura ajustada à da análise (Equação 2);

$\mathrm{f}_{2}$ - fator de correção da massa específica da partícula (Equação 3);

$\mathrm{f}_{3}$ - fator de correção da vazão real de água para o ensaio (Equação 4);

$\mathrm{f}_{4}$ - fator de correção do tempo real utilizado (Equação 5).

\subsubsection{PIPETA DE ANDREASEN}

A pipeta de Andreasen consiste de um cilindro graduado ( 0 a $20 \mathrm{~cm}$ de altura) e volume entre 500 e 600 mL. Por meio do uso da pipeta de Andreasen, as partículas sedimentam sob a influência da força da gravidade. É uma técnica de análise granulométrica que se baseia na lei de Stokes [8].

0 intervalo de tamanho típico de aplicação dessa técnica é de 100 a $1 \mu \mathrm{m}$. Uma das vantagens do método são a simplicidade e o baixo custo do equipamento. Entretanto, desvantagens do método estão associadas ao fato que a suspensão é perturbada toda vez que uma amostra é retirada. Além disso, o volume da suspensão diminui após a retirada de cada amostra, alterando a altura de sedimentação.

Para o cálculo da velocidade terminal, e tamanho de partículas será utilizado o do método de ConchaAlmendra (Equações 2 a 4).

$$
\begin{aligned}
& V_{\infty}^{*}=\left[\frac{3 \rho_{f}^{2}}{4\left(\rho_{s}-\rho_{f}\right) \mu}\right]^{1 / 3} V_{\infty} \\
& d_{p}^{*}=0,07\left[\left(1+\frac{68,49}{V_{\infty}^{* 3 / 2}}\right)^{1 / 2}+1\right]^{2} V_{\infty}^{* 2} \\
& d_{p}=\left[\frac{3 \mu^{2}}{4\left(\rho_{s}-\rho_{f}\right) \rho_{f}}\right]^{1 / 3} d_{p}^{*}
\end{aligned}
$$

Onde:

$$
\begin{aligned}
& \boldsymbol{V}_{\infty}^{*} \text { - velocidade terminal adimensional; } \\
& \boldsymbol{\rho}_{\boldsymbol{f}} \text { - densidade do fluido; } \\
& \rho_{s} \text { - densidade do sólido; } \\
& \mu \text { - viscosidade do fluido; } \\
& V_{\infty} \text { - velocidade terminal; } \\
& d_{p}^{*} \text { - tamanho de partícula adimensional; } \\
& d_{p} \text { - tamanho de partícula. }
\end{aligned}
$$




\subsubsection{DIFRATÔMETRO A LASER}

O Granulômetro a laser é um equipamento que possibilita as medidas em diversos meios: ar, suspensões, emulsões e aerossóis. Possui amplitude de 0,01 a $3500 \mu \mathrm{m}$, dependendo do equipamento, sendo a faixa de aplicação recomendada de 0,1 a $3000 \mu \mathrm{m}$ [9].

O Mastersizer 2000 é um aparelho que realiza uma medição rápida e confiável de uma ampla variedade de amostras, com alta resolução. 0 equipamento possui um sistema de detectores com luz vermelha, que detectam o espalhamento frontal, lateral e posterior. Possui uma fonte de luz vermelha é o Laser néon de Hélio, cujo comprimento de onda define a faixa de tamanho de partícula que o aparelho mede [10].

Para a elaboração das curvas de distribuição granulométrica podem ser utilizados dois princípios de medida denominados: Mie e Fraunhofer. A teoria de Mie descreve a medida de tamanho de partícula por esferas homogêneas de tamanho arbitrário. Para partículas não esféricas, a teoria de Mie considera o diâmetro esférico equivalente por volume-peso. Nesse caso é necessário que se saiba o índice de refração da partícula.

Essa teoria não tem limitação quanto ao tamanho de partícula a ser medido, e apresenta uma teoria é a mais rigorosa, gerando resultados bem próximos à realidade. Com relação à teoria de Fraunhofer, essa por ser uma aproximação, não leva em consideração o índice de refração do material. Ela apresenta uma grande limitação, pois para partículas muito pequenas, com tamanho muito inferior ao comprimento de onda do feixe a ser utilizado, o resultado apresenta um maior erro. Além disso, partículas planas ou transparentes não podem ser medidas através dessa teoria [11].

\section{MATERIAL E MÉTODOS}

Foi utilizada uma amostra de fosfato. A metodologia utilizada neste estudo envolveu cinco etapas

$\checkmark \quad$ Preparação das amostras;

$\checkmark \quad$ Determinação da densidade do material;

$\checkmark \quad$ Execução dos ensaios de análise granulométrica por peneiramento;

$\checkmark \quad$ Execução dos ensaios de sedimentação;

$\checkmark \quad$ Execução dos ensaios de análise no Cyclosizer.

\subsection{PROCEDIMENTO EXPERIMENTAL}

O método de peneiramento não possui uma grande eficiência para a determinação da distribuição granulométrica de material com tamanhos menores que $37 \mu \mathrm{m}$. E é exatamente por este motivo que usamse os métodos de sedimentação e elutriação para a classificação por granulometria do material particulado. Inicialmente foi utilizado o método de picnometria para determinar a densidade do sólido (Equação 5).

$$
\rho_{S}=\frac{M 2-M 1}{(M 4-M 1)-(M 3-M 2)} \times \rho_{f}
$$

Onde:

$$
\begin{aligned}
& M_{1}=\text { massa do picnômetro vazio e tampado; } \\
& M_{2}=\text { massa do picnômetro com + massa do material; } \\
& M_{3}=\text { massa do picnômetro + amostra + água; } \\
& M_{4}=\text { massa do picnômetro completamente cheio com água. }
\end{aligned}
$$


Como foram encontrados dois valores para a densidade do sólido durante a picnometria, causados por erros experimentais, utilizamos o valor médio, $2,84 \mathrm{~g} / \mathrm{cm}^{3}$, estando próxima da densidade dos argilominerais que apresenta densidades variando entre 2,4 e $2,9 \mathrm{~g} / \mathrm{cm}^{3}$. Em seguida realizado o peneiramento convencional a seco sendo utilizadas as seguintes peneiras com malhas $(\mu \mathrm{m}): 1180 ; 600$; 300; 150; 106; 75; 53 e $<53$.

\subsubsection{MÉTODO DE SEDIMENTAÇÃO}

Este método de distribuição granulométrica foi realizado separando inicialmente uma amostra do material passante na peneira de $53 \mu \mathrm{m}$ com massa 10,35 g (utilizada experimentalmente). Em seguida foram adicionados $100 \mathrm{ml}$ de água gerando uma suspensão. Então a polpa foi transferida para a pipeta de Andreasen e nela foi preenchida com água até a altura correspondente a $20 \mathrm{~cm}$. Posteriormente a polpa foi agitada formando uma suspensão uniforme. A pipeta é colocada na vertical e começamos então há cronometrar o tempo.

Depois de decorrido um tempo pré-estipulado, foram retiradas amostras da polpa e colocadas em Becheres, que foram pesados previamente, para secagem na estufa. Após a secagem completa, os Becheres foram pesados novamente. Sabendo-se o tempo transcorrido para a retirada de cada amostra, altura da superfície de suspensão, o peso do recipiente e do recipiente mais a amostra, obtém-se os valores do peso da amostra, velocidade terminal de partícula e tamanho de partícula.

\subsubsection{MÉTODO DE ELUTRIAÇÃO}

0 método de elutriação é o método mais comum para analisar a granulometria de materiais com intervalo de tamanho inferior a $75 \mu \mathrm{m}$. Este processo é realizado através de uma sequência de cinco hidrociclones invertidos. Cada um com $75 \mu \mathrm{m}$ de diâmetro com diamentros de vortex finder decrescentes, de modo que o produto de cada vortex finder é a alimentação do ciclone seguinte.

\section{RESULTADOS E DISCUSÃO}

\subsection{MÉTODO DE SEDIMENTAÇÃO}

Para determinar a velocidade terminal é necessário dividir a altura da superfície de suspensão pelo tempo. Se considerarmos para cada amostra retirada o mesmo volume de $10 \mathrm{ml}$, através deste valor de velocidade terminal, e usando as equações do método de Concha-Almendra, obtemos os valores de tamanho de partícula para cada amostra. Os devidos cálculos utilizando o método de Concha-Almendra seguem abaixo na Tabela 1.

Tabela 1- Tabela de resultados

\begin{tabular}{|c|c|c|c|c|c|c|c|c|}
\multicolumn{2}{|c|}{ Condições do ensaio } & \multicolumn{2}{|c|}{$\begin{array}{c}\text { Altura } \\
(\mathrm{cm})\end{array}$} & $\begin{array}{c}\text { Tempo } \\
(\mathrm{min})\end{array}$ & $\begin{array}{c}\text { Velocidade } \\
\text { terminal (m/seg) }\end{array}$ & Vo* & $\mathrm{dp}^{*}$ & $\mathrm{dp}$ \\
\hline $\begin{array}{c}\rho \text { solido } \\
\left(\mathrm{kg} / \mathrm{m}^{3}\right)\end{array}$ & 2840 & 20,1 & 1 & 0,00335 & 0,12 & 1,63 & 56,63 \\
\hline $\begin{array}{c}\rho \text { fluido } \\
\left(\mathrm{kg} / \mathrm{m}^{3}\right)\end{array}$ & 1000 & 19,5 & 2 & 0,00163 & 0,05 & 1,06 & 36,66 \\
\hline $\begin{array}{c}\text { Visc. fluido } \\
\left(\mathrm{kg} / \mathrm{m}^{*} \mathrm{~s}\right)\end{array}$ & 0,001 & 19,1 & 4 & 0,00080 & 0,02 & 0,74 & 25,66 \\
\hline $\begin{array}{c}\text { Gravidade } \\
\left(\mathrm{m} / \mathrm{s}^{2}\right)\end{array}$ & 9,81 & 18,5 & 10 & 0,00031 & 0,01 & 0,46 & 15,96 \\
\hline
\end{tabular}

Agora, para obter os valores de acumulado passante de cada amostra, é necessário usarmos o volume da pipeta de Andreasen, que foi medida experimentalmente: $V \approx 500 \mathrm{~cm}^{3}$. 
A concentração inicial da polpa é dada pela massa inicial da amostra dividida pelo volume da pipeta:

$$
C_{0}=\frac{m_{0}}{V}=\frac{10,35}{500}=0,0207 \mathrm{~g} / \mathrm{cm}^{3} .
$$

Para determinar a distribuição acumulada passante em relação às concentrações divide-se a concentração de cada amostra pela concentração inicial na pipeta Andreasen: $P(d p)=\frac{C_{i}}{C_{0}}$ (adimensional).

\subsection{MÉTODO DE ELUTRIAÇÃo}

O cicloclassificador está calibrado para amostras de quartzo com densidade diferente da amostra utilizada. Logo foi necessário calcular os fatores de correção para o cicloclassificador e o tamanho efetivo do corte, conforme Tabela 2.

Onde:

$\rho=2,84 \mathrm{~g} / \mathrm{cm}^{3}$ densidade do sólido;

$T=25^{\circ} \mathrm{C}$ temperatura da água;

$r=170 \mathrm{~mm}$ leitura do rotâmetro;

$t=10$ min tempo de elutriação.

Tabela 2-Fatores de correção e tamanho efetivo do corte

\begin{tabular}{|c|c|c|c|c|}
\hline \multicolumn{2}{|c}{$\begin{array}{c}\text { Fatores de } \\
\text { Correção }\end{array}$} & $\begin{array}{c}\text { Ciclone } \\
\mathrm{n}^{\circ}\end{array}$ & $\begin{array}{c}\text { Tamanho do corte } \\
\text { calibrado }(\mu \mathrm{m})\end{array}$ & $\begin{array}{c}\text { Tamanho efetivo } \\
\text { do corte }(\mu \mathrm{m})\end{array}$ \\
\hline f1 & 0,95 & 1 & 44 & 36,46 \\
\hline f2 & 0,99 & 2 & 33 & 27,34 \\
\hline f3 & 0,97 & 3 & 23 & 19,06 \\
\hline f4 & 0,91 & 4 & 15 & 12,43 \\
\hline f0 & 0,83 & 5 & 11 & 9,11 \\
\hline
\end{tabular}

\subsection{COMPARAÇÃO DAS DISTRIBUIÇÕES GRANULOMÉTRICAS}

A Figura 1 apresenta o resultado da distribuição granulométrica para as três técnicas utilizadas. Dada a comparação, podemos perceber que entre as faixas granulométricas de 25 e $40 \mathrm{~m} \mu$ ocorreu a melhor adequação entre as técnicas, porém, há uma tendência de ocorrer resultados diferentes a medida que as partículas se distanciam de uma esfera, sendo necessário a aplicação de fatores de correção.

Figura 1- Comparação entre as técnicas

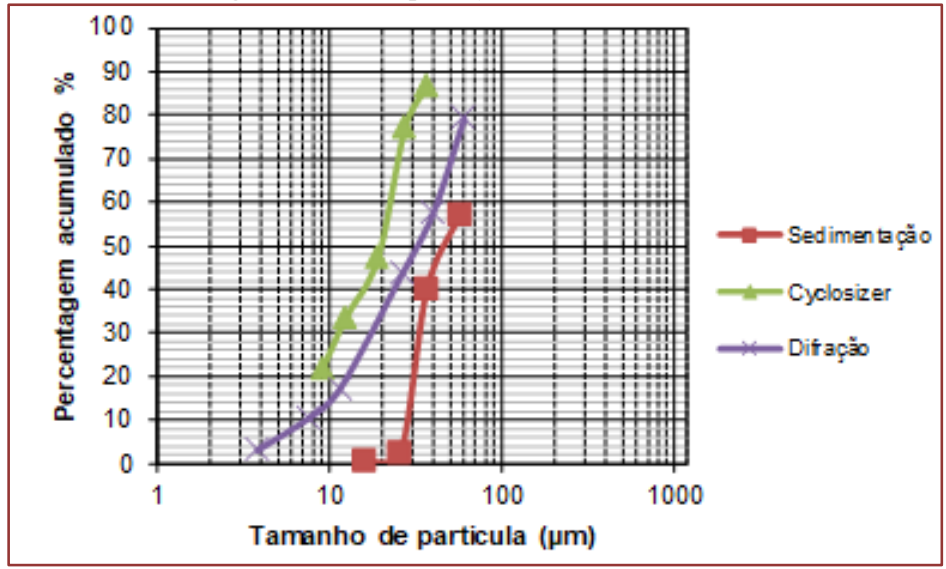




\section{CONCLUSÃO}

Dada à comparação é possível observar que há uma tendência de ocorrer resultados diferentes à medida que as partículas se distanciam de uma esfera, sendo necessário a aplicação de fatores de correção.

Os métodos de análise granulométrica de elutriação e sedimentação são muito semelhantes. No entanto o método por elutriação possui menor abrangência que o método por sedimentação porque o tamanho máximo de partícula foi menor que na sedimentação. Já o método por sedimentação atinge um maior intervalo de tamanho de partícula, adquirindo valores mais próximo em relação ao peneiramento.

0 difratômetro a laser permite realizar medidas de forma rápida, sendo fáceis de utilizar e oferecendo resultados muito reprodutíveis. A teoria de espalhamento de luz não oferece uma definição de tamanho que seja compatível com outros métodos, como o peneiramento. Na maior parte das operações de processamento mineral, como por exemplo, distribuições de tamanhos de partículas obtidas por espalhamento laser tendem a parecer mais grossas que aquelas obtidas por outros métodos, incluindo o peneiramento, sugerindo um procedimento de conversão.

Para análises de rotina, no qual se desejam detectar apenas mudanças na distribuição de tamanho de partícula, esses equipamentos são, provavelmente, imbatíveis. Para comparações entre diferentes meios ou materiais, ou a resultados de análise obtidos com o auxílio de diferentes métodos, extremo cuidado deve ser usado na interpretação dos resultados. Além disso, esses instrumentos não permitem o fracionamento da amostra para análises posteriores.

\section{REFERÊNCIAS}

[1] KING, R.P., SCHNEIDER, C.L. An effective SEM-based image analysis system for quantitative mineralogy, KONA Powder and Particle,vol. 11, pp. 165-177. 1993.

[2] CARRISSO, R.C.C. e Correia, J.C.G. Classificação e peneiramento. In: Luz, A. B., Sampaio, J. A. e Almeida, S. L. M. (Ed.). Tratamento de minérios. 4a ed. Rio de Janeiro: CETEM/MCT, p.197-240, 2004.

[3] JILlaVEnKATESA, A.; DAPKUNAS S. J.; LUM L.H. GOETZEL, G. C. Particle Size Characterization, NIST Recommended Practice guide - Special Publication 960-1, Washington, 2001.

[4] VALIRE, S. B. E WENNEN, J. E. Screening in Mineral Processing Operations. In: Mular, A.L., Bhappu, R.B. Mineral Processing Plant Design, 2nd Edition. Littleton, USA: SME, p.917-928, 1980.

[5] VALIRE, S. B. E WENNEN, J. E. Screening in Mineral Processing Operations. In: Mular, A.L., Bhappu, R.B. Mineral Processing Plant Design, 2nd Edition. Littleton, USA: SME, p.917-928, 1980.

[6] SAMPAIO, J. A. FRANÇA, S. C. A. BRAGA, P. F. A. Tratamento de minérios: práticas laboratoriais. Rio de Janeiro: CETEM, 570p, 2007.

[7] Cicloclassificador, Manual do equipamento, Cimaq, [s.d.].

[8] ALLEN, T. Incremental Methods of Sedimentation Size Analysis. Chapter 9. In: Particles Size Measurement. Powder Technology. Third Edition. Scarlett, B. Editor, p.267-297, 1981.

[9] Malvern Instruments, Getting Started, Manual MAN 0106, Issue 1.0, 1996a.

[10] Malvern Instruments, Sample Dispersion \& Refractive Index Guide, Manual MAN 0079, Version 3.0, 1996b.

[11] ENGLAND. Malven Instruments Ltd. 1998,1999. MAN 0247: Operators Guide. England, 108p, 2003. 


\section{Capítulo 2}

Evolução do desenvolvimento do secador solar de exposição indireta na UFCG

\section{Nancy Lima Costa}

Jonas Fernando de Souza Fernandes

Ítalo de Andrade Gomes

Maria de Sousa Leite Filha

João Marcos Domingues Botelho

Marcelo Bezerra Grilo

Resumo: Este trabalho apresenta, por meio de uma revisão bibliográfica, as principais características dos secadores solares de exposição indireta desenvolvidos e testados no Laboratório Experimental de Máquinas Térmicas (LEMT) da Universidade Federal de Campina Grande (UFCG), direcionados à secagem de frutas, que utilizam exclusivamente energia solar como fonte de energia. Desde 2007 que são desenvolvidos na UFCG secadores solares com materiais de baixo custo e facilmente encontrados na região. Nos últimos quatro anos as pesquisas têm se dedicado a investigar como melhorar a eficiência dos secadores solares de exposição indireta. A eficiência do processo de secagem obtidas foram de $95,10 \%, 86,15 \%, 86,95 \%$, para os protótipos desenvolvidos por Gomes, Nunes e Melo respectivamente. Quanto ao rendimento térmico os valores obtidos por Gomes, Nunes, Melo e Lima foram, respectivamente, 35,92\%, 20,47\%, $28,30 \%, 28,31 \%$. Isto mostra que os equipamentos em desenvolvimento estão avançando na direção de um aumento da eficiência, e também que estes resultados estão de acordo com os reportados na literatura. Ao realizar a comparação entre o experimento realizado nas cidades de Patos e Campina Grande, fica claro a importância do local da realização do experimento, uma vez que os dados meteorologias, principalmente, a radiação solar incidente, a temperatura e a umidade relativa do ar de secagem, são fundamentais para qualidade da secagem.

Palavras-chave: Secador solar, Secagem, Energia Solar, Eficiência do Processo, Rendimento Térmico. 


\section{INTRODUÇÃO}

O Brasil é o terceiro produtor mundial de frutas, com participação de 4,8\% na produção mundial (FAO, 2017). As frutas mais produzidas no Brasil são banana, laranja, abacaxi e uva (IBGE, 2015). Segundo dados da SEAD (2017), mais de 50\% dos alimentos que compõem a cesta básica brasileira, dentre eles a banana, são provenientes de sistemas de agricultura familiar. Nesse sistema a produção agrícola é realizada com poucos recursos financeiros devido ao baixo poder aquisitivo dos agricultores familiares (BRAGA et al., 2015). Para incentivar o crescimento da agricultura familiar no país faz-se necessário o desenvolvimento de tecnologias de baixo custo e alta eficiência voltadas para o cultivo, processamento e distribuição da produção agrícola.

Nos países em desenvolvimento, cerca de 30 a $40 \%$ da produção é perdida nas etapas de pós-colheita, processamento e distribuição (GUSTAVSSON et al., 2011). Uma alternativa para minimizar a perda da produção pós-colheita e aumentar o tempo de prateleira mantendo as propriedades nutricionais dos produtos é através dos processos de secagem. De maneira simplificada, a secagem pode ser definida como um processo remoção de água, através da transferência de calor e massa, no produto ao ponto de reduzir a atividade biológica e as mudanças fisíco-químicas que ocorrem durante o armazenamento (MENEGHETI et al., 2012; BARBOSA DE LIMA et al., 2016).

A secagem pode ser realizada de forma natural até de formas mais sofisticadas como a liolifilização (GUIMARÃES, 2010). A secagem de produtos agrícolas ao sol de forma natural, também chamada de secagem solar de exposição direta, por ser um método de baixo custo, é o método mais tradicional empregados na maioria dos países em desenvolvimento. Contudo, esse processo pode resultar em produtos de qualidade inferior dos produtos devido à sua dependência das condições meteorológicas e ao ataque de poeira, sujeiras, chuvas, insetos, pragas e micro-organismos.

Em contrapartida, o uso de metódos convencionais, como estufas e fornos, que utilizam como fonte de energia a eletricidade e combustiveis fósseis têm apresentado custos muitos elevados, principalmente devido a crise energética e ao aumento do preço dos combustíveis fósseis, exigindo a busca de novas metodologias (FALÇÃO FILHO, 2011). Nesse contexto, a utilização de secador solar vem ganhando destaque por ser uma fonte de energa livre, renovável e não poluente e tem sido objeto de estudo de pesquisadores de IES brasileiras e internacionais.

Diante desse cenário, o Grupo de Pesquisa em Energia e Desenvolvimento Sustentável (GEDS), da Universidade Federal de Campina Grande (UFCG), vem trabalhando no desenvolvimento e aprimoramento de um secador solar de baixo custo que propiciem o desenvolvimento regional sustentável atendendo as demandas da agricultura familiar. Os equipamentos são construídos e testados no Laboratório de Máquinas Térmicas (LEMT) desde 2007. Em 2007 (Figura 1), Moura desenvolveu um secador solar de exposição direta para ser utilizado em atividades didáticas na UFCG, após a verificação da eficiência deste equipamento foi desenvolvido um projeto de extensão na comunidade de Natuba para disseminar a utilização de secadores de exposição direta para a produção de banana passas (Figura 2).

Figura 1. Secador Solar de exposição direta

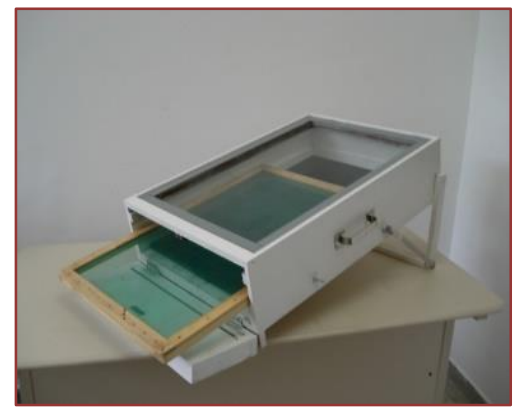

Fonte: Moura (2007)
Figura 2. Projeto de Extensão desenvolvido em Natuba (PB) (2007

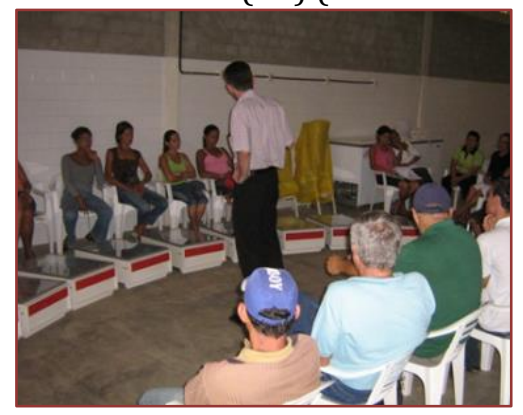

Fonte: Moura (2007)

Desde então, diversos protótipos foram construídos e testad əs, resultando em 5 Projetos de Iniciaçãc Científica (PIBIC), 3 Trabalhos de Conclusão de Curso, 3 Dis sertações e 4 Teses. Os resultados dessas 
pesquisas vêm sendo divulgado na comunidade acadêmica e entre os pequenos produtores da região. Este artigo tem o objetivo de apresentar as principais características construtivas, o rendimento térmico dos secadores solares de exposição indireta desenvolvidos e testados no LEMT entre 2015 e 2017, e comprar a eficiência dos processos de secagem e das cinéticas de secagem dos trabalhos desenvolvidos cujo produto a ser seco tenha sido a banana prata (Mussa sapientum).

Foi realizado uma revisão bibliográfica das teses e dissertações sobre secagem solar desenvolvidas no LEMT no período de 2015 a 2017. A partir dos dados obtidos foi elencado as características do secador solar de exposição indireta, elaborado uma tabela comparativa com o desempenho dos equipamentos e a eficiência do processo de secagem da banana prata desenvolvidos nesse período.

Para avaliar o desempenho dos equipamentos e do processo de secagem, com a finalidade de aperfeiçoalos, é necessário levarem consideração alguns parâmetros básicos no projeto dos secadores, como por exemplo: as dimensões, temperatura, umidade relativa do ar, fluxo de ar e característica dos produtos a serem secos (SILVEIRA, 2016).

\section{SECADORES SOLARES}

O uso de sistemas de energia solar para secagem de produtos agrícolas é viável, econômico e ideal para agricultores em muitos países em desenvolvimento (MUSTAYEN et al. 2014). Diante da crise energética e da demanda de irradiação solar no Brasil, particularmente no Nordeste, a operação de secagem utilizando energia solar é uma opção viável para a secagem de diversas culturas por ser um equipamento simples, de baixo custo e adaptável desde a utilização domestica até a produção industrial.

Segundo Imre (2015), as principais partes dos secadores solares são:

- $\quad$ espaço de secagem, onde o material é colocado;

- $\quad$ coletor para a converter a radiação solar em radiação térmica;

- fonte de energia auxiliar (opcional);

- $\quad$ equipamentos de transferência de energia térmica, para transferir energia térmica ao ar de secagem ou ao material;

- $\quad$ meios para manter o ar de secagem em movimento;

- unidade de armazenamento de energia térmica (opcional), equipamento para controle e aquisição de dados(opcional); dutos, tubos e aparatos.

O coletor solar é o principal componente do secador solar, pois desempenha o papel de fonte de energia primária (SILVEIRA, 2016). Ele é definido como um tipo específico de trocador de calor que visa o aquecimento do ar ambiente (CARVALHO e SIONEK, 2015). Esse aquecimento ocorre através do efeito estufa, ilustrado na Figura. 3.

Figura 3. Representação esquemática do efeito estufa)

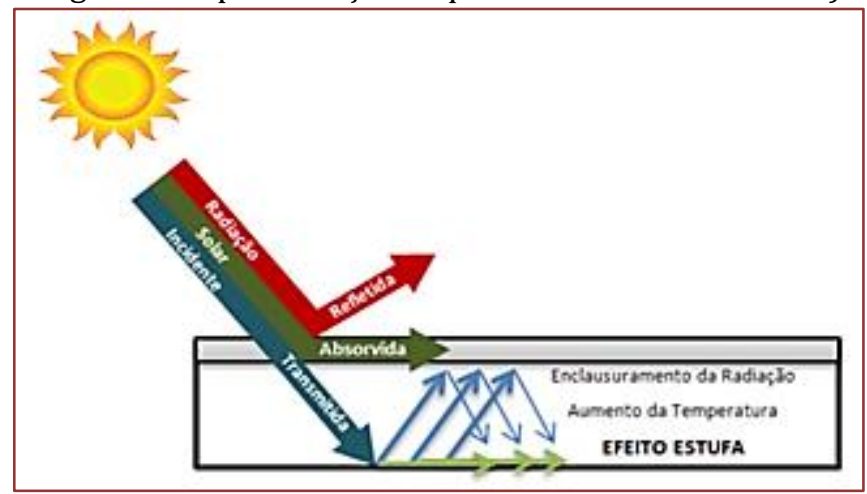

Fonte: Adaptado Gomes (2015) 
A radiação ao incidir sobre a superfície do coletor, parte é absorvida, parte refletida e parte transmitida. A radiação transmitida ao entrar no coletor, com um determinado comprimento de onda, incide sobre o capacitor térmico é aquecido, por sua vez seu comprimento é alterado e ao ser refletido sobre a superfície coletora a sua passagem é bloqueada, fazendo com que a radiação seja transmitida e absorvida continuamente, e consequentemente o aumento da temperatura, provocando o efeito estufa.

Os secadores solares podem ser classificados como: secador de exposição direta, indireta ou misto, sob convecção natural ou forçada. No secador de exposição direta, o produto é depositado em bandejas no coletor e receber diretamente a radiação solar, já no secador de exposição indireta a radiação direta incide sob coletor e é conduzido, devido ao gradiente de temperatura e pressão, para uma câmara de secagem onde se encontra o produto a ser seco, como ilustrado na Figura 4, e ainda pode-se ter uma chaminé para que haja uma melhor circulação na câmara e consequentemente no produto.

Figura 4. Funcionamento de um secador solar de exposição indireta.

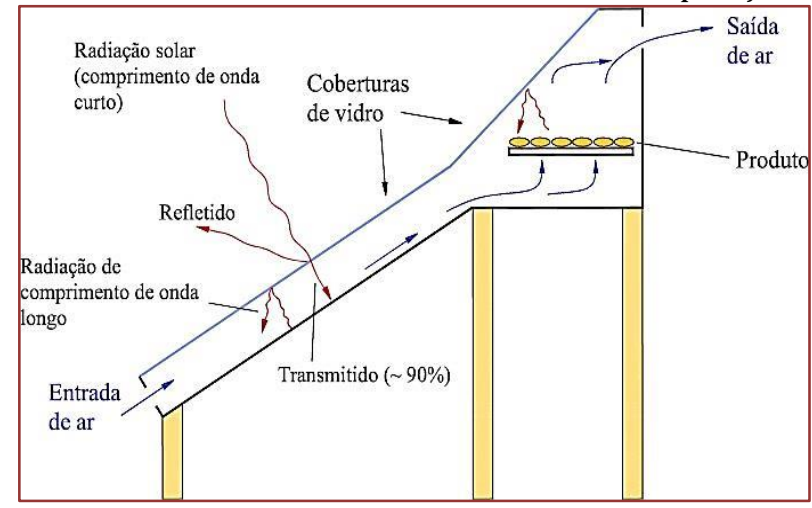

Fonte: Silveira (2011)

Para otimizar o aproveitamento da irradiação incidente, os coletores solares devem ser posicionados de forma que a incidência da radiação ocorra o mais perpendicularmente possível ao plano da superfície coletora incidente (GRILO, 2007).

\section{O PRODUTO A SER SECO: A BANANA}

A banana é o principal produto agrícola comercializado no mundo, entre os países, a Índia é o principal produtor mundial, respondendo por cerca de $26 \%$ do total, seguida pela China, Filipinas e Brasil que produz aproximadamente $6 \%$ da banana do mundo. (FAOSTAT, 2017). No Brasil, a região responsável pela maior produção da fruta é o Nordeste, conforme é possível observar na Figura 5.

Figura 5. Produção brasileira de banana por região fisiográfica em 2017

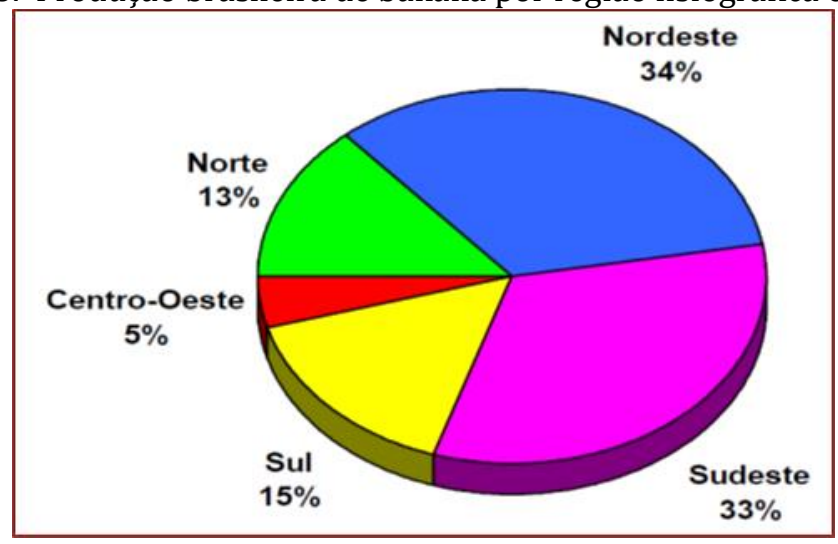

Fonte: IBGE-Produção Agrícola Municipal ( 2017). 
A banana por ser um fruto climatérico (fruto sensível ao etileno, ou seja, amadurece pela a ação do etileno) apresenta alta taxa respiratória e alta produção de etileno após a colheita, o que a torna altamente perecível (NUNES et al., 2013). Em média a massa de água da fruta é 70\%, favorecendo ao crescimento microbiano, levando a perda do valor nutricional e, por conseguinte, perda no valor comercial. A fim de evitar essa perca, espera-se que a fruta destinada a um tempo de armazenamento maior esteja com massa de água reduzida, em torno de 25-30\%. Para isso, faz-se necessário que esse produto seja submetido a um processo de secagem (NUNES, et al., 2013).

\section{CARACTERÍSTICAS CONSTRUTIVAS DOS SECADORES DESENVOLVIDOS NO LEMT}

Os secadores solares de exposição direta desenvolvidos no LEMT são compostos, basicamente, por um coletor solar que e uma câmara de secagem. As coberturas dos coletores solares são de policarbonato alveolar cristal, as caixas são de madeira do tipo MDF ultra e utiliza-se uma telha de fibrocimento pintada de preto fosco (é utilizada como capacitor térmico). Os secadores desenvolvidos, a partir de 2015, apresentam dispositivo de ventilação forçada com a utilização de coolers, alimentados por um painel solar fotovoltaico de $12 \mathrm{~V}$ e $6 \mathrm{~W}$ com função de propiciar a movimentação do ar de secagem através do sistema (convecção forçada).

Os componentes do sistema desenvolvido por Gomes (2015) apresentado na Figura 6 são: um coletor solar de 120 litros de volume interno com uma superfície transparente de $0,80 \mathrm{~m}^{2}$ e uma câmara de secagem de 224 litros, apresentando, portanto, uma razão de volumes do coletor em relação à câmara de 0,54, o que representa, aproximadamente, uma câmara de secagem duas vezes maior que o coletor solar. Foram realizados cinco testes experimentais na cidade de Patos, localizada no sertão paraibano e o produto a ser seco foi o abacaxi. 0 processo de secagem durou $1200 \mathrm{~min}$. As temperaturas foram medidas com um Multímetro digital portátil, modelo ET 1400, marca Minipa, com a utilização de termopares tipo k.

O secador desenvolvido por Nunes (2016), apresentado na Figura 7, foi constituído por um coletor solar de dimensões $1,24 \mathrm{~m}$ x 0,77 $\mathrm{m}$ x 0,18 m, com volume interno de 176 litros e área de incidência 1,0 $\mathrm{m}^{2}$. A câmara de secagem tem dimensões de $0,43 \mathrm{~m} \mathrm{x} \mathrm{0,35} \mathrm{m}$ x 0,50 m e volume interno de 67 litros. Portanto, o volume do coletor solar é superior a 2,5 vezes ao volume da câmara. Nunes (2016) realizou 6 experimentos de secagem de banana prata, no solarium do LEMT no Campus da UFCG em Campina Grande, o tempo de secagem foi de $960 \mathrm{~min}$.

No equipamento desenvolvido por Melo (2016), Fig. 8, o coletor solar possui dimensões de 0,80 m x 1,25 $\mathrm{m} \times 0,20 \mathrm{~m}$, com $0,175 \mathrm{~m}^{3}$ de volume interno e área de incidência de 1,0 $\mathrm{m}^{2}$. A câmara de secagem possui um volume interno de $0,035 \mathrm{~m}^{3}$. Neste caso, o volume do coletor é 5 vezes maior que o volume da câmara. Melo (206) realizou 4 experimentos de secagem de banana para, no solarium do LEMT no Campus da UFCG de Campina Grande, o tempo de secagem foi de $840 \mathrm{~min}$.

Figura 6: Secador Solar desenvolvido por Gomes

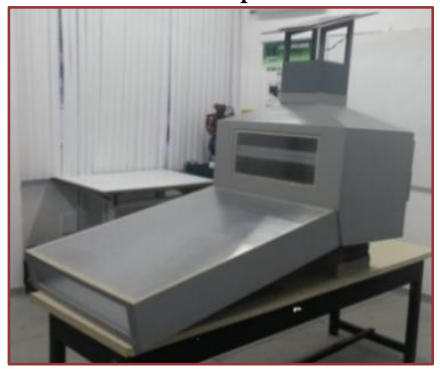

Fonte: Gomes (2015)

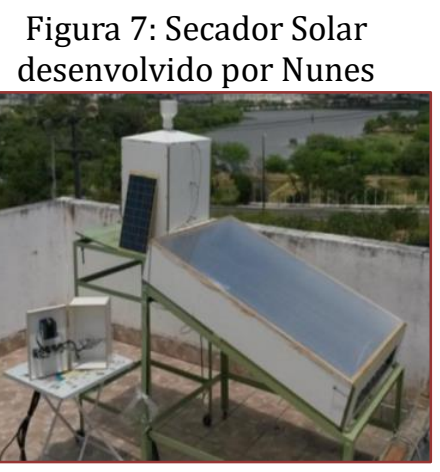

Fonte: Gomes (2015)
Figura 8: Secador Solar desenvolvido por Melo

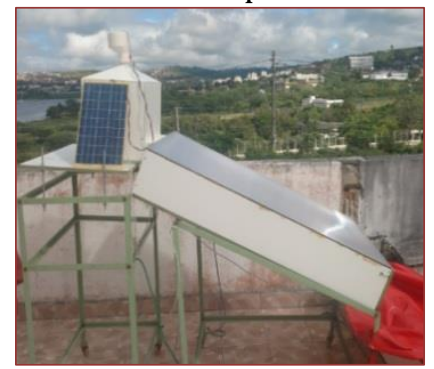

Fonte: Melo (2016)

Lima (2017), desenvolveu um secador solar cujas características construtivas são semelhantes ao desenvolvido por Nunes (2016), com o diferencial da realização de uma comparativo entre a secagem solar, a secagem hibrida (solar + elétrica) e secagem elétrica, e a utilização de um sistema de controle das propriedades termodinâmicas do ar. Lima (2017) realizou um experimentos utilizando a secagem solar sem controle de das propriedades termodinâmicas do ar e um com o controle das propriedades. 0 produto 
utilizado foi de banana prata, o experimento foi realizado no solarium do LEMT no Campus da UFCG em Campina Grande, o tempo de secagem foi de 840 min.

De forma resumida as principais características construtivas estão dispostas na Tabela 1.

Tabela 1. Características construtivas do Secador Solar de exposição indireta.

\begin{tabular}{|c|c|c|c|c|c|}
\hline Autor & $V_{C}(\mathrm{l})$ & $V_{C m}(\mathrm{l})$ & Fonte de Energia & \multicolumn{2}{c|}{$S_{M}$} \\
\hline Gomes (2015) & 120 & 224 & Solar & Multímetro digital & Não \\
\hline Nunes (2016) & 176 & 67 & Solar & Arduino Uno & Não \\
\hline Melo (2016) & 175 & 35 & Solar & Arduino Uno & Não \\
\hline Lima (2017) & 176 & 67 & Solar + Elétrico & Arduino Uno & Sim \\
\hline
\end{tabular}

$V_{C}$ - Volume do Coletor ; $V_{C m}$ - Volume da câmara ; $S_{M}=$ Sistema de Medição; $C_{D^{-}}$controle de dados.

\section{AVALIAÇÃO DOS SISTEMAS E DO PROCESSO DE SECAGEM}

A partir do conceito básico de rendimento termodinâmico, como sendo a razão entre a potência entregue pelo sistema e a potência disponível ao mesmo, Guerra e Varella (2014) afirmam que o rendimento de um secador solar pode ser determinado pela Equação 1.

$$
\eta_{t}=\frac{P_{u}}{A_{1} \cdot \bar{G}} \cdot 100
$$

onde,

$\eta_{t}$ - rendimento do secador solar [\%]; $P_{u}$ - potência transferida ao fluido de trabalho [W]; $A_{1}$ - área de cobertura transparente $\left[\mathrm{m}^{2}\right] ; \bar{G}$ - média da radiação solar incidente $\left[\mathrm{W} / \mathrm{m}^{2}\right]$.

A potência transferida ao fluido de trabalho, no caso do secador solar é o ar ambiente, também denominada de potência útil, pode ser obtida pela Eq. 2. Essa potência representa a quantidade de energia transferida ao fluido de trabalho.

$$
P_{u}=\dot{m} \cdot c_{p} \cdot \Delta T
$$

onde,

$\dot{m}$ - vazão mássica do fluido de trabalho $[\mathrm{kg} / \mathrm{s}] ; c_{p^{-}}$calor específico do fluido de trabalho [J/kg.K]; $\Delta T-$ variação de temperatura [K].

0 rendimento térmico de um coletor solar é expresso em função da potência útil, da irradiação solar incidente, da área de cobertura transparente e da vazão do fluido de trabalho, do calor específico do mesmo e da variação de temperatura obtida (NUNES, 2016).

Em secador solar que possuem sistema de medição da umidade relativa do ar e temperatura, na entrada e saída de cada parte que compõe o sistema de secagem, como os desenvolvidos por Nunes (2016) e Lima (2017), o rendimento térmico do equipamento pode ser calculado a partir da Eq. 3 e com a aplicação do balanço de energia em cada parte do equipamento. A Equação 3 representa matematicamente o Princípio de Conservação da Energia (1를 Lei da Termodinâmica) ao volume de controle. 


$$
\frac{d E_{v c}}{d t}=\dot{Q}_{v c}-\dot{W}_{v c}+\sum_{e} \dot{m}_{e} \cdot\left(h_{e}+\frac{v_{e}^{2}}{2}+g z_{e}\right)-\sum_{e} \dot{m}_{s} \cdot\left(h_{s}+\frac{v_{s}^{2}}{2}+g z_{s}\right)
$$

onde,

$\frac{d E_{v c}}{d t}$ - taxa temporal da variação da energia contida no interior do volume de controle, [J];

$\dot{Q_{v c}}$ - taxa de transferência de calor ao longo da fronteira (superfície de controle) do volume de controle [J];

$\dot{W}_{v c}$ - taxa de transferência por trabalho ao longo da fronteira (superfície de controle) do volume de controle [J];

$\dot{m}_{e}$ e $\dot{m}_{s}$ - vazões mássicas instantâneas na entrada e saída do volume de controle, respectivamente e, $[\mathrm{kJ} / \mathrm{kg}]$;

$\dot{m}_{e} \frac{v_{e}^{2}}{2}$ e $\dot{m}_{s} \frac{v_{s}^{2}}{2}$ - energias cinéticas específicas na entrada e saída do volume de controle, respectivamente, $[\mathrm{J}]$;

$\dot{m}_{e} g z_{e}$ e $\dot{m}_{s} g z_{s}$ - as energias potenciais específicas na entrada e saída do volume de controle, respectivamente, [J];

$h_{e}$ e $h_{s}$ - as entalpias na entrada e saída do volume de controle, respectivamente, [kJ/kg].

Para determinar a eficiência térmica a partir das propriedades termodinâmicas envolvidas no processo de secagem, é calculado a eficiência em cada parte do sistema de secagem, a partir do balanço de energia aplicado ao coletor solar e câmara de secagem.

Ao analisar separadamente o volume de controle do coletor solar e da câmara de secagem, descritas conforme as Figura 9 e Figura 10.

Figura 9. Representação do volume de controle

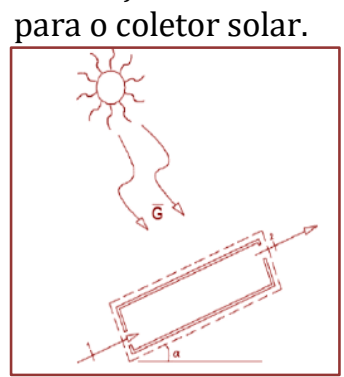

Figura 10. Representação do volume de controle para a câmara de secagem.

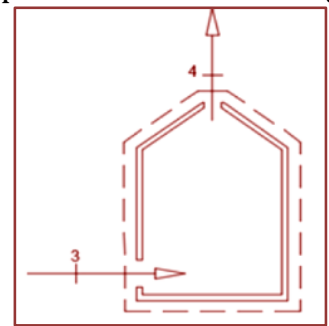

Fonte: Nunes (2016)

Aplicar o Princípio de Conservação de Massa e considerar que: a energia cinética e a energia potencial na entrada e saída tanto do coletor quanto da câmara de secagem são iguais, devido as características construtivas e operacionais do coletor solar; o trabalho realizado pelo coletor solar e pela câmara de secagem é nulo, pois este é um equipamento térmico e não uma máquina térmica; e a massa que entra no coletor é igual a massa que saí, a massa que sai da câmara de secagem é maior do que a massa que entra, uma vez que sai a massa de ar que entrou, vindo do coletor solar, mais a massa de água que é retirada da fruta durante o processo de secagem.

Obtém-se o rendimento térmico do sistema de secagem aplicando as Equações 4 e 5 no coletor solar e na câmara de secagem. 


$$
\begin{aligned}
& \eta_{\text {coletor }}=\frac{\dot{m}\left(h_{2}-h_{1}\right)}{A \dot{Q}_{\text {solar }}} \\
& \eta_{\text {câmara }}=\frac{\dot{m}_{4} h_{4}+\dot{E}_{b}}{\dot{m}_{3} h_{3}}
\end{aligned}
$$

onde,

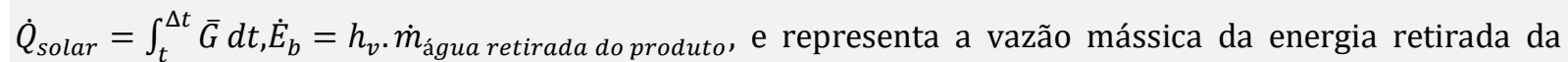
fruta durante o processo de secagem; $h_{v}$ é a entalpia da água saturada como vapor saturado na temperatura média de saída, em [kJ/kg].

0 rendimento do sistema de secagem $\left(\eta_{\text {secador }}\right)$ é igual ao produto entre o rendimento do coletor solar $\left(\eta_{\text {coletor }}\right)$ e o rendimento da câmara de secagem $\left(\eta_{\text {câmara }}\right)$.

Já a eficiência mássica do processo de secagem, pode ser obtida através da medição da variação das massas do produto a ser seco, através da Equação 6.

$$
\eta_{p}=\frac{m_{\text {inicial }}-m_{\text {final }}}{m_{\text {total de água }}} .100
$$

onde,

$\eta_{p^{-}}$eficiência mássica do processo [\%]; $m_{\text {inicial }}$ - massa inicial do produto [kg]; $m_{\text {final }}$ - massa final do produto [kg]; $m_{\text {total de água }}$ - massa total de água presente no produto a ser secado [kg].

\subsection{AVALIAÇÃO DOS SECADORES SOLARES DE EXPOSIÇÃO INDIRETA DESENVOLVIDOS NO LEMT}

Nos experimentos realizados foram medidas, no intervalo de $60 \mathrm{~min}$, a variação de massa do produto a ser seco, temperatura do ar ambiente, temperatura do ar na entrada do coletor solar, temperatura do ar no interior do coletor solar, temperatura do ar na junção do coletor solar com a câmara de secagem e a temperatura do ar na saída da câmara de secagem.

Nesta subseção serão suprimidos os resultados de Lima (2017), pois foi desenvolvido um secador solar de exposição direta misto (elétrico e solar), e a eficiência do processo de secagem obtido por de Gomes (2015), pois o teor inicial de água do abacaxi é maior que o teor de água da banana, e a massa de água do produto a ser seco está diretamente relacionada a esse parâmetro. Os valores apresentados nas Tabelas 2 e 3 foram obtidos através da média aritmética dos dados obtidos experimentalmente nos secadores solares.

Tabela 2. Parâmetros de massa e eficiência mássica

\begin{tabular}{|c|c|c|c|c|c|}
\hline \multicolumn{2}{|c}{ Autor } & Data & $X_{B U_{i}}[\%]$ & $X_{B U_{f}}[\%]$ & $\eta_{p}$ \\
\hline \multicolumn{2}{|c|}{ Nunes (2016) } & 25 a $26 / 02 / 2016$ & 68,24 & 23,58 & 86,00 \\
\hline \multicolumn{2}{|c|}{ Melo (2016) } & 08 a 09/06/2016 & 65,30 & 25,70 & 81,63 \\
\hline \multirow{2}{*}{ Lima (2017) } & Sem controle & 07 a 08/06/2016 & 70,00 & 17,44 & 90,95 \\
\cline { 2 - 6 } & Com controle & 03 a 04/10/2016 & 70,00 & 24,22 & 86,30 \\
\hline
\end{tabular}

Como pode ser observado na Tabela 2 , o teor de água em base úmida final $\left(X_{B U_{f}}[\%]\right)$ está compatível com a Resolução RDC n 272/05 da ANVISA, dentro dos padrões exigidos para comercialização que deve ser menor que $25 \%$. Quanto as eficiências do processo de secagem $\left(\eta_{p}\right)$, as inovações realizadas no período em estudo dos secadores desenvolvidos na UFCG resultaram no aumento de 7 \% na eficiência do processo.

De acordo com a Tabela 3, o rendimento do equipamento está de acordo com os reportados na literatura (FUDHOLI et al., 2014; HUBACKOVA et al. ,2014), é observado um aumento na potência útil e no rendimento térmico dos secadores solares. 
Tabela 3. Parâmetros medidos no processo de secagem.

\begin{tabular}{|c|c|c|c|c|c|c|c|c|}
\hline \multirow{2}{*}{ Autor } & $\bar{I}(W$ & $P_{u}[\%]$ & \multicolumn{2}{|c|}{$\eta_{t}[\%]$} & $T_{\text {amb }}\left[{ }^{\circ} \mathrm{C}\right]$ & $T_{c}\left[{ }^{\circ} \mathrm{C}\right]$ & $T_{s, \text { cam }}$ & \multicolumn{4}{c|}{$U R_{e}\left[{ }^{\circ} \mathrm{C}\right]$} & $\begin{array}{c}U{ }^{\circ} \mathrm{Cent,cam} \\
{\left[{ }^{\circ} \mathrm{C}\right]}\end{array}$ \\
\hline Nunes (2016) & 720,00 & 144,63 & 20,00 & 28,67 & 47,71 & 34,27 & 49,00 & 24,00 \\
\hline Melo (2016) & 618,13 & 179,48 & 29,00 & 35,00 & 52,38 & 41,25 & 46,50 & 19,25 \\
\hline Lima (2017) & 572,62 & 167,66 & 29,27 & 32,49 & 49,96 & 35,25 & 48,00 & 30,65 \\
\hline
\end{tabular}

$T_{c}$ - Temperatura entrada da câmara; $T_{s, c a m}$ - Temperatura saída da câmara; $U R_{e}$ - Umidade relativa do ar na entrada do coletor; $U R_{\text {ent,cam }}$ - Umidade relativa do ar na entrada da câmara .

\section{CINÉTICA DE SECAGEM DA BANANA}

A cinética de secagem é um assunto vastamente coberto pela literatura para diferentes produtos e mostra que, dentre as variáveis mais importantes, estão temperatura e velocidade do ar de secagem (GIRALDOZUNIGA et al., 2006; CORREAA et al., 2007; NAGLE et al., 2008; KAYA; AYDIN; DINCER, 2008).

Para descrever a cinética de secagem de um produto é necessário determinar o teor de umidade em base seca e a razão de umidade, calculados através das Equação 7 e 8, respectivamente.

$$
\begin{aligned}
\mathrm{X}_{\mathrm{bs}} & =\frac{m_{\mathrm{H}_{2} \mathrm{O}}}{m_{m s}} \\
\mathrm{RU} & =\frac{\mathrm{X}-\mathrm{X}_{\mathrm{e}}}{\mathrm{X}_{0}-\mathrm{X}_{\mathrm{e}}}
\end{aligned}
$$

onde:

$X$ - Teor de umidade do produto em base seca;

$X_{e}$ - Teor de umidade de equilíbrio do produto em base seca;

$X_{0}$ - teor de umidade inicial do produto em base seca.

Os dados experimentais obtidos pelos autores em estudo foram ajustados pelo modelo matemático empírico de Page, dado pela Equação 9.

$$
\mathrm{RU}=\exp \left(-\mathrm{kt}^{\mathrm{n}}\right)
$$

onde,

$$
\begin{aligned}
& \text { k- constante; } \\
& t \text { - tempo (min). }
\end{aligned}
$$

0 modelo de Page foi ajustado aos dados experimentais através de regressão não linear, pelo método Quasi-Newton, empregando-se o programa computacional STATISTICA 7.0. Para avaliar a qualidade dos ajustes dos modelos matemáticos aos dados experimentais foram avaliados o coeficiente de determinação $\left(\mathrm{R}^{2}\right)$.

Nas Figuras 11 e 14 são apresentadas, respectivamente, as plotagens das curvas da cinética de secagem do experimento realizados por Nunes (2016), Melo (2016) e Lima (2017), mostrando as curvas dos experimentos no período de maior radiação solar incidente. 
Figura 11. Cinética de secagem ajustado pelo modelo de Page (secagem solar sem controle).

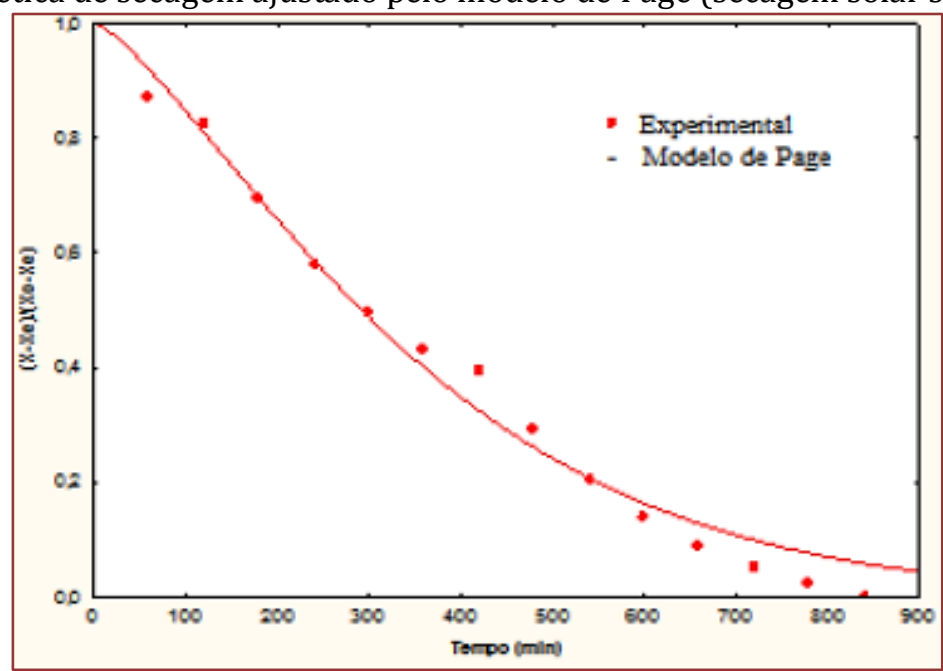

Fonte: Nunes (2016)

Figura 12. Cinética de secagem ajustado pelo modelo de Page (secagem solar sem controle).

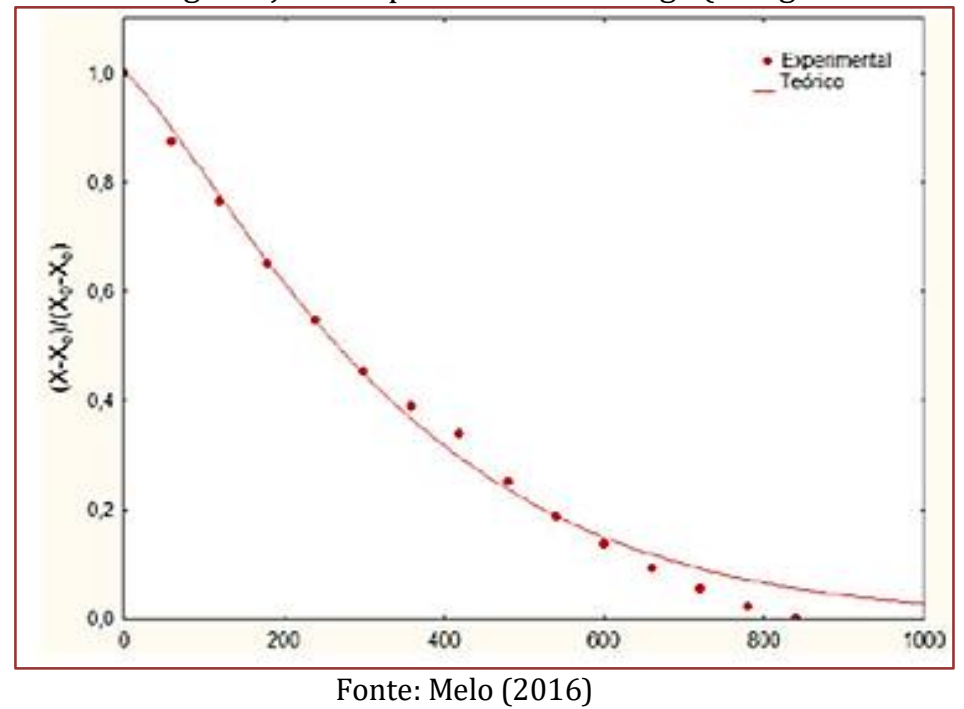

Figura 13. Cinética de secagem ajustado pelo modelo de Page (secagem solar sem controle).

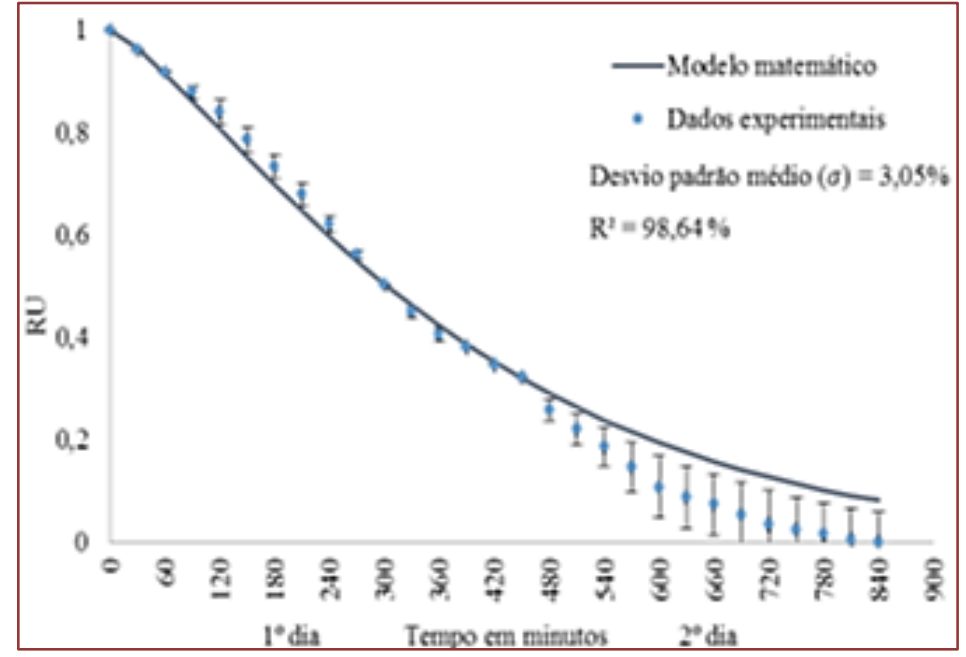


Figura 14. Cinética de secagem ajustado pelo modelo de Page (secagem solar com controle).

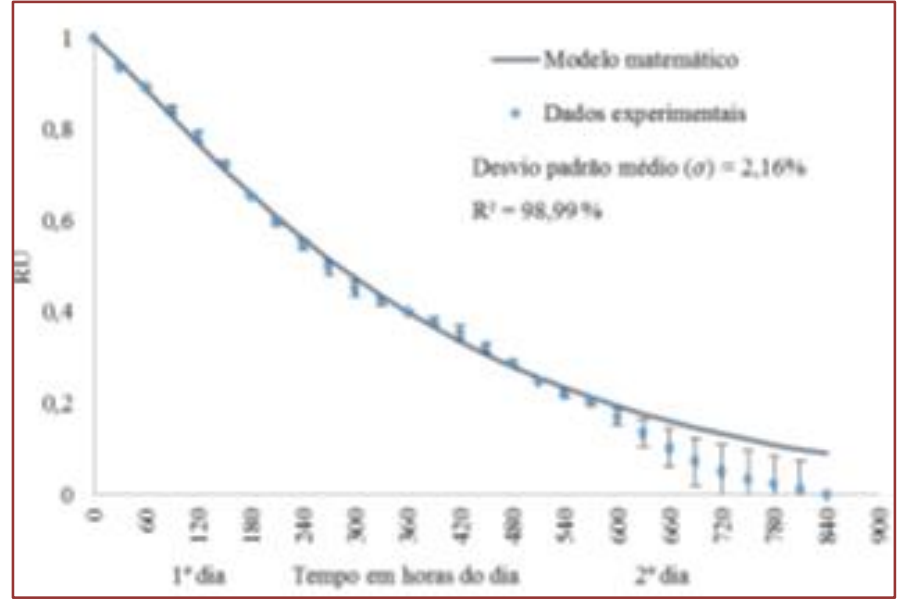

Fonte: Lima (2017)

Podem ser observados nos gráficos das cinéticas de secagem que os experimentos realizados se ajustaram satisfatoriamente ao modelo matemático proposto, apresentando, portanto, significância estatística que corrobora os resultados com os encontrados na literatura.

Nestes experimentos foi utilizada apenas a energia solar no fornecimento de calor para realização do processo de secagem, mesmo assim pode-se verificar que a estratégia adotada é bastante eficiente no que se propõe, mas que depende das condições climáticas que apresentam características intermitentes ao longo do dia e das estações do ano.

\section{CONCLUSÕES}

Analisando os aspectos construtivos dos sistemas de secagem solar apresentados é possível concluir que estes equipamentos são tecnicamente viáveis para realização do processo de secagem de frutas e, por serem fabricados com materiais de baixo custo, configuram-se como de tecnologia social que pode ser utilizados pelos agricultores da região e que contribuem para promover o desenvolvimento sustentável, pois agregam valor aos produtos comercializados e utiliza como fonte energética apenas energia solar.

As pesquisas desenvolvidas têm representado um aperfeiçoamento desses modelos ao longo dos anos de produção desses equipamentos. Ao realizar a comparação entre os experimentos realizados nas cidades de Patos e Campina Grande, fica nítido que a região da realização do experimento é relevante na análise do processo, uma vez que a localização altera fatores importantes no processo de secagem, principalmente, a temperatura e a umidade relativa do ar de secagem.

\section{AGRADECIMENTOS}

Os autores agradecem o apoio da CAPES no desenvolvimento deste trabalho, através da concessão de bolsa de pesquisa.

\section{REFERÊNCIAS}

[1] ANVISA, Brasil. 2005 “Resolução RDC no 272, da Agência Nacional de Vigilância Sanitária.” Aprova o regulamento técnico para produtos de vegetais, produtos de frutas e cogumelos comestíveis. Diário Oficial: Brasília, 23 de set.

[2] Barbosa de Lima, A. G., Delgado, J.M.P.Q., Neto, S.R.F., Franco, C.M.R, 2016. “Intermittent Drying: Fundamentals, Modeling and Applications", Springer International Publishing Switzerland.

[3] Falcão Filho, R. S., 2011. Produção de passas de talo de abacaxi pérola por processo osmo-solar, Dissertação (Mestrado em Engenharia Mecânica). Programa de Pós-Graduação em Engenharia Mecânica, Universidade Federal da Paraíba, UFPB, João Pessoa.

[4] FAO. Food and Agriculture Organization of the United Nations. Production, 2017. Disponível em: < http://www.fao.org/faostat/en/\#data/QC>. Acesso em: 27 set.. 
[5] FUDHOLI, A., SOPIAN, K., YAZDI, M. H., RUSLAN, M. H., GABBASA, M., KAZEM, H. A. 2014. Performance analysis of solar drying system for red chili. Solar Energy. v. 99, p. 4754.

[6] GOMES, I. A. GRILO, M. B. 2017. Secador solar de frutas: Análise experimental de um modelo multienergético. Editora da Novas Edições Acadêmicas, 149 p.

[7] GOMES, I. A. 2015. Desenvolvimento Experimental de um Secador Solar de Frutas com Aproveitamento Multienergético. Dissertação (Mestrado em Engenharia Mecânica). Programa de Pós-Graduação em Engenharia Mecânica, Universidade Federal de Campina Grande, UFCG. Campina Grande, PB.

[8] GRILO, Marcelo Bezerra. 2007. Fundamentos da Energia Solar: Conceitos básicos e aplicações. Editora da UFCG, Campina Grande, 61p. Campina Grande.

[9] GUSTAVSSON, J.; CEDERBERG, C.; SONESSON, U.; OTTERDIJK, R.; MEYBECK, A. 2011. Global food losses and food waste: extent, causes and prevention. Rome: Food and Agriculture Organization of the United Nations, p. 1-38.

[10] HUbACKOVA, A., KUCEROVA, I., CHRUN, R., CHALOUPKOVA, P., BANOUT, J. 2014. Development of solar drying model for selected cambodian fish species. The Scientific World Journal. p. 10 v. 01, 10 p.

[11] IBGE. Banco de Dados Agregados. Sistema IBGE de Recuperação Automática - SIDRA, 2015. Disponível em: http://www2.sidra.ibge.gov.br/bda/tabela/listabl.asp?c=1613\&z=t\&o=11. Acesso em: 11 out. 2019.

[12] ITAL. 2010. Apresentaçao do curso sobre desidrataçao de frutas e hortaliças. disponível em: <http: // www. ital. sp. gov. br / fruthotec / eventos / desidratacao / apresentacao.html>.

[13] LIMA, W. S. 2017. Análises de Sistemas de Secagem: Solar, Elétrico e Misto na Produção de Banana Passa. Tese (Doutorado em Engenharia de Processos). Programa de Pós-Graduação em Engenharia de Processos, Universidade Federal de Campina Grande, UFCG> Campina Grande, PB.

[14] MELO, C. T. M. C. B. 2016. Desenvolvimento e Estudo Experimental de um Secador Solar Aplicado na Secagem de Banana. Dissertação (Mestrado em Engenharia Mecânica). Programa de Pós-Graduação em Engenharia Mecânica, Universidade Federal de Campina Grande, Campina Grande, PB.

[15] MELO, E. L.; LOPES, J. S.; DEODORO, R. N.; MARUYAMA, U.; GUIMARÃES, A. A 2013.0 desafio do planejamento de demanda no setor hortifrutigranjeiro: um estudo de caso da Empresa Nova Casbri. In: SIMPÓSIO DE EXCELÊNCIA EM GESTÃO E TECNOLOGIA, 9., 2012, Anais. Maceió, Alagoas: UFAL, 2013.

[16] MENEGHETTI, V. L., AOSANI, E., ROCHA, J. C., OLIVEIRA, M., ELIAS, M. C., POHNDORF, R. S., 2012. Modelos matemáticos para a secagem intermitente de arroz em casca. Revista Brasileira de Engenharia Agrícola e Ambiental, vol. 16, n. 10, pp.1115-1120.

[17] MOURA, J. L.F.P.2007. Projeto e Construção de um Secador Solar para ser utilizado em Atividades Didáticas na UFCG. Trabalho de Conclusão de Curso. (Graduação em Engenharia Mecânica), Universidade Federal de Campina Grande, UFCG. Campina Grande, PB.

[18] NUNES, A. G. 2016. Desenvolvimento experimental de um secador solar multienergético para a secagem de frutas. Tese (Doutorado em Engenharia de Processos). Programa de Pós-Graduação em Engenharia de Processos, Universidade Federal de Campina Grande, UFCG. Campina Grande, PB.

[19] SILVEIRA, L. 2011. Sistema de aquisição de dados utilizando telemetria: aplicação em secador solar de produtos agrícolas. 106 p. Dissertação (Mestrado em Ciências Agrícolas) - Escola Superior de Agricultura Luiz de Queiroz Universidade de São Paulo, Piracicaba.

\section{RESPONSABILIDADE AUTORAL}

Os autores são os únicos responsáveis pelo conteúdo deste trabalho 


\section{Capítulo 3}

Caracterização reológica e térmica de blendas de pet reciclado com pead compatibilizadas com Anidrido Maleico

Raquel Marques dos Santos

Antonio Gilson Barbosa de Lima

Resumo: 0 objetivo desse estudo foi avaliar a influência do compatibilizante anidrido maleico nas propriedades reológicas e térmicas de blendas de PEAD com PET virgem e PET reciclado, através do processamento de blendas contendo diferentes porcentagens de PET virgem e reciclado no misturador interno de laboratório Haake Rheomix. Para isso, foram preparadas blendas puras e aditivadas com 10\% de compatibilizante (PE-gMA) contendo 25, 50 ou 75\% de PETV ou PETR, estudando o comportamento do toque em função da temperatura nos últimos 3 minutos finais do processamento e o processo de cristalização das blendas através do DSC. Observou-se que efeito do compatibilizante na temperatura do processamento é mínimo (aproximadamente $1^{\circ} \mathrm{C}$ de aumento da temperatura média), a incorporação do agente compatibilizante (10\% PE-g-MA) blendas BLM - aumentou moderada, mas significativamente, o torque de todas as blendas, os incrementos foram na faixa de 30 a $75 \%$ em relação à blenda não compatibilizada. Em geral, a cristalização do PET na blenda é totalmente afetada pela presença do compatibilizante, chegando a ser nula para as blendas contendo $75 \%$ de PEAD. Em contraste, a cristalização de PEAD não é afetada pela presença de PET, e a incorporação de compatibilizante incrementa a cristalinidade do PEAD em 30\% para a blenda contendo $75 \%$ de PET. A compatibilização (10\% PE-g-MA) resultou na desaparição do pico de cristalização do PET nas blendas com 50\% e 75\% PEAD (em combinação com PETV) e nas blendas com 75\% PEAD (em combinação com PETR); 0 grau de cristalinidade do PET exibido na cristalização das blendas decresce com o aumento de PEAD na blenda. 0 PEAD não foi afetado significativamente pela presença de compatibilizante PE-g-MA. A partir dos resultados concluímos que o aditivo melhorou as propriedades reológicas de todas as blendas tanto com PETV quanto com PETR, diminui a cristalinidade do PET em 50\% e incrementa a do PEAD em 30\%.

Palavras-chave: Processamento, polímeros, Misturador interno 


\section{INTRODUÇÃO}

O poli(tereftalato de etileno) (PET) é o principal polímero da classe dos poliésteres aromáticos, que se tornou um dos principais rejeitos de plásticos pós-consumo, devido as suas qualidades, houve uma alta produção, que o transformou em um sério problema ambiental, porque a maior parte destes produtos manufaturados derivados de sua resina é de rápida descartabilidade, causando um crescente acúmulo deste material nos aterros sanitários (Kint e Munõz, 2001; Baldissera, 2005). A reciclagem de polímero é uma questão muito importante, bastante significativa devido a múltiplos aspectos: necessidade da diminuição da abundância de rejeito urbano, conservação de reservas de energia não renováveis e agregação de valor social e ecológico a produtos, melhorando a qualidade de vida e promoção da extensão de uma nova oportunidade de recuperação e equilíbrio ao meio-ambiente (Ward et al., 1997).

Politereftalato de etileno (PET) e poliolefinas (PO) como polietileno de alta densidade (PEAD), polietileno de baixa densidade (PEBD) são os termoplásticos mais largamente utilizados como materiais de embalagem (garrafas, recipientes, filmes, etc.) e por esta razão, misturas de PET/PO representam uma parte significativa dos resíduos pós-consumo. Uma solução para esse problema é a reutilização desses dois polímeros na produção de blendas poliméricas, já que a sua fabricação é um processo menos dispendioso do que a produção de novos polímeros e uma forma de reciclagem. Contudo, a produção de artefatos a partir destes resíduos é uma tarefa desafiadora, porque os mesmos são imiscíveis entre si e as propriedades de suas blendas não compatibilizadas são insatisfatórias (Chiu e Hsiao, 2006).

A compatibilidade de misturas poliméricas heterogêneas pode ser aumentada por vários métodos, incluindo processos reativos e não reativos. Normalmente, a compatibilidade é promovida pela presença de copolímeros, em bloco ou enxertado, cujos segmentos podem dar origem a interações físicas e/ou químicas com os componentes da mistura, com o efeito de reduzir a tensão interfacial e melhorar a dispersão de fase e a adesão através de interpenetração e emaranhados na interface polímero/polímero (Xanthos e Dagli, 1991).

De acordo com Kim et al. (2000), Pawlak et al. (2002), Pracella et al. (2002) e Chiu e Hsiao, 2006, os agentes ou grupos funcionais reativos mais utilizados para a compatibilização de PET e PO são ácido acrílico, anidrido maleico e grupos epóxi, que reagem com os grupos terminais carboxila ou hidroxila do PET.

Diante do exposto, esse trabalho teve como objetivo avaliar a influência do anidrido maleico na compatibilização de misturas de PET virgem (PETV) e PET pós-consumo (PETR) e PEAD virgem.

\section{MATERIAIS E MÉTODOS}

\subsection{MATERIAIS}

O polietileno de alta densidade (PEAD) JV060U foi fornecido pela Braskem; de acordo com a folha técnica possui índice de fluidez de $7 \mathrm{dg} / \mathrm{min}$ (ASTM D1238, $190^{\circ} \mathrm{C} / 2,16 \mathrm{~kg}$ ) e densidade de $0,957 \mathrm{~g} / \mathrm{cm}^{3}($ Braskem, 2017). Teste de DSC revelam que o PEAD utilizado neste trabalho funde entre 105 e $140^{\circ} \mathrm{C}$, com uma temperatura pico de $134^{\circ} \mathrm{C}$ (Lima, 2017).

O politereftalato de etileno virgem (PETV) Cleartuf Turbo foi fornecido pela M\&G Poliéster, que de acordo com informações fornecidas pelo fabricante tem viscosidade intrínseca de $0,8 \mathrm{dL} / \mathrm{g}$, densidade de 1,39 $\mathrm{g} / \mathrm{cm}^{3}$ e ponto de fusão de $246^{\circ} \mathrm{C}$ (M\&G, 2013). O PET reciclado pós-consumo (PETR) utilizado neste estudo é proveniente de embalagens de refrigerante (garrafas) incolores do estado da Paraíba e foi fornecido pela empresa DEPET/PB/Brasil na forma de flakes.

0 polietileno exertado com anidrido maleico (PE-g-MA) foi fornecido pela Chemtura, de nome comercial Polybond 3009, e foi utilizado como compatibilizante das misturas de PEAD/PETR. De acordo com a ficha técnica do produto, o PE-g-MA utilizado tem um teor de anidrido maleico de $1 \%$ e apresenta índice de fluidez de 3 a $6 \mathrm{dg} / \mathrm{min}$ (ASTM D1238, $190^{\circ} \mathrm{C} / 2,16 \mathrm{~kg}$ ), com densidade $0,95 \mathrm{~g} / \mathrm{cm}^{3}$ e temperatura de fusão de $127^{\circ} \mathrm{C}$ (Addivant, 2013). 


\subsection{MÉTODOS}

\subsubsection{PROCESSAMENTO DAS BLENDAS}

O PETV e PETR foram secos em estufa antes do processamento a $130^{\circ} \mathrm{C}$ por 6 horas. O PEAD e o compatibilizante foram usados como recebidos. As amostras foram processadas em um misturador interno de laboratório Haake Rheomix 3000 com rotores de alta intensidade tipo roller operado à velocidade nominal $(N)$ de $60 \mathrm{rpm}$ por um tempo de processamento $\left(t_{P}\right)$ de 15 minutos, com a parede da câmara de processamento mantida à temperatura constante $\left(T_{0}\right)$ de $265^{\circ} \mathrm{C}$.

Foram preparadas blendas contendo $10 \%$ de compatibilizante (PE-g-MA) contendo 25, 50 ou 75 de percentagem de PETV e PETR.

\subsubsection{REOMETRIA DE TORQUE E DEGRADAÇÃO}

A metodologia utilizada na caracterização por reometria de torque descrita nesta seção foi baseada nos modelos desenvolvidos por Canedo e Alves (2015) e Alves et al (2016) e aplicados para o estudo de polímeros aditivados, blendas e compósitos de matriz polimérica (Costa et al, 2015; Duarte et al, 2016; Tavares et al, 2016; Almeida et al, 2016; Marinho et al, 2017; Lima et al, 2017; Falcão et al, 2017; Reul et al, 2018; Lima et al, 2018; Sousa et al, 2018).

Em testes realizados em um misturador interno a velocidade constante do rotor, durante o último estágio de processamento (processamento de fundição), o torque $\mathrm{Z}$ é diretamente proporcional à viscosidade do material fundido Eq. (1) (Dealy, Larson, 2006), e a viscosidade do derretimento é muito sensível a mudanças na massa molar. Portanto:

$$
Z=k \exp \left\{-\beta\left(T-T^{*}\right)\right\}
$$

onde $k$ é constante para testes realizados com a mesma composição, na mesma combinação de misturador/rotores, com o mesmo fator de preenchimento e a mesma velocidade de rotação que depende exponencialmente da temperatura $T$ no interior da câmara de processamento; onde $T^{*}$ é uma temperatura de referência (arbitrária) e $\beta$ é o coeficiente de temperatura da viscosidade.

0 efeito da temperatura pode ser eliminado definindo o torque ajustado $Z^{*}$ à temperatura de referência $T^{*}$ Eq.(2):

$$
Z^{*}=Z \exp \left\{+\beta\left(T-T^{*}\right)\right\}
$$

\subsubsection{CALORIMETRIA EXPLORATÓRIA DIFERENCIAL (DSC)}

As análises de calorimetria exploratória diferencial (DSC) foram realizadas em um instrumento Mettler Toledo DSC-1 utilizando cadinho de alumínio padrão $(40 \mu \mathrm{L})$ fechado e perfurado sob atmosfera de nitrogênio de fluxo aproximadamente de $50 \mathrm{~mL} / \mathrm{min}$ e com amostras de massa $5 \mathrm{a} 7 \mathrm{mg}$. Para as amostras de PET e das blendas um programa térmico em três estágios foi implementado: aquecimento de 20 a $280^{\circ} \mathrm{C}$, resfriamento até $20^{\circ} \mathrm{C}$ e reaquecimento até $280^{\circ} \mathrm{C}$. Para as amostras de PEAD um programa térmico semelhante foi escolhido, mas com a temperatura máxima de aquecimento e reaquecimento de $200^{\circ} \mathrm{C}$. A razão de aquecimento/resfriamento foi mantida em $10^{\circ} \mathrm{C} / \mathrm{min}$. Os testes foram conduzidos com um fluxo de nitrogênio de $50 \mathrm{~mL} / \mathrm{min}$.

A metodologia de análise dados empregada é discutida em detalhe em Canedo et al. (2016), e foi amplamente testada (Wellen e Canedo, 2014; Wellen e Canedo, 2015; Wellen et al., 2015a; Wellen et al., 2015b; Wellen et al., 2015; Sousa et al., 2016; Lima Jr et al., 2016; Wellen e Canedo, 2016; Ries et al., 2016; Vitorino et al., 2016; Silva et al., 2017; Jaques et al., 2017; Jaques et al., 2018; Costa et al., 2018; Reul et al., 2018; Lima et al., 2018; Sousa et al., 2018; Arruda et al., 2018). 
Os cálculos foram conduzidos utilizando software customizado (INTEGRAL). 0 calor latente de cristalização/fusão por unidade de massa do polímero cristalizável é avaliado como a Eq. (3):

$$
\Delta H=\frac{E_{0}}{w_{P} m_{S}}
$$

onde $E_{0}$-é a energia total transferida durante o evento (exotérmico de cristalização ou endotérmico de fusão), $m_{S}$ é a massa de amostra e $w_{P}$ é a fração mássica do polímero em questão. A mudança de cristalinidade durante o evento é estimada como a Eq.(4):

$$
\Delta X=\frac{\Delta H}{\Delta H_{m}^{0}}
$$

onde $\Delta H_{m}^{\circ}$ é o calor latente de fusão do polímero $100 \%$ cristalino. Valores de $293 \mathrm{~J} / \mathrm{g}$ e $145 \mathrm{~J} / \mathrm{g}$ para o PEAD e o PET, respectivamente, são citados na literatura (Madelkern, 2007; van Krevelen, 2009).

\section{RESULTADOS E DISCUSSÃO}

\subsection{REOMETRIA DO TORQUE PARA BLENDAS NÃO COMPATIBILIZADAS}

A Fig. 1 apresenta os resultados para PEAD, PETV e PETR puros e para as blendas não compatibilizadas; na Tab. 1são apresentados, o torque e temperatura média no intervalo final de processamento. Observa-se que o PEAD, PETV e suas blendas se encontram substancialmente no estado fundido aos 3 minutos de processamento; já o PETR e suas blendas fundem aos 6 minutos, provavelmente devido o maior volume (menor densidade aparente) dos flaques do PET reciclado, o que dificultou o preenchimento da câmara de processamento. Temperatura e torque não atingem um platô (estado estacionário) durante o tempo de processamento. Nos últimos 3 minutos de processamento a temperatura - em torno de 268 a $270^{\circ} \mathrm{C}-$ é $^{\circ}$ praticamente independente da composição. 0 torque, que é proporcional à viscosidade do fundido, varia significativamente como a composição, sendo quase o triplo para o PEAD $(10 \mathrm{Nm})$ do que para o PET $(3,5$ $\mathrm{Nm}$ ). 0 torque para blenda com $75 \%$ PEAD é praticamente igual à do PEAD puro e o torque para blenda com 75\% PET é praticamente igual à do PET puro, atingindo um valor intermédio $(5,5 \mathrm{Nm})$ na blenda com $50 \%$ de cada componente. Não se observaram diferenças significativas entre as blendas com PETV e PETR.

Tabela 1: Temperatura e torque médios dos polímeros puros e das blendas PEAD/PET no intervalo de 12 a 15 minutos de processamento (BLV25: blenda contendo 25\% de PETV; BLR25: blenda contendo 25\% de PETR; BLV50: blenda contendo 50\% de PETV; BLR50: blenda contendo 50\% de PETR; BLV75: blenda contendo 75\% de PETV; BLR75: blenda contendo 75\% de PETR)

\begin{tabular}{|c|c|c|c|c|}
\hline \multirow{2}{*}{ Sistema } & \multicolumn{2}{|c}{$\bar{T}\left({ }^{\circ} \mathrm{C}\right)$} & \multicolumn{2}{c|}{$\bar{Z}(\mathrm{Nm})$} \\
& Virgem & Reciclado & Virgem & Reciclado \\
\hline PEAD & $269,3 \pm 0,6$ & ------ & $10,2 \pm 0,1$ & ------ \\
\hline PETV/PETR & $268,7 \pm 0,3$ & $265,9 \pm 0,6$ & $3,6 \pm 0,1$ & $3,2 \pm 0,2$ \\
\hline BLV25/BLR25 & $271,1 \pm 0,7$ & $271,5 \pm 0,7$ & $10,2 \pm 0,1$ & $9,8 \pm 0,1$ \\
\hline BLV50/BLR50 & $270,2 \pm 0,2$ & $268,5 \pm 0,5$ & $4,9 \pm 0,2$ & $6,2 \pm 0,5$ \\
\hline BLV75/BLR75 & $268,7 \pm 0,2$ & $266,9 \pm 0,4$ & $3,1 \pm 0,3$ & $3,8 \pm 0,3$ \\
\hline
\end{tabular}


Figura 1: Curvas de temperatura (a-c) e torque (b-d) em função do tempo para os polímeros puros e as blendas contendo PETV (a-b) e PETR (c-d) a $265^{\circ} \mathrm{C}$ e $60 \mathrm{rpm}$ durante 15 minutos com respectivas quantidades de PET e PEAD (BLV25: blenda contendo 25\% de PETV; BLR25: blenda contendo 25\% de PETR; BLV50: blenda contendo 50\% de PETV; BLR50: blenda contendo 50\% de PETR; BLV75: blenda contendo 75\% de PETV; BLR75: blenda contendo 75\% de PETR)

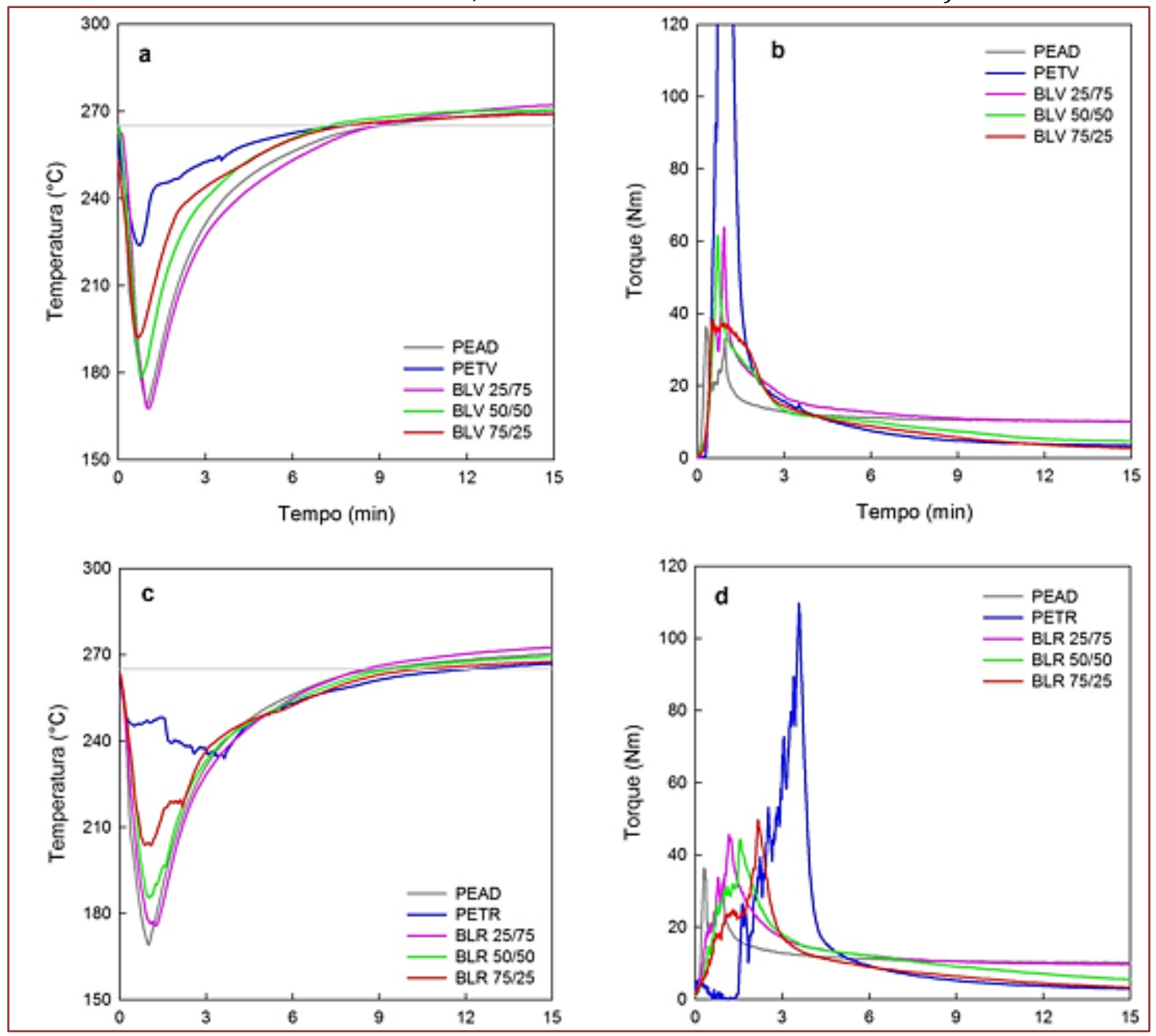

\subsection{REOMETRIA DO TORQUE PARA BLENDAS COMPATIBILIZADAS}

A Fig. 2 apresenta os resultados para PET puro e para as blendas compatibilizadas com 10\% com o PE- $g$ MA, nas mesmas condições (processamento a $60 \mathrm{rpm}$ e $265^{\circ} \mathrm{C}$ ). Na Tab. 2 são apresentados os dados de temperatura média do processamento e torque médio para PET puros e para as blendas compatibilizadas no intervalo de tempo de 12 a 15 minutos. As blendas contendo PET virgem e reciclado apresentaram comportamento semelhante após a compatibilização. 
Figura 2: Curvas de temperatura (a-c) e torque (b-d) em função do tempo para PETV, PETR e as blendas contendo PETV (a-b) e PETR (c-d) compatibilizadas com 10\% de PE-g-MA, processadas a $265^{\circ} \mathrm{C}$ e $60 \mathrm{rpm}$ durante 15 minutos (BLVM25: blenda contendo 25\% de PETV; BLRM25: blenda contendo 25\% de PETR;

BLVM50: blenda contendo 50\% de PETV; BLRM50: blenda contendo 50\% de PETR; BLVM75: blenda contendo 75\% de PETV; BLR75: blenda contendo 75\% de PETR).

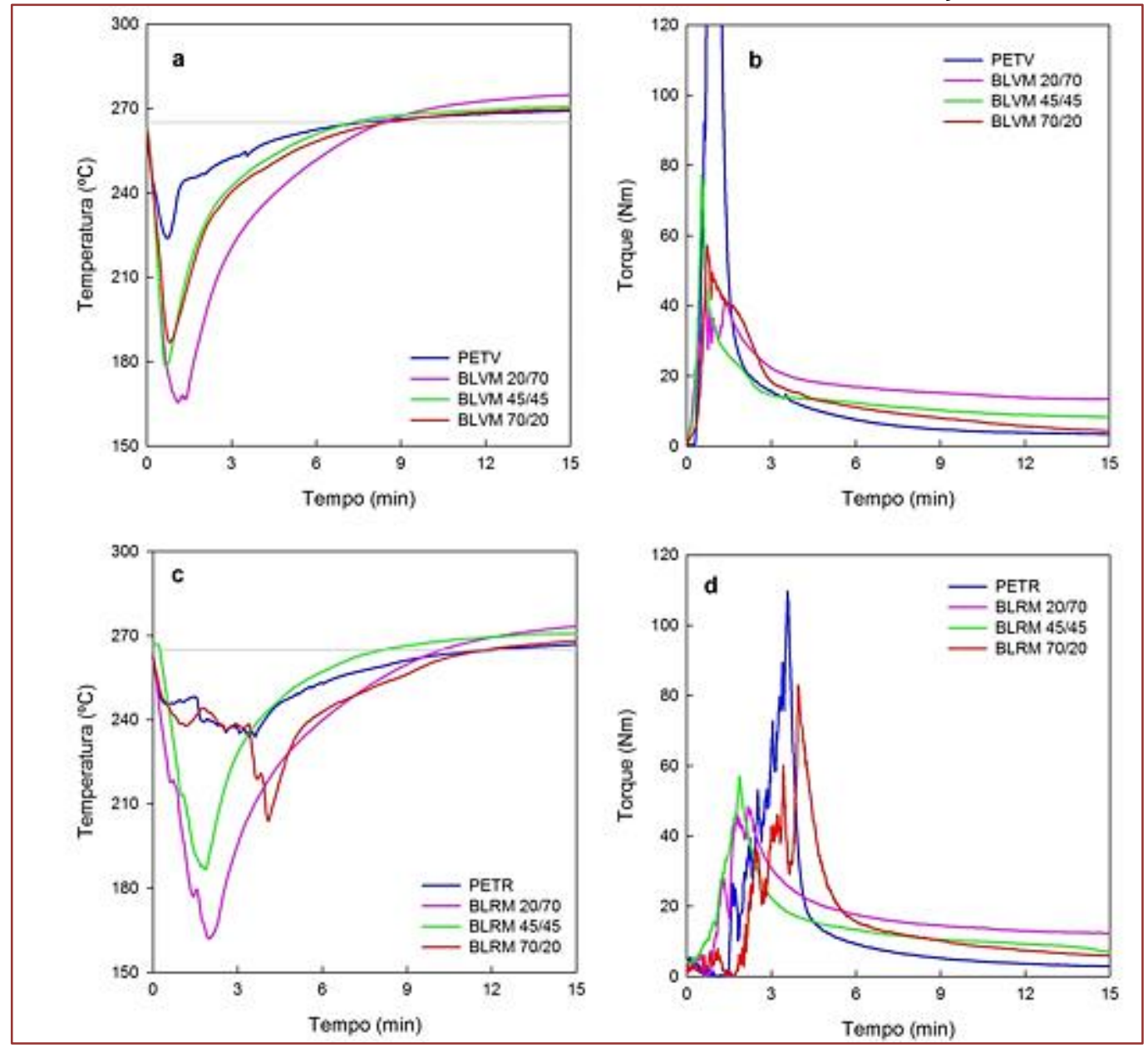

Tabela 2: Temperatura e torque médios das blendas PEAD/PET compatibilizadas com 10\% de PE-g-MA no intervalo de 12 a 15 minutos de processamento (BLVM25: blenda contendo 25\% de PETV; BLRM25: blenda contendo 25\% de PETR; BLVM50: blenda contendo 50\% de PETV; BLRM50: blenda contendo 50\% de PETR; BLVM75: blenda contendo 75\% de PETV; BLR75: blenda contendo 75\% de PETR).

\begin{tabular}{|c|c|c|c|c|}
\hline \multirow{2}{*}{ Sistema } & \multicolumn{2}{|c|}{$\bar{T}\left({ }^{\circ} \mathrm{C}\right)$} & \multicolumn{2}{c|}{$\bar{Z}$ (Nm) } \\
& Virgem & Reciclado & Virgem & Reciclado \\
\hline BLVM25/BLRM25 & $273,9 \pm 0,6$ & $271,6 \pm 1,1$ & $13,5 \pm 0,1$ & $12,6 \pm 0,2$ \\
\hline BLVM50/BLRM50 & $270,2 \pm 0,4$ & $270,3 \pm 0,4$ & $8,6 \pm 0,2$ & $8,4 \pm 0,7$ \\
\hline BLVM75/BLRM75 & $269,3 \pm 0,3$ & $266,8 \pm 0,8$ & $5,0 \pm 0,4$ & $6,6 \pm 0,4$ \\
\hline
\end{tabular}

$\mathrm{O}$ efeito do compatibilizante na temperatura do processamento é mínimo (aproximadamente $1^{\circ} \mathrm{C}$ de aumento da temperatura média nos últimos 3 minutos de processamento). Com relação ao torque, a incorporação do agente compatibilizante (10\% PE-g-MA) - blendas BLM - aumentou moderada, mas significativamente. Observam-se incrementos na faixa de $30 \%$ a $75 \%$ em relação à blenda não compatibilizada. 


\subsection{CALORIMETRIA EXPLORATÓRIA DIFERENCIAL (DSC)}

Os eventos de mudança de fase (fusão durante os aquecimentos, cristalização a partir do fundido durante o resfriamento) foram identificados nos gráficos dos resultados "brutos" registrados pelo instrumento, o fluxo de calor $(U)$ versus tempo $(t)$. No caso das blendas observaram-se picos separados para a fusão e cristalização de cada componente, como ilustra o exemplo na Fig. 3:

Figura 3: Fluxo de calor e temperatura da amostra versus tempo para amostra da blenda PEAD/PETV em proporção 1:1, com a identificação dos eventos de fusão (F) e cristalização (C) do PET (1) e do PEAD (2).

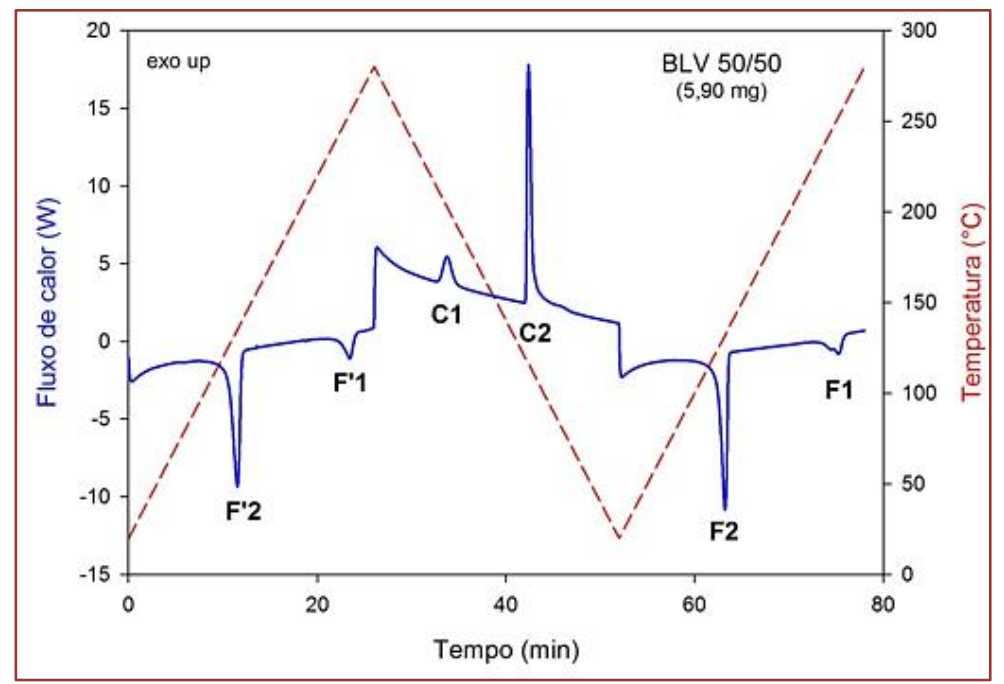

Os eventos de mudança de fase foram codificados como se indica a seguir: F'2: fusão do PEAD durante o primeiro aquecimento; F'1: fusão do PET durante o primeiro aquecimento; C1: cristalização do PET durante o resfriamento; C2: cristalização do PEAD durante o resfriamento; F2: fusão do PEAD durante o reaquecimento; F1: fusão do PET durante o reaquecimento.

Nas Figuras 4, 5, 6 E 7 são apresentadas a análise detalhada dos eventos cristalização de PET e PEAD a partir do fundido em todas as amostras, realizados com ajuda do programa INTEGRAL. Em todos os casos, para cada evento C1 e C2 (isto é, para cada polímero na amostra) são apresentados os valores estimados de: $T_{0,1 \%}=$ Temperatura em que $0,1 \%$ do polímero cristalizável muda de fase; $T_{50 \%}=$ Temperatura em que $50 \%$ do polímero cristalizável muda de fase; $T_{99,9 \%}=$ Temperatura em que 99,9\% do polímero cristalizável muda de fase; $T_{\mathrm{c}}=$ Temperatura pico de cristalização; $C_{\max }$ = Taxa máxima de cristalização (avaliada à temperatura $T_{c}$ ); $\tau_{1 / 2}=$ Tempo necessário para atingir a cristalinidade relativa de $50 \% ; \Delta H_{c}=$ Calor latente de cristalização por unidade de massa de polímero cristalizável na amostra; $\Delta X_{c}=$ Cristalinidade (absoluta) do polímero na amostra.

A Tab. 3 apresenta os parâmetros de cristalização a partir do fundido para as blendas PETV/PEAD e PETR/PEAD compatibilizadas com 10\% PE-g-MA. Nas blendas com 20 e 45\% PETV e com 20\% PETR não foi observado o evento de cristalização de PET (C1). As Figs. 4 e 5 mostram a cristalinidade relativa e a taxa de cristalização, respectivamente, como funções da temperatura, e as Figs. 6 e 7 ilustram graficamente a dependência da temperatura de cristalização e da cristalinidade do PEAD e do PET com o tipo e teor de PET nas blendas. 
Tabela 3: Parâmetros de cristalização - Blendas compatibilizadas.

\begin{tabular}{|c|c|c|c|c|c|c|c|c|c|}
\hline Sistema & & $T_{0,1 \%}$ & $T_{50 \%}$ & $T_{99,9 \%}$ & $T_{\mathrm{c}}$ & $\begin{array}{c}C_{\max } \\
\left(\min ^{-1}\right)\end{array}$ & $\begin{array}{c}\tau / 2 \\
(\mathrm{~min})\end{array}$ & $\begin{array}{c}\Delta H_{c} \\
(\mathrm{~J} / \mathrm{g})\end{array}$ & $\begin{array}{l}\Delta X_{c} \\
(\%)\end{array}$ \\
\hline PETV & $\mathrm{C} 1$ & 216,1 & 204,5 & 175,0 & 204,9 & 1,044 & 1,18 & 43,1 & 30,8 \\
\hline PETR & $\mathrm{C} 1$ & 216,0 & 205,7 & 188,7 & 205,5 & 1,127 & 1,06 & 43,7 & 31,2 \\
\hline PEAD & $\mathrm{C} 2$ & 119,6 & 115,5 & 95,6 & 117,5 & 1,486 & 0,48 & 172,9 & 59,0 \\
\hline BLVM70/20 & $\mathrm{C} 1$ & 213,2 & 198,3 & 173,8 & 198,7 & 0,752 & 1,50 & 43,9 & 31,4 \\
\hline BLVM45/45 & $\mathrm{C} 1$ & --- & --- & --- & --- & --- & --- & --- & --- \\
\hline BLVM20/70 & $\mathrm{C} 1$ & --- & --- & --- & --- & --- & --- & --- & --- \\
\hline BLVM70/20 & $\mathrm{C} 2$ & 119,3 & 115,3 & 88,3 & 106,0 & 1,847 & 0,43 & 244,3 & 83,4 \\
\hline BLVM45/45 & $\mathrm{C} 2$ & 119,3 & 116,9 & 104,8 & 117,7 & 2,409 & 0,32 & 180,4 & 61,6 \\
\hline BLVM20/70 & $\mathrm{C} 2$ & 119,6 & 116,5 & 96,4 & 117,8 & 1,836 & 0,41 & 188,2 & 64,2 \\
\hline BLRM70/20 & $\mathrm{C} 1$ & 212,2 & 199,2 & 178,1 & 198,9 & 0,890 & 1,32 & 42,2 & 30,2 \\
\hline BLRM45/45 & $\mathrm{C} 1$ & 210,0 & 188,7 & 165,1 & 188,4 & 0,541 & 2,14 & 21,8 & 15,6 \\
\hline BLRM20/70 & C1 & --- & --- & --- & --- & --- & --- & --- & --- \\
\hline BLRM70/20 & $\mathrm{C} 2$ & 119,6 & 115,7 & 99,6 & 105,6 & 2,056 & 0,44 & 224,7 & 76,7 \\
\hline BLRM45/45 & $\mathrm{C} 2$ & 119,9 & 117,5 & 105,2 & 118,0 & 2,630 & 0,33 & 188,5 & 64,3 \\
\hline BLRM20/70 & $\mathrm{C} 2$ & 119,9 & 117,8 & 106,6 & 118,4 & 2,373 & 0,35 & 174,1 & 59,4 \\
\hline
\end{tabular}

Figura 4: Cristalinidade relativa a partir do fundido - durante o resfriamento - para a blendas PET/PEAD compatibilizadas com 10\% PE-g-MA preparadas com PET virgem (a) e reciclado (b) correspondentes à cristalização do PET (evento C1, linhas cheias) e do PEAD (evento C2, linhas de traços).
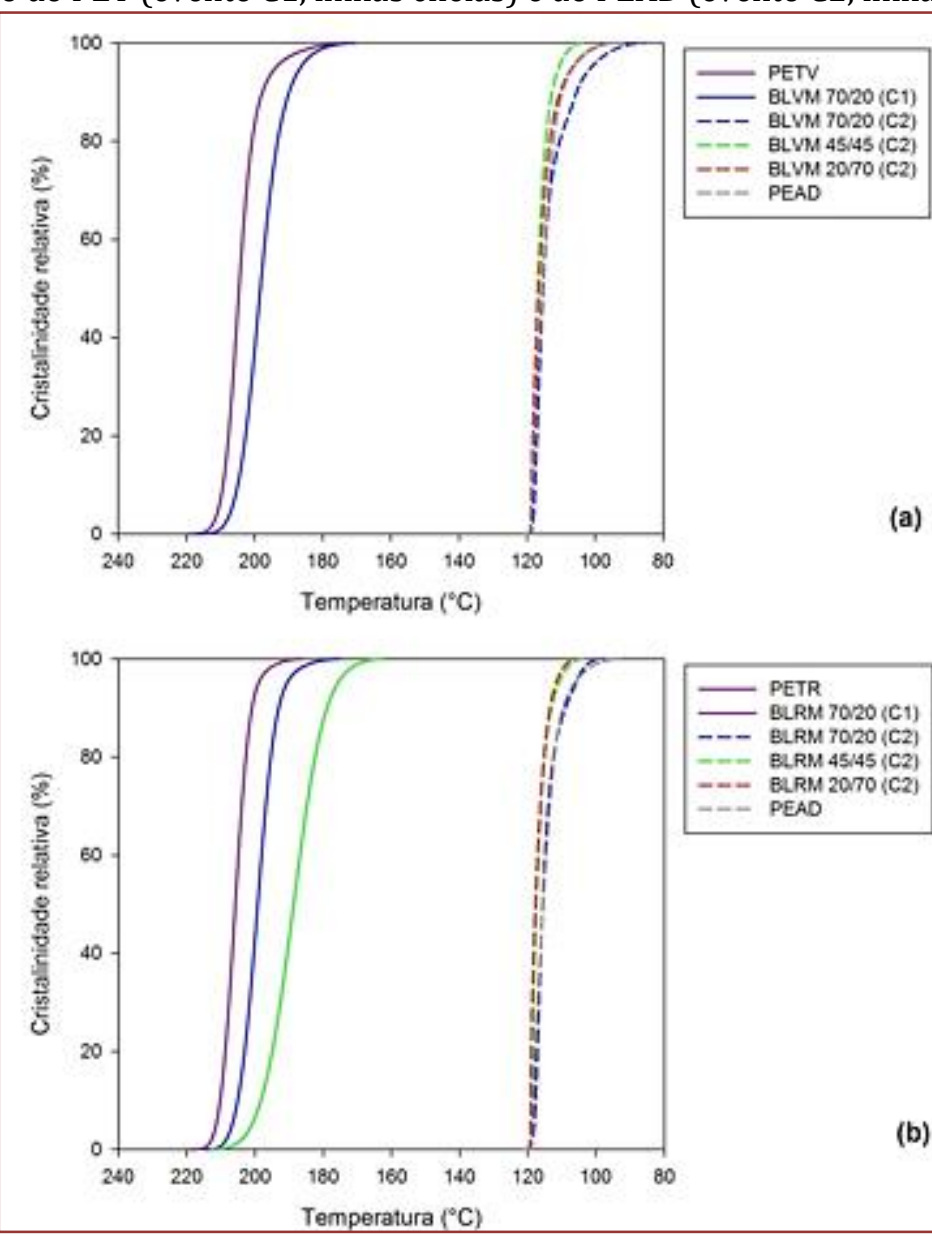
Figura 5: Taxa de cristalização a partir do fundido - durante o resfriamento - para a blendas PET/PEAD compatibilizadas com $10 \%$ PE- $g$-MA preparadas com PET virgem (a) e reciclado (b) correspondentes à cristalização do PET (evento C1, linhas cheias) e do PEAD (evento C2, linhas de traços). As amostras dos componentes puros (PETV, PETR e PEAD) não foram compatibilizadas.

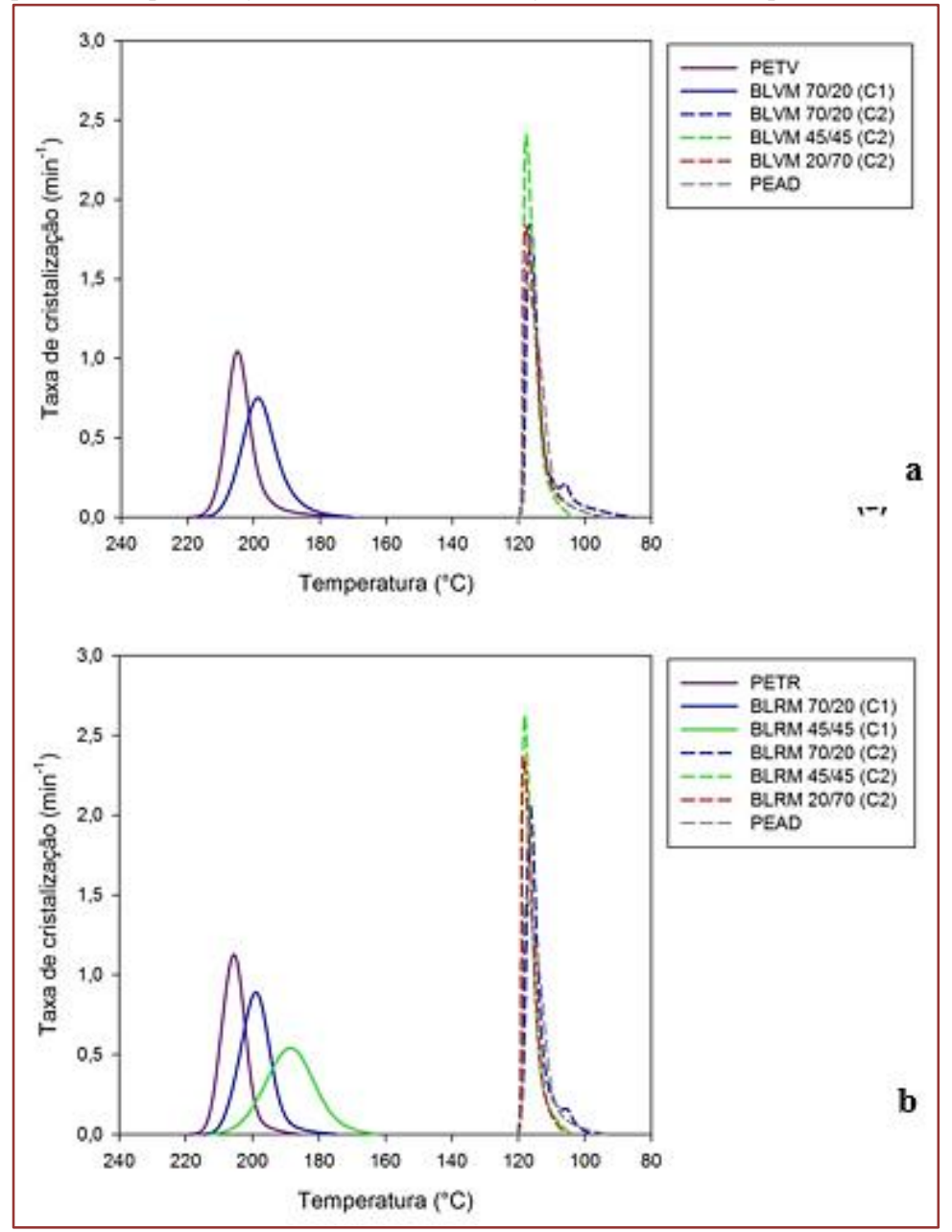

Figura 6: Temperatura pico de cristalização do PET e do PEAD nas blendas PET/PEAD compatibilizadas com $10 \%$ PE- $g$-MA e preparadas com PET virgem (a) e reciclado (b). As amostras dos componentes puros (PETV, PETR e PEAD) não foram compatibilizadas.
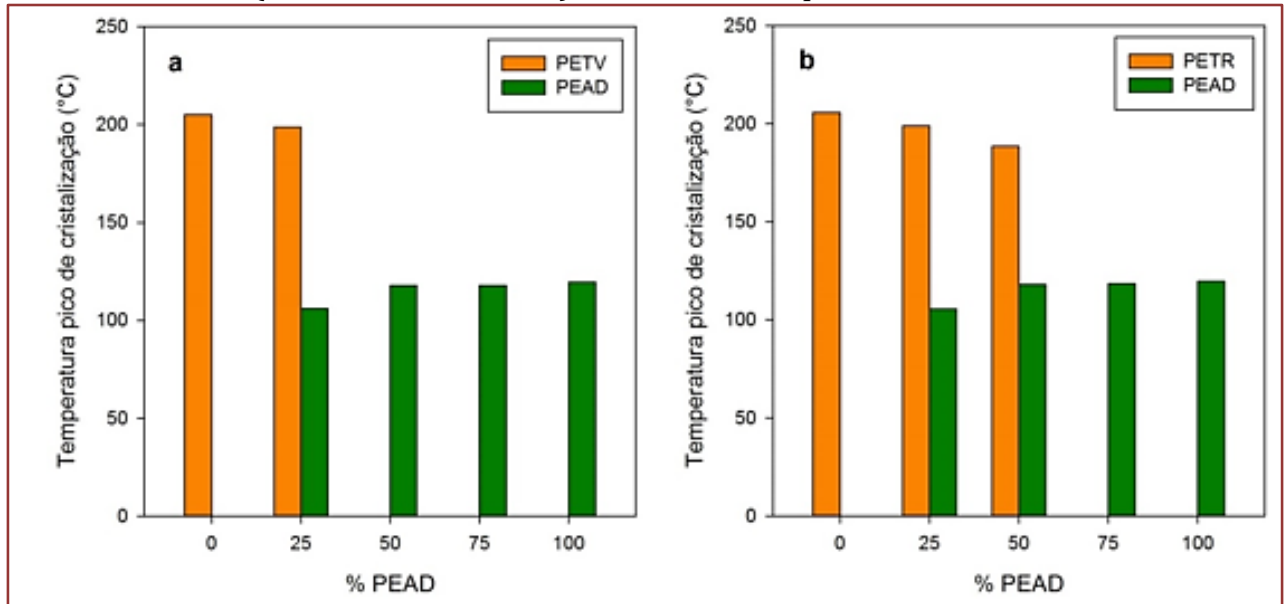
Figura 7: Cristalinidade do PET e do PEAD nas blendas PET/PEAD compatibilizadas com 10\% PE- $g$-MA e preparadas com PET virgem (a) e reciclado (b). As amostras dos componentes puros (PETV, PETR e PEAD) não foram compatibilizadas.

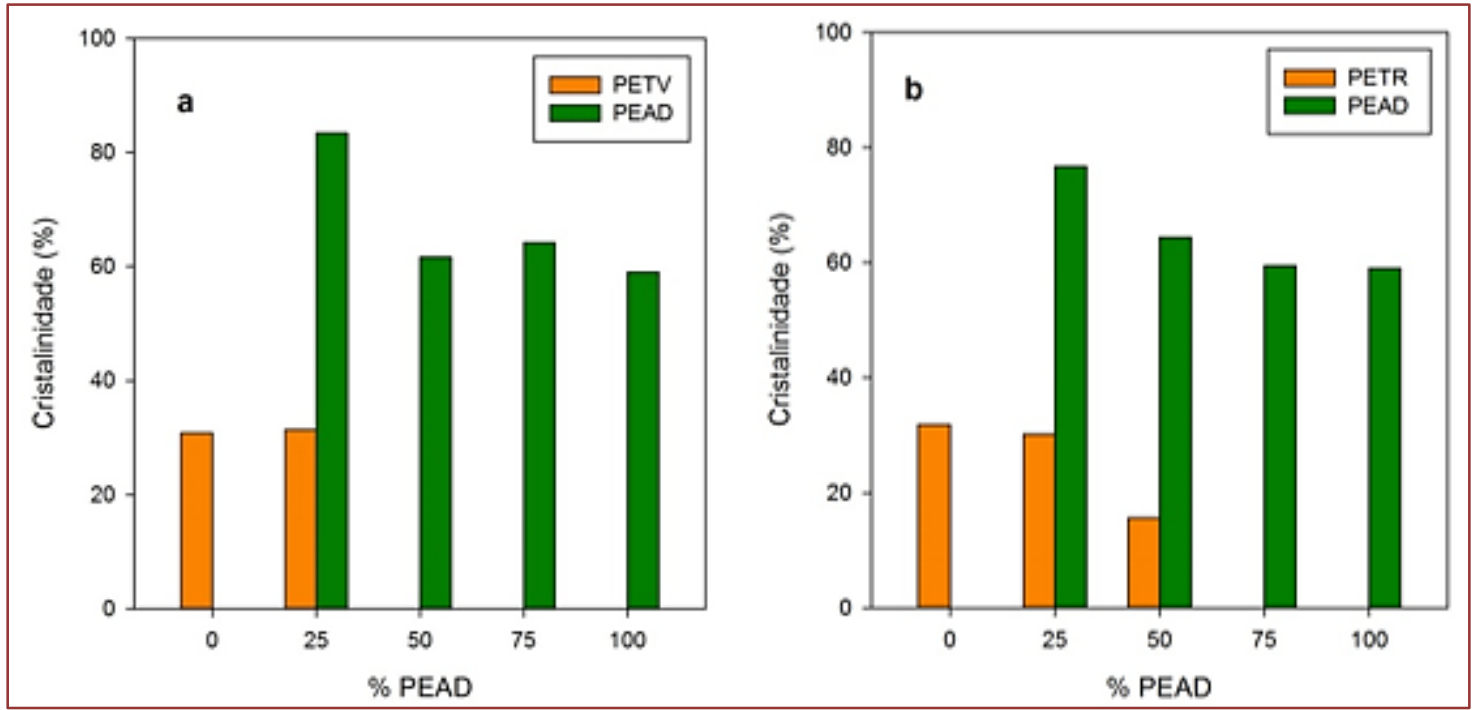

A adição de compatibilizante PE-g-MA tem mínimo efeito na cristalização do PEAD, mas perturba significativamente a cristalização do PET - especialmente do PETV. O evento de cristalização a partir do fundido de PET não foi observado nas blendas com 20 e 45\% PETV e com 20\% PETR. Porém, uma pequena fração de PET funde no segundo aquecimento nesses materiais, o que indica a presença de uma fase cristalina de PET. A discrepância pode ser atribuída (talvez) à co-cristalização dessa pequena quantidade de PET com o PEAD.

Em geral, a cristalização do PET na blenda é significativamente afetada pela presença de PEAD; a compatibilização aumenta a dificuldade da cristalização. Em contraste, a cristalização de PEAD não é muito afetada pela presença de PET.

Em relação à cristalização de PEAD (evento C2) notou-se que a presença do compatibilizante ou tipo de PET (V ou R) não afetaram significativamente a temperatura de cristalização do PEAD. O grau de cristalinidade do PEAD exibido na cristalização das blendas não foi afetado significativamente pela presença de PET, porém, a incorporação de compatibilizante incrementou a cristalinidade. Em relação à cristalização de PET (evento C1), foi observado que nas blendas puras preparadas com PETR houve a diminuição da temperatura de cristalização do PET na blenda com 75\% PEAD, em comparação com as blendas preparadas com PETV. A compatibilização (10\% PE-g-MA) resultou na desaparição do pico de cristalização do PET nas blendas com 50\% e 75\% PEAD (em combinação com PETV) e nas blendas com 75\% PEAD (em combinação com PETR). O grau de cristalinidade do PET exibido na cristalização das blendas decresceu com o conteúdo de PEAD que mostrou ser significativamente afetado pela presença de compatibilizante PE-g-MA.

\section{CONCLUSÕES}

A adição de $10 \%$ de PE-g-MA se mostrou eficiente no aumento do torque em todas as blendas tanto com o PET Virgem quanto com o PET reciclado.

A cristalização do PET é afetada significativamente pela presença do PEAD.

A presença do PE-g-MA não afeta a cristalização do PEAD, no entanto incrementa a sua cristalinidade. No caso do PET a presença do compatibilizante dificulta a cristalização do mesmo. 


\section{AGRADECIMENTOS}

\section{A Santíssima Trindade e Nossa Senhora por tudo!}

Em memória ao Professor Doutor Eduardo Luis Canedo pelo projeto, dedicação a minha instrução quanto ao assunto abordado no artigo e pelo pai que se tornou durante os três anos com que convivi.

Ao meu orientador o Professor Doutor Antonio Gilson Barbosa de Lima por todo apoio acadêmico.

A Professora Doutora Yêda Medeiros Bastos de Almeida pelas colaborações e amizade.

A UFCG pela oportunidade de estudo e crescimento acadêmico.

Ao Laboratório de Caracterização de Materiais da UFCG na pessoa da Professora Doutora Laura Hecker.

Aos colegas do grupo de pesquisa.

A CAPES pela concessão da bolsa sem a qual seria possível a realização desse trabalho.

\section{REFERÊNCIAS}

[1] Addivant, 2013, Polybond $® 3009$ Polymer Modifier - Technical Information.

[2] Almeida, T. G., Silva Neto, J. E., Costa, A. R. M., Silva, A. S., Carvalho, L. H., Canedo, E. L., 2016, Degradation during processing in poly (butylene adipate-co-terephthalate)/vegetable fiber compounds estimated by torque rheometry. Polymer Testing 55, 204-211.

[3] Alves, T. S., Silva Neto, J. E., Silva, S. M. L., Carvalho, Canedo, L. H., E. L., 2016, Process simulation of laboratory internal mixers. Polymer Testing 50, 94-100.

[4] Arruda, S. A., Sousa, J. C., Lima, J. C., Vitorino, M. B. C., Canedo, E. L., Almeida, Y. M. B., 2018, Nonisothermal melt crystallization kinetics of PHB/babassu compounds. Materials Research, in press.

[5] Braskem, 2017, High Density Polyethylene JV060U Data Sheet.

[6] Baldissera, A. F.; Pezzin, A. P. T.; Duek, E. A. R.; Tessier, M.; Fradet, A.; Einlof, S., 2005. Reciclagem de PET PósConsumo: Síntese de Copolímeros Alifático-Aromáticos (PET-co-PEA). Revista Matéria, v. 10, n. 4, p. 577-585.

[7] Canedo, E. L., Wellen, R. M. R., Almeida, Y. M. B., 2016, Cristalização de Polímeros. Tratamento de Dados e Modelagem Macrocinética. ANP-PRH28/UFPE: Recife.

[8] Canedo, E. L., Alves, T. S., 2015, Processamento de Polímeros no Misturador Interno de Laboratório. Workshop CFD/UFCG: Campina Grande. DOI: 10.13140/ RG.2.1.1892. 5921.

[9] Costa, A. R. M., Almeida, T. G., Silva, S. M. L., Carvalho, L. H., Canedo, E. L., 2015, Chain extension in poly (butylene-adipate-terephthalate). Inline analysis in a laboratory internal mixer. Polymer Testing 42, 115-121.

[10] Costa, A. R. M., Ito, E. N., Cavalho, L. H., Canedo, E. L., 2018, Non-isothermal melt crystallization kinetics of poly (3-hydroxybutyrate), poly (butylene adipate-co-terphthalate) and its mixture. Polímeros: Ciência e Tecnologia, in press.

[11] Chiu, H.-T., Hsiao, Y.-K., 2006, Compatibilization of poly (ethylene terephthalate)/ polypropylene blends with maleic anhydride grafted polyethylene-octene elastomer. Journal of Polymer Research 13, 153-160.

[12] Dealy, J. M., Larson, R. G., 2006, Structure and Rheology of Molten Polymers. Hanser: Munich \& Cincinnati,.

[13] Duarte, I. S., Tavares, A. A., Lima, P. S., Andrade, D. L. A. C. S., Carvalho, L. H., Canedo, E. L., Silva, S. M. L., 2016, Chain extension of virgin and recycled poly (ethylene terephthalate): Effect of processing conditions and reprocessing. Polymer Degradation and Stability 124, 26-34.

[14] Falcão, G. A. M., Vitorino, M. B. C., Almeida, T. G., Bardi, M. A. G., Carvalho, L. H., Canedo, E. L., 2017, PBAT/organoclay composite films: preparation and properties. Polymer Bulletin 74, 4423-4436.

[15] Jaques, N. G., Silva, I. D. S., Ries, A., Canedo, E. L., Wellen, R. M. R., 2017, Nonisothermal crystallization studies of PBT/ZnO compounds. Ozawa and Mo models. Journal of Thermal Analysis and Calorimetry, DOI: 10.1007/s10973017-6754-x.

[16] Jaques, N. G., Silva, I. D. S., Barbosa Neto, M. C., Ries, A., Wellen, R. M. R., Canedo, E. L., 2018, Effect of heat cycling on melting and crystallization of PBT/TiO2 compounds. Polímeros: Ciência e Tecnologia, in press.

[17] Kim, D.-H., Park, K.-Y., Kim, J.-Y., Suh, K.-D., 2000, Improved compatibility of high-density polyethylene/poly (ethylene terephthalate) blend by the use of blocked isocyanate group. Journal of Applied Polymer Science 78, 10171024. 
[18] Kint, D. P. R.; Ilarduya, A. M. D.; Munoz-GuerrA, S., 2001 - J. Poly(ethylene terephthalate) copolymers containing 5-tert-butyl isophthalic units. Polymer Scienc. Part. A: Polymer Chemical, v. 39, p.1994.

[19] Lima, J. C., Sousa, J. C., Arruda, S. A., Almeida, Y. M. B., Canedo, E. L., 2018, Polycaprolactone matrix composites reinforced with brown coir: rheological, crystallization and mechanical behavior. Polymer Composites, DOI: $10.1002 /$ pc.24951.

[20] Lima, P. S., 2017, Compósitos PEAD/quitosana preparados por fusão. Influência do teor de compatibilizante e de antioxidantes. Tese de doutorado em Ciência e Engenharia de Materiais, Universidade Federal de Campina Grande (UFCG).

[21] Lima Jr, R. G., Arruda, S. A., Wellen, R. M. R., Carvalho, L. H., Canedo, E. L., Almeida, Y. M. B., 2016, Nonisothermal melt crystallization in poly (ethylene terephthalate)/zinc oxide compounds. 3rd Brazilian Conference on Composite Materials (BCCM3), Gramado RS, August 28-31.

[22] Lima, P. S., Brito, R. S. F., Santos, B. F. F., Tavares, A. A., Agrawal, P., Andrade, D. L. A. C. S., Wellen, R. M. R., Canedo, E. L., Silva, S. M. L., 2017, Rheological properties of HDPE/chitosan composites modified with PE-g-MA. Journal of Materials Research 32, 775-787.

[23] Lima, J. C., Sousa, J. C., Arruda, S. A., Almeida, Y. M. B., Canedo, E. L., 2018, Polycaprolactone matrix composites reinforced with brown coir: rheological, crystallization and mechanical behavior. Polymer Composites, DOI: $10.1002 /$ pc.24951.

[24] Mandelkern, L., 2007, Thermodynamic quantities governing melting. In: J. E. Mark (ed), Physical Properties of Polymers Handbook, 2nd Edition. Springer: Berlin.

[25] Marinho, V. A. D., Pereira, C. A. B., Vitorino, M. B. C., Silva, A. S., Carvalho, L. H., Canedo, E. L., 2017, Degradation and recovery in poly (butylene adipate-co-terephthalate)/ thermoplastic starch blends. Polymer Testing $58,166-172$

[26] Mosso \& Ghisolfi (M\&G), Polyethylente Terephthalate (PET) Cleartuf® Turbo II Data Sheet (2013).

[27] Pawlak, J. Morawiec, F. Pazzagli, M. Pracella, A. Galeski., 2002, Recycling of postconsumer poly (ethylene terephthalate) and high-density polyethylene by compatibilized blending. Journal of Applied Polymer Science 86, 1473-1485.

[28] Pracella, M., Rolla, L., Chionna, D., Galeski, A., 2002, Compatibilization and properties of poly (ethylene terephthalate)/polyethylene blends based on recycled materials. Macromolecular Chemistry and Physics 203, 14731485 .

[29] Reul, L. T. A., Pereira, C. A. B., Sousa, F. M., Santos, R. M., Carvalho, L. H., Canedo, E. L., 2018, Polycaprolactone/babassu compounds: rheological, thermal, and morphological characteristics. Polymer Composites, DOI: $10.1002 /$ pc.24861.

[30] Ries, A., Canedo, E. L., Monteiro, A. E. G., Almeida, Y. M. B., Wellen, R. M. R., 2016, Model-free non-isothermal crystallization kinetics of poly (3-hydoxybutyrate) filled with carbon black. Polymer Testing 50, 241-246.

[31] Ries, A., Canedo, E. L., Wellen, R. M. R., 2016, Non-isothermal cold crystallization kinetics of poly (3hydoxybutyrate) filled with zinc oxide. Thermochimica Acta 637, 74-81.

[32] Silva, I. D. S., Jaques, N. G., Barbosa Neto, M. C., Agrawal, P., Ries, A., Wellen, R. M. R., Canedo, E. L., 2017, Melting and crystallization of PBT/ZnO compounds. Effect of heating and cooling cycles on phase transition. Journal of Thermal Analysis and Calorimetry, DOI: 10.1007/s10973-017-6749-7.

[33] Sousa, J. C., Carvalho, L. H., Almeida, Y. M. B., Canedo, E. L., 2016, Crystallization and melting of poly (butylene adipate terephtalate) in biocomposites with coconut fiber. 3rd Brazilian Conference on Composite Materials (BCCM3), Gramado RS, August 28-31.

[34] Sousa, F. M., Costa, A. R. M., Reul, L. T. A., Cavalcanti, F. B., Carvalho, L. H., Almeida, T. G., Canedo, E. L., 2018, Rheological and thermal characterization of PCL/PBAT blends. Polymer Bulletin, DOI: 10.1007/s00289-018-2428-5.

[35] Tavares, A. A., Silva, D. F. A., Lima, P. S., Andrade, D. L. A. C. S., Silva, S. M. L., Canedo, E. L., 2016, Chain extension of virgin and recycled polyethylene terephthalate. Polymer Testing 50, 26-32.

[36] Van Krevelen, D. W., Te Nijenhuis, K., 2009, Properties of Polymers, 4th Edition. Elsevier: Amsterdam.

[37] Vitorino, M. B. C., Cipriano, P. B., Wellen, R. M. R., Canedo, E. L., Carvalho, L. H., 2016, Nonisothermal crystallization of poly ( $\beta$-hydroxybutyrate)/babassu eco-composites. Kinetics of crystallization. Journal of Thermal Analysis and Calorimetry 126, 755-769.

[38] Ward, S.; Jones, K. M.; Marbrow, R. A., 1997 - "Recycling of Polyester: An Industry Perspective”, in: Chemical Aspects of Plastics Recycling. Hoyle, W. and Karsa, D.R. The Royal Society of Chemistry, Cambridge, U.K: 79.

[39] Wellen, R. M. R., Canedo, E. L., 2014, On the Kissinger equation and the estimate of activation energies for non-isothermal cold crystallization of PET. Polymer Testing 40, 33-38. 
[40] Wellen, R. M. R., Canedo, E. L., 2015, Complex cold crystallization peaks in PET/PS blends. Polymer Testing 41, 26-32.

[41] Wellen, R. M. R., Canedo, E. L., Lima, C. A. V., Almeida, Y. M. B., Rabello, M. S., 2015, The effect of polystyrene on the crystallization of poly (3-hydroxybutyrate). Materials Research 18, 235-239.

[42] Wellen, R. M. R., Rabello, M. S., Fechine, G. J. M., Canedo, E. L., 2015, Melting and crystallization of poly (3hydroxybutyrate). Effect of heating/ cooling rates on phase transformation. Polímeros: Ciência e Tecnologia 25, 296304.

[43] Wellen, R. M. R., Canedo, E. L., Rabello, M. S., 2015, Melting and crystallization of PHB/carbon black compounds. Effect of heating and cooling cycles on phase transition. Journal of Materials Research 30, 3211-3226.

[44] Wellen, R. M. R., Canedo, E. L., 2016, Nonisothermal melt and cold crystallization kinetics of PHB and PHB/CB compounds. Evaluation of Pseudo-Avrami, Ozawa, and Mo models. Journal of Materials Research 31, 729-739.

[45] Xanthos, M., Dagli, S., 1991, Compatibilization of polymer blends by reactive processing. Polymer Engineering and Science 31, 929-935.

\section{RESPONSABILIDADE AUTORAL}

Direitos autorais reservados aos autores Raquel Marques dos Santos e Antonio Gilson Barbosa de Lima. 


\section{Capítulo 4}

Gradientes de temperatura e pressão: Um risco de dano industrial em tubulações industriais

\section{Adriano de Sousa Cabral \\ Fabiany Bento da Silva \\ Herllange Chaves de Brito \\ José Jefferson da Silva Nascimento \\ Rubenia de Oliveira Costa}

Resumo: As tubulações industriais são produzidas para as mais diversas aplicações, desde tubos sem requisitos até tubos para troca térmicas e estruturais e estão submetidos a severos carregamentos, devido às mudanças na quantidade de movimento do fluido ou na estrutura da tubulação. 0 objetivo deste trabalho é avaliar os gradientes de temperatura e pressão como precaução de evitar danos em tubulações industriais e potenciais acidentes. 0 escoamento no interior do tubo foi modelado pelas equações de conservação da massa, quantidade de movimento e energia. 0 problema físico em estudo está relacionado com uma mistura de fluídos em temperaturas diferentes em duas entradas numa tubulação do tipo " $\mathrm{T}$ ". As simulações numéricas foram realizadas empregando-se o método dos volumes finitos baseado em elementos, com o software Ansys-CFX 16.1, em regime permanente e utilizando malhas estruturadas com 8.200 nós e 20.793 elementos. Diante os resultados ficou evidente que significativos gradientes de temperatura e pressão localizados na interseção dos dutos, nominados inlety e inletz, favorecem sobremaneira a ocorrência de danos estruturais (trincas e fraturas) na união quando os limites de resistência/fadiga do material e da solda forem ultrapassados. Como forma de mitigar possíveis danos, sugere-se a mudança da geometria da união visando diminuição de concentradores de tensões e/ou escolha de material dos dutos baseando-se nas pressões e temperaturas encontradas.

Palavras-chave: Acidentes, Simulação Numérica, CFD. 


\section{INTRODUÇÃO}

A agroindústria é um setor próspero que superou grandes desafios nos últimos anos, com o crescimento das fronteiras agrícolas e a expansão da produção agroindustrial com isso, é de grande importância para sistemas de tubulações industriais a análise de suas peças mecânicas, evitando assim aumento de custos operacionais bem como eventuais acidentes trabalhistas.

As tubulações industriais são produzidas para as mais diversas aplicações, desde tubos sem requisitos até tubos para troca térmicas e estruturais, estando presente nas mais diversas indústrias, tais como: indústrias químicas, mecânicas, petroquímicas, alimentícias, farmacêuticas, agroindústrias, dentre outras (BENTES, 2007).

Os sistemas de tubulação industrial estão submetidos a severos carregamentos, devido às mudanças na quantidade de movimento do fluido ou na estrutura da tubulação são abruptamente induzidas devido a ações planejadas ou acidentais (ROCHA, 2011).

0 estudo em tubulações industriais, principalmente pressurizadas e sob temperaturas elevadas, apresenta grande importância para a manutenção do sistema, redução dos custos industriais e prevenção de acidentes trabalhistas. Nessas tubulações, operando acima de determinadas temperaturas e sob carregamentos diversos, observa-se que o material estrutural altera suas propriedades mecânicas originais à temperatura ambiente (DOMINGUEZ, 2008).

Para Raeder (2012) os danos inesperados em componentes de uma tubulação está diretamente associado a risco de acidentes, aumento de custos operacionais e perda de produção da indústria. Risco é todo evento futuro e incerto que possa comprometer a realização de um ou mais objetivos do projeto ou da indústria. Para tanto, a indústria deve trabalhar de forma preventiva, evitando assim que danos sejam causados em sua tubulação, para isso, é necessário que a empresa esteja sempre planejando e gerenciamento ações de resposta a estes riscos (BENTES, 2007).

Os principais benefícios do gerenciamento de riscos são a minimização da probabilidade de eventos inesperados que causem perdas, ampliando assim as chances de sucesso, o que é vital no desempenho organizacional da indústria.

Uma ferramenta bastante utilizada em aplicações industriais é a Fluidodinâmica Computacional (CFD computacional fluid dynamics), em que utiliza técnicas numéricas avançadas para solucionar problemas complexos da engenharia e da física, que por meio desse tipo de simulação computacional é capaz de predizer fenômenos físicos e físico-químicos que ocorrem em um dado escoamento (SANTOS E MEDRONHO, 2007).

A simulação computacional permite a indústria simular um fenômeno físico, reduzindo custos e auxiliando na tomada de decisão, além de atuar de forma preventiva, uma vez, que se consegue visualizar possíveis problemas por meio da simulação. Outra vantagem da simulação computacional é permitir a visualização tridimensional do escoamento, facilitando o conhecimento pleno das características do movimento do fluído (NETO et al., 2009).

A aplicação da CFD em análise de escoamentos é utilizada em várias indústrias tais como: metalurgia, aerodinâmica, alimentícia, automotiva, química, aeroespacial, biomédica, pás de turbinas, máquinas de fluxo e geração de energia.

Essa ferramenta auxilia no conhecimento a respeito de como os fluidos vão escoar e quais são os efeitos quantitativos de suas interações em tubulações industriais (NETO et al., 2009). Assim, ante o exposto, este trabalho tem como objetivo avaliar os gradientes de temperatura e pressão como precaução de evitar danos em tubulações industriais e potenciais acidentes.

\section{TUBULAÇÃO INDUSTRIAL}

As tubulações industriais são produzidas para as mais diversas aplicações, desde tubos sem requisitos até tubos para troca térmicas e estruturais, sendo aplicada as mais diversas industriais (BENTES, 2007).

Sistemas de tubulação industrial para transporte de líquidos estão submetidos a severos carregamentos transientes sempre que mudanças na quantidade de movimento do fluido ou na estrutura da tubulação são abruptamente induzidas devido a ações planejadas ou acidentais (ROCHA, 2011).

Estruturalmente, tubulação é considerada como sendo um vaso de pressão, isto é, urna estrutura curva, fechada e que contém líquido e/ou gás sob pressão (BENTES, 2007). 
Alguns equipamentos usados em operações unitárias de plantas químicas e petroquímicas, bem como em centrais de geração de energia, operam com maior eficiência quando sua temperatura é aumentada. Portanto, há uma relação direta com os materiais aplicados e sua resistência à degradação de suas propriedades em elevadas temperaturas (DOMINGUEZ, 2008).

Esta característica é aumentada com a introdução de elementos de liga ao aço e, também de forma direta, há um aumento de custo. Casos como estes têm um tratamento diferenciado em seu dimensionamento e especificação (DOMINGUEZ, 2008).

Os principais sistemas industriais que envolvem grandes conjuntos de tubulações de aço carbono estão nas indústrias químicas, petroquímicas e em suas utilidades energéticas, isto por causa do número de unidades existentes e da quantidade em peso das tubulações utilizadas (DOMINGUEZ, 2008).

Existem diversos tipos de fluidos, mas os corrosivos e de temperaturas elevadas são os que mais afetam os sistemas de tubulação e dutos (FALUHELYI, 2006).

\subsection{DANOS EM TUBULAÇÕES INDUSTRIAIS}

A possibilidade de eventos indesejados, previsíveis ou não, se concretizarem, estará sempre presente ao dia-a-dia das empresas. Para evitar a concorrência destes, ou ainda, minimizar seus impactos danosos, quer sobre o homem, sobre os meios materiais, quer sobre o meio ambiente, haverá a necessidade de o gestor incorporar ao cotidiano da organização uma série de práticas.

Dessa forma, deverá investigar incessantemente todas as possibilidades de incidentes, acidentes e de perdas, para conhecer suas causas e efeitos e, em seguida, estabelecer os instrumentos eficazes de sua prevenção, monitoramento e controle (FILHO,2001).

Os principais danos que as tubulações industriais e prediais apresentam, em geral, são trechos amassados e/ou com sulcos superficiais e perda de material por corrosão. Existem vários danos que são causados em tubulações industriais, dentre eles: falhas por fraturas, falhas estruturais, rupturas de tubulação, trincas e fraturas (BENTES, 2007).

Um tipo particularmente sério de dano em tubos de aço são as trincas por fadiga, as quais podem ocorrer durante o transporte, quase sempre por longas distâncias e por intermédio de diferentes formas (OTEGUI E KUNERT, 2004).

De acordo com Bruno (1998) a fadiga devido ao trânsito (Transit Fatigue) é resultante de tensões cíclicas induzidas por forças gravitacionais e inerciais.

Há três cenários principais de danos em tubulações industriais: perda de metal na parede externa, perda de metal na parede interna e componente da tubulação com vazamento. Ainda pode-se citar a ocorrência de trincas em solda ou do próprio tubo original, sem ser por perda de metal ou vazamento da tubulação, que exigem considerações especiais (AEA, 2001).

Além disso, ao transportar fluido em tubulação, especialmente substância que reage com a parede interna de um tubo, acarretando corrosão, erosão, ou uma combinação destes dois tipos de deteriorações (FALUHELYI, 2006).

\section{METODOLOGIA}

O escoamento no interior do tubo foi modelado pelas equações de conservação da massa, quantidade de movimento e energia, sendo escritas de forma geral de acordo com Maliska (2004) e Mariano (2008), conforme exposto na equação [1] e representa a equação de conservação da massa, quando $S^{\varnothing}$ for igual a zero e $\varnothing=1$.

$$
\begin{gathered}
\quad \frac{\partial}{\partial t}(\rho \phi)+\frac{\partial}{\partial x}(\rho u \phi)+\frac{\partial}{\partial x}(\rho v \phi)+\frac{\partial}{\partial x}(\rho w \phi)= \\
=\frac{\partial}{\partial x}\left(\Gamma^{\phi} \frac{\partial \phi}{\partial x}\right)+\frac{\partial}{\partial y}\left(\Gamma^{\phi} \frac{\partial \phi}{\partial y}\right)+\frac{\partial}{\partial z}\left(\Gamma^{\phi} \frac{\partial \phi}{\partial z}\right)+S^{\phi} .
\end{gathered}
$$


As equações da quantidade de movimento nas três direções coordenadas foram obtidas fazendo-se $\varnothing$ igual a $u, v$ e $w$ com o apropriado termo fonte, que neste caso, inclui o gradiente de pressão. A equação da energia foi obtida fazendo-se $\varnothing=T$, também com o termo fonte apropriado. $\Gamma^{\varnothing}$ representa o produto da difusividade pela massa especifica da propriedade transportada em consideração.

Assim, $\Gamma^{\varnothing}=\mu$ e para a equação da energia $\Gamma^{\varnothing}=\mathrm{k} / \mathrm{cp}$, quando o escoamento é laminar, e é igual a $\mu_{\text {efetivo }} \mathrm{e}$ $(\mathrm{k} / \mathrm{cp})_{\text {efetivo, }}$ quando o escoamento for turbulento, se acordo com Maliska (2004).

A modelagem da turbulência foi realizada por equações que descrevem os termos adicionais gerados na aplicação das equações médias de Navier-Stokes, associadas a forças gravitacionais, viscosas e de pressão. Os termos adicionais, Tensores de Reynolds, foram modelados por duas equações.

Os modelos diferenciais de duas equações são amplamente utilizados em aplicações industriais e utilizam duas equações de transporte para a modelagem da turbulência. 0 modelo de turbulência utilizado foi de duas equações, $\mathrm{k}$-epsilon, sendo este modelo o mais adequado para a maior parte dos equipamentos industriais, tal modelo correlaciona os termos de flutuação de velocidade com duas equações de transporte, uma de energia cinética turbulenta e uma de taxa de dissipação turbulenta (MALISKA,2004).

Baseando-se na referência Timoshenko e Goodier (1982), as tensões térmicas estão associadas a incrementos nos níveis de temperatura de tal forma que considerando a Equação 2 e à medida em que a temperatura aumenta no sistema, as tensões térmicas também aumentam de maneira que se os valores ultrapassarem os limites de resistência, ocorrerão fraturas e caso ultrapassem os valores de escoamento ocorrem deformações na estrutura.

$$
\sigma_{x}=\sigma_{z}=\frac{\alpha E T}{1-v}
$$

Neste contexto é importante ressaltar que fraturas e deformações podem ocasionar acidentes representando perdas irreparáveis tanto materiais, como humanas, além de prejudicar a própria imagem da instituição, o que pode significar até mesmo o fim da empresa (BENTES, 2007).

O problema físico em estudo está relacionado com uma mistura de fluídos com temperaturas e pressões diferentes e, em duas entradas numa tubulação do tipo "T", de modo que possam ser avaliados os seus gradientes, sendo as entradas em cores vermelha e azul, conforme exposto na Figura 1.

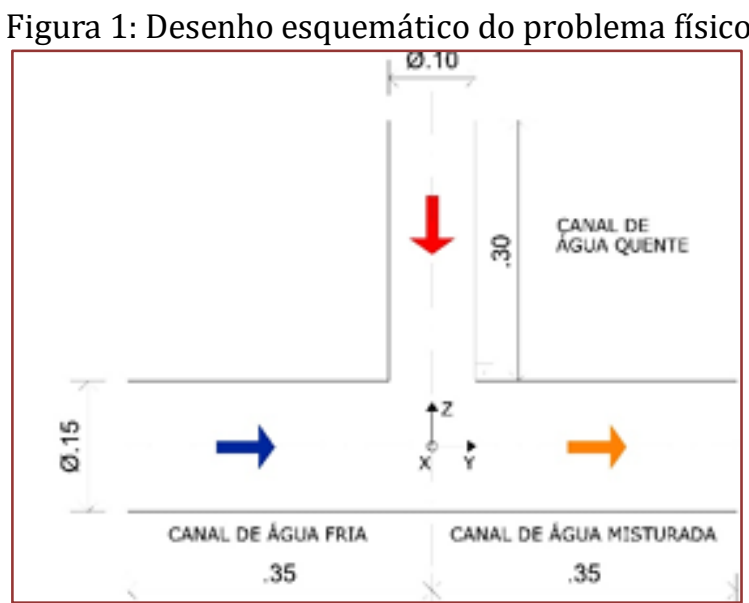

Fonte: Autoria própria (2019).

As simulações numéricas, para este estudo, foram realizadas empregando-se o método dos volumes finitos baseado em elementos, com o software Ansys-CFX 16.1, em regime permanente e utilizando malhas estruturadas. A malha tetraédrica possui 8.200 nós e 20.793 elementos, ilustrado na Figura 02. 
Figura 2: Malha da junção em T do problema físico.

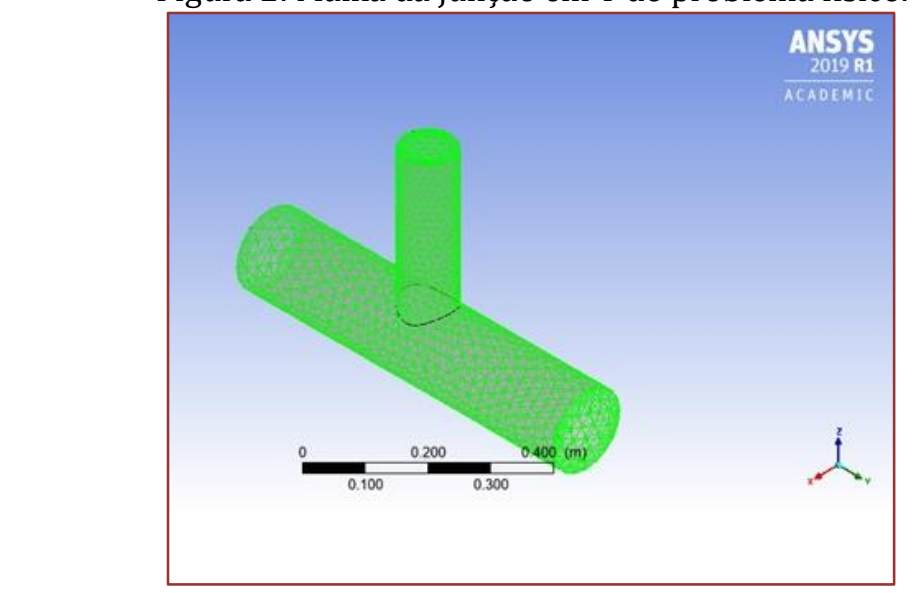

Fonte: Autoria própria (2019) | Desenvolvido no ANSYS 2019 R1- ACADEMIC.

As condições de contorno, foram no inlety (entrada y) com temperatura de $283 \mathrm{~K}$ e no inletz (entrada z) com temperatura de $363 \mathrm{~K}$. As pressões foram de $1 \mathrm{~atm}$ para os fluxos de entrada (inlety e inletz) e $0 \mathrm{~atm}$ para o fluxo de saída (outlet).

O fluido utilizado foi água com propriedades físicas e parâmetro de simulação sendo os seguintes: densidade $997 \mathrm{~kg} / \mathrm{m}^{3}$ e a viscosidade dinâmica de 1,002 cP. 0 critério de convergência utilizado foi 10-8.

\section{RESULTADOS E DISCUSSÃO}

Na Figura 3, representada através de perspectiva isométrica (a) e corte longitudinal no plano zy (b), a seguir, podem se observar as representações da simulação, sendo mostrado o perfil de temperatura, onde as maiores temperaturas se encontram no eixo $\mathrm{Z}$ convergindo em sentido ao fluxo no eixo $\mathrm{Y}$, expressando grande incidência de temperatura no encontro dos dutos que formam a conexão "T".

Figura 3: Distribuição de temperatura:

(a) modelo 3D

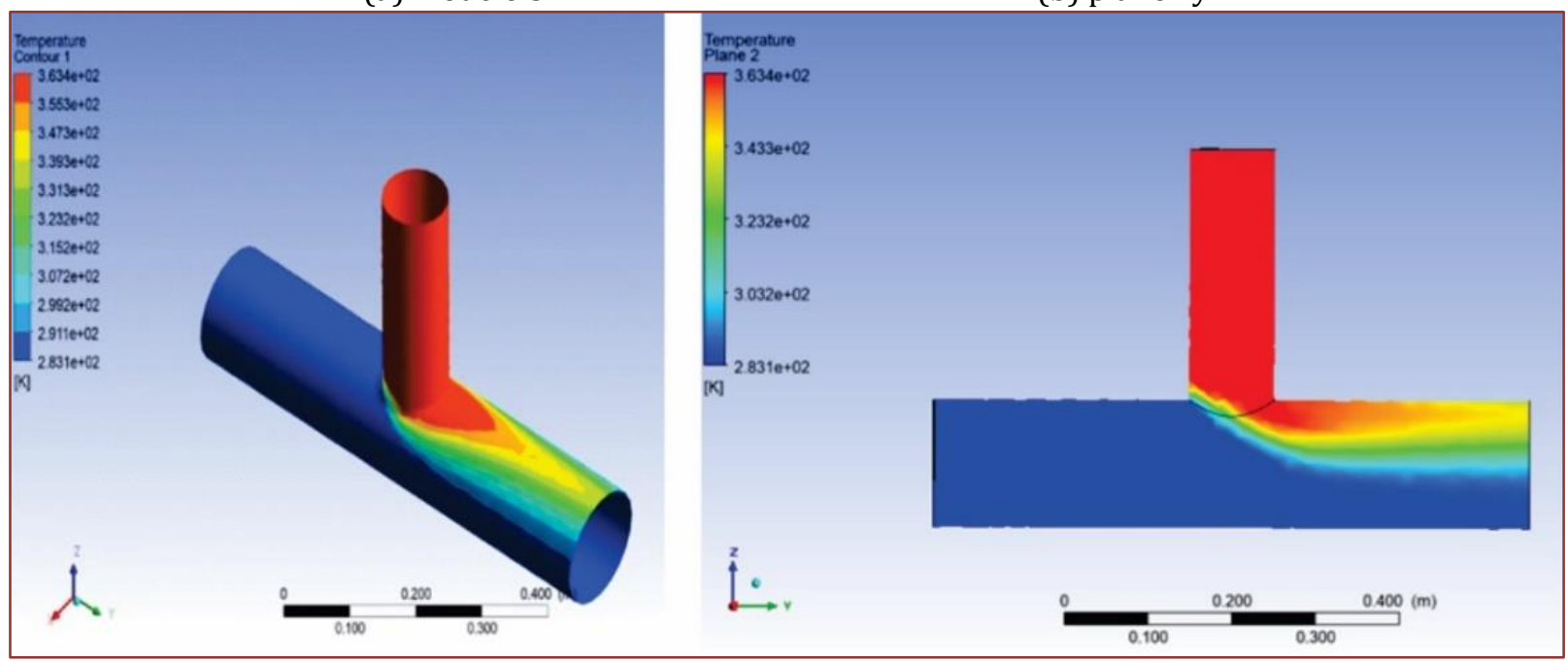

Fonte: Autoria própria (2019) | Desenvolvido no ANSYS 2019 R1- ACADEMIC. 
Como consequência destes significativos valores, pode-se elencar a existência de gradientes de temperatura, conforme Tabela 1 e observaram-se, nas áreas limitadas nos retângulos azuis, os seguintes gradientes de temperatura para os eixos Y e Z no Gráfico 1 e Gráfico 2.

Tabela 1: Gradientes de Temperatura nos eixos Y e Z.

\begin{tabular}{|c|c|}
\hline Gradiente $\Delta \mathrm{T} / \Delta \mathrm{Y}$ & Gradiente $\Delta \mathrm{T} / \Delta \mathrm{Z}$ \\
\hline $0,100 \mathrm{a} 0,150 \mathrm{~m}=244,47 \mathrm{~K} / \mathrm{m}$ & $0,0416 \mathrm{a} 0,083 \mathrm{~m}=1.568 \mathrm{~K} / \mathrm{m}$ \\
\hline$-0,200 \mathrm{a}-0,100 \mathrm{~m}=0$ & $-0,200 \mathrm{a}-0,100 \mathrm{~m}=0$ \\
\hline
\end{tabular}

Fonte: Autoria própria (2019).

Gráfico 1: Distribuição de Temperatura no eixo Y.

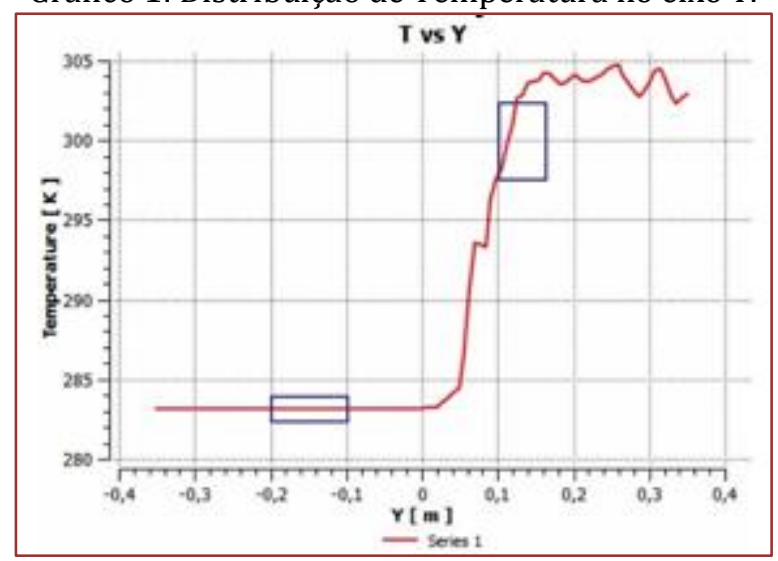

Fonte: Autoria própria (2019).

Gráfico 2: Distribuição de Temperatura no eixo Z.

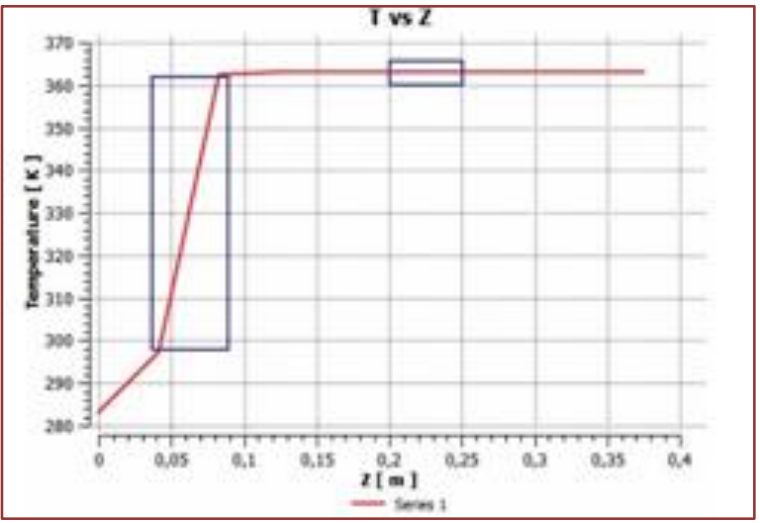

Fonte: Autoria própria (2019).

A partir do Gráfico 1 é possível observar a distribuição de Temperatura ao longo do eixo Y desde a alimentação da corrente fria $(-0,35 \mathrm{~m})$ até a saída da peça $(0,35 \mathrm{~m})$, percebe-se que inicialmente a temperatura se mantém constante ao longo do duto alimentado pela corrente fria, em seguida observa-se uma mudança brusca de temperatura no encontro dos dutos que formam a conexão "T" que representa o encontro das correntes quente e fria.

De modo semelhante para o Gráfico 2, têm-se a distribuição de temperatura ao longo do eixo $\mathrm{Z}$ desde o centro da peça $(0 \mathrm{~m})$ até a alimentação da corrente quente $(0,4 \mathrm{~m})$. Observa-se um maior gradiente de temperatura na região de encontro das duas correntes, de modo que até o encontro das correntes a temperatura ao longo do duto alimentado pela corrente quente se mantém com temperatura aproximadamente igual a temperatura de alimentação. 
Neste contexto, caso os gradientes citados ultrapassem os limites de escoamento dos materiais de construção mecânica, haverá deformação plástica. Caso, ultrapasse os limites de ruptura dos materiais, a estrutura irá colapsar causando danos irreparáveis.

Na Figura 4 também representada através de perspectiva isométrica (a) e corte longitudinal plano ZY (b), a seguir, podem se observar as representações da simulação, sendo evidenciado o gradiente de pressão, semelhante aos dados da análise para a temperatura onde, os maiores gradientes de pressões se encontram no eixo $\mathrm{Z}$ convergindo em sentido ao fluxo no eixo $\mathrm{Y}$, expressando maiores níveis de pressão no encontro dos dutos que formam a conexão "T".

Deste modo, para o gradiente de pressão, analisaram-se os Gráfico 3 e Gráfico 4. Nos mesmos, observaram-se os seguintes gradientes de pressão para os eixos Y e Z. Observaram-se os seguintes gradientes de temperatura para os eixos Y e Z na Tabela 2.

(a) modelo 3D

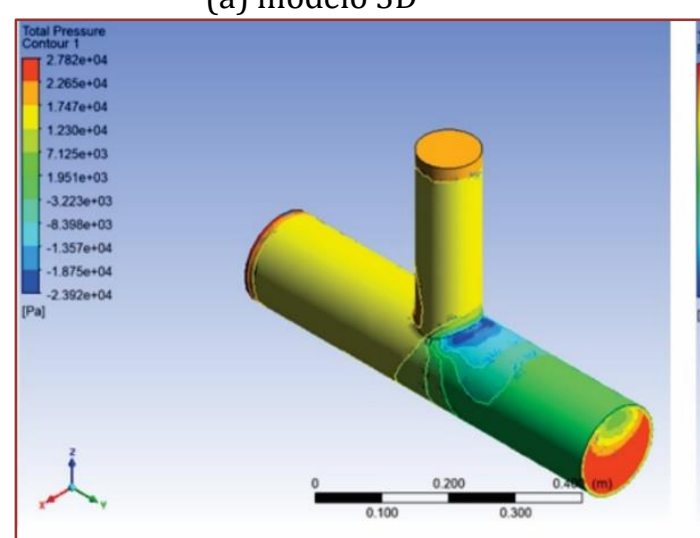

Fonte: Autoria própria (2019) | Desenvolvido no ANSYS 2019 R1- ACADEMIC. (b) plano zy.

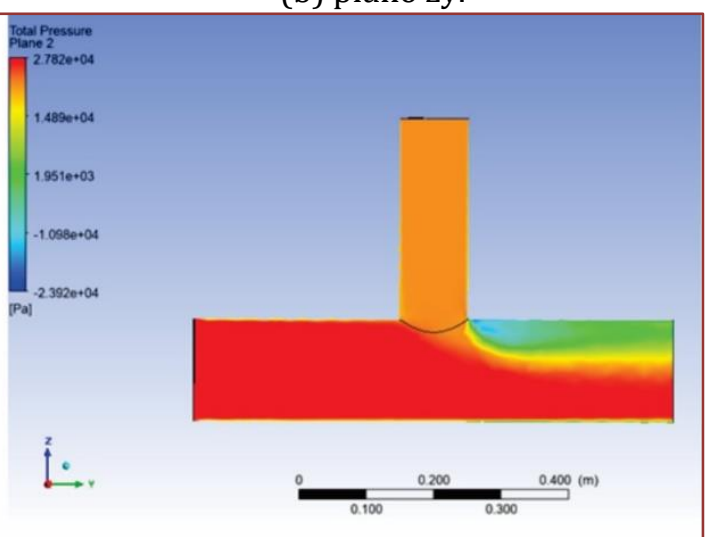

Tabela 2: Gradientes de Pressão nos eixos Y e Z.

\begin{tabular}{|c|c|}
\hline Gradiente $\Delta \mathrm{P} / \Delta \mathrm{Y}$ & Gradiente $\Delta \mathrm{P} / \Delta \mathrm{Z}$ \\
\hline $0,119 \mathrm{a} 0,153 \mathrm{~m}=45.631 \mathrm{~Pa} / \mathrm{m}$ & $0,041 \mathrm{a} 0,08 \mathrm{~m}=79.256 \mathrm{~Pa} / \mathrm{m}$ \\
\hline $0,049 \mathrm{a}-0,105 \mathrm{~m}=0$ & $0,333 \mathrm{a} 0,374 \mathrm{~m}=0$ \\
\hline
\end{tabular}

Fonte: Autoria própria (2019).

Gráfico 4: Distribuição de Pressão no eixo Y.

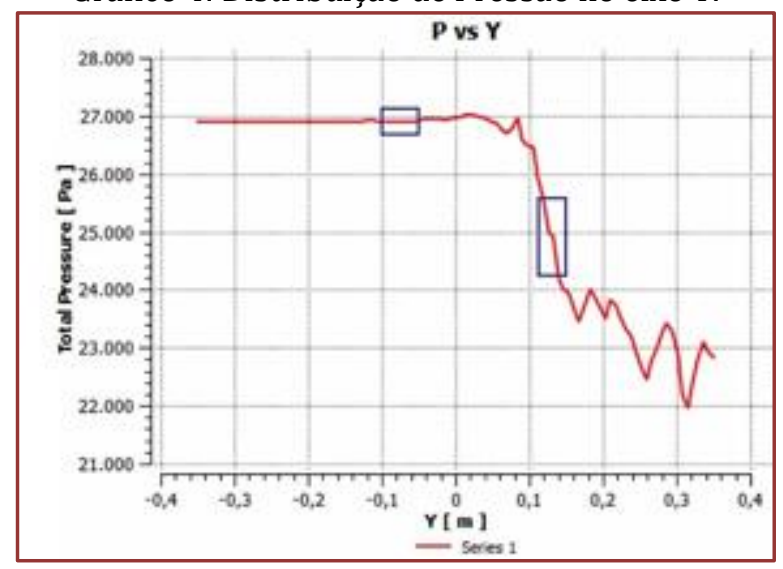

Fonte: Autoria própria (2019). 
Gráfico 5: Distribuição de Pressão no eixo Z.

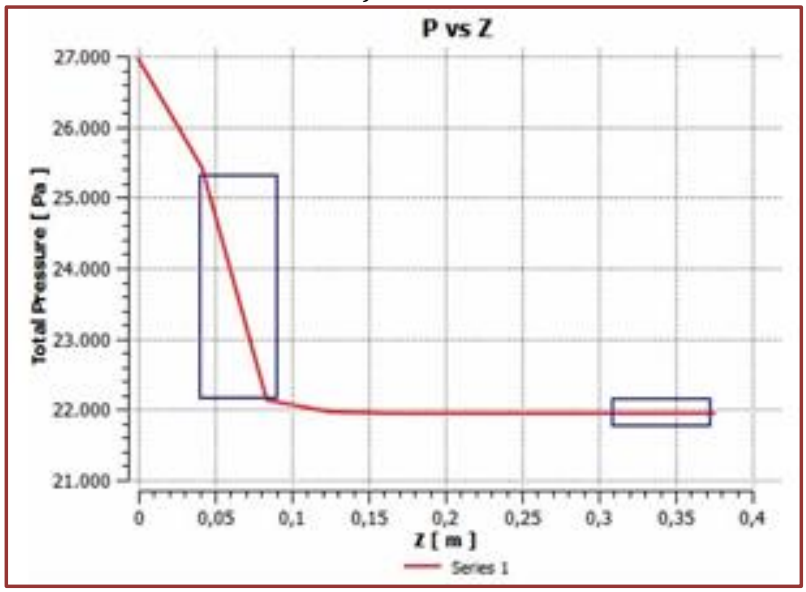

Fonte: Autoria própria (2019)

De posse dos resultados supramencionados, ficam evidentes que significativos gradientes de temperatura e pressão localizados na interseção dos dutos favorecem sobremaneira a possibilidade da ocorrência de danos estruturais (trincas e fraturas) conforme afirmam Timoshenko e Goodier (1982).

Os gradientes que agem sobre um objeto, no caso em tela uma união "T", devem ser uniformemente distribuídas sobre sua área. Fato posto, a simulação mostrou-se eficiente em seus objetivos iniciais.

\section{CONSIDERAÇÕES FINAIS}

De posse dos resultados supramencionados, ficam evidentes que significativos gradientes de temperatura e pressão localizados na interseção dos dutos favorecem sobremaneira a possibilidade da ocorrência de danos estruturais (deformações, trincas e fraturas).

Os gradientes que agem sobre um objeto, no caso em tela uma união "T", devem ser uniformemente distribuídas sobre sua área. Fato posto, a simulação mostrou-se eficiente em seus objetivos iniciais.

\section{AGRADECIMENTO}

Agradecemos à CAPES pelo apoio financeiro fornecido para realização deste trabalho através da concessão de bolsa.

\section{REFERÊNCIAS}

[1] AEA Technology Consulting, Temporary/permanent pipe repair - Guidelines. In:Offshore Technology Report, 038, HSE Books, Oxfordshire, UK, 2001, 60p

[2] ANDRADE, P. R. L.; SILVA, G. B.; SILVA, B. T. A.; LIMA, A. G. B.; NASCIMENTO, J. J.S. Risco De Fraturas Em Tubulações Petrolíferas, Uma Análise Com Simulação Computacional Usando CFX. In: I Congresso Nacional de Engenharia de Petróleo, Gás e Biocombustíveis. 2015.

[3] BENTES, F. M. Programa de Gestão de Riscos para Tubulações Industriais. Dissertação de Mestrado em Ciências Mecânicas, Departamento de Engenharia Mecânica, Universidade de Brasília, Brasília, DF. 2007.

[4] BRUNO,T.V. How to prevent transit fatigue to tubular goods. The Oil and Gas Journal. 1998.

[5] DOMINGUEZ, F.R. Análise estrutural direcionada à redução de espessuras em tubulações industriais. Tese de Doutorado em Engenharia Mecânica. Universidade de São Paulo. São Paulo. 2008.

[6] FALUHELYI, P. (2006). Análise de tensões em tubulações com e sem reparo compósito, submetidas a pressões hidrostáticas internas. Dissertação de Mestrado em Sistemas Mecatrônicos, Publicação DM-nº 07, Departamento de Engenharia Mecânica, Universidade de Brasília, Brasília, DF, 2006.

[7] FILHO, A. B. N. - Segurança do Trabalho \& gestão ambiental. São Paulo: Atlas. 2001

[8] MALISKA, C. R., Transferência de Calor e Mecânica dos Fluidos Computacional. LTC Editora. 2004. 
[9] MARIANO, G. C. Estudo do Escoamento Imiscível Água/Óleo Mediante Experimentação em Célula de HeleShaw e Simulação CFD. Dissertação de mestrado, Universidade Federal de Santa Catarina, Santa Catarina, 2008.

[10] NETO, H. J. et al. Modelagem e simulação do comportamento de uma válvula de fluxo hidráulica com o uso de ferramenta de hidroinformática. Revista Tecnologia, v. 29, n. 2, 2009.

[11] OTEGUI, J.L. KUNERT, H.G. Factors influencing transit fatigue of seamless pipes. Universidade de Mar del Plata. 2004.

[12] READER, T. S. A. Estudo Experimental De Esforços Dinâmicos Em Tubulações Com Escoamento Bifásico. Dissertação de Mestrado. Mestrado em Engenharia Mecânica. Universidade Federal Fluminense. 2012.

[13] RoCHA, R. G. Interação Fluido-Estrutura Em Sistemas De Tubulações Conduzindo Líquidos Via Método De Glimm. Tese de Doutorado. Pós-graduação em Engenharia Mecânica. Universidade Federal Fluminense. 2011.

[14] SANTOS, FP dos; MEDRONHO, Ricardo A. Simulação numérica da fluidodinâmica de um riser de craqueamento catalítico. In: CONGRESSO BRASILEIRO DE PESQUISA E DESENVOLVIMENTO EM PETRÓLEO E GÁSPDPETRO. 2007.

[15] TIMOSHENKO S. P. \& GOODIER J. N., Theory of Elasticity, 3rd Edition, Mc-Graw Hill,. 1982. 


\section{Capítulo 5}

Cinética de secagem de sementes de Sorgo (Sorghum Bicolor l. Moench) e avaliação física e química da farinha

\section{Antonio Daniel Buriti de Macedo \\ Ana Paula Moisés de Sousa \\ Renato Alexandre Costa de Santana \\ Ana Regina Nascimento Campos \\ Josivanda Palmeira Gomes}

Resumo: 0 sorgo (Sorghum bicolor L. Moench) apresenta facilidade de produção e estima-se que seja utilizado como alimento básico de boa parte da população que vive em países em desenvolvimento da África e da Ásia. Neste trabalho, objetivou-se avaliar a cinética de secagem de sementes de sorgo sob diferentes temperaturas e as características físicas e químicas da farinha produzida. As sementes de sorgo foram secas em estufa sob as temperaturas de 40, 50 e 60ํㅡ até atingirem massa constante. Os resultados de secagem foram ajustados a modelos matemáticos usados para representação da secagem de produtos agrícolas. Após a secagem, as sementes foram trituradas e a farinha produzida foi analisada quanto ao teor de água, $\mathrm{pH}$, atividade de água, proteína bruta, composição e quantificação mineral. Dos modelos testados, o de Logarítmico foi o mais adequado para predizer o fenômeno de secagem das sementes. 0 tempo necessário de secagem foi de 480, 420, e 360 min para as temperaturas de 40, 50 e $60{ }^{\circ} \mathrm{C}$, respectivamente. A farinha_apresentou teor de água $(6,7 \%)$ dentro do limite estabelecido pela legislação brasileira e foi caracterizada como pouco ácida e boa fonte de minerais, principalmente de fósforo e potássio, demonstrando potencialidades como matéria-prima para possível utilização na elaboração de novos produtos alimentícios.

Palavras-chave: secagem, sorgo, modelos matemáticos, produto farináceo, características físicas e químicas 


\section{INTRODUÇÃO}

Sorgo (Sorghum bicolor L. Moench) pertencente à família das gramíneas, representa o quinto grão mais cultivado no mundo, ficando atrás apenas do trigo, arroz, milho e cevada. Espécie conhecida por apresentar boa tolerância à seca e resistência a outras condições climáticas extremas, bem como sua resistência a fungos e micotoxinas (SADAKA; ATUNGULU, 2018).

No Brasil, a cultura do sorgo vem se expandindo a cada ano, a área plantada está aumentando e consequentemente à produção deste cereal. Segundo o Instituto Brasileiro de Geografia e Estatística, IBGE (2018) a maior parte da produção do sorgo é derivada de segunda safra, quando o índice de chuvas é baixo, pois resiste bem a essas condições. Estimou-se a produção de sorgo para 2018 em 2,3 milhões de toneladas, um aumento de 9,2\% em relação a 2017. Goiás e Minas Gerais são os maiores produtores do país, responsáveis por cerca de $65 \%$ do total produzido.

A produção de grãos de sorgo pode ser afetada por diversos fatores, o que pode comprometer sua qualidade, sendo que o mais importantes é o tempo certo da colheita, pois o grau de maturação das sementes no momento da colheita afeta diretamente na sua qualidade (SOUZA et al., 2009). Após a colheita, os grãos de sorgo devem ser rapidamente secos a um grau de umidade de $12 \%$, aproximadamente, para um armazenamento adequado, especialmente se for armazenado por vários meses. A redução da umidade é feita pela passagem de quantidades relativamente grandes de ar seco através dos grãos após a colocação no recipiente de secagem (SADAKA et al., 2015).

A secagem é um dos importantes processos de pós-colheita de produtos agrícolas. Resende et al. (2008) salientam que a secagem dos produtos agrícolas é o processo mais utilizado para assegurar a sua qualidade e estabilidade, considerando que a diminuição da quantidade de água do material reduz a atividade biológica e as mudanças químicas e físicas que ocorrem durante o armazenamento.

Existem diferentes métodos de secagem de produtos agrícolas que podem ser realizados de forma natural ou artificial. Na secagem natural é utilizada a radiação solar para aumentar o potencial de secagem do ar. Esse tipo de secagem é bastante utilizado no Brasil para a secagem de café, cacau, feijão e milho. Esse método apresenta como desvantagem a dependência das condições climáticas adequadas, no entanto, o fato de propiciar menor ocorrência de grãos trincados ou quebrados é a maior vantagem. A secagem artificial consiste no emprego de artifícios para acelerar o processo de secagem (SILVA, 2005).

Secagem artificial de grãos tem como característica o controle dos procedimentos e modificação das características do ar de secagem, possibilitando a secagem de grandes volumes de grãos e diminuição do tempo de secagem (PORTELLA; EICHELBERGER, 2001). Existem diferentes sistemas de secagem artificial de grão que podem ser utilizados, no entanto, nesse estudo foi empregada a secagem por convecção.

A secagem convectiva, muito empregada na secagem de produtos agrícolas, consiste na redução do teor de água do produto através da passagem forçada de ar aquecido, com baixa umidade relativa, através do produto (VILLA-CORRALES et al., 2010). 0 processo de secagem é normalmente apresentado como uma curva de secagem que representa a relação entre o conteúdo de unidade de grãos e duração de secagem. As curvas de secagem oferecem informações valiosas para entender o mecanismo de migração de água do produto, bem como seus parâmetros cinéticos de secagem (CHEN et al. 2001).

Para a simulação são empregados modelos matemáticos que reproduzem de maneira satisfatória a perda do teor de água do produto durante o período de secagem. Os modelos de cálculo da cinética de secagem são aplicados de modo diferente, dependendo do período considerado (CAMICIA et al., 2015). Há pouca informação na literatura sobre a cinética de secagem ou mesmo sobre o efeito do manejo da semente de sorgo sobre a qualidade da farinha produzida. Assim, obter um modelo de secagem que representa satisfatoriamente os dados experimentais é de fundamental importância para minimizar as alterações promovidas pela secagem, levando, consequentemente, a produtos de boa qualidade.

Diante do exposto, o presente trabalho tem como objetivo avaliar a cinética de secagem de semente de sorgo a 40,50 e $60^{\circ} \mathrm{C}$ em estufa de circulação de ar, ajustando modelos matemáticos aos dados experimentais do processo. Assim como, a obtenção da farinha de sorgo submetida ao processo de secagem em estufa e determinação de suas características físicas e químicas, visando suas potencialidades como matéria-prima para possível utilização na elaboração de novos produtos alimentícios. 


\section{METODOLOGIA}

Os experimentos foram realizados no Laboratório de Bioquímica e Biotecnologia de Alimentos da Universidade Federal de Campina Grande, Centro de Educação e Saúde (UFCG/CES), Cuité, PB.

As sementes de sorgo foram obtidas de plantas semeadas na estufa agrícola do Horto Florestal Olho D'Água da Bica (UFCG/CES) sob condições de rega e solo adequados. A colheita ocorreu em julho de 2017 quando os grãos aparentavam aspectos pastosos a farináceos, isso ocorreu após 104 dias do plantio.

A padronização do teor de água dos grãos foi realizada em estufa de circulação de ar utilizando a temperatura de $40^{\circ} \mathrm{C}$ por $72 \mathrm{~h}$. Em seguida os grãos de sorgo foram limpos e selecionados manualmente, a fim de retirar sujeiras e a palha que recobre os grãos (Figura 1A), obtendo assim sementes com aspecto limpo e homogêneo (Figura 1B).

Figura 1. Sementes de sorgo utilizadas na cinética de secagem e no processo de obtenção da farinha, (A) antes do tratamento e (B) após o tratamento de limpeza.

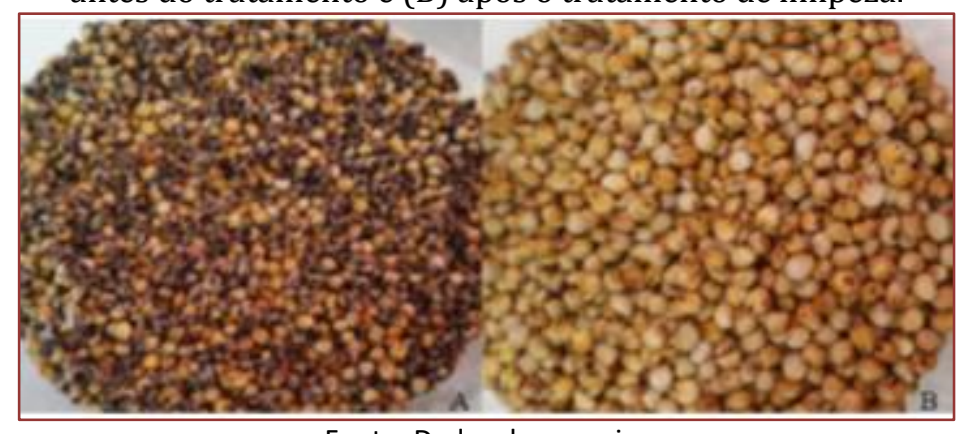

Fonte: Dados da pesquisa

A cinética de secagem foi realizada em estufa com circulação de ar (marca American Lab, modelo AL102/480), nas temperaturas de 40,50 e $60^{\circ} \mathrm{C}$. Antes e ao término de cada secagem, foram retiradas amostras de sementes para determinação do teor de água (TA). Para isso, foi utilizada uma estufa de esterilização e secagem (marca Solab, modelo $\mathrm{Sl} 100)$ a $105 \pm 3^{\circ} \mathrm{C}$ até massa constante, de acordo com metodologia descrita pelo Instituto Adolfo Lutz (2008). 0 teor de água, expresso em base úmida (b.u.), foi calculado a partir da Equação (1).

$$
T A(\%)=\frac{m i-m f}{m i}
$$

Onde:

$$
\begin{aligned}
& \text { TA - teor de água (b.u); } \\
& \mathrm{m}_{\mathrm{i}} \text { - massa inicial da amostra (g); } \\
& \mathrm{m}_{\mathrm{f}} \text { - massa da amostra seca (g). }
\end{aligned}
$$

Posteriormente, os materiais foram colocados individualmente em bandejas circulares de alumínio com dimensões $15 \mathrm{~cm}$ de diâmetro e $2 \mathrm{~cm}$ de altura, contendo aproximadamente $150 \mathrm{~g}$ de amostra, destacando que os experimentos foram realizados em triplicatas. 0 conjunto (amostras + bandeja), foi pesado em balança semi-analítica (marca Weblabosp, modelo L303i (máx. $310 \mathrm{~g}$; e = 0,001 g)) e colocados na estufa de circulação de ar para o início do processo.

As leituras em relação à perda de massa de cada amostra foram realizadas em intervalos de tempos distintos ao longo dos experimentos, e as bandejas contendo as amostras eram retiradas, pesadas e recolocadas rapidamente na estufa até que apresentassem massa constante durante três pesagens consecutivas, demonstrando assim que atingiu o teor de água de equilíbrio. Obtendo-se com isto, dados que relacionavam a massa da amostra com o tempo de secagem. Ao final de cada processo, as amostras de sementes de sorgo foram submetidas à determinação do teor de água final. 
Determinou-se o teor de água de equilíbrio $\left(\mathrm{X}_{\mathrm{e}}\right)$ através de pesagens consecutivas em intervalos de tempo até que as amostras atingissem massa constante. Após isso, calculou-se o teor de água (X) e a razão de teor de água (RX) para as amostras em cada temperatura e intervalo de tempo.

As curvas de secagem foram obtidas pela conversão dos dados referentes à perda de água no parâmetro adimensional razão de teor de água (RX), para as diferentes condições de secagem das sementes, de acordo com a Equação (2).

$$
R X=\frac{X-X_{e}}{X_{0}-X_{e}}
$$

Onde:

$\mathrm{RX}$ - razão de teor de água (adimensional);

$X$ - teor de água, base seca (b.s.);

$\mathrm{X}_{\mathrm{e}}$ - teor de água de equilíbrio (b.s.);

$\mathrm{X}_{0}$ - teor de água inicial (b.s.).

Os modelos matemáticos de Page, Newton, Henderson e Pabis, Aproximação da Difusão, Logarítmico, Thompson e Wang e Sing estão descritos na Tabela 1, e foram ajustados às curvas experimentais de secagem. Para o ajuste de cada equação matemática aos dados experimentais, realizaram-se as análises de regressão não-linear pelo método Quasi-Newton, empregando-se o programa computacional Statistica 8.0 (Statsoft, 2007).

Tabela 1. Modelos de regressão não-linear aplicados às curvas de secagem de sementes de sorgo

\begin{tabular}{|c|c|c|}
\hline Modelos & Equações & Referências \\
\hline Page & $\mathrm{RX}=\exp \left(-\mathrm{K}^{*} \mathrm{t} * * \mathrm{n}\right)$ & Page (1949) \\
\hline Newton & $\mathrm{RX}=\exp \left(-\mathrm{K}^{*} \mathrm{t}\right)$ & Togrul; Pchlivan (2002) \\
\hline Henderson e Pabis & $\mathrm{RX}=\mathrm{a} * \exp \left(-\mathrm{k}^{*} \mathrm{~T}\right)$ & Henderson \& Pabis (1961) \\
\hline Aproximação da difusão & $\mathrm{RX}=\mathrm{a}^{*} \exp \left(-\mathrm{k}^{*} \mathrm{~T}\right)+(1-\mathrm{a}) * \exp \left(-\mathrm{k}^{*} \mathrm{~b}^{*} \mathrm{~T}\right)$ & Côrrea et al. (2010) \\
\hline Logarítmico & $\mathrm{RX}=\mathrm{a} * \exp \left(-\mathrm{k}^{*} \mathrm{~T}\right)+\mathrm{c}$ & Costa et al. (2011) \\
\hline Thompson & $\mathrm{RX}=\exp ((-\mathrm{a}-(\mathrm{a} * * 2+4 * \mathrm{~b} * \mathrm{t}) * * 0,5) / 2 * \mathrm{~b})$ & Leite et al. (2016) \\
\hline Wang e Sing & $\mathrm{RX}=1+\mathrm{a} * \mathrm{~T}+\mathrm{b} * \mathrm{~T} * * 2$ & Wang \& Singh (1978) \\
\hline
\end{tabular}

$\mathrm{RX}$ - razão de teor de água (adimensional); T - tempo de secagem (min.);K - constante de secagem (adimensional);a,b, c e n - coeficientes dos modelos matemáticos.

Os critérios utilizados para determinação do melhor ajuste das equações aos dados experimentais foi o coeficiente de determinação ( $\mathrm{R}^{2}$ ) e o desvio quadrático médio (DQM), calculado pela Equação (3).

$$
\mathrm{DQM}=\sqrt{\frac{\sum(\text { RXexp-RXpre })^{2}}{N}}
$$

Onde:

$$
\begin{aligned}
& \mathrm{RX}_{\mathrm{exp}} \text { : razão de teor de água experimental; } \\
& \mathrm{RX}_{\text {pre: }} \text { razão de teor de água predito; }
\end{aligned}
$$

$\mathrm{N}$ : número de dados experimentais.

A partir da cinética de secagem verificou-se a temperatura mais adequada para o processo de obtenção da farinha de sementes de sorgo, bem como o tempo de secagem. 
As sementes de sorgo foram dispostas em recipientes, como descrito acima, e colocadas em estufa de circulação de ar para a secagem. Posteriormente, foram trituradas em micro moinho de facas (Fortinox, modelo Star ft48L) para a obtenção das farinhas. Estas foram acondicionadas em recipientes de plástico com tampa e estocadas a temperatura ambiente até o momento da realização das análises físicas e químicas.

As análises físicas e químicas foram determinadas quanto ao teor de água (método 012/IV), resíduo mineral fixo (método 018/IV), sólidos solúveis totais (método 010/IV), potencial hidrogenionico (método 017/IV), conforme metodologia descrita por IAL (2008). A atividade de água foi determinada por meio de leitura direta em higrômetro AQUA-LAB digital, modelo CX-2 (Decagon Devices Inc., EUA) com temperatura à $25^{\circ} \mathrm{C}$, e proteína bruta, na matéria seca, através do método de Kjeldahl, descrito por Tedesco, Bohnen e Volkweiss (1995).Todas as análises foram realizadas em triplicata.

Os minerais contidos no resíduo mineral foram identificados e quantificados por Espectrômetro de Fluorescência de Raios-X por Energia Dispersiva, o equipamento utilizado foi o Shimadzu EDX-7000.

\section{RESULTADOS E DISCUSSÃO}

Na Tabela 2 são apresentados os parâmetros dos ajustes dos modelos matemáticos de Page, Newton, Henderson e Pabis, Aproximação da difusão, Logarítmico, Thompson e Wang e Sing, ajustados às curvas de secagem em estufa com circulação de ar das sementes de sorgo nas diferentes temperaturas, seus respectivos coeficientes de determinação $\left(R^{2}\right)$ e desvios quadráticos médios (DQM).

Tabela 2. Parâmetros de ajuste dos modelos das curvas de cinética de secagem de sementes de sorgo (Sorghum bicolor L. Moench), para as diferentes temperaturas.

\begin{tabular}{|c|c|c|c|c|c|c|c|c|}
\hline \multirow{2}{*}{ Modelos } & & \multicolumn{7}{|c|}{ Parâmetros } \\
\hline & & $\mathrm{a}$ & $\mathrm{K}$ & b & c & $\mathrm{N}$ & $\mathrm{R}^{2}$ & DOM \\
\hline \multirow{3}{*}{ Page } & $40^{\circ} \mathrm{C}$ & & 0,00442 & & & 1,0436 & 99,479 & 0,02604 \\
\hline & $50^{\circ} \mathrm{C}$ & & 0,00266 & & & 1,1446 & 99,316 & 0,02960 \\
\hline & $60^{\circ} \mathrm{C}$ & & 0,00807 & & & 1,0105 & 99,762 & 0,01769 \\
\hline \multirow{3}{*}{ Newton } & $40^{\circ} \mathrm{C}$ & & 0,00556 & & & & 99,438 & 0,02704 \\
\hline & $50^{\circ} \mathrm{C}$ & & 0,00565 & & & & 98,915 & 0,03729 \\
\hline & $60^{\circ} \mathrm{C}$ & & 0,00848 & & & & 99,759 & 0,01779 \\
\hline \multirow{3}{*}{$\begin{array}{l}\text { Henderson } \\
\text { ePabis }\end{array}$} & $40^{\circ} \mathrm{C}$ & 0,99983 & 0,00556 & & & & 99,438 & 0,02704 \\
\hline & $50^{\circ} \mathrm{C}$ & 1,01424 & 0,00576 & & & & 98,971 & 0,03610 \\
\hline & $60^{\circ} \mathrm{C}$ & 1,00117 & 0,00849 & & & & 99,759 & 0,01778 \\
\hline \multirow{3}{*}{$\begin{array}{c}\text { Aproximação } \\
\text { da difusão }\end{array}$} & $40^{\circ} \mathrm{C}$ & $-22,9289$ & 0,00773 & 0,98518 & & & 99,542 & 0,02441 \\
\hline & $50^{\circ} \mathrm{C}$ & $-44,2449$ & 0,00917 & 0,98798 & & & 99,412 & 0,02746 \\
\hline & $60^{\circ} \mathrm{C}$ & 0,00258 & 0,08330 & 0,10144 & & & 99,759 & 0,01778 \\
\hline \multirow{3}{*}{ Logarítmico } & $40^{\circ} \mathrm{C}$ & 1,12557 & 0,00413 & & $-0,1420$ & & 99,861 & 0,01270 \\
\hline & $50^{\circ} \mathrm{C}$ & 1,28597 & 0,00347 & & $-0,2954$ & & 99,930 & 0,00906 \\
\hline & $60^{\circ} \mathrm{C}$ & 1,04481 & 0,00747 & & $-0,0527$ & & 99,871 & 0,01278 \\
\hline \multirow{3}{*}{ Thompson } & $40^{\circ} \mathrm{C}$ & $-5967,57$ & & 5,75979 & & & 99,438 & 0,02704 \\
\hline & $50^{\circ} \mathrm{C}$ & $-6163,35$ & & 5,90120 & & & 98,915 & 0,03730 \\
\hline & $60^{\circ} \mathrm{C}$ & $-4324,09$ & & 6,05623 & & & 99,759 & 0,01779 \\
\hline \multirow{3}{*}{ Wang e sing } & $40^{\circ} \mathrm{C}$ & $-0,00409$ & & 0,00001 & & & 99,267 & 0,03090 \\
\hline & $50^{\circ} \mathrm{C}$ & $-0,00414$ & & 0,00001 & & & 99,747 & 0,01802 \\
\hline & $60^{\circ} \mathrm{C}$ & $-0,00619$ & & 0,00001 & & & 98,799 & 0,03969 \\
\hline
\end{tabular}

A partir da Tabela 2, podemos observar que todos os ajustes apresentaram coeficientes de determinação superior a 98,0\% e desvios quadráticos médios inferiores a 0,04, podendo assim ser utilizados todos os modelos matemáticos testados na predição das curvas de secagem de sementes de sorgo. Resultados semelhantes foram encontrados por Resende et al. (2010), que determinando a cinética de secagem do feijão adzuki (Vigna angularis) obtiveram valores de coeficientes de determinação superiores a 98\%, sendo assim, uma representação satisfatória do fenômeno de secagem em estudo.

Também foram encontrados resultados próximos por Silva et al. (2014) que estudaram a cinética de secagem em camada fina dos grãos de guandu (Cajanus cajan) submetidos a diferentes temperaturas de secagem, onde obteve coeficientes de determinação superiores a 97,93\% e valores de desvios quadráticos médios inferiores a 0,0022. 
Em geral, verificou-se que dentre as equações testadas o modelo que melhor se ajustou aos dados experimentais foi o de Logarítmico, comprovado através dos coeficientes de determinação em destaque, estando para todas as temperaturas acima de 99,86\%, e os menores valores de desvios quadráticos médios (Tabela 2). Os resultados encontrados estão de acordo com os obtidos por Sadaka \& Atungulu (2018) que estudando o efeito da temperatura e do tempo sobre a cinética de secagem de grãos de sorgo, os modelos matemáticos de Logarítmico e Henderson ajustaram-se satisfatoriamente nas temperaturas de 60 e $70^{\circ} \mathrm{C}$ aos dados experimentais, com coeficientes de determinação superiores a 0,99.

Ainda de acordo com a Tabela 2, o parâmetro k dos modelos semi-teórico de Page e Logarítmico teve uma pequena diminuição quando a temperatura passou de 40 para $50^{\circ} \mathrm{C}$, e aumentou quando foi para a temperatura de $70^{\circ} \mathrm{C}$. Já o parâmetro k dos modelos Newton, Henderson \& Pabis e Aproximação da difusão aumentaram com o aumento da temperatura de secagem, significando que a temperatura é o fator que acelera o processo de secagem.

A Figura 2 mostra a representação gráfica das curvas de secagem em estufa de circulação de ar das sementes de sorgo para as temperaturas em estudo, ajustadas para o modelo matemático de Logarítmico.

Figura 2. Cinética de secagem de sementes de sorgo (Sorghum bicolor L. Moench) em diferentes temperaturas ajustadas pelo modelo matemático de Logarítmico.

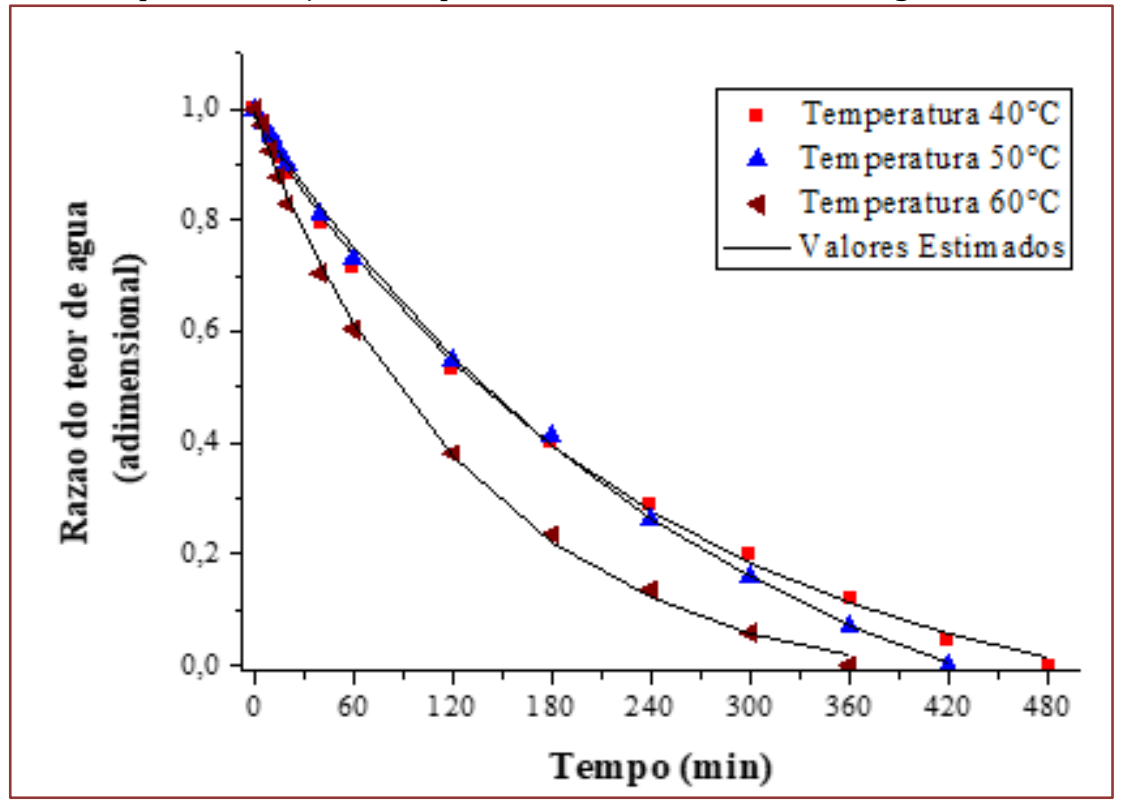

Fonte: Dados da pesquisa.

As secagens em estufa a temperaturas de 40,50 e $60{ }^{\circ} \mathrm{C}$ necessitaram de tempos de 480, 420 e $360 \mathrm{~min}$, respectivamente, para atingir o teor de água de equilíbrio. Como é possível observar na Figura 2, a temperatura tem influência direta na cinética de secagem, uma vez que quanto maior a temperatura menor o tempo de secagem. Esse comportamento, típico de secagem de produtos agrícolas, também foi observado por Botelho et al. (2015), ao estudarem a cinética de grãos de sorgo e por Smaniotto et al. (2017), ao estudarem a cinética de secagem dos grãos de girassol (Helianthus annuus). Vale ainda salientar que este comportamento ocorre, pois o aumento da temperatura do ar de secagem ocasiona maior remoção de água do produto, em consequência da maior pressão de vapor entre o grão e o ar.

A partir dos dados da cinética de secagem, a farinha de sementes de sorgo foi obtida à $60^{\circ} \mathrm{C}$, uma vez que essa temperatura necessitou de $360 \mathrm{~min}$. para atingir a menor taxa de secagem. A Figura 3 apresenta a farinha de sorgo obtida por secagem em estufa, mostrando que esse processo não interferiu na aparência, mantendo as propriedades sensoriais do produto. 
Figura 3. Farinha de sorgo (Sorghum bicolor L. Moench) obtida a partir da secagem em estufa de circulação de ar à $60^{\circ} \mathrm{C}$.

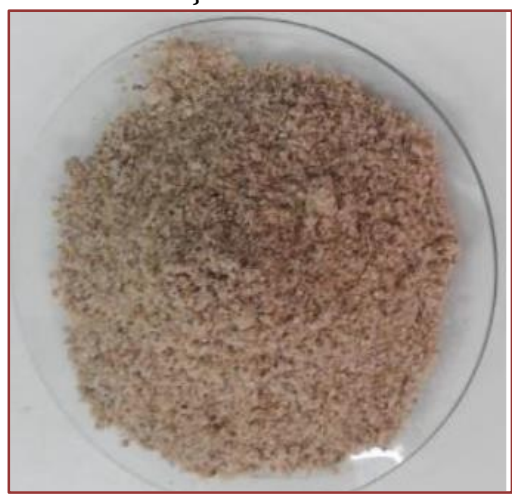

Fonte: Dados da pesquisa

Na Tabela 3, encontram-se os resultados obtidos para a caracterização física e química da farinha de sorgo submetida ao processo de secagem em estufa na temperatura de $60^{\circ} \mathrm{C}$. 0 resultado médio de teor de água encontrado na farinha de sorgo foi de 6,74\%. 0 teor de água encontrado está de acordo com a legislação brasileira para farinhas que recomenda no máximo 15\% de teor de água (Brasil, 2005). Resultados semelhantes foram encontrados por Ferreira, Lima e Silva (2017), 6,79\%, que estudaram a caracterização da farinha de sorgo granífero de cor vermelho, e resultado inferior ao encontrado por Carvalho et al. (2014), 13,96\%, ao estudarem a elaboração de farinhas instantâneas utilizando sorgo integral.

Tabela3. Caracterização física e química da farinha de sementes de sorgo (Sorghum bicolor L. Moench) submetida a secagem em estufa à $60^{\circ} \mathrm{C}$.

\begin{tabular}{|c|c|} 
Parâmetros & Farinha de sementes de sorgo \\
\hline Teor de água (\%) & $6,74+0,13$ \\
\hline Atividade de água & $0,297 \pm 0,008$ \\
\hline Resíduo mineral fixo (\%) & $1,59 \pm 0,13$ \\
\hline pH & $6,63 \pm 0,01$ \\
\hline Proteína bruta (\%) & $13,05 \pm 0,64$ \\
\hline
\end{tabular}

O controle do teor de água presente nas farinhas é muito importante devendo ser controlado com eficácia, pois esse fator é o principal responsável para o início das reações químicas na farinha, o que acarretará nas alterações das características sensoriais, nutricionais e tecnológicas. Portanto, para garantir a qualidade das farinhas, a conservação durante o armazenamento no seu período de estocagem comercial, faz-se necessário que o teor de água se encontre abaixo de 15\% (FARONI et al., 2007).

0 valor de atividade de água, conforme Tabela 3 , foi de 0,297 , sendo considerado um produto com atividade de água dentro do limite ideal para a conservação, levando em consideração que a atividade de água mínima capaz de permitir o desenvolvimento de microrganismo é 0,60, evidenciado pelo fato de alimentos desidratados serem considerados microbiologicamente estáveis (CHISTÉ et al., 2006).

Com relação ao resultado de resíduo mineral fixo, a farinha de sorgo apresentou um teor de 1,59\% (Tabela 3). Observou-se que o resultado alcançado foi superior ao encontrado por Ferreira et al., (2009), que foi 1,44\% para farinha de sorgo em base seca, e próximo do encontrado por Carvalho et al. (2014) que foi de $1,76 \%$. Quando comparando com farinhas de trigo, a farinha se sorgo apresentou quantidade de resíduo mineral superior ao encontrado por Lanzarini (2015) que encontrou valores que variaram de 0,40 a 0,78\% em farinhas de trigo produzidas em diferentes moinhos do estado do Paraná. Sendo assim, a farinha de sorgo pode apresentar em sua composição quantidade satisfatória de minerais.

Levando em consideração os mesmos critérios de classificação tomados pelo Ministério da agricultura, pecuária e abastecimento (2005), que classifica a farinha de trigo em três tipos de acordo com a quantidade cinza (resíduo mineral fixo), as farinhas de sorgo podem ser classificadas como sendo do tipo integral, pois apresentou teor de cinza inferior a 2,5\%. 
$\mathrm{O} \mathrm{pH}$, assim como o teor de água e atividade de água, é um fator muito importante para limitar o desenvolvimento de microrganismos nos alimentos. Segundo Soares \& Freire Júnior et al. (1992), os alimentos podem ser classificados em: pouco ácidos ( $\mathrm{pH}>4,5)$, ácidos $(4,5$ a 4,0) e muito ácidos ( $\mathrm{pH}<$ 4,0 ). Desta forma, ainda de acordo com a Tabela 3, a farinha de sorgo obtida pode ser considerada como pouco ácida, pois obteve uma média de 6,63. Portanto, está sujeita as multiplicações microbianas, tanto de espécies patogênicas quanto de espécies deteriorantes, fazendo necessário uso do máximo de higiene e cuidado durante o processamento.

A farinha de sorgo apresentou resultado de proteína bruta de 13,05\% (Tabela 3). Esse resultado foi superior ao encontrados por Carvalho et al. (2014) que encontraram o valor médio de 9,55\% em farinhas de sorgo BRS310, e por Trappey et al. (2014) que encontraram valores que variaram entre 7,74 e 9,81\% em farinhas de sorgo moídas em laboratório e comercialmente, e próximo ao encontrado por Mohammed; Ahmed e Babiker (2011), 12,25\%, em farinha de Sorgo (S. bicolor L. Moench).

A farinha de sorgo obtida nesse estudo apresentou percentual de proteína próxima ou superior à farinha de trigo comercial. Boen et al. (2007) ao avaliarem a composição centesimal de 3 marcas de farinhas de trigo em diferentes lotes encontrou valores de proteína que variaram de 9,92 a 11,38\%. Desta forma, a farinha de sorgo apresenta grande potencial nutricional, podendo ser empregada na produção de diferentes produtos substituindo, parcialmente e totalmente, a farinha de trigo.

A tabela 4 mostra os valores dos minerais presentes na farinha de sorgo, sendo valores para magnésio (Mg), fósforo $(\mathrm{P})$, potássio $(\mathrm{K})$, cálcio $(\mathrm{Ca})$, manganês $(\mathrm{Mn})$, ferro $(\mathrm{Fe})$, cobre $(\mathrm{Cu})$ e zinco $(\mathrm{Zn})$.

Tabela 4. Constituintes minerais da farinha de sorgo (Sorghum bicolor L. Moench) obtida por secagem em estufa à $60^{\circ} \mathrm{C}$.

\begin{tabular}{|ccc|c|c|c|c|c|c|c|c|}
\multicolumn{10}{c}{} & \multicolumn{10}{c}{ Minerais (mg.100g-1) } \\
Farinha sorgo & $\mathrm{Mg}$ & $\mathrm{P}$ & $\mathrm{K}$ & $\mathrm{Ca}$ & $\mathrm{Mn}$ & $\mathrm{Fe}$ & $\mathrm{Cu}$ & $\mathrm{Zn}$ \\
\cline { 2 - 12 } & 323,16 & 645,99 & 563,13 & 25,77 & 1,18 & 3,64 & 0,27 & 1,96 \\
\hline
\end{tabular}

De acordo com a Tabela 4, a farinha de sorgo apresentou valores significativos de Mg: 323,16 mg.100g-1, P: 645,99 mg. $100 \mathrm{~g}^{-1}$ e K; 563,13 mg.100g-1, sendo esses os que foram quantificados em maior quantidade. Esses minerais estão entre os minerais classificados como macroelementos uma vez que são necessários em maiores concentrações para o crescimento e desenvolvimento de plantas e animais, deficiências ou excesso desses nutrientes provocam diversos distúrbios metabólicos (Damodaran; Parkin \& Fennema, 2010). Quanto aos valores de Ca, a farinha obtida apresentou o valor de 25,77 mg.100g-1. O Ca é o mineral em maior quantidade no corpo humano, fundamental para a mineralização de ossos e dentes e para a regulação de eventos intracelulares em diversos tecidos (FRANÇA; MARTINI, 2014).

A farinha de sorgo apresentou ainda, quantidade de Mn; 1,18 mg.100g-1, Fe; 3,63 mg.100g-1, Cu; 0,27

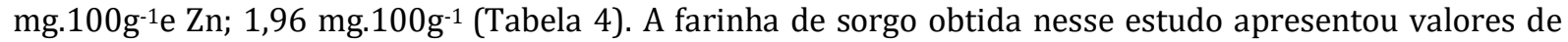
$\mathrm{Ca}, \mathrm{P}, \mathrm{Fe}, \mathrm{Mg}$ e Zn superiores aos encontrados por Mohammed; Ahmed; Babiker (2011) que avaliaram a valor nutricional da farinha de sorgo durante o processamento de injera (pão sem fermento), e ainda, valores superiores de Mg, P, K e Ca, e próximos de Fe e Zn encontrados por Carvalho (2014) em farinhas instantâneas de sorgo integral.

A farinha obtida pelo método de secagem em estufa apresentou composição mineral superior ao estabelecida para a farinha de trigo exposta na TACO (2011). Segundo Ferreira et al. (2009), a farinha de sorgo proporciona características físicas e químicas semelhantes a farinha de trigo e aos parâmetros de qualidade indicados pelo Codex Alimentarius, com exceção do teor de fibra alimentar total.

0 produto farináceo obtido por estufa à $60^{\circ} \mathrm{C}$ apresentou características dentro dos padrões estabelecidos pela legislação brasileira. A aplicação da estufa para a secagem demonstrou ser uma tecnologia promissora para a obtenção da farinha, podendo ser empregado para qualquer produto agrícola. Desta forma, a farinha de sorgo pode ser utilizada como ingrediente para a formulação de diversos produtos alimentícios. 


\section{CONCLUSÕES}

Na secagem em estufa de circulação de ar, o aumento da temperatura proporcionou a redução no tempo de secagem das sementes de sorgo em função da maior taxa de remoção de água do material.

O modelo matemático Logarítmico foi o que melhor se ajustou aos dados experimentais para a secagem em estufa para as temperaturas de 40,50 e $60^{\circ} \mathrm{C}$, obtendo para os coeficientes de determinação valores acima de 99,86\% e os menores valores de desvios quadráticos médios.

A farinha de sorgo foi obtida a partir da secagem em estufa à $60^{\circ} \mathrm{C}$ e apresentou teor de água, $6,74 \%$, dentro do limite estabelecido pela legislação brasileira, demonstrando ser um produto de difícil ataque microbiano e elevado teor de proteína bruta.

A farinha obtida foi caracterizada como pouca ácida e pode ser considerada boa fonte de minerais, principalmente de fósforo e potássio.

De acordo com as características físicas e químicas, observou-se que a farinha de sementes de sorgo é uma alternativa alimentar, que poderá ser utilizada como ingrediente de produto de panificação, visando uma diversidade de público consumidor.

\section{REFERÊNCIAS}

[1] Boen, T. R. et al., 2007, Avaliação do teor de ferro e zinco e composição centesimal de farinhas de trigo e milho enriquecidas. Revista Brasileira de Ciências Farmacêuticas, v. 43, n. 4, p. 1-8.

[2] Brasil, 2005, Ministério da Saúde. Agência de Vigilância Sanitária. Resolução no 263 de 22 de setembro de 2005. Regulamento Técnico para produtos de cereais, amidos, farinhas e farelos. Diário Oficial da União, Brasília, DF.

[3] Botelho, F. M. et al., 2015, Cinética de secagem e determinação do coeficiente de difusão efetivo de grãos de sorgo. Revista Brasileira de Milho e Sorgo, v. 14, n. 2, p. 260-272.

[4] Camicia, R. G. M. et al., 2015 Modelagem do processo de secagem de sementes de feijão-caupi. Revista Caatinga, v. 28, n. 3, p. 206-214.

[5] Carvalho, C. W. P. et al., 2014, Elaboração de Farinhas Instantâneas à Base de Sorgo Integral Cultivar BRS310. Comunicadi Técnico 203, Embrapa, v. 1, n. 1, p. 1-3.

[6] Chen, C.; Wu, P. C. Thin-layer drying model for rough rice with high moisture content. Journal of Agriculture Engineering Research, v.80, p.45-52, 2001.

[7] Chisté, R. C. et al., 2006, Qualidade da farinha de mandioca do grupo secA. Ciência e Tecnologia de Alimentos. Campinas, v. 26, n. 4, p. 861-864.

[8] Corrêa, P. C. et al., 2010, Modelagem matemática e determinação das propriedades termodinâmicas do café (Coffeaarábica L.) durante o processo de secagem. Revista Ceres, v. 57, n. 5, p. 595-601.

[9] Costa, L. M. et al., 2011, Coeficiente de difusão efetivo e modelagem matemática da secagem de sementes de crambe. Revista Brasileira de Engenharia Agrícola e Ambiental, Campina Grande, v. 15, n. 10, p. 1089-1096.

[10] Damodaran, S.; Parkin, K.L.; Fennema, O.R., 2010, Química de Alimentos de Fennema. 4. ed., Porto Alegre: Artmed, 2010, 900p.

[11] Faroni, L. R. D. et al., 2007, Qualidade da farinha obtida de grãos de trigo fumigados com dióxido de carbono e fosfina. Revista Brasileira de Engenharia Agrícola e Ambiental, Campina Grande, v. 6, n. 2, p. 115-119.

[12] Ferreira, M. R. M.; Lima, M. C. P. M.; Silva, J. L., 2017, Caracterização da farinha de sorgo granífero de cor vermelho. VI Congresso Estadual de Iniciação Científica e Tecnológica do IF Goiano. Anais....

[13] Ferreira, S. M. R. et al., 2009, Glutenfree cookies prepared with sorghum flour. Archivos Latino americanos de Nutrición-ALAN, Caracas , $\quad$ v. 59, n. 4, p. 433-440. Disponível em<http://www.scielo.org.ve/scielo.php?script=sci_arttext\&pid=S0004-06222009000400012\&lng=es\&nrm=iso >. Acesso em 09 nov. 2018.

[14] França, N. A. G. \& Martini, L. A., 2014 Funções Plenamente Reconhecidas de Nutrientes: Cálcio. ILSIInternational Life Sciences Institute do Brasil, v. 1, n. 1, p. 1-24.

[15] Henderson, S. M.; Pabis, S., 1961, Grain drying the oryI: temperature effect on drying coefficient. Journal of Agricultural Engineering Research, v.6 ,n.3, p.169-174.

[16] IBGE, 2018, Estatística mensal da Produção Agrícola Levantamento Sistemático da Produção Agrícola. Indicadores IBGE, p. 81. 
[17] Instituto Adolfo Lutz - IAL, 2008, Odair Zenebon; Neus Sadoco Pascuet \& Pablo Tigea. (Coord.). Métodos físico-químicos para análises de alimentos. em<http://www.ial.sp.gov.br/resources/editorinplace/ial/2016_3_19/analisedealimentosial_2008.pdf> Acesso em 23 agosto de 2018.

[18] Lanzarini, D. P., 2015, Controle de qualidade aplicado a farinha de trigo panificável produzida em moinhos do estado do paraná. [s.l.] Universidade Tecnológica Federal do Paraná.

[19] Leite, D. D. F. et al., 2016, Avaliação da cinética de secagem da carambola em secador convectivo. Revista Verde, v. 11, n. 2, p. 01-04.

[20] Ministério da Agricultura, Pecuária e Abastecimento. Instrução normativa no 8, de 2 de junho de 2005. Regulamento técnico de identidade e qualidade da farinha de trigo. Disponívelem<http://sistemasweb.agricultura.gov.br/sislegis/action/detalhaAto.do?method=visualizarAtoPortalMap a\&chave $=803790937>$ acesso em 09 nov. 2018 .

[21] Mohammed, N. A.; Ahmed, I. A. M.; Babiker, E. E., 2011, Nutritional Evaluation of Sorghum Flour (Sorghum bicolor L. Moench) During Processing of Injera. International Journal of Biological, Biomolecular, Agricultural, Food and Biotechnological Engineering, v. 5, n. 3, p. 99-103.

[22] Page, G. E., 1949, Factors influencing the maximum of air drying shelled corn in thin layer. Dissertation (Master'sThesis)-Department of Mechanical Engineering, Purdue University, Purdue.

[23] Portella, J. A.; Eichelberger, L., 2001, Secagem de Grãos. 1a ed. Passa Fundo, RS: [s.n.].

[24] Sadaka, S. et al., 2015, On-Farm Grain Sorghum Drying and Storage. In: Arkansas Grain Sorghum Production Handbook. [s.l: s.n.]. p. 13.

[25] RESENDE, O.; CORRÊA, P. C.; GONELI, A. L. D.; RIBEIRO, D. M. Propriedades físicas do feijão durante a secagem: determinação e modelagem. Ciência e Agrotecnologia, Lavras, v. 32, n. 1, p. 225-230, 2008.

[26] Resende, O.; Ferreira, L. U.; Almeida, D. P. Modelagem matemática para descrição da cinética de secagem do feijão adzuki (Vignaangularis). Revista Brasileira de Produtos Agroindustriais, Campina Grande, v. 12, n. 2, p. 171-178, 2010.

[27] Sadaka, S.; Atungulu, G., 2018, Grain sorghum drying kinetics under isothermal conditions using thermogravimetric analyzer. BioResources, v. 13, n. 1, p. 1534-1547.

[28] Silva, L. C., 2005, Secagem de grãos. Grãos Brasil: da semente ao consumo, v. 3, n. 14, p. 10-14.

[29] Silva, L. M. M. . et al., 2014, Modelos de predição da cinética de secagem dos grãos de guandu Prediction models of kinetic drying of pigeon pea grains. Brazilian Journal of Food Technology, v. 17, n. 4, p. 310-318.

[30] Smaniotto, T. A. S. et al., 2017, Drying kinetics of sunflower grains. Revista Brasileira de Engenharia Agrícola e Ambiental, v. 21, n. 3, p. 203-208.

[31] Soares, A. G.; Freire-Júnior, R. S., 1992, Curso de higiene e sanificação na indústria de alimentos. Embrapa, CTAA, Rio de Janeiro, pp. 97.

[32] Souza, G. F. M. V. et al, 2009, Armazenamento de sementes de sorgo submetidas a diferentes graus de umidade de colheita. Semina: Ciências Agrárias, v. 30, n. 4, p. 745-752.

[33] Statsoft, Inc. (2007). Statistica (data analysis software system), version 8. https://statistica.software.informer.com/8.0/.

[34] TACO - Tabela Brasileira de Composição de Alimentos, 2011, NEPA - UNICAMP.- 4. ed. rev. e ampl.. -Campinas: NEPA- UNICAMP.

[35] Tedesco, J. M.; Bohnen, H.; Volkweiss, S. J., 1995, Análise de solo, plantas e outros materiais. UFRGS, Porto Alegre-RS.

[36] Trappey, E. F. et al., 2014, Effect of sorghum flour composition and particle size on quality properties of gluten-free bread. Food Science and Technology International, v. 1, n. 2014, p. 1-17.

[37] Togrul, I. T.; Pchlivan, D., 2002, Mathematical modeling of solar drying of apricots in thinlayers. Journal of Food Engineering, v. 40, n. 3, p. 219-226.

[38] Villa-Corrales, L. et al., 2010, Numerical and experimental analysis of heatand moisture transferduring drying of Ataulfo mango. Journal of Food Engineering, v. 98, n. 2, p. 198-206.

[39] Wang, C Y.; Singh, R. P., 1978, Use of variable equilibrium moisture content in modeling rice drying. Transaction of ASAE, v.11, n.78, p.668-672. 


\section{Capítulo 6}

Comportamento fluidodinâmico da interface água-ar: Modelagem e simulação

\section{Marcella Mayara Costa Araújo Aragão \\ Severino Rodrigues Farias Neto \\ Boniek Evangelista Leite}

Resumo: A poluição das regiões aquosas como rios, lagos e mares com contaminantes que se dispersam tem causado uma grande preocupação na sociedade nos últimos tempos. A dispersão dos variados contaminantes presentes nas regiões aquosas é influenciada por variados parâmetros tais como: velocidade da água e do ar. Sendo assim é de fundamental importância o conhecimento da relação dessas propriedades no deslocamento do contaminante. A utilização de ferramentas que empregam métodos numéricos são aplicadas para prever o comportamento da dispersão de contaminantes presentes em escoamentos de superfície livre. 0 objetivo deste estudo foi avaliar a influência das correntes de ar sobre a superfície d’água. No modelo matemático proposto foi adotado a abordagem Euleriana-Euleriana para o escoamento bifásico (arágua) assumindo o modelo de superfície livre, modelo de turbulência k-e padrão. Adotou-se as propriedades físico-químicas constantes. As simulações numéricas foram realizadas com auxílio do pacote comercial Ansy CFXR variando-se os valores da velocidade do ar e altura do nível de água. Os resultados das simulações ratificam que o comportamento da interface água - ar são afetados pela variação da grandeza da velocidade do ar e da altura do nível de água do reservatório.

Palavras-chave: dispersão, bifásico, meio ambiente, poluentes, velocidade 


\section{INTRODUÇÃO}

Na atualidade grande é a preocupação da humanidade com o meio ambiente, em especial o meio aquoso, isso porque o desenvolvimento populacional e industrial tem ocasionado impactos ambientais negativos. Estudos vêm sendo realizados com a finalidade de minimizar os danos sofridos pelos mares, rios e lagos.

De acordo com Beneditti (2013) a água é um elemento vital no desenvolvimento da humanidade, sendo cerca de $75 \%$ da superfície da Terra ocupada por ela. 0 uso deste recurso tem como finalidade suprir necessidades pessoais, o desenvolvimento industrial, comercial e nas produções agrícolas.

Carmo et al., (2013) realizou um estudo que mostrou que $20 \%$ da água utilizada no Brasil destinam-se às atividades industriais e 62\% às atividades agrícolas. Enquanto que Duarte et al., (2015) afirmaram que 40\% das águas usadas em residências são para fins não potáveis.

Diversos poluentes são causadores da contaminação do meio aquático. 0 mau gerenciamento dos resíduos gerados pelas atividades domiciliares, urbanas e industriais ocasionam danos à saúde pública e principalmente aos recursos naturais.

Segundo Marchesan et al., (2009) os produtos químicos e fertilizantes são exemplos de contaminantes que geram impactos negativos nos recursos naturais e provocam contaminação nas águas sendo resultado do crescimento populacional.

Setores industriais como petróleo e mineração são responsáveis pelo despejo de resíduos químicos tais como benzeno, tolueno, xileno, enxofre, mercúrio entre outros. Sendo estes poluentes causadores da contaminação de solos e rios e de provocarem danos irreversíveis as pessoas e meio, Rattner (2009).

A poluição dos ambientes aquosos é um problema sério e de nível global que afeta a saúde e bem estar dos seres humanos, plantas e animais. Geralmente, a introdução dos poluentes é através de fontes pontuais e fontes não pontuais. Portanto, o estudo do destino destes contaminantes e como se propagam tornou-se um fator preponderante para garantir a redução da poluição ambiental. Para isso é preciso ter uma boa compreensão do comportamento do fluxo em superfície livre, Rattner (2009).

Segundo Mayerhoff (2007) vários estudos estão sendo realizados buscando novas tecnologias com o intuito de garantir a qualidade da água e o tratamento de efluentes industriais. Para que seja realizado a prevenção e correção da contaminação dos meios é conhecer de maneira prévia o comportamento do poluente no meio e as propriedades que influenciam na sua dispersão.

De acordo com Paz (2003) a identificação do comportamento hidrodinâmico da água nos diferentes meios auxilia no processo de planejamento e gerenciamento dos recursos hídricos, como também, na dinâmica dos nutrientes, poluentes e na distribuição do fitoplâncton e zooplâncton.

Ferramentas como a modelagem computacional são essenciais para o estudo ambiental, podendo ser aplicadas na determinação do comportamento hidrodinâmico e na modelagem da qualidade da água nas regiões de lago, rios, mares e estuários, Barros (2012).

0 estudo de um modelo fluidodinâmico computacional tridimenssional para simular a dispersão de substâncias solúveis em rios foi realizado por Machado (2006). Foram utilizados o método de volumes finitos, o modelo algébrico de turbulência da ordem zero, o modelo de Streeter - Phelps para predizer a concentração de substâncias orgânicas. Observou-se ainda o efeito da ocorrência de múltiplos pontos de emissão no trecho estudado. Viu-se com este trabalho que a metodologia aplicada foi uma boa ferramenta para a avaliação de impactos ambientais causado pela emissão de efluentes em rios. Os resultados experimentais apresentaram boa concordância com os dados obtidos no modelo.

O estudo de parâmetros tais como: velocidade da água, velocidade do ar, temperatura, pressão, tipos de injeção do poluente, características físico-químicas do poluente é necessário para que seja realizada a correlação, entre esses parâmetros é o deslocamento do contaminante. Sendo assim, o objetivo deste trabalho foi avaliar a influência da varação da velocidade do ar sobre a superfície da água. 


\section{METODOLOGIA}

\subsection{DOMÍNIO DE ESTUDO}

O domínio físico adotado para o estudo da hidrodinâmica da água consiste em uma simplificação de um canal aberto estudado experimentalmente por Buil (1999) com as seguintes dimensões: com 4 metros de comprimento, altura de 0,5 metros e largura de 0,25 metros com uma elevação na saída de 0,09 metros. A altura da água foi definida igual a 0,1425 metros. A representação do domínio computacional foi feita no ANSYS ICEM - CFD ${ }^{\circledR} 15.0$.

A malha representativa é do tipo hexaédrica, com aproximadamente 57 mil elementos de controle, com maior refinamento na região de interesse (interface água-ar). A Figura 1 apresenta a malha utilizada.

Figura 1. Malha hexaédrica refinada na região do interesse.

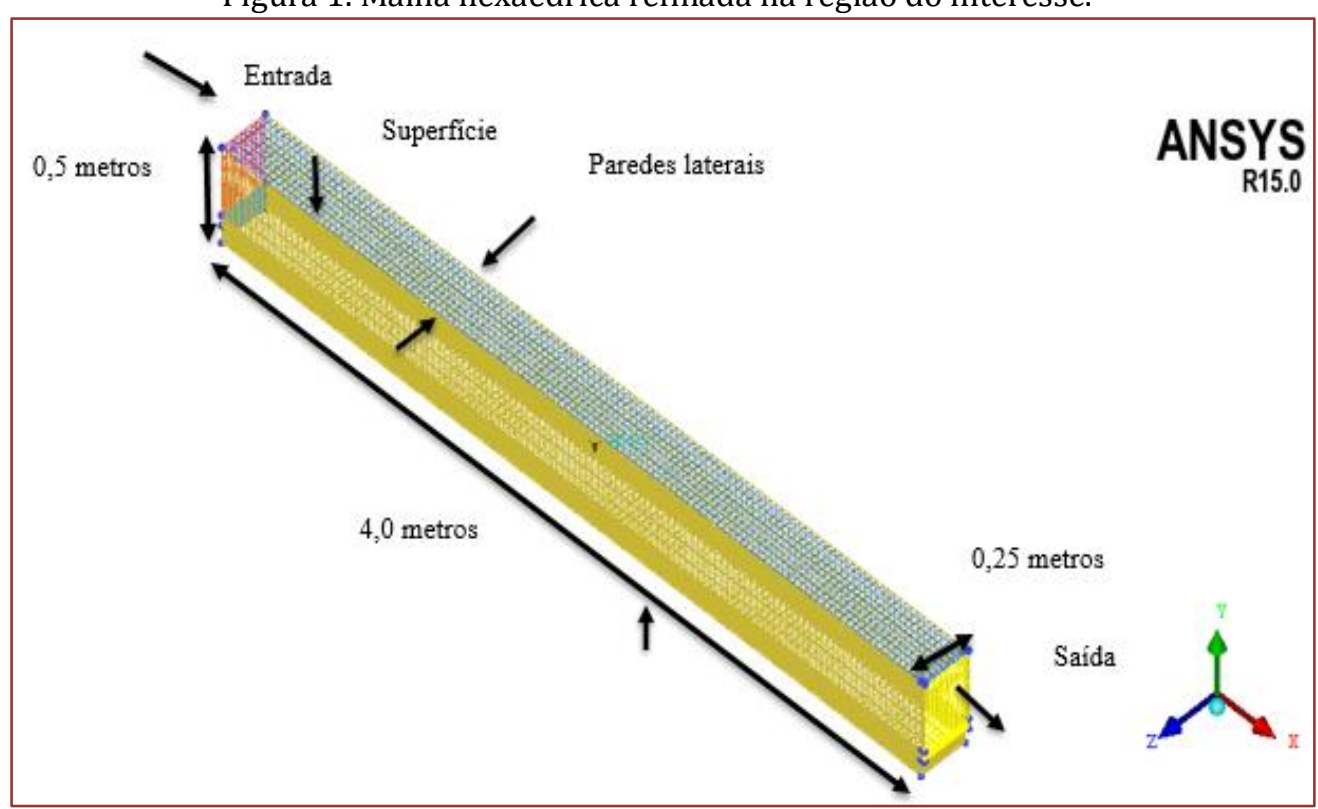

Fonte: Própria do autor.

\subsection{MODELAGEM MATEMÁTICA}

Nas simulações numéricas, para os casos estudados, foram adotadas algumas considerações para o escoamento bifásico (água-ar) em regime transiente e isotérmico. Tais considerações foram:

- Domínio tridimensional e escoamento isotérmico e transiente;

- Fluidos incompressíveis com propriedades físico-químicas constantes;

- Os fluidos estudados foram adotados como newtonianos e imiscíveis;

- Transferência de massa e fonte de massa são desconsideradas;

- $\quad 0$ efeito da gravidade não foi considerado;

- Não há ocorrência de reações químicas;

- Foi adotada a abordagem Euleriana-Euleriana, empregando o modelo de transferência interterfacial de superfície livre, adotando-se a água e o ar como fases contínuas;

- $\quad$ Modelo de turbulência utilizado foi o k- $\varepsilon$;

- As forças interfaciais de não arraste (forças de sustentação, lubrificação de parede, massa virtual, dispersão turbulenta e pressão do sólido) foram desprezadas;

- Foi adotado o valor de coeficiente de arraste constante e igual a 0,44. 
Com base nestas considerações as equações de conservação de massa e momento linear são simplificadas nas equações (1), (2) e (3):

- $\quad$ Equação da conservação de massa:

$$
\frac{\partial}{\partial t}\left(f_{\alpha} \rho_{\alpha}\right)+\nabla\left(f_{\alpha} \rho_{\alpha} \vec{U}_{\alpha}\right)=0
$$

- $\quad$ Equação do momento linear:

$$
\begin{aligned}
& \frac{\partial}{\partial t}\left(f_{\alpha} \rho_{\alpha} \overrightarrow{U_{\alpha}}\right)+\nabla\left[f_{\alpha}\left(\rho_{\alpha} \overrightarrow{U_{\alpha}} \otimes \overrightarrow{U_{\alpha}}\right)\right]= \\
& -f_{\alpha} \nabla \rho_{\alpha}+\nabla \cdot\left\{f_{\alpha} \mu_{e f}\left[\nabla \overrightarrow{U_{\alpha}}+\left(\nabla{\overrightarrow{U_{\alpha}}}^{T}\right)\right]\right\}+\overrightarrow{M_{\alpha}}
\end{aligned}
$$

Onde

$$
\begin{aligned}
& \mu_{e f} \text { é a viscosidade efetiva } \\
& f_{\alpha} \text { é a fração volumétrica da fase } \alpha .
\end{aligned}
$$

0 termo $M_{\alpha}$ corresponde as forças interfaciais da fase $\alpha$, e neste trabalho foi considerada somente a força de arraste, definida por:

$$
\overrightarrow{M_{\alpha}}=\frac{3}{4} C_{d} f_{\alpha} \rho_{\alpha}\left|\overrightarrow{U_{\beta}}-\overrightarrow{U_{\alpha}}\right|\left(\overrightarrow{U_{\beta}}-\overrightarrow{U_{\alpha}}\right)
$$

Onde

$$
\begin{aligned}
& \overrightarrow{U_{\beta}} \text { é a velocidade na fase } \beta \\
& \vec{U}_{\alpha} \text { é a velocidade na fase } \alpha \\
& C_{d} \text { é o o coeficiente de arrasto. }
\end{aligned}
$$

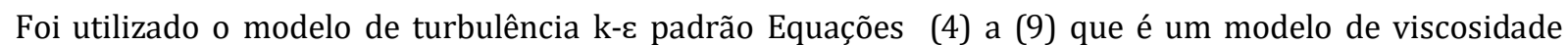
turbulenta, na qual os tensores de Reynolds são proporcionais aos gradientes de velocidade média, sendo a constante de proporcionalidade, identificada por uma viscosidade turbulenta, Ansys CFX (2015).

Para energia cinética turbulenta $(\mathrm{k})$ e a taxa de dissipação turbulenta $(\varepsilon)$, respectivamente pode-s escrever: 


$$
\begin{aligned}
& \frac{\partial\left(\rho_{\alpha} f_{\alpha} k_{\alpha}\right)}{\partial t}+\nabla \bullet\left\{f_{\alpha}\left[\rho_{\alpha} \overrightarrow{U_{\alpha}} k_{\alpha}-\left(\mu+\frac{\mu_{t \alpha}}{\sigma_{k}}\right) \nabla k_{\alpha}\right]\right\}= \\
& f_{\alpha}\left(G_{\alpha}-\rho_{\alpha} \varepsilon_{\alpha}\right) \\
& \frac{\partial\left(\rho_{\alpha} f_{\alpha} \varepsilon_{\alpha}\right)}{\partial t}+\nabla \bullet\left\{f_{\alpha} \rho_{\alpha} \overrightarrow{U_{\alpha}} \varepsilon_{\alpha}-\left(\mu+\frac{\mu_{t \alpha}}{\sigma_{\varepsilon}}\right) \nabla \varepsilon_{\alpha}\right\}= \\
& f_{\alpha} \frac{\varepsilon_{\alpha}}{k_{\alpha}}\left(C_{1} G_{\alpha}-C_{2} \rho_{\alpha} \varepsilon_{\alpha}\right)
\end{aligned}
$$

Nestas equações, $G_{\alpha}$ é a geração de energia cinética no interior da fase $\alpha, \mathrm{C}_{1}$ e $\mathrm{C}_{2}$ são constantes empíricas de valores iguais a 1,44 e $1,92, \sigma_{k}, \sigma_{\varepsilon}$ são constantes iguais 1,0 e 1,3 respectivamente, o termo ${ }_{\alpha}$ corresponde a taxa de dissipação de energia cinética turbulenta da fase $\alpha$ e $k_{\alpha}$ fase $\alpha$, sendo expresso da seguinte forma:

$$
\begin{gathered}
\varepsilon_{\alpha}=\frac{c_{\mu} q_{\alpha}^{3}}{l_{\alpha}} \\
k_{\alpha}=\frac{q_{\alpha}^{2}}{2}
\end{gathered}
$$

Na qual $l_{\alpha,} q_{\alpha}, c_{\mu}$ é o comprimento da escala espacial, é a escala da velocidade e uma constante empírica igual a 0,09 , respectivamente.

$$
c_{\mu}=4 c_{\alpha}^{2}
$$

Na qual ${ }^{c} \alpha$ uma constante empírica. A viscosidade turbulenta:

$$
\mu_{t \alpha}=c_{\mu} \rho_{\alpha} \frac{k_{\alpha}^{2}}{\varepsilon_{\alpha}}
$$

\subsection{CONDIÇÕES INICIAL E DE CONTORNO}

Adotaram-se velocidades nulas nas três direções no instante inicial. Na seção de entrada (Figura 1) foi assumida uma velocidade do ar constante na direção $\mathrm{x}, \mathrm{U}_{\mathrm{x}}=\mathrm{U}_{\mathrm{ar}}$, cujo valor está apresentado na Tabela. 1 . Para água foi assumido um valor constante igual a $0,2 \mathrm{~m} / \mathrm{s}$. Na seção de saída (Figura 1) foi assumida a condição de pressão nula. Foi assumida a pressão de referência igual a $1 \mathrm{~atm}$. Nas paredes laterais e na base (Figura 1) foram assumidas $U_{x}=U_{y}=U_{z}=0$. Na superfície superior (Figura 1) foi assumida a condição de pressão igual a pressão de $1 \mathrm{~atm}$.

Tabela 1. Dados utilizados na simulação.

\begin{tabular}{l|l} 
Simulação & Velocidade do ar (m/s)
\end{tabular}

\begin{tabular}{|c|c|}
\hline Caso 1 & 0,2 \\
\hline Caso 2 & 2,0 \\
\hline Caso 3 & 6,0 \\
\hline Caso 4 & 15,0 \\
\hline
\end{tabular}




\subsection{PROPRIEDADES FÍSICO - QUÍMICAS DA ÁGUA E DO AR}

As propriedades da água e do ar utilizadas nas simulações foram extraídas de Evangelista (2019) e Gomes (2012), respectivamente.

Tabela 2. Propriedades físico - químicas da água e do ar.

\begin{tabular}{|l|c|c|}
\hline \multicolumn{1}{|c|}{ Propriedades } & Água & $\mathrm{Ar}$ \\
\hline Densidade $\left(\mathrm{kg} / \mathrm{m}^{3}\right)$ & 998,2 & 1,23 \\
\hline Viscosidade cinemática $(\mathrm{m} 2 / \mathrm{s})$ & $1,003 \times 10-6$ & $15,06 \times 10-6$ \\
\hline Tensão superficial $(\mathrm{N} / \mathrm{m})$ & \multicolumn{2}{|c|}{0,0728} \\
\hline
\end{tabular}

\section{RESULTADOS E DISCUSSÕES}

Na Figura 2 está representado o plano XY sobre o qual estão representados os campos de fração volumétrica da água onde foi analisado o comportamento da interface água - ar com o aumento da velocidade do ar em relação à da água que foi mantida igual a $0,2 \mathrm{~m} / \mathrm{s}$.

Das Figuras 3 a 5 estão representados os campos de fração volumétrica da água sobre o plano XY para quarto velocidades do ar ( $2 \mathrm{~m} / \mathrm{s}, 6 \mathrm{~m} / \mathrm{s}$ e $15 \mathrm{~m} / \mathrm{s}$ ) mantendo-se a velocidade da água em $0,2 \mathrm{~m} / \mathrm{s}$ para os tempos $\mathrm{t}_{0}=0 \mathrm{~s} \mathrm{t}_{1}=50 \mathrm{~s}$ e t $2=100 \mathrm{~s}$, respectivamente. Esses resultados são apresentados nos tempos $\mathrm{t} 1=$ 50 s e t $2=100$ s.

A Figura 3 apresenta a fração volumétrica da água para o caso 4 em diferentes instantes de tempo. É possível observar a partir das figuras a evolução da formação das ondas na interface água -ar. Semelhante às instabilidades de Kelvin - Helmholtz , White (2006) são estruturas de turbulência originadas a partir das tensões viscosas na interface de dois meios em velocidades diferentes. A diferença de velocidade dos fluidos (água-ar) origina uma camada cisalhante que gera a formação de cristas e vales (evidenciadas nos tempos $\mathrm{t}_{1}$ e $\mathrm{t}_{2}$ para o caso 4). A diferença de velocidade ocasiona um escoamento instável e consequentemente forma essas instabilidades.

A Figura 4 apresenta o campo de a fração volumétrica da água para o tempo $\left(t_{1}=50 \mathrm{~s}\right)$ para os casos $1,2,3$ e 4. A partir das imagens verificou-se uma pequena variação na superfície da água ocasionando um comportamento diferente na região de entrada e de saída com um formato de ondas evidenciados principalmente no caso 4 que possuía maior velocidade do $\operatorname{ar}(\operatorname{Var}=15 \mathrm{~m} / \mathrm{s}$ ).

A Figura 5 apresenta o campo de fração volumétrica da água para o tempo $\left(t_{2}=100 \mathrm{~s}\right)$ para os casos $1,2,3$ e 4. Para os resultados no tempo final ficou nítido uma variação na região de saída para todos os casos. A

Figura 5 (d) mostrou que, com o aumento da velocidade do ar, é possível observar que as ondas formadas estiveram presentes até o tempo final deixando nítido a influência da velocidade do ar sobre a superfície da água. Assim, é possível afirmar que com o aumento da velocidade do ar tem-se uma variação no comportamento hidrodinâmico da água.

As Figuras 6, 7, 8 e 9 apresentam a relação da velocidade superficial da água com a altura da lâmina d'água, respectivamente, para os casos 1, 2, 3 e 4. Observa-se a partir das imagens que na região inicial $(\mathrm{L}=1 \mathrm{~m})$ a velocidade superficial da água aumentou com o aumento da velocidade do ar variando para os casos de $0,21 \mathrm{~m} / \mathrm{s}$ a $0,58 \mathrm{~m} / \mathrm{s}$ para o caso 4 . Verificou-se ainda que para os casos 1 e 2 os quais as velocidades da água e do ar eram próximas a alteração da velocidade superficial da água e o formato das curvas apresentaram-se de maneira semelhante.

Para $\mathrm{L}=2 \mathrm{~m}$ o comportamento com relação a região $\mathrm{L}=1 \mathrm{~m}$ foi semelhante, houve um aumento da velocidade da água a mediada que a velocidade do ar crescia, porém foi possível identificar que o comportamento na região mediana não variou muito com relação ao comportamento na posição inicial.

Para $\mathrm{L}=3 \mathrm{~m}$ a velocidade superficial da água foi a que apresentou uma menor variação no valor para todos os casos, com valores de $0,21 \mathrm{~m} / \mathrm{s}$ a $0,25 \mathrm{~m} / \mathrm{s}$.

Nas Figuras 6 e 7 se observa que o perfil velocidade apresentou comportamento característico de canais conforme visto em Porto (1999), as tensões de cisalhamento entre a água e o ar e a resistência entre as paredes e o fundo do canal originam diferentes velocidades, tendo um valor tendendo a zero nas paredes e no fundo do canal e um valor máximo na direção da superfície livre. Observa-se que para os casos 1 e 2 os quais a velocidade do ar e da água eram semelhantes. 0 perfil de velocidade apresentou um formato mais parabólico como mostra a literatura. 
Figura 2. Plano escolhido para análise da velocidade superficial da água.

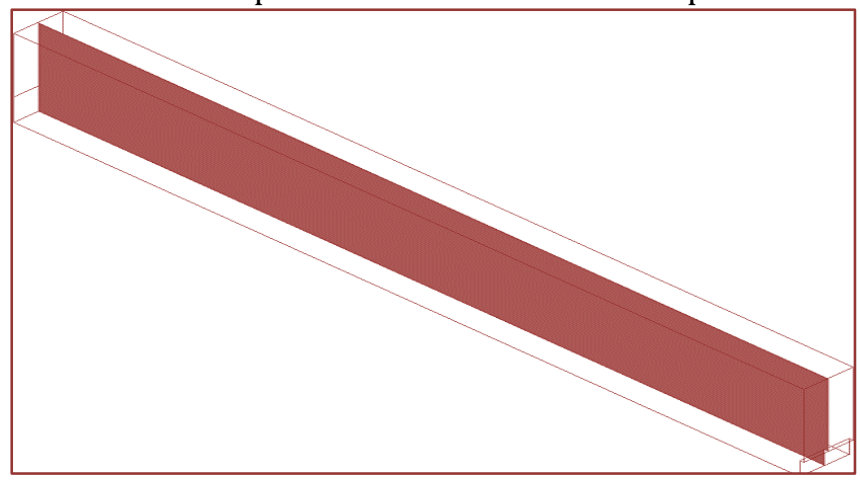

Fonte: Própria do autor.

Figura 3. Evolução do comportamento da interface água -ar para o caso 4 nos tempos: (a) t0 = 0 s, (b) t1 = $5 \mathrm{~s}$, (c) t2 = $15 \mathrm{~s}$, (d) t $3=25 \mathrm{~s}$, (e) t $4=45 \mathrm{~s}$, (f) t $5=70 \mathrm{~s}$, (g) t6 $=100 \mathrm{~s} \mathrm{e} \mathrm{(h)} \mathrm{t7}=110 \mathrm{~s}$.

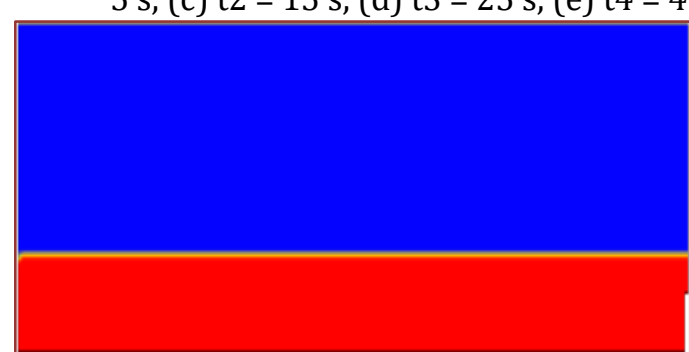

(a)

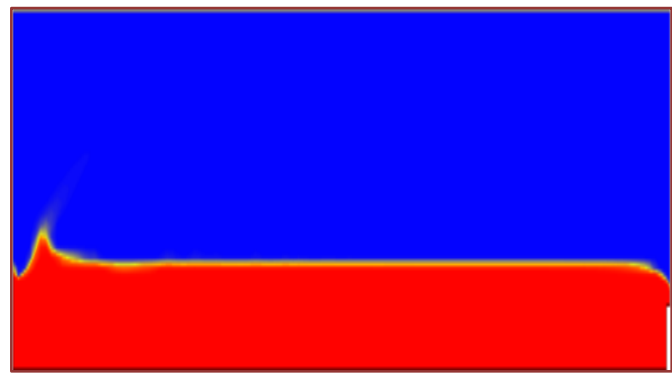

(c)

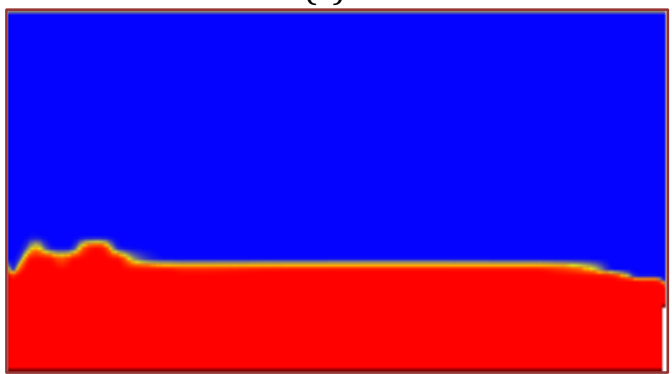

(e)

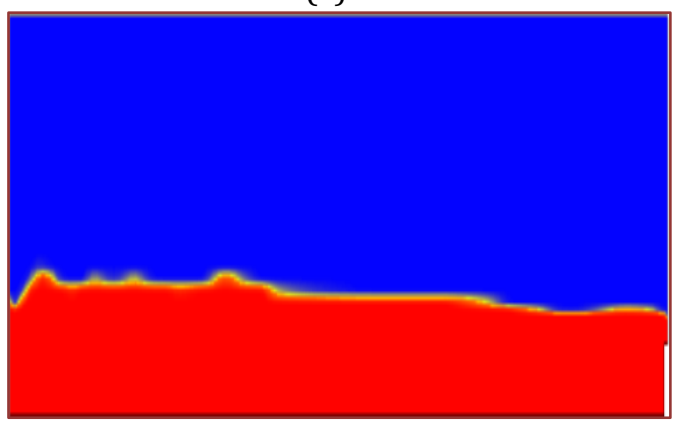

(g)

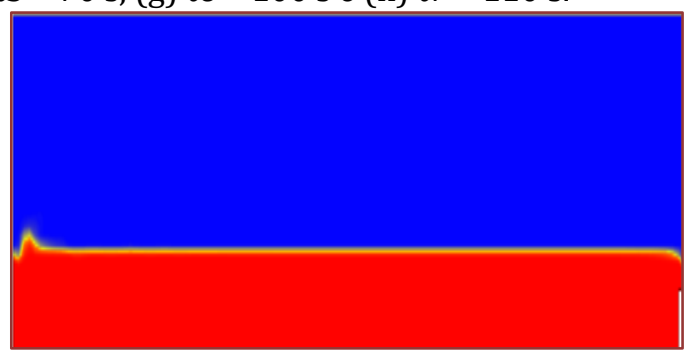

(b)

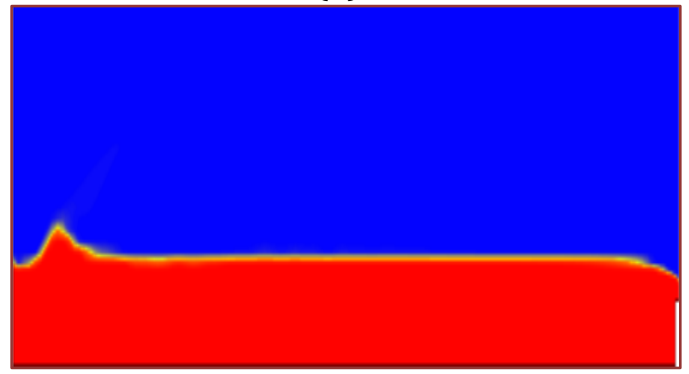

(d)

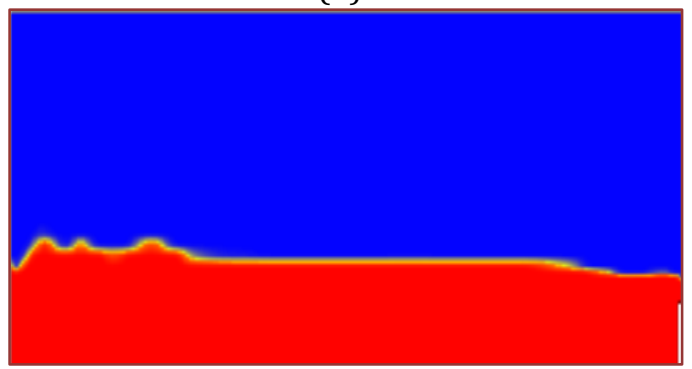

(f)

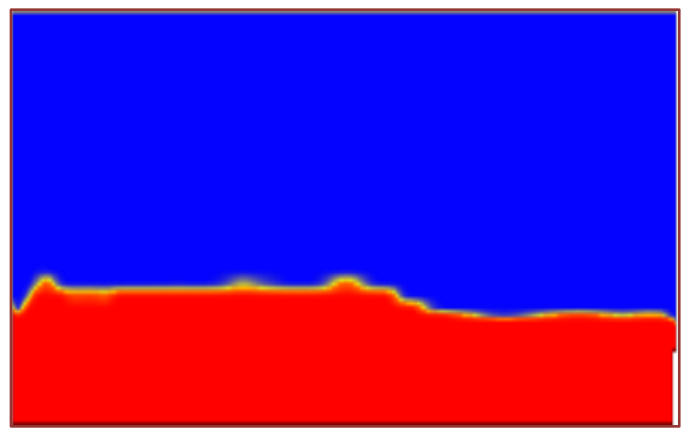

(h) 
Fonte: Própria do autor.

Figura 4. Fração volumétrica da água no tempo $\mathrm{t} 1=50 \mathrm{~s}$. (a) Para velocidade da água e do ar = 0,2 m/s. (b) Para velocidade da água e do $\mathrm{ar}=2 \mathrm{~m} / \mathrm{s}$. (c) Para velocidade da água e do $\mathrm{ar}=6 \mathrm{~m} / \mathrm{s}$. (d) Para velocidade da água e do ar $=15 \mathrm{~m} / \mathrm{s}$.

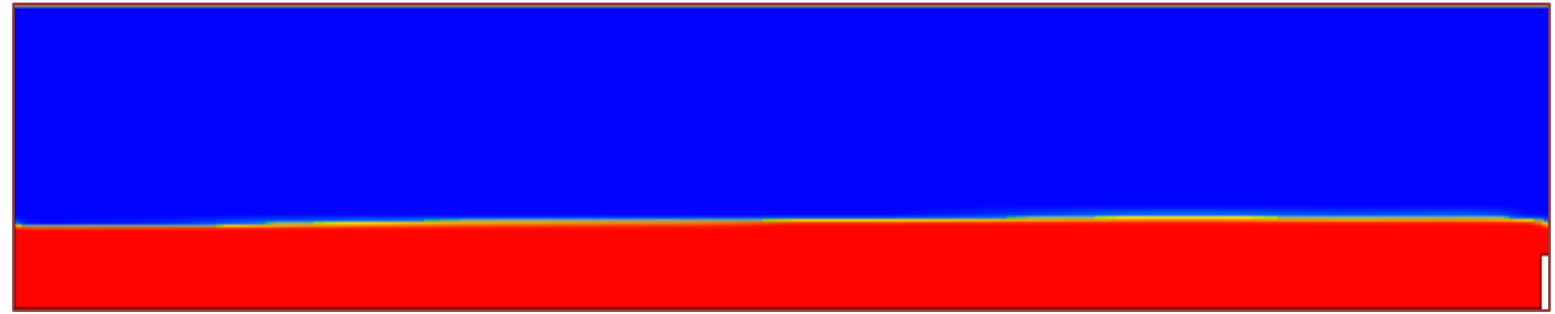

(a)

(b)

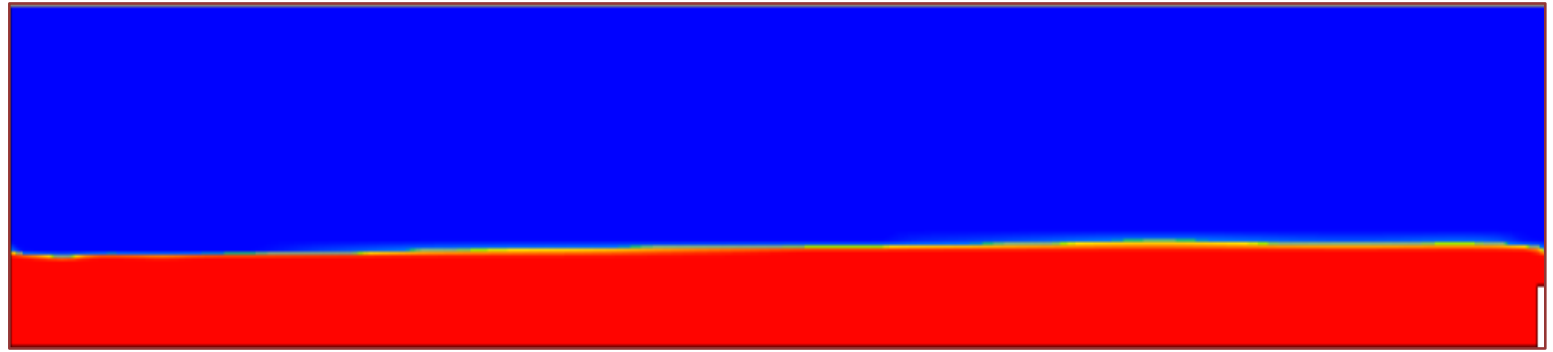

(c)

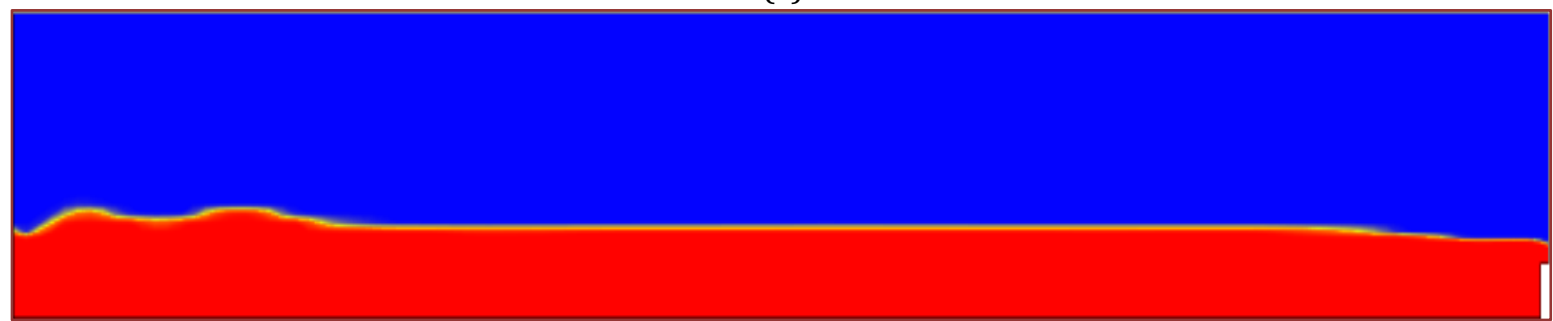

(d)

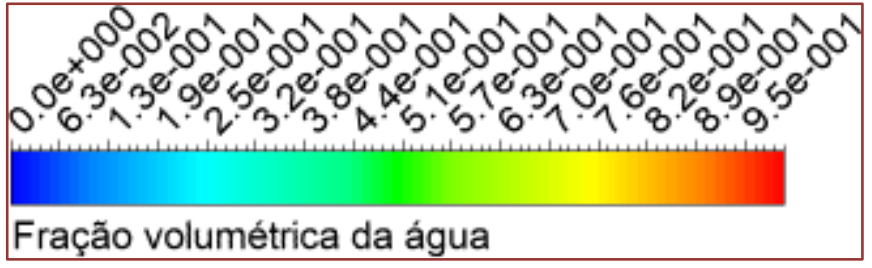

Fonte: Própria do autor. 
Figura 5. Fração volumétrica da água no tempo t2 = $100 \mathrm{~s}$. (a) Para velocidade da água e do ar $=0 \mathrm{~m} / \mathrm{s}$. (b) Para velocidade da água e do ar $=2 \mathrm{~m} / \mathrm{s}$. (c) Para velocidade da água e do $\mathrm{ar}=6 \mathrm{~m} / \mathrm{s}$. (d) Para velocidade da água e do $a r=15 \mathrm{~m} / \mathrm{s}$.

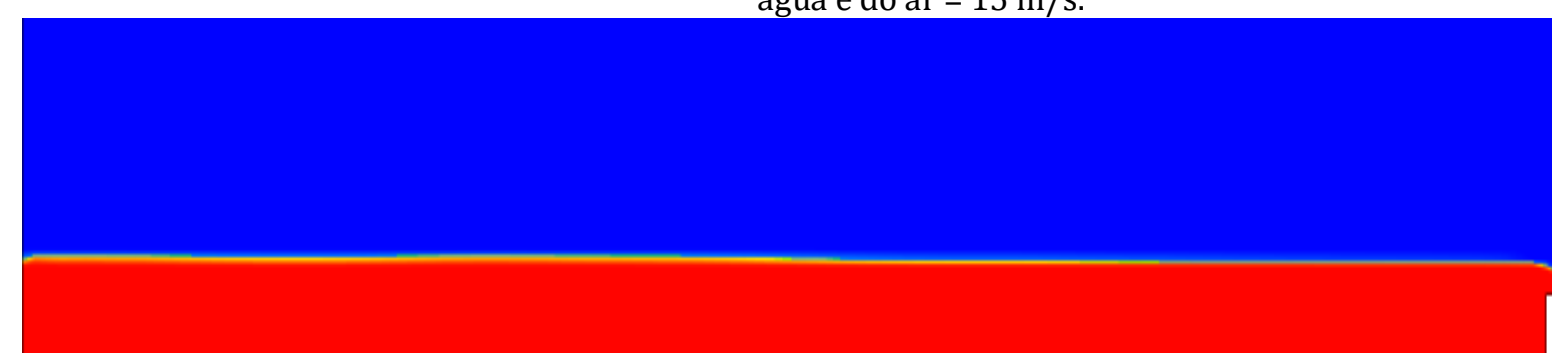

(a)

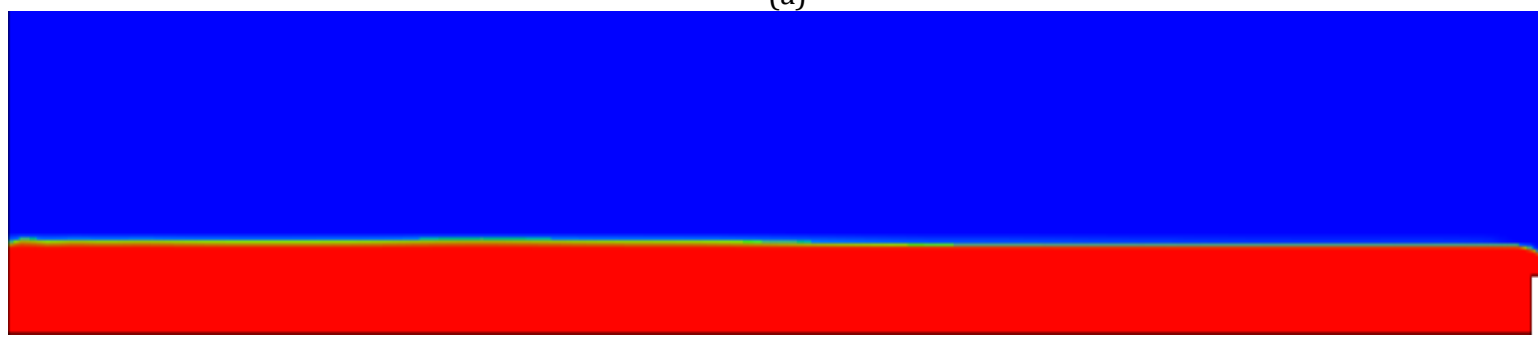

(b)

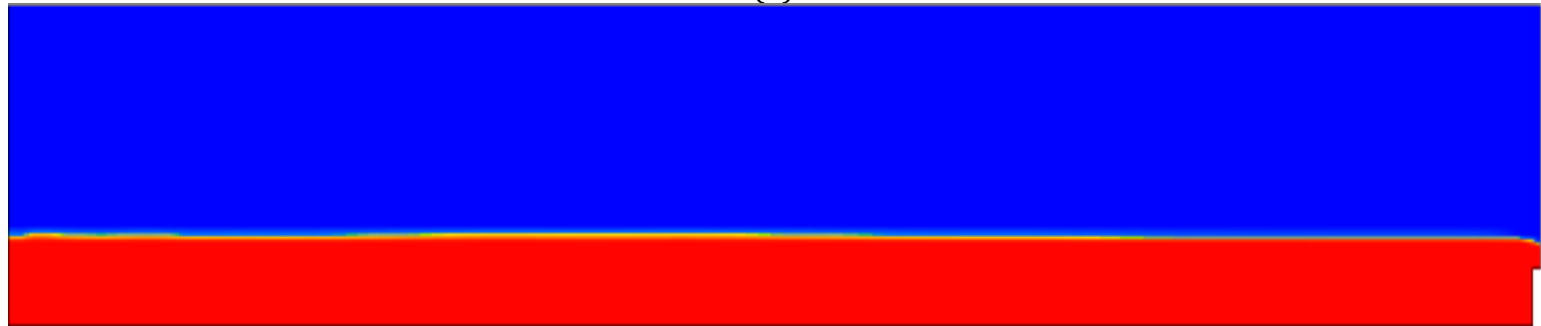

(a)

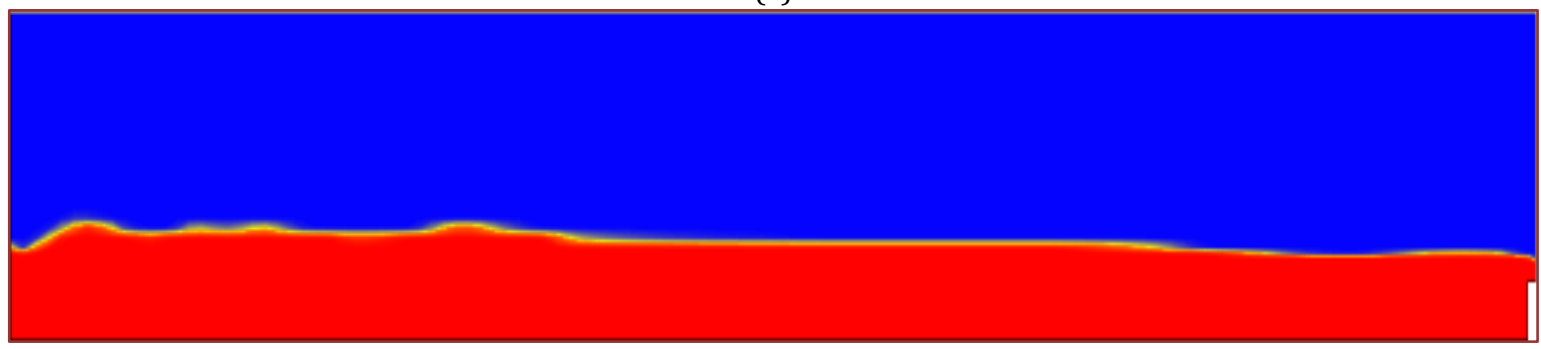

(b)

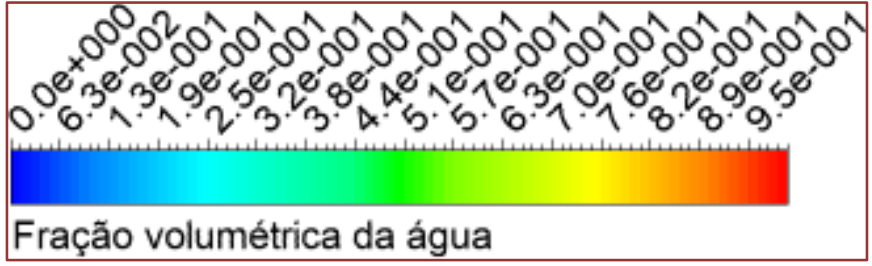

Fonte: Própria do autor. 
Figura 6. Variação da velocidade superficial da água nas posições ( $\mathrm{L}=1 \mathrm{~m}, \mathrm{~L}=2 \mathrm{~m}$ e L= $3 \mathrm{~m}$ ) para o caso 1.

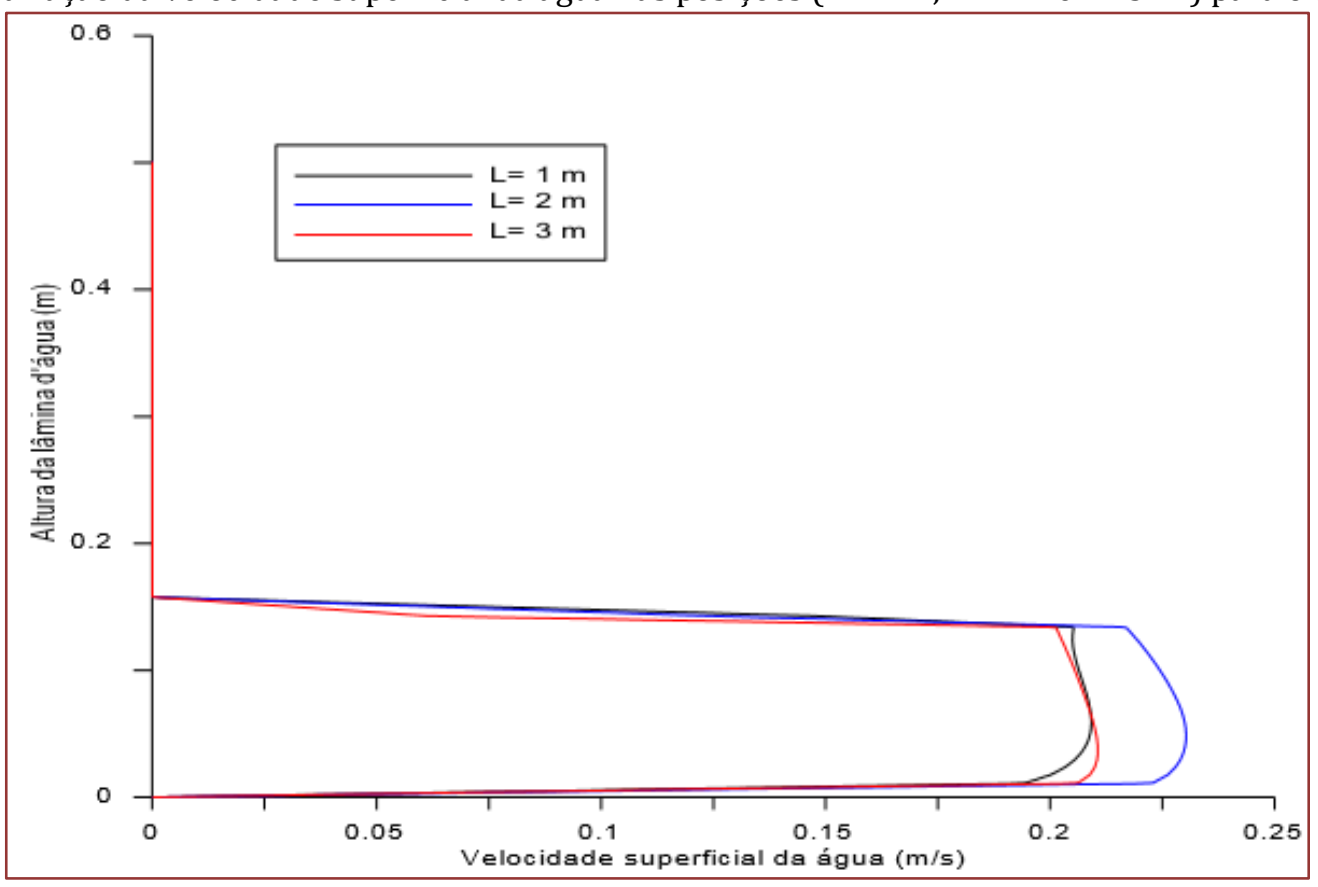

Fonte: Própria do autor.

Figura 7. Variação da velocidade superficial da água nas posições ( $L=1 \mathrm{~m}, \mathrm{~L}=2 \mathrm{~m}$ e L= $3 \mathrm{~m}$ ) para o caso 2.

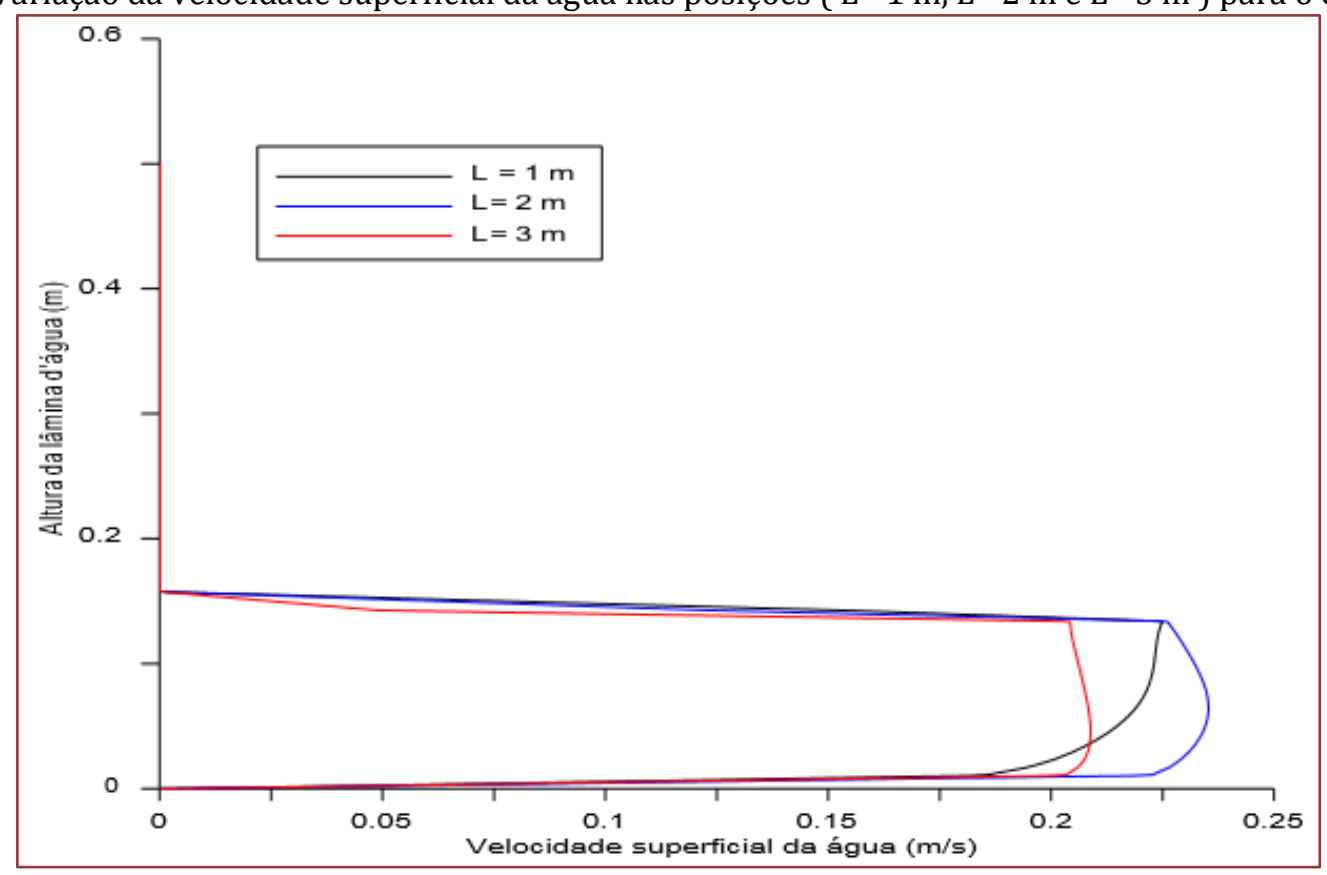

Fonte: Própria do autor. 
Figura 8. Variação da velocidade superficial da água nas posições ( $L=1 \mathrm{~m}, \mathrm{~L}=2 \mathrm{~m}$ e L= $3 \mathrm{~m}$ ) para o caso 3.

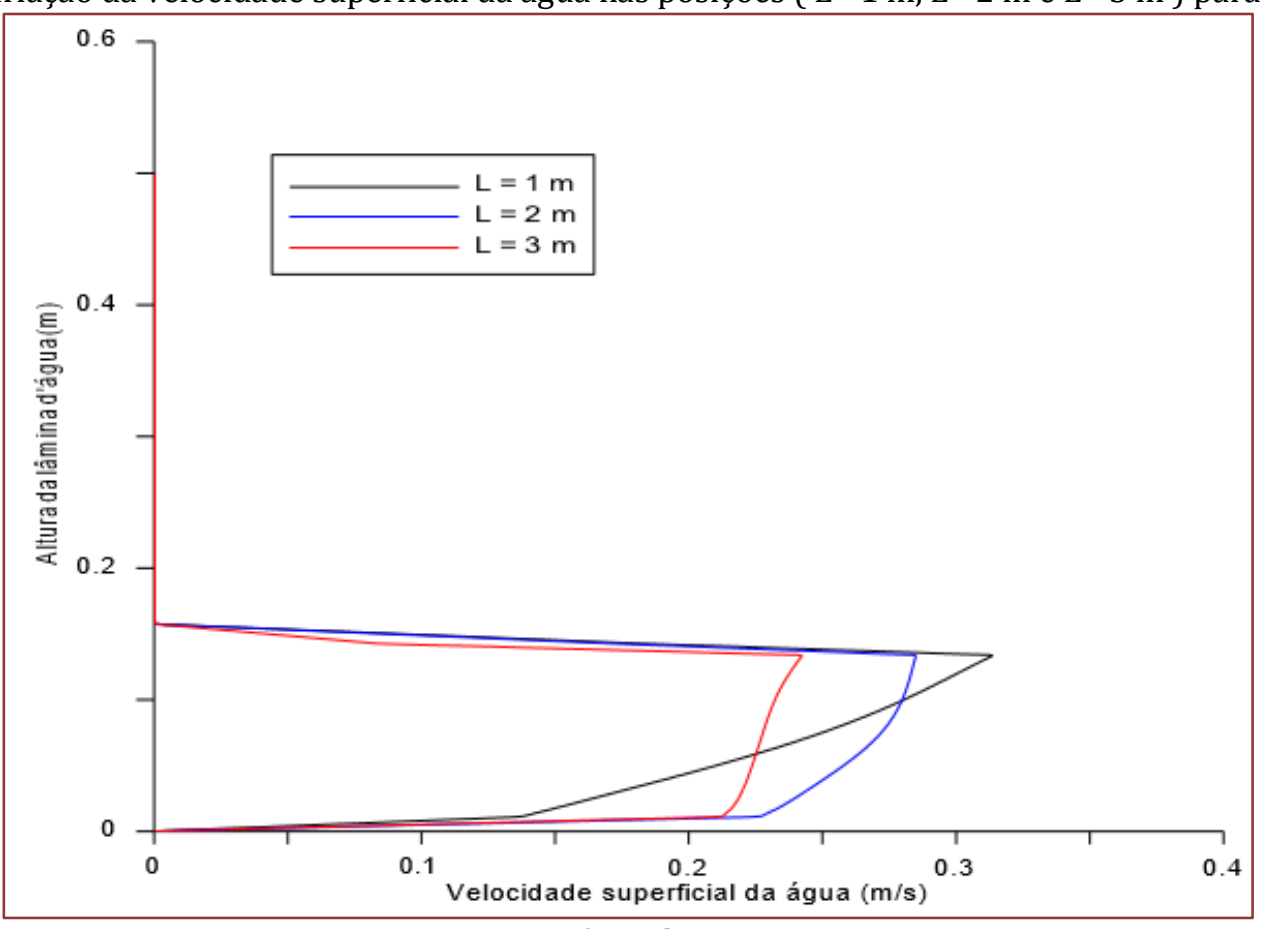

Fonte: Própria do autor

Figura 9. Variação da velocidade superficial da água nas posições ( $L=1 \mathrm{~m}, \mathrm{~L}=2 \mathrm{~m}$ e L= $3 \mathrm{~m}$ ) para o caso 4.

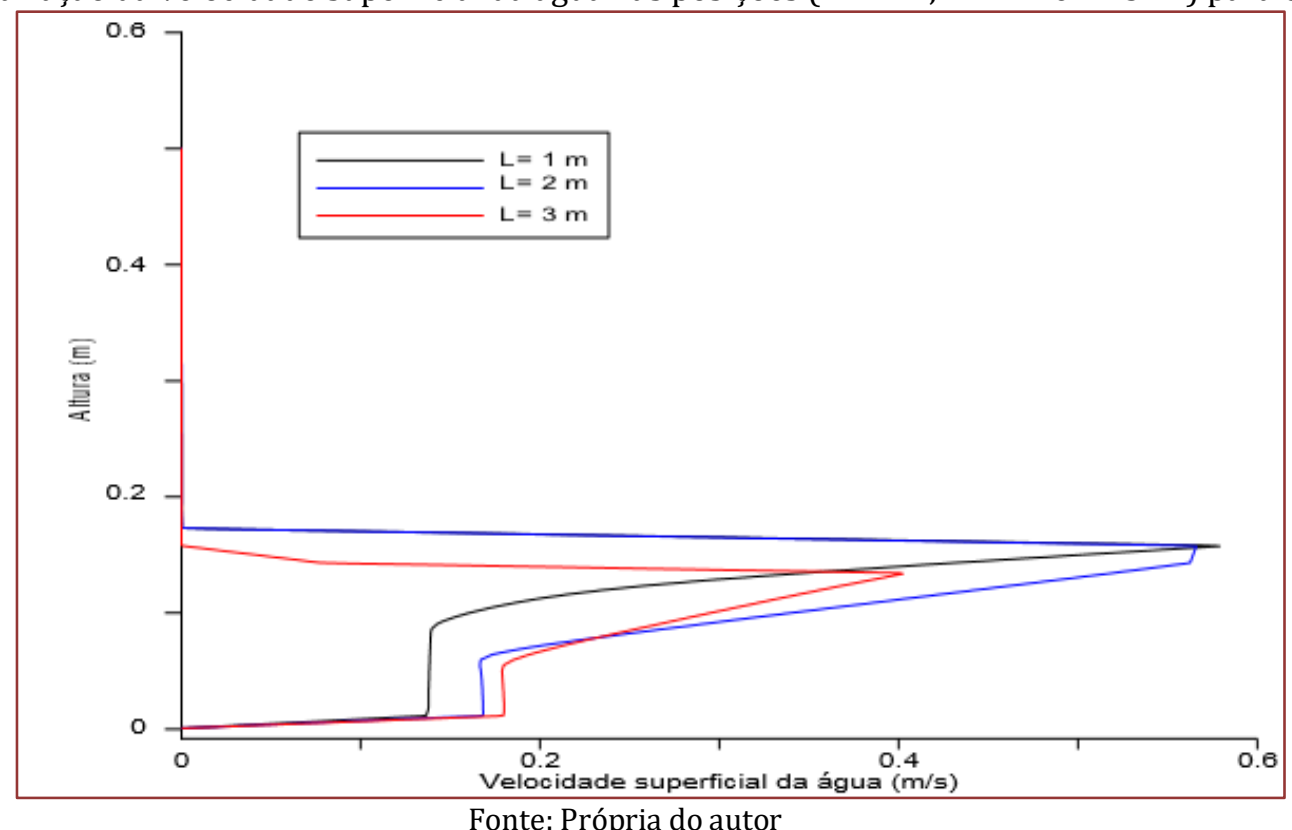

Nas Figuras 8 e 9 observa-se uma modificação no comportamento da velocidade, isso aconteceu devido ao aumento da velocidade do ar, a consequência deste aumento ocasionou um maior arraste das camadas do líquido, influenciando nas tensões de cisalhamento. Na região inicial $(\mathrm{L}=1 \mathrm{~m})$ o impulso de arraste devido a velocidade foi maior e reduzindo ao longo do comprimento, devido as perdas de carga a velocidade superficial da água foi reduzindo.

A Figura 10 apresenta os vetores da velocidade superficial dos fluidos. Observam-se áreas de recirculação geradas pelos seguintes fatores: diferença de velocidade dos fluidos, densidades e as tensões de cisalhamento. Na saída a presença do peitoral provocou também a formação de uma área de recirculação acompanhada por um aumento na turbulência dos fluidos. Os vetores mostrados foram plotados no plano $\mathrm{Z}(0,125 \mathrm{~m})$ região com desenvolvimento significativo e altas velocidades de fluidos. 
Figura 10. Vetores da velocidade superficial dos fluidos na região próximo entrada (a) e na saída (b) para o

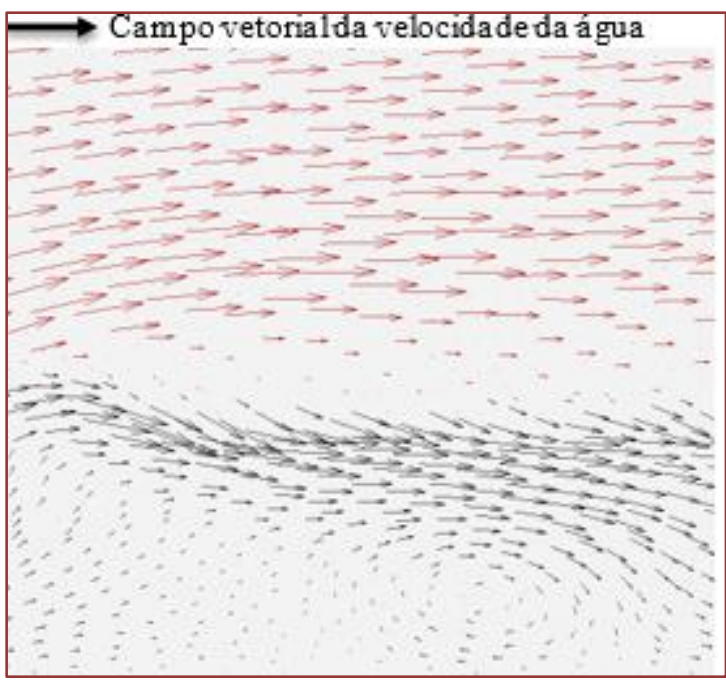

(a) caso 4

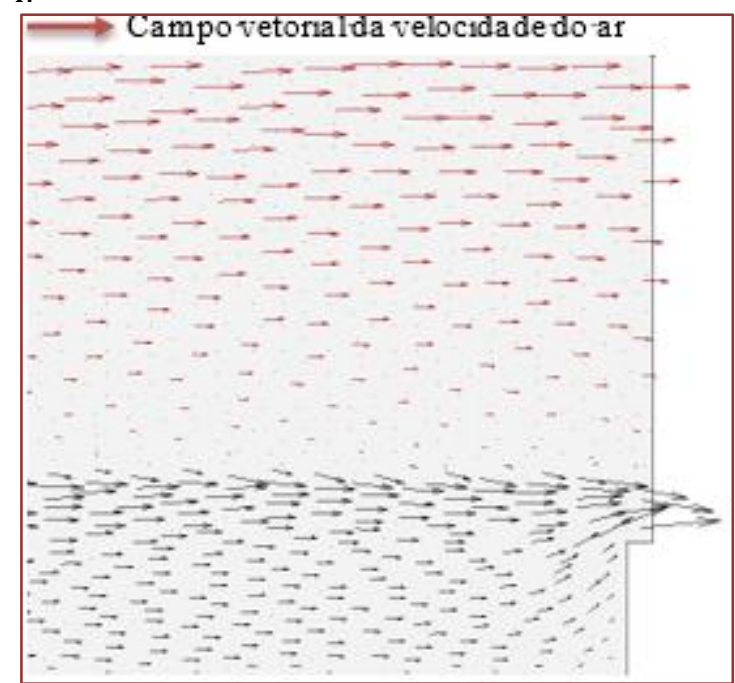

(b)

Fonte: Própria do autor.

\section{CONCLUSÕES}

Com os resultados das simulações numéricas para os casos estudados do comportamento fluidodinâmico da água-ar em um tanque pode-se concluir:

- comportamento da água na interface variou significativamente com o aumento da velocidade do ar;

- Observou-se que o aumento da velocidade do ar provocou a formação de ondas na superfície da água;

- A variação na interface água - ar foi diretamente proporcional ao aumento da velocidade do ar;

- Comprovou-se que o modelo matemático proposto foi capaz de avaliar o escoamento bifásico estudado.

\section{AGRADECIMENTOS}

Ao programa de Pós- Graduação em Engenharia de Processos (UFCG), ao Laboratório de Pesquisa em Fluidodinâmica e Imagem, como também ao Laboratório Computacional de Térmica e Fluidos e a Capes pelo apoio financeiro.

\section{REFERÊNCIAS}

[1] Benedetti, E., 2013, “Água - Fonte da vida”, Revista veterinária notícias, v. 18, n. 1, Uberlândia, Brasil, p. 1-5.

[2] Carmo, R. L., Dagnino, R. S., Feitosa, F. F., Johansen, I. C., Craice, C., 2013, "População e consumo urbano de água no Brasil: Interfaces e desafios”, XX Simpósios Brasileiro de Recursos Hídricos.

[3] Duarte, W. G., Mattos, A. N., Eing, C.,Silva, D. L., Frasson, K. C., Eckert, C. L. , 2015, “Aproveitamento de Água Pluvial para Fins não Potáveis: estudo de caso na jardinagem”, Revista Ciência \& Cidadania, v. 1, n. 1, p. 8-18.

[4] Marchesan, E., Sartori, G. M. S., Reimche, G. B., Avila, L. A., Zanela, R., Machado, S. L. O., Macedo, V.

[5] R. M., Cogo, J. P., 2009, “Qualidade de água dos rios Vacacaí e Vacacaí-Mirim”, Ciência Rural, v.39, n.7, Rio Grande do Sul, Brasil, p.2050-2056.

[6] Rattner, H., 2009, "Meio ambiente, saúde e desenvolvimento sustentável", Ciência \& Saúde Coletiva, v.14, n.6, p.1965-1971.

[7] Mayerhoff, Z. D. V. L., 2007, "Inovações estão em aperfeiçoar o tratamento de águas e efluentes", Propriedade Intelectual. Instituto Nacional da Propriedade Industrial. 
[8] Paz, A. R., 2003, “Análise dos principais fatores intervenientes no comportamento hidrodinâmico do banhado do Taim", Dissertação de Mestrado, Instituto de Pesquisas Hidráulicas, Universidade Federal do Rio Grande do Sul, Porto Alegre.

[9] Barros, M. L., 2012, "Modelagem hidrodinâmica e de qualidade de água em corpos de água com alagamento e secamento", Tese de Doutorado apresentada ao Programa de Pós-graduação em Engenharia Civil, COPPE, da Universidade Federal do Rio de Janeiro.

[10] Buil, N., 1999, "Modelagem tridimensional de transporte de poluentes em fluxos de superfície livre.", Tese de Doutorado apresentada ao Programa de Pós-Graduação em Engenharia mecânica, Universidade Claude Bernard Lyon1.

[11] Ansys I., 2015, CFX-Theory Manual Guide.

[12] Evangelista, A, W, P., 2019, "Propriedades fundamentais dos fluidos", Escola de Agronomia e engenharia de alimentos, setor de engenharia rural. Disponível em: https://www.agro.ufg.br/up/68/o/1.1.2 Propriedades_dos_fluidos.pdf. Acesso em: Outubro de 2019.

[13] Gomes, M. H. R., 2019, “Apostila de mecânica dos fluidos”, Universidade Federal de Juiz de Fora. Disponível em: http://www.ufjf.br/engsanitariaeambiental/files/2012/09/Apostila-de-Mec\%C3\%A2nica-dos- Fluidos.pdf . Acesso em: Outubro de 2019.

[14] White, F.M., 2006, “Viscous Flow”, Ed. McGraw Hill, Estados Unidos, 652 p.

[15] Porto, R. M., 1999, “Hidráulica básica” Ed. São Carlos, EESC - USP, São Paulo, 519 p. 


\section{Capítulo 7}

\section{Cinética de secagem de banana nanica utilizando modelos empíricos}

\section{Emmanuel Fabiano Marques da Silva \\ Arnaldo Bezerra Lopes de Almeida \\ Fagno Dallino Rolim \\ José Jefferson da Silva Nascimento}

Resumo: Na busca de um método para conservação de alimentos, pesquisadores continuam a realizar pesquisas com determinados tipos de alimentos através do método da secagem ou desidratação, método utilizado desde a antiguidade, que tem como finalidade diminuir o teor de água do produto, permitindo a armazenagem por períodos mais longos. Diante disso o presente trabalho objetivou realizar estudo com objetivo de determinar a cinética de secagem da banana - Nanica (musa paradisíaca) nas temperaturas de $40,50,60$ e $70^{\circ} \mathrm{C}$ e velocidade do ar $1,5 \mathrm{~m} \mathrm{~s}-1$ ajustando com os modelos matemáticos empíricos (Page, Newton, Henderson e Pabis, Dois termos e Aproximação da Difusão) e difusivos. A análise dos resíduos, do coeficiente de determinação e do erro médio relativo, calculada para cada modelo ajustado será utilizada para se avaliar qual o modelo que melhor se ajustará aos dados experimentais da secagem. Observou-se que os melhores ajustes foram os da equação de Page, equações de Dois termos e Aproximação da Difusão, para o modelo difusivo a equação que melhor se ajustou foi a convectiva.

Palavras-chave: cinética de secagem, ajustes, teor de água. 


\section{INTRODUÇÃO}

O cultivo da banana é desenvolvido em aproximadamente 115 países, a atividade está presente em todos os continentes. Entre as frutíferas, a banana ocupa a segunda posição na produção mundial, sendo superada apenas pela melancia, com 100,7 milhões de toneladas (FAO, 2011).

Apesar de colhida em quantidades e qualidade praticamente iguais ao longo do ano, a fruta deve ser consumida em até 25 dias após a colheita. Do total de bananas colhidas, somente cerca de 40 a $50 \%$ chegam efetivamente às mãos dos consumidores. Segundo TAGLIARI E FRANCO (1994), isso ocorre devido às perdas causadas por danos ocorridos do plantio até a colheita, devido à falta de planejamento do manejo da lavoura. 0 desperdício ocorre principalmente no momento da colheita e na comercialização.

Do ponto de vista biológico, é uma das frutas que apresenta uma das maiores perdas por decomposição pós-colheita, pois é altamente perecível e, além disso, não permite o uso de frio para o armazenamento (SOUSA, 2002; BORDIN, 1998).

Com base nos problemas citados acima, pesquisadores estudam cada vez mais alguma metodologia para conservação, como por exemplo, a secagem ou desidratação, que tem como finalidade diminuir o teor de água do produto, permitindo a armazenagem por períodos mais longos. Para tanto, é necessário o fornecimento de calor para evaporar a água do material e também deve haver um sorvedor para remover o vapor d'água da superfície do material a ser seco (BROD et al., 1999).

A conservação de frutas através da desidratação ou secagem é um dos processos comerciais mais usados na conservação de produtos agropecuários. A redução do teor de umidade do produto, e consequentemente, de sua atividade de água, tem por objetivo evitar o desenvolvimento de microrganismos e de reações químicas indesejáveis que podem deteriorar o produto tornando-o impróprio para o consumo (MADAMBA, 2007).

Dessa forma, o presente trabalho teve como objetivo o estudo da cinética de secagem da banana nanica utilizando o secador de leito fixo, submetendo-os a quatro temperaturas diferentes $(40,50,60$ e $70 \stackrel{\circ}{\circ}$ ) e velocidade do ar de secagem de $1,5 \mathrm{~m} / \mathrm{s}$, para comparar os resultados com os modelos matemáticos empíricos, tais como: Page, Henderson e Pabis, Newton, Aproximação da difusão e Equação duas exponenciais e verificar aquele que melhor se ajusta aos dados experimentais obtidos.

Assim, pelo exposto acima, considerando a importância da banana para a alimentação da humanidade tendo em vista as perdas em função da rápida deterioração. Justifica-se realizar este trabalho, visando abastecer de informações relacionadas à secagem de bananas como forma de melhorar o tempo de utilização do produto.

\section{METODOLOGIA}

A banana, matéria-prima para realização deste trabalho foi a Musa acuminata subgrupo Cavendish $c v$ nanica, adquirida em feira livre do município de Campina Grande e teve origem no Sítio Honorato que está localizado no município de Alagoa Nova, Paraíba.

Para realização da medição do diâmetro, foi utilizado um paquímetro digital TDS da marca Digimess, modelo $100.174 \mathrm{~L}$, com resolução de $0,01 \mathrm{~mm}$ e fundo de escala de $150 \mathrm{~mm}$, e a medida do comprimento da banana foi feita com trena de $0,50 \mathrm{~m}$. A temperatura e a umidade relativa do ar no ambiente foi medida por um termo-higrômetro digital da Minipa modelo MTH 1362W. Foi utilizado, ainda balança digital da marca Diagtech, resolução de 0,001 g com capacidade máxima de $510 \mathrm{~g}$, para realização das pesagens das bananas. A secagem foi realizada em secador convectivo de fluxo vertical, peneiras removíveis, modelo S.S.4500W e para obtenção da massa seca do produto, utilizou-se estufa de circulação de ar. 


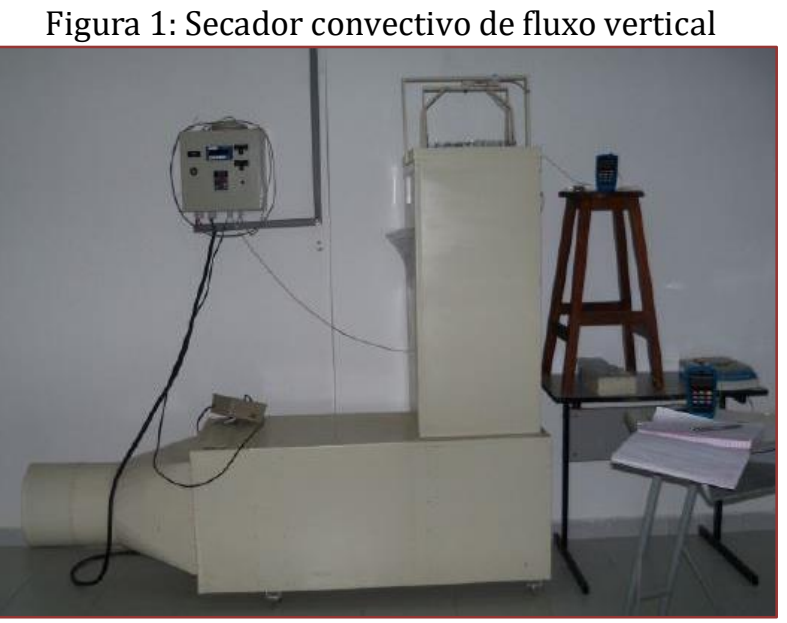

Fonte: 0 autor

Figura 2: Balança Diagtech

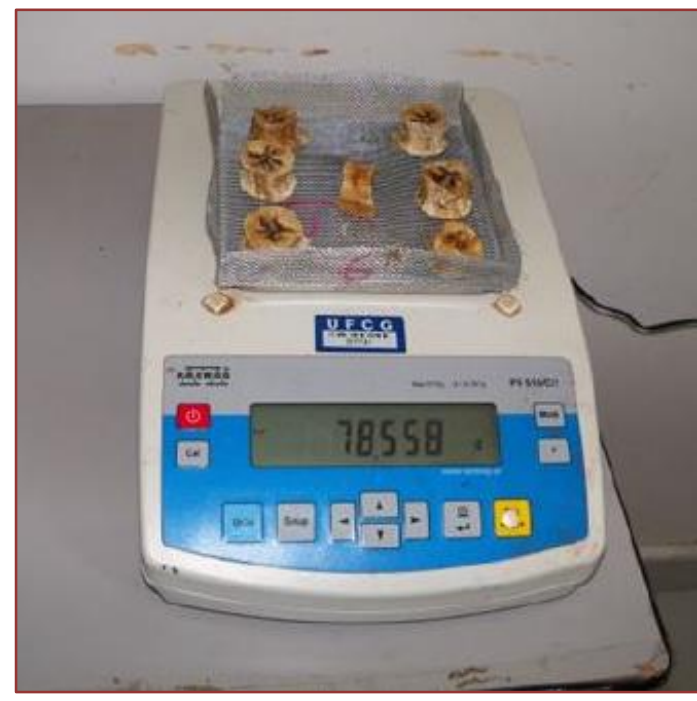

Fonte: $\mathrm{O}$ autor
Figura 3: Paquímetro digital, trena e termohigrômetro

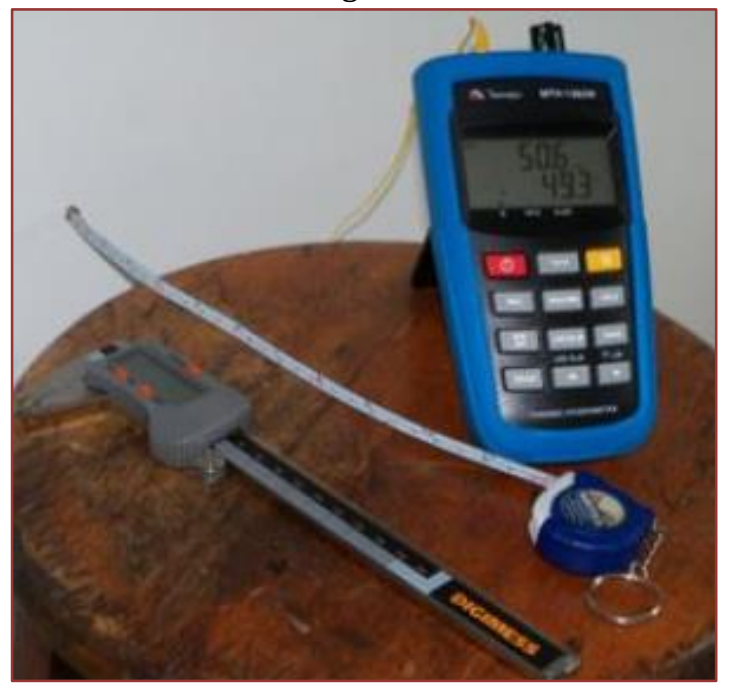

Fonte: 0 autor

\section{DESENVOLVIMENTO}

O presente trabalho foi conduzido no Laboratório de Armazenamento e Processamento de Produtos Agrícolas da Unidade Acadêmica de Engenharia Agrícola, do Centro de Tecnologia e Recursos Naturais da Universidade Federal de Campina Grande, PB.

As bananas foram compradas quando as cascas ainda estavam totalmente verdes, amadurecendo naturalmente e foram levadas para o laboratório em cachos, sendo em seguida despencadas e posteriormente selecionadas, os frutos com algum tipo de dano mecânico foram desprezados, os frutos considerados bons foram colocados em sextos, deixados em temperatura ambiente. 0 grau de maturação escolhido para realização deste trabalho foi o amarelo com muitas pintas pretas de acordo com a escala 7 da classificação de Haendler.

Tendo atingido o grau de maturação desejado, os frutos foram descascadas com descarte das cascas e posterior seleção dos frutos, procurando obter aquelas com diâmetro entre 26 e $34 \mathrm{~mm}$, e comprimento médio de $157 \mathrm{~mm}$.

De posse desse material, os frutos foram colocadas em cestos de tela fina de alumínio, medindo $13 \times 13$ $\mathrm{cm}$, devidamente pesado para obtenção da massa inicial de fruta. Então foram levados ao secador com temperatura devidamente controlada para $40{ }^{\circ} \mathrm{C}$ e velocidade do ar de secagem, está foi fixada em $1,5 \mathrm{~m} / \mathrm{s}$. 
Após coleta dos resultados, o procedimento foi repetido para as temperatura do ar de secagem a 50, 60 e $70{ }^{\circ} \mathrm{C}$ sendo mantida a velocidade do ar.

Em cada experimento, o produto foi pesado no inicio da secagem, em espaços de 5 min por aproximadamente 2 horas. Em seguida, o produto foi pesado a cada 10, 15, 20, 25, 30 minutos, depois em espaços de tempo de 1, 2, 4, 6, 12 e 24 horas até o final do processo, ou seja, até que o produto atingisse seu teor de água de equilíbrio, de forma a possibilitar o cálculo da razão de umidade da banana. Em paralelo as pesagens foram ainda realizadas medições de raio e comprimento, bem como a medida e o cálculo das propriedades psicrométricas do ar, conforme pode ser observado na Tabela 1.

Tabela 1: Dados das condições do ar de secagem e do ar ambiente.

\begin{tabular}{|c|c|c|c|c|}
\multicolumn{3}{c}{ AR DE SECAGEM } & \multicolumn{3}{c|}{ AR AMBIENTE } \\
$\mathrm{T}\left({ }^{\circ} \mathrm{C}\right)$ & $\overline{\mathrm{UR}} \%$ & $\mathrm{v}\left(\mathrm{m} \mathrm{s}^{-1}\right)$ & $\overline{\mathrm{T}}_{\mathrm{a}}\left({ }^{\circ} \mathrm{C}\right)$ & $\overline{\mathrm{UR}} \%$ \\
\hline 40,0 & 30,5 & 1,59 & 29,5 & 52,0 \\
\hline 50,0 & 20,3 & 1,84 & 30,3 & 59,3 \\
\hline 60,0 & 10,4 & 1,70 & 30,2 & 48,3 \\
\hline 70,0 & 6,6 & 1,50 & 30,1 & 48,4 \\
\hline
\end{tabular}

Quando alcançado o teor de umidade de equilíbrio, as amostras foram deixadas por um período de 24 horas no secador, e em seguida, para determinar a massa seca, as amostras foram levadas para a estufa a uma temperatura de $105^{\circ} \mathrm{C}$ por 6 horas. Depois as amostras foram levadas para o dessecador até atingir a temperatura ambiente, sendo obtida então a massa seca, o que possibilitou determinar os teores de umidade, como visto na Tabela 2.

Tabela 2: Informações gerais sobre a banana, inclusive com os tempos totais de secagem para cada temperatura

\begin{tabular}{|c|c|c|c|c|c|c|}
\hline $\mathrm{T}\left({ }^{\circ} \mathrm{C}\right)$ & $\mathrm{C}(\mathrm{mm})$ & $\mathrm{d}(\mathrm{mm})$ & $\mathrm{Xeq}(\mathrm{bs})$ & $\mathrm{Xi}(\mathrm{bs})$ & $\mathrm{Xf}(\mathrm{bs})$ & $\mathrm{t}(\mathrm{min})$ \\
\hline 40 & 179,00 & 31,48 & 0,1352 & 3,2162 & 0,4156 & 3625 \\
\hline 50 & 141,00 & 29,80 & 0,1213 & 3,4336 & 0,4260 & 2005 \\
\hline 60 & 143,00 & 29,54 & 0,1075 & 3,1420 & 0,3836 & 1420 \\
\hline 70 & 165,00 & 30,60 & 0.0936 & 2,8990 & 0,3545 & 1200 \\
\hline
\end{tabular}

As curvas de secagem das amostras foram obtidas a partir do cálculo das razões de água em função do tempo. Os modelos matemáticos de secagem, dados na Tabela 3, serão ajustados aos dados experimentais.

Tabela 3: Modelos empíricos utilizados no presente trabalho

\begin{tabular}{|c|c|c|}
\hline \multicolumn{2}{|c|}{$^{\circ}$ Nome do modelo } & Modelo empírico \\
\hline 1 & Newton & $\mathrm{Ru}=\exp (-\mathrm{kt})$ \\
\hline 2 & Page & $\mathrm{Ru}=\exp \left(-\mathrm{kt}^{\mathrm{n}}\right)$ \\
\hline 3 & Henderson e Pabis & $\mathrm{Ru}=\mathrm{a} \exp (-\mathrm{kt})$ \\
\hline 4 & Aproximação da Difusão & $\mathrm{Ru}=\mathrm{a} \exp \left(-\mathrm{k}_{0} \mathrm{t}\right)+(1-\mathrm{a}) \exp (-\mathrm{Kat})$ \\
\hline 5 & Dois termos & $\mathrm{Ru}=\mathrm{a} \exp (\mathrm{b} \mathrm{x})+\mathrm{c} \exp (\mathrm{d} \mathrm{x})$ \\
\hline
\end{tabular}

Os cinco modelos empíricos apresentados foram aplicados aos dados experimentais, utilizando o programa computacional Lab Fit Curve Fitting Software disponível na Internet.

$\mathrm{Na}$ avaliação da representatividade dos modelos foram adotados o coeficiente de determinação $\left(\mathrm{R}^{2}\right)$ e o qui-quadrado $\left(\mathrm{X}^{2}\right)$. Quanto menor for o qui-quadrado e mais próximo de 1 for valor de $\mathrm{R}^{2}$, melhor será o ajuste da equação aos dados experimentais.

\section{RESULTADOS E DISCUSSÃO}

O processo de secagem consiste na remoção de grande parte da água contida no produto a determinado nível, originando condições desfavoráveis à continuidade de suas atividades metabólicas e ao desenvolvimento de microrganismos (Martinazzo et al., 2007a). Sabendo disso, neste tópico apresentaremos as informações gerais iniciais importantes no processo de secagem da banana. 
As informações referentes à secagem convectiva de bananas para as quatro temperaturas estudadas, ar de secagem e ar ambiente, umidade relativa e velocidade do ar de secagem são apresentadas na Tabela 1 , bem como os dados relativos ao experimento na Tabela 2 acima.

As razões de umidade foram determinadas em cada instante e os resultados obtidos para as quatro temperaturas do ar de secagem são apresentados na Figura 4 a seguir. percebe-se que os processos de secagem foram acompanhados até o equilíbrio, apesar das análises de tais processos serem realizadas até cerca de $\mathrm{RU}=0,1$, evitando, assim, a região de transição vítrea.

Figura 4: Dados da secagem de bananas inteiras para as temperaturas do ar de secagem de: (a) $40,0{ }^{\circ} \mathrm{C}$; (b) $50,0^{\circ} \mathrm{C}$; (c) $60,0^{\circ} \mathrm{C}$; (d) $70,0^{\circ} \mathrm{C}$.
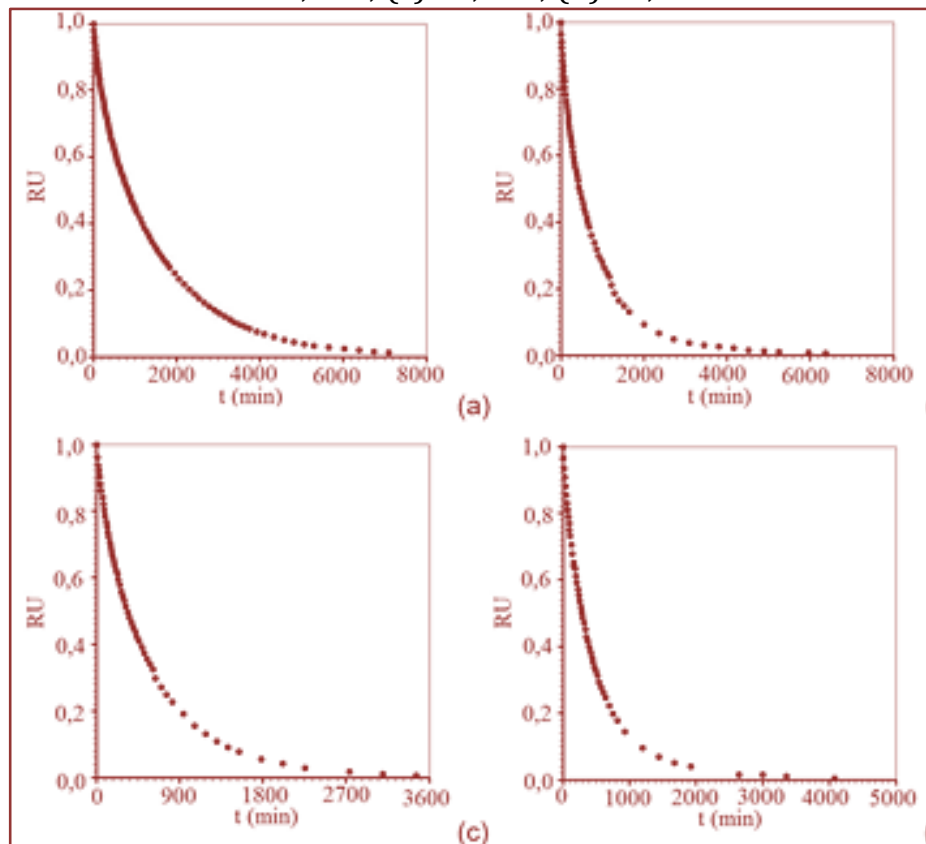

(a)

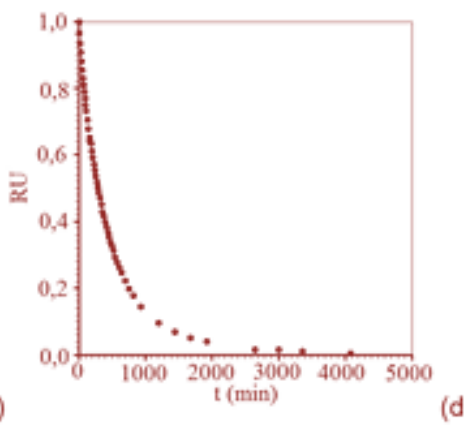

Fonte: $\mathrm{O}$ autor

Inicialmente, modelos empíricos serão usados para descrever as cinéticas de secagem.

Equação de Newton - RU = exp(-at)

Em regressão não-linear, os valores iniciais dos parâmetros a serem determinados devem ser informados. No presente caso, o valor inicial do parâmetro de ajuste, para as quatro temperaturas, foi estabelecido como a $0=1,0 \times 10^{-4}$. Os resultados dos ajustes para as quatro temperaturas podem ser observados através da Figura 5. 
Figura 5: Cinéticas de secagem descritas pela equação de Newton para as temperaturas do ar em: (a) $40,0{ }^{\circ} \mathrm{C}$; (b) $50,0^{\circ} \mathrm{C}$; (c) $60,0^{\circ} \mathrm{C}$; (d) $70,0^{\circ} \mathrm{C}$.
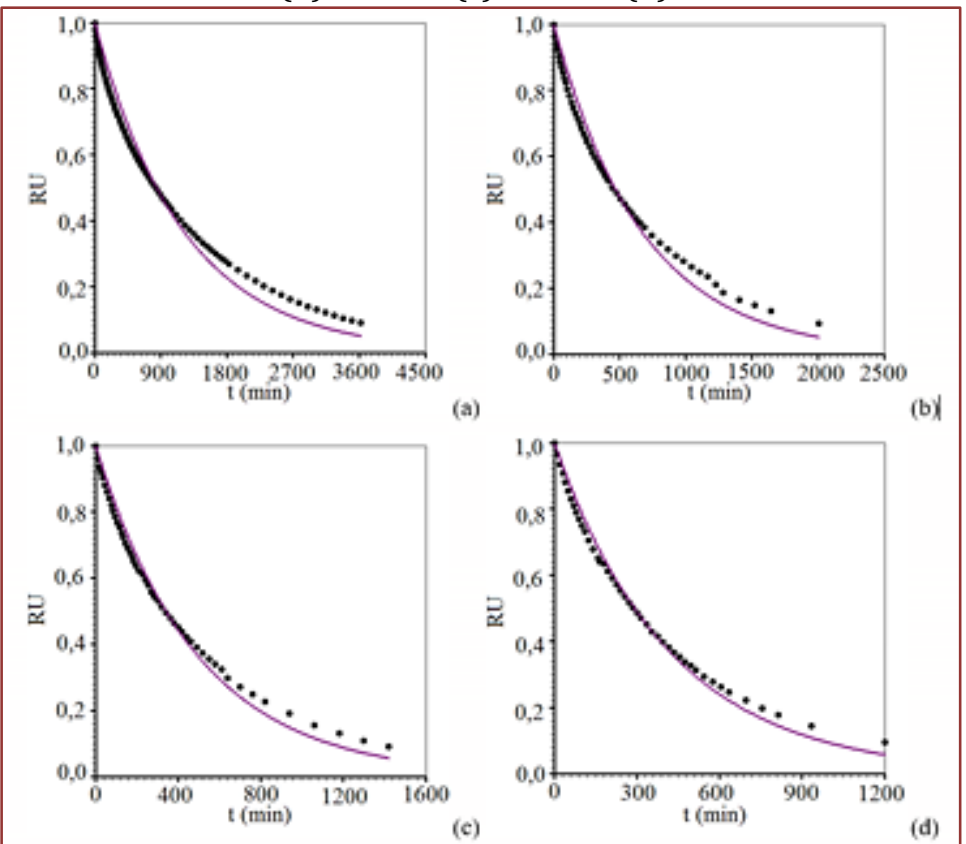

Fonte: $\mathrm{O}$ autor

Na Tabela 4 são dados os valores do parâmetro "a" para cada temperatura, bem como a sua incerteza, e também os indicadores estatísticos.

Tabela 4: Resultados da equação de Newton.

\begin{tabular}{|c|c|c|c|}
\hline $\mathrm{T}\left({ }^{\circ} \mathrm{C}\right)$ & $a_{0} \times 10^{3}$ & $\mathrm{R}^{2}$ & $X^{2}$ \\
\hline 40,0 & $0,826 \pm 0,014$ & 0,996107 & 0,141144 \\
\hline 50,0 & $1,483 \pm 0,030$ & 0,995560 & 0,078969 \\
\hline 60,0 & $2,036 \pm 0,032$ & 0,997310 & 0,043667 \\
\hline 70,0 & $2,383 \pm 0,031$ & 0,997888 & 0,002383 \\
\hline
\end{tabular}

Equação de Page $-\mathrm{RU}=\exp (-\mathrm{atb})$

Nos ajustes da equação de Page aos dados de secagem para todas as temperaturas, foram usados os seguintes valores iniciais para os parâmetros de ajuste: $\mathrm{a}_{0}=0,5$ e $\mathrm{b}_{0}=0,1 \times 10^{-3}$. Uma vez realizadas as regressões não-lineares, os resultados obtidos para os parâmetros de ajuste. Os gráficos que representam as cinéticas de secagem descritas pela equação de Page são apresentados na Figura 6 e a Tabela 5.

Tabela 5: Tabela com os resultados da equação de Page.

\begin{tabular}{|c|c|c|c|c|}
\hline $\mathrm{T}\left({ }^{\circ}\right)$ & $\mathrm{a} \times 102$ & $\mathrm{~b}$ & $\mathrm{R} 2$ & $\chi 2 \times 103$ \\
\hline 40,0 & $0,345 \pm 0,005$ & $0,7920 \pm 0,0024$ & 0,999698 & 1,779070 \\
\hline 50,0 & $0,5282 \pm 0,0012$ & $0,7980 \pm 0,0036$ & 0,999551 & 1,466410 \\
\hline 60,0 & $0,526 \pm 0,008$ & $0,8399 \pm 0,0027$ & 0,999781 & 0,662714 \\
\hline 70,0 & $0,534 \pm 0,009$ & $0,8616 \pm 0,0029$ & 0,999790 & 0,553260 \\
\hline
\end{tabular}


Figura 6: Cinéticas de secagem descritas equação de Page para as temperaturas em: (a) 40,0 ${ }^{\circ} \mathrm{C}$; (b) $50,0^{\circ} \mathrm{C}$; (c) $60,0^{\circ} \mathrm{C}$; (d) $70,0^{\circ} \mathrm{C}$.
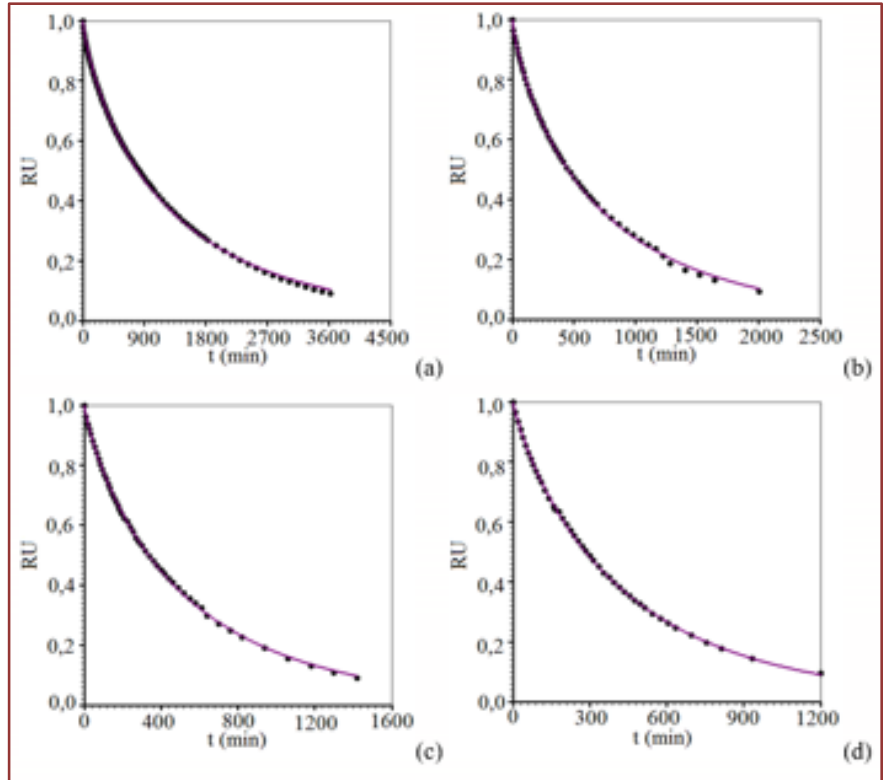

Fonte: $\mathrm{O}$ autor

Note que o modelo de Page é amplamente utilizado, geralmente com sucesso, na descrição da cinética de secagem de vários produtos agrícolas. É interessante observar, através dos indicadores estatísticos da Tabela 5 e de uma inspeção visual da Figura 6, o completo acordo entre o modelo de Page e os dados experimentais obtidos neste trabalho de pesquisa.

\section{Equação de Henderson e Pabis - RU = a exp(-bt)}

Em todos os ajustes do modelo de Henderson-Pabis aos dados de secagem, serão usados os seguintes valores iniciais para as regressões não-lineares: $\mathrm{a}_{0}=0,5$ e $\mathrm{b}_{0}=0,1 \times 10^{-3}$. Os gráficos referentes aos ajustes para as quatro temperaturas de secagem podem ser observados na Figura 7, que é dada a seguir.

Figura 7: Cinética de secagem equação de Henderson e Pabis para as temperaturas em: (a) 40,0 ${ }^{\circ} \mathrm{C}$; (b) $50,0^{\circ} \mathrm{C}$; (c) $60,0^{\circ} \mathrm{C} \mathrm{e} \mathrm{(d)} 70,0^{\circ} \mathrm{C}$.
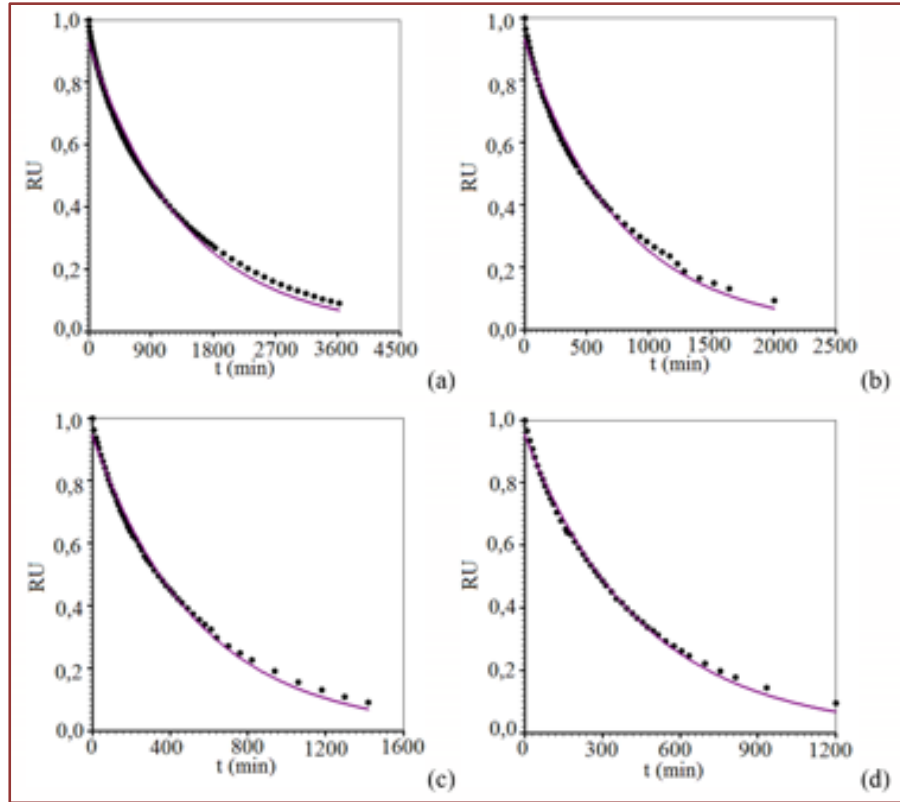

(b)

Fonte: $\mathrm{O}$ autor 
Os resultados para os parâmetros de ajuste e suas incertezas, bem como os indicadores estatísticos, são apresentados na Tabela 6.

Tabela 6: Tabelas com os resultados da equação de Henderson e Pabis.

\begin{tabular}{|c|c|c|c|c|}
\hline $\mathrm{T}\left({ }^{\circ}\right)$ & $\mathrm{a}$ & $\mathrm{b} \times 103$ & $\mathrm{R} 2$ & $\chi 2 \times 102$ \\
\hline 40,0 & $0,926 \pm 0,005$ & $0,720 \pm 0,010$ & 0,993263 & 4,124460 \\
\hline 50,0 & $0,930 \pm 0,006$ & $1,308 \pm 0,022$ & 0,995829 & 2,43390 \\
\hline 60,0 & $0,945 \pm 0,005$ & $1,845 \pm 0,025$ & 0,997006 & 1,442600 \\
\hline 70,0 & $0,9524 \pm 0,005$ & $2,212 \pm 0,026$ & 0,997537 & 0,965531 \\
\hline
\end{tabular}

Embora o modelo dado pela equação de Henderson e Pabis seja razoável, de acordo com a Tabela 6 tal modelo é inferior à equação de Page na descrição da cinética de secagem de bananas inteiras.

Equação de aproximação da difusão - RU = a exp(-b x) + (1 - a) exp(-cx)

Os valores iniciais para os parâmetros de ajuste usados na equação de aproximação da difusão são dados na Tabela 7.

Tabela 7: Valores iniciais dos parâmetros.

\begin{tabular}{|c|c|c|}
\hline $\mathrm{a}_{0}$ & $\mathrm{~b}_{0}$ & $\mathrm{c}_{0}$ \\
\hline 0,90 & $0,80 \times 10^{-3}$ & $0,19 \times 10^{-3}$ \\
\hline
\end{tabular}

Realizadas as regressões não lineares, os resultados podem ser observados através da Figura 8.

Figura 8: Gráfico da cinética de secagem equação aproximação da difusão para as temperaturas do ar de secagem de: (a) $40,0{ }^{\circ} \mathrm{C}$; (b) $50,0{ }^{\circ} \mathrm{C}$; (c) $60,0^{\circ} \mathrm{C}$ e (d) $70,0^{\circ} \mathrm{C}$.
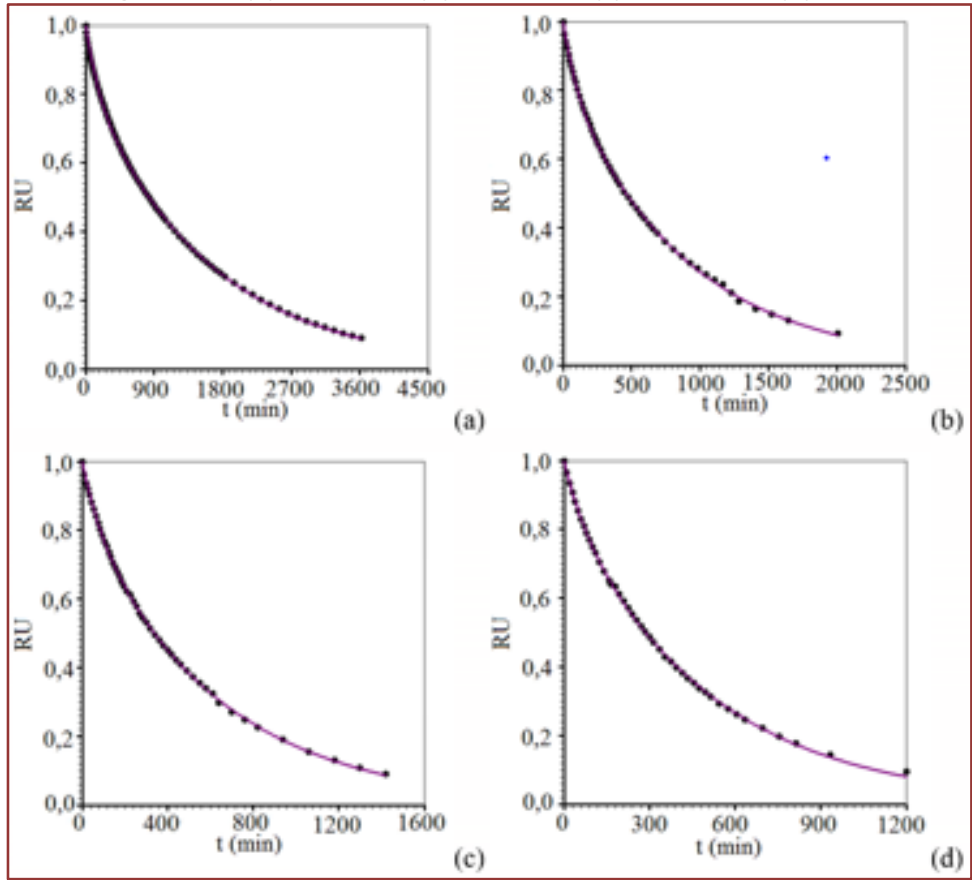

Fonte: $\mathrm{O}$ autor

Os indicadores estatísticos dos ajustes, bem como os valores dos parâmetros e suas incertezas, são dados na Tabela 8. 
Tabela 8: Resultado dos ajustes da equação da aproximação da difusão aos dados experimentais.

\begin{tabular}{|c|c|c|c|c|c|}
\hline $\mathrm{T}\left({ }^{\circ}\right)$ & $\mathrm{a}$ & $\mathrm{b} \times 10^{2}$ & $\mathrm{c} \times 10^{3}$ & $\mathrm{R}^{2}$ & $\mathrm{X}^{2} .10^{2}$ \\
\hline 40,0 & $0,1646 \pm 0,0032$ & $0,588 \pm 0,018$ & $0,6217 \pm 0,0032$ & 0,99998 & 0,1304 \\
\hline 50,0 & $0,163 \pm 0,005$ & $1,00 \pm 0,05$ & $1,129 \pm 0,010$ & 0,99967 & 0,1127 \\
\hline 60,0 & $0,143 \pm 0,005$ & $1,15 \pm 0,05$ & $1,6140 \pm 0,0012$ & 0,99983 & 1,5488 \\
\hline 70,0 & $0,119 \pm 0,006$ & $1,4270 \pm 0,0010$ & $1,999 \pm 0,017$ & 0,99975 & 0,0667 \\
\hline
\end{tabular}

Embora os indicadores estatísticos para o modelo da aproximação da difusão possam ser considerados excelentes, equivalentes aos indicadores do modelo de Page, deve ser observado que tal modelo envolve três parâmetros de ajuste, ao invés de dois.

$$
\text { Equação com duas exponenciais }-\mathrm{RU}=\mathrm{a} \exp (\mathrm{b} \mathrm{x})+\mathrm{c} \exp (\mathrm{d} \mathrm{x})
$$

Na Tabela 9, os valores iniciais dos parâmetros de ajuste para a equação com duas exponenciais são apresentados.

Tabela 9: Valores iniciais dos parâmetros.

\begin{tabular}{|c|c|c|c|}
\hline $\mathrm{a}_{0}$ & $\mathrm{~b}_{0}$ & $\mathrm{c}_{0}$ & $\mathrm{~d}_{0}$ \\
\hline 0,6823 & $-0,1214 \times 10^{-2}$ & 0,3060 & $-0,5985 \times 10^{-3}$ \\
\hline
\end{tabular}

Figura 9: Cinéticas de secagem usando a equação com duas exponenciais para as temperaturas em: (a) $40,0{ }^{\circ} \mathrm{C}$; (b) $50,0{ }^{\circ} \mathrm{C}$; (c) $60,0{ }^{\circ} \mathrm{C}$; (d) $70,0^{\circ} \mathrm{C}$.
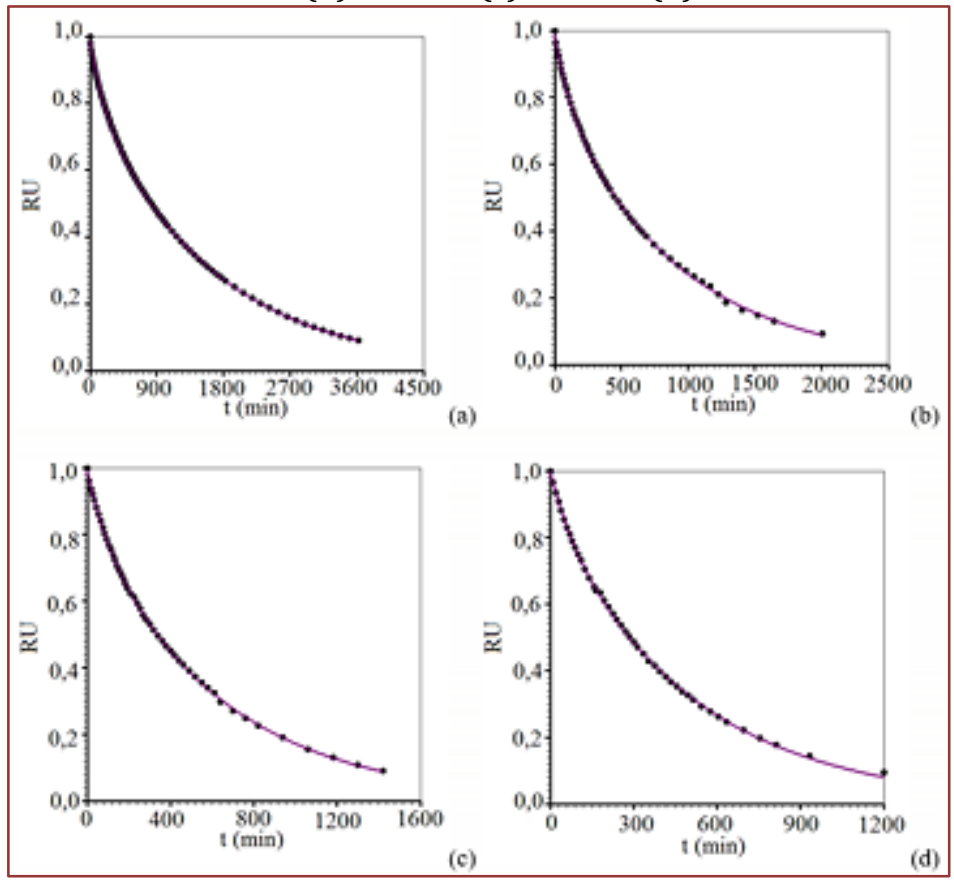

Fonte: 0 autor

Através dos ajustes da equação com duas exponenciais aos dados experimentais relativos às quatro temperaturas, são obtidos os resultados apresentados na Tabela 10. 
Tabela 10: Resultados da equação com duas exponenciais.

\begin{tabular}{|c|c|c|c|c|c|c|}
\hline $\mathrm{T}\left({ }^{\circ}\right)$ & $\mathrm{a}$ & $\mathrm{b} \times 10^{2}$ & $\mathrm{c}$ & $\mathrm{d}$ & $\mathrm{R}^{2}$ & $\mathrm{X}^{2} \times 10^{3}$ \\
\hline 40 & $0,1631 \pm 0,0026$ & $-0,474 \pm 0,0013$ & $0,8228 \pm 0,0027$ & $-0,6125 \pm 0,0025$ & 0,999905 & 0,53941 \\
\hline 50 & $0,163 \pm 0,005$ & $-0,83 \pm 0,05$ & $0,827 \pm 0,006$ & $-0,111 \pm 0,009$ & 0,999765 & 0,75297 \\
\hline 60 & $0,144 \pm 0,005$ & $-0,10 \pm 0,05$ & $0,848 \pm 0,006$ & $-1,598 \pm 0,012$ & 0,999867 & 0,39756 \\
\hline 70 & $0,119 \pm 0,007$ & $-0,0136 \pm 0,0012$ & $0,879 \pm 0,007$ & $-1,993 \pm 0,019$ & 0,999754 & 0,65869 \\
\hline
\end{tabular}

Conforme os resultados, embora a equação com duas exponenciais seja ligeiramente superior a todos os modelos anteriores, tal modelo tem como desvantagem o uso de quatro parâmetros.

Conforme já foi discutido, os modelos empíricos são muito úteis para descrever a cinética de secagem de um produto, embora não possibilite prever a distribuição de umidade em seu interior, para um instante de tempo previamente estipulado.

No caso específico das secagens de bananas realizadas neste trabalho, baseando-se nos indicadores estatísticos obtidos, as equações de Newton e de Henderson e Pabis poderiam ser descartadas na descrição do processo. Baseando-se, ainda, nos indicadores estatísticos, a equação com dois termos apresenta as melhores descrições das cinéticas de secagem. Entretanto, como um fator negativo, há que se ressaltar a quantidade excessiva de parâmetros de ajuste: quatro. Por outro lado, a equação da aproximação por difusão tem indicadores estatísticos ligeiramente superiores aos indicadores da equação de Page, mas tem a desvantagem de envolver três parâmetros de ajuste, enquanto que esta última só envolve dois. Assim, a escolha do melhor modelo empírico para representar as cinéticas de secagem de bananas inteiras fica subordinada ao número de parâmetros que for estipulado para a equação referente ao modelo

\section{CONSIDERAÇÕES FINAIS}

De acordo com os resultados obtidos é possível concluir que o modelo de Newton é apenas razoável na descrição das cinéticas de secagem de bananas inteiras.

0 modelo de Page se justou bem para as quatro temperaturas estudadas.

A equação de Henderson e Pabis foi razoável, porém tal modelo é inferior à equação de Page.

O modelo da aproximação da difusão foi excelente, equivalente aos indicadores do modelo de Page, porém tal modelo envolve três parâmetros de ajuste, ao invés de dois.

A equação com duas exponenciais foi ligeiramente superior a todos os modelos anteriores, porém tal modelo tem como desvantagem o uso de quatro parâmetros.

\section{REFERÊNCIAS}

[1] BORDIN, M.R. Embalagem para frutas e hortaliças in: Tecnologia de resfriamento de frutas e hortaliças. Campinas. 1998. p. 19-27.

[2] BROD, F. P. R.; ALONSO, L. F. T.; PARK, K. J. Secagem de produtos agrícolas. In: SEMANA DE ENGENHARIA AGRÍCOLA DA UNICAMP (SEMEAGRI0, 11., 1999. Campinas. Anais... Campinas: Agrológica - Empresa Junior de Engenharia Agrícola. 1999, 122p.

[3] FAO, Food and Agriculture Organization of the United Nations. Summary of Food and Agriculture Statistics. Disponivel em http://www.fao.org, acessado em Junho de 2011.

[4] FIOREZE, R. Princípios de secagem de produtos biológicos, João Pessoa. Editora Universitária - UFPB, p.229, 2004.

[5] HANDLER, L. Productos de transformacion del banana. Instituto Frances de Invescaciones Fruteras de UltraMar. 1ํㅡㄹ Congresso Internacional de Industrias Agrícolas y Alimenticias de Las Zonas Tropicales y Sub-Tropicales. Abidjan, 14-19 de Deciembre de 1964.

[6] MADAMBA, P.S.; DRISCOLL, R.H.; BUCKLE, K.A. The thin-layer drying characteristics of garlic slices. Journal of Food Engineering v.29, p.75-97, 2007.

[7] MARTinAzZO, A. P.; CORRÊA, P. C.; MELO, E. C.; BARBoSA, F. F. Difusividade efetiva em folhas de Cymbopogon citratus (DC.) Stapf submetidas à secagem com diferentes comprimentos de corte e temperaturas do ar. Revista Brasileira de Plantas Medicinais, v.9, p.68-72, 2007a. 
[8] SOUZA, P, H. M. Desidratação osmótica de banana com e sem vácuo com complemento de secagem em estufa de circulação de ar. 2002. 88p. Dissertação (Mestrado em tecnologia de Alimento), Universidade Federal do Ceará, Ceará, Brasil.

[9] TAGLIARI, P. S.; FRANCO, H. M. Manejo pós-colheita da banana. Agropecuário Catarinense, v. 7, n. 2, Junho 1994 


\section{Unidade II}

\section{Desenvolvimento e}

Tecnologia de Materiais 


\section{Capítulo 8}

\section{Composição centesimal e compostos bioativos do alho refrigerado}

\section{Charlene Maria Alcântara \\ Ana Marinho do Nascimento \\ Jéssica Leite da Silva \\ Tatiana Marinho Gadelha \\ Larissa Félix Macêdo \\ Franciscleudo Bezerra da Costa}

Resumo: 0 alho pode atuar inibindo substâncias nocivas que prejudicam a saúde. Diante disso, objetivou-se avaliar a composição centesimal e os compostos bioativos do alho em duas temperaturas. Foram utilizados alho provenientes da cidade do Crato no Ceará. Para a obtenção das amostras os bulbilhos foram macerados e acondicionados em recipientes plásticos, rotuladas, envolvidas em papel alumínio e movidas para análises. Para a composição centesimal foi verificado os valores de umidade, cinzas, lipídios, proteínas, carboidratos e valor energético; para os compostos bioativos determinou-se os teores de ácido ascórbico, clorofila, carotenoides, flavonoides, antocianinas e compostos fenólicos. Verificou-se que o alho mantido em temperatura ambiente controlada e refrigerado obtiveram teores de umidade próximos, com 66,9 e 67,8\%, respectivamente. 0 conteúdo de cinzas não diferiu entre si. Ambos os tratamentos exibiram valores de carboidratos distintos, com 22,7\% a temperatura ambiente e 14,5\% na temperatura refrigerado. O valor energético foi de 587,1 a 852,3 kcal $100 \mathrm{~g}$, respectivamente. Não houve diferença significativa nos teores de ácido ascórbico. A proporção de clorofila do alho sob refrigeração foi de 806,2 $\mu$ g 100 g-1. Não houve diferença significativa para os resultados de flavonoides e antocianinas. Os valores de compostos fenólicos foram de 87,8 mg $100 \mathrm{~g}-1$ para o alho na temperatura ambiente e 120,5 mg 100 g-1, quando refrigerado. Foi identificado que a concentração de ácido ascórbico, flavonoides e antocianinas se mantiveram nos tratamentos estudados. Observou-se que a refrigeração conservou os teores de clorofila, carotenoides e compostos fenólicos, entretanto, o valor energético do alho na temperatura ambiente foi melhor.

Palavras-chave: Alliaceae, bulbilhos, carboidratos, fenólicos. 


\section{INTRODUÇÃO}

Acredita-se que o alho seja originário da Ásia central e ocidental (CUNHA et al., 2009). De acordo com os dados publicados pela a Organização das Nações Unidas para Agricultura e Alimentação no ano de 2014, o alho apresentou uma ampla distribuição geográfica, com uma produção de 24,9 mil toneladas. Conforme o Instituto Brasileiro de Geografia e Estatística no ano de 2014, o alho proporcionou uma grande relevância sócio-econômica, sendo o Brasil o segundo maior consumidor de alho no mundo, alcançando cerca de 1,50 $\mathrm{kg}$ de alho consumido por habitante ao ano, perdendo somente para a China. Cerca de $10 \%$ do alho utilizado no Brasil é sob forma industrializada, sendo adicionado em temperos prontos, molhos, sopas desidratadas e outros produtos.

De acordo com a Associação Nacional dos Produtores de Alho (ANAPA) no ano de 2014, a produção nacional abasteceu $40 \%$ do consumo interno, sendo $60 \%$ importados para outros países, entre eles a China $40 \%$ e a Argentina 20\%. Sendo assim, a procura por inovações durante o beneficiamento e armazenagem para o alho permite ampliar os lucros e a formação de novos nichos de comercialização para o produtor, visto que existe uma demanda ao longo do ano, sendo necessário considerar aspectos relacionados a oferta e distribuição.

Desde a antiguidade o alho é utilizado como condimento devido ao seu sabor marcante de interesse gastronómico e propriedades medicinais. Em sua composição existe uma diversidade de compostos bioativos, destacando-se os organosulfurados, fenólicos e fitosteróis. Dentre os compostos fenólicos, encontram-se flavonoides tais como a quercetina, apigenina e miricetina (QUEIROZ, 2010). É um alimento que leva beneficios ao organismo através de um mecanismo mediado pelo óxido nítrico e alicina que apresentam capacidade de remover os radicais livres (MARCHIORI, 2014). De acordo com pesquisas feitas por Apolinário et al. (2008) já foram identificados cerca de 30 componentes no alho que possuem efeitos terapêuticos, entre eles a ação antibacteriana e antioxidante.

Alguns ingredientes ativos presentes no alho, possuem propriedades capazes de inibir as substâncias nocivas que prejudicam a saúde humana. As propriedades funcionais, juntamente com suas características de sabor, fizeram do alho um verdadeiro ícone cultural pelo mundo, sendo ele utilizado tradicionalmente como um intensificador de sabor e reconhecido não somente como um condimento alimentar. Em sua composição existem, óleos essências, compostos sulfurados, proteínas, carboidratos, vitaminas e sais minerais (MARCHIORI, 2014).

Uma técnica muito utilizada para a conservação dos alimentos é a refrigeração, ela consiste num sistema de três fatores criteriosamente controlados, são eles: a circulação de umidade, temperatura e umidade relativa, sendo a temperatura o fator mais importante, visto que além de interferir na deterioração dos produtos, modifica o efeito causado pelos outros fatores (ÁLVARES, 2006; CHITARRA; CHITARRA, 2005). Com a refrigeração é possível reduzir a velocidade das transformações microbiológicas e bioquímicas, prolongando assim a sua vida útil dos alimentos (JAY, 2005). Com o intuito de avaliar a qualidade do alho sob condições de refrigeração, objetivou-se analisar a composição centesimal e os compostos bioativos do alho em duas temperaturas.

\section{MATERIAL E MÉTODOS}

Foram utilizados alho provenientes da cidade de Crato no Ceará. Os alhos foram acondicionados em caixas de papelão e transportados para o Laboratório de Química Bioquímica e Análise de Alimentos da Universidade Federal de Campina Grande, Campus Pombal. Os mesmos foram lavados em água corrente para retirada de sujidades superficiais. Logo após, os bulbilhos foram separados e as cascas foram retiradas com auxílio de facas de aço inoxidável. Para a obtenção das amostras os bulbilhos foram macerados e acondicionados em recipientes plásticos, rotulados, envolvidos em papel alumínio e movidos para análises posteriores.

\subsection{DELINEAMENTO}

o delineamento esperimental utilizado foi o inteiramente casualizado, com dois tratamentos representando as temperaturas ambiente e refrigerado. 


\subsection{UMIDADE}

As amostras foram pesadas em cadinho previamente tarados, posteriormente, foram colocados na estufa a $105^{\circ} \mathrm{C}$ por 24 horas, em seguida, foram resfriadas em dessecador até temperatura ambiente e pesadas novamente. 0 procedimento foi realizado seguindo as normas Analíticas do Instituto Adolfo Lutz (2008).

\subsection{CINZAS}

As amostras foram pesadas em cadinho previamente tarado e carbonizadas em mufla até a temperatura 550 ํ. . Logo após, foram resfriadas em dessecador até temperatura ambiente e pesadas novamente. 0 procedimento foi realizado seguindo as normas Analíticas do Instituto Adolfo Lutz (2008).

\subsection{LIPÍDIOS}

Determinado a partir da pesagem de $5 \mathrm{~g}$ da amostra em papel filtro, em seguida transferiu as mesmas para o extrator de Soxhlet, acoplando o extrator ao balão tarado a $105^{\circ} \mathrm{C}$ por uma hora com hexano. Mantevese por 8 horas sob aquecimento até a extração, em seguida retirou-se as amostras e pesou-as. 0 procedimento foi realizado segundo as normas Analíticas do Instituto Adolfo Lutz (2008).

\subsection{PROTEÍNAS}

Foram determinadas a partir da pesagem de 0,2 da amostra em um tubo kjeldahl, em seguida adicionou-se 1,5 da mistura catalítica e $3 \mathrm{~mL}$ de ácido sulfúrico. Colocou-se o tubo no digestor a $100^{\circ} \mathrm{C}$ e a cada 30 minutos aumentou-se a temperatura a $50{ }^{\circ} \mathrm{C}$ até atingir $400{ }^{\circ} \mathrm{C}$. Ao chegar à temperatura final, deixou-se o tubo no digestor por mais 20 minutos, logo após desligou-se o aparelho deixando as amostras na capela até esfriarem. A destilação foi adicionando-se $40 \mathrm{~mL}$ água e 03 gotas de fenolftaleína em cada tubo, depois transferiu-se a amostra para um destilador adicionando-se $15 \mathrm{~mL}$ de $\mathrm{NaOH}$ 63\%, em um erlenmeyer colocou-se $10 \mathrm{~mL}$ de ácido bórico 2\%, 4 gotas de alanrajado de metila e 6 gotas de verde de bromocresol, procedeu-se a destilação até atingir $50 \mathrm{~mL}$ no erlenmeyer. 0 destilado foi titulado com uma solução de ácido clorídrico 0,1 M. 0 procedimento foi realizado segundo as normas Analíticas do Instituto Adolfo Lutz (2008).

\subsection{CARBOIDRATOS}

0 teor de carboidratos foi calculado pela a diferença entre 100 e a soma das percentagens de umidade, proteína, lipídeos e cinzas. Os valores foram expressos em percentagem conforme Equação 10 descrita por Brasil (2011).

\subsection{VALOR ENERGÉTICO}

O valor energético foi calculado multiplicado os valores de proteínas, carboidratos e lipídios pelos fatores atwater propostos pela tabela brasileira de composição de alimentos (BRASIL, 2011).

\subsection{CLOROFILA E CAROTENOIDES}

Foram determinados de acordo com o método de Lichtenthaler (1987), a partir de 1,0 g de amostra macerada em almofariz com $0,2 \mathrm{~g}$ de carbonato de cálcio e $5 \mathrm{~mL}$ de acetona a $80 \%$. 0 extrato foi transferido para tubos falcon e centrifugados a $10{ }^{\circ} \mathrm{C}$ e $3.000 \mathrm{rpm}$ por 10 minutos. Alíquotas dos sobrenadantes foram colocados em cubeta e as leituras realizadas em espectrofotômetro nas absorbâncias de 470, 646 e $663 \mathrm{~nm}$. Todos os procedimentos foram realizados em ambiente escuro e os resultados expressos em mg $100 \mathrm{~g}^{-1}$.

\subsection{FLAVONOIDES}

Foram quantificados de acordo com o método de Francis (1982), a partir de 1,0 g de amostra macerada em almofariz com $10 \mathrm{~mL}$ de etanol: HCL. Os extratos foram transferidos para tubos falcon e deixados na 
geladeira por 24 horas. No dia seguinte, os extratos foram centrifugados a $10{ }^{\circ} \mathrm{C}$ e $3.000 \mathrm{rpm}$ por 10 minutos. Alíquotas dos sobrenadantes foram colocadas em cubeta e as leituras realizadas em espectrofotômetro nas absorbâncias de 374. Todos os procedimentos foram realizados em ambiente escuro e os resultados expressos em $\mathrm{mg} 100 \mathrm{~g}^{-1}$.

\subsection{ANTOCIANINAS}

Foram determinadas a partir de 1,0 g de amostra macerada em almofariz com $10 \mathrm{~mL}$ de etanol: HCL. Os extratos foram transferidos para tubos falcon e deixados na geladeira por 24 horas. No dia seguinte, os extratos foram centrifugados a $10{ }^{\circ} \mathrm{C}$ e $3.000 \mathrm{rpm}$ por 10 minutos. Alíquotas dos sobrenadantes foram colocadas em cubeta e as leituras realizadas em espectrofotômetro nas absorbâncias de $535 \mathrm{~nm}$. Todos os procedimentos foram realizados em ambiente escuro e os resultados expressos em mg $100 \mathrm{~g}^{-1}$. Os procedimentos foram realizados de acordo com o método de Francis (1982).

\subsection{COMPOSTOS FENÓLICOS}

A análise foi realizada conforme o método descrito por Waterhouse (2006). Foram pesados 1 g das amostras e maceradas em almofariz e diluídas em $50 \mathrm{~mL}$ de água destilada, logo após, foram deixadas em repouso por 30 minutos. Alíquotas dos extratos foram transferidas para tubos de ensaio, onde foram adicionados de água e Folin ciocalteau. As misturas permaneceram em repouso por 5 minutos e logo após, foi adicionado o carbonato de sódio a $20 \%$, seguida de agitação e repouso em banho-maria a $40{ }^{\circ} \mathrm{C}$, por 30 minutos. A curva padrão foi preparada com ácido gálico e as leituras realizadas em espectrofotômetro a $765 \mathrm{~nm}$. Os valores de polifenóis foram expressos em mg $100 \mathrm{~g}^{-1}$.

\subsection{CORRELAÇÃO DE PEARSON}

Os coeficientes de correlação de Pearson foram determinados entre a coloração, características físicoquímica e compostos bioativos a partir do software Microsoft Excel 2013.

\subsection{ANÁLISE ESTATIISTICA}

Os dados obtidos foram submetidos à análise de variância, sendo as médias comparadas pelo teste de Tukey, considerando-se um nível de significância 5\% de probabilidade. A análise estatística foi realizada utilizando-se o software AgroEstat ${ }^{\circ}$ (BARBOSA; MALDONATO JR, 2015).

\section{RESULTADOS E DISCUSSÃO}

Observou-se que não houve diferença significativa no teor de umidade dos tratamentos estudados (Tabela 1). Nota-se que o alho se manteve estável nas condições em que foi submetido. Foi verificado que ambos os tratamentos apresentaram teor de umidade próximos, sendo de 66,9\% a temperatura ambiente e 67,8 a temperatura refrigerada. Novo (2018) ao avaliar os teores de umidade para bulbo de alho picado em temperatura ambiente e congelada encontrou valores de 63,1 e 61,9\%, respectivamente. De acordo com a tabela brasileira de composição de alimentos os resultados obtidos nesta pesquisa estão dentro do parâmetro mínimo aceitável para alho (BRASIL, 2006).

Tabela 1. Avaliação da composição centesimal do alho (Allium sativum L.).

\begin{tabular}{|c|c|c|c|}
\hline \multicolumn{1}{|c|}{ COMPOSIÇÃO } & AMBIENTE & REFRIGERADO & CV (\%) \\
\hline Umidade (\%) & $66,9 \pm 0,13 \mathrm{a}$ & $67,8 \pm 2,24 \mathrm{a}$ & 2,3 \\
\hline Cinzas (\%) & $1,6 \pm 0,13 \mathrm{a}$ & $1,8 \pm 0,35 \mathrm{a}$ & 5,5 \\
\hline Lipídios (\%) & $0,6 \pm 0,00 \mathrm{a}$ & $0,6 \pm 0,00 \mathrm{a}$ & 0,1 \\
\hline Proteínas (\%) & $8,1 \pm 0,77 \mathrm{~b}$ & $15,3 \pm 2,68 \mathrm{a}$ & 6,8 \\
\hline Carboidratos (\%) & $22,7 \pm 0,79 \mathrm{a}$ & $14,5 \pm 0,14 \mathrm{~b}$ & 3,0 \\
\hline Valor energético (kcal 100g-1) & $852,3 \pm 25,27 \mathrm{a}$ & $587,1 \pm 5,92 \mathrm{~b}$ & 2,5 \\
\hline
\end{tabular}

Os teores de cinzas não diferiram entre si. Sendo de 1,6 a temperatura ambiente e 1,8 sob temperatura refrigerada (Tabela 1). Queiroz (2010) encontrou um percentual de cinzas no alho de 4,2\%, no entanto, o valor mínimo apresentado por Brasil (2011) foi de 1,3\%. Para os teores de lipídios observou-se que não 
houve diferença significativa entre os tratamentos avaliados (Tabela 1). Os resultados obtidos informam que o alho possui baixo teor de gorduras, sugerindo uma estabilidade nos processos oxidativos. De acordo com tabela brasileira de composição de alimentos o valor de referência para lipídios em alho foi de 0,2\%, sendo os resultados adquiridos neste estudo superiores a o citado (BRASIL, 2011).

Houve diferença significativa no teor de carboidratos dos tratamentos estudados (Tabela 1). Nota-se que o alho não se manteve estável nas condições em que foi submetido. Foi observado que ambos os tratamentos apresentaram teor de carboidratos distintos, sendo de 22,7\% a temperatura ambiente e $14,5 \%$ na temperatura refrigerada. Queiroz (2010) ao avaliar os teores de carboidratos em alho obteve valor de 60,1\%. Segundo Brasil (2011) os resultados obtidos nesta pesquisa estão abaixo do valor mínimo aceitável para alho in natura que é de $23,9 \%$. No porte energético foi observado que ambos os tratamentos exibiram valores diferentes, sendo de 852,3 kcal na temperatura ambiente e 587,1 kcal na temperatura refrigerada, deferindo significativamente entre si (Tabela 1). Botas (2017) ao avaliar as propriedades bioativas do alho encontrou um valor energético de $177 \mathrm{kcal}$, sendo os resultados expostos nesta pesquisa superiores.

Houve correlação significativa entre a composição centesimal (Tabela 2). A umidade se correlacionaram negativamente com os lipídios, proteínas, carboidratos e o valor energético, contudo, percebeu-se uma forte correlação positiva entre as cinzas. Não houve correlação entre a umidade e os lipídios. As cinzas se correlacionaram negativamente com os lipídios, proteínas, carboidratos e o valor energético (Tabela 2). Os lipídios se correlacionaram negativamente com as proteínas, carboidratos e o valor energético. Verificouse uma forte correlação positiva entre as proteínas e carboidratos e valor energético. Já as cinzas se correlacionou fortemente com a umidade. Nota-se que houve uma baixa correlação entre os teores de umidade, lipídios e valor energético.

Tabela 2. Coeficientes de correlação de Pearson (r) entre a composição centesimal do alho.

\begin{tabular}{|c|c|c|c|c|c|c|}
\hline COMPOSIÇÃO & U & C & L & CA & VE \\
\hline Umidade (U) & 1,000 & & & & & \\
\hline Cinzas (C) & 0,781 & 1,000 & & & & \\
\hline Lipídios (L) & $-0,060$ & $-0,085$ & 1,000 & & & \\
\hline Proteínas (P) & $-0,320$ & $-0,234$ & $-0,926$ & 1,000 & & \\
\hline Carboidratos (CA) & $-0,361$ & $-0,270$ & $-0,908$ & 0,999 & 1,000 & \\
\hline Valor energético (VE) & $-0,120$ & $-0,380$ & $-0,353$ & 0,396 & 0,397 & 1,000 \\
\hline
\end{tabular}

Não apresentou diferença significativa nos teores de ácido ascórbico (Tabela 3), ambos os tratamentos obtiveram valores próximos, sendo $9,4 \mathrm{mg} 100 \mathrm{~g}^{-1}$ na temperatura ambiente e 8,6 mg $100 \mathrm{~g}^{-1} \mathrm{na}$ temperatura refrigerada. De acordo com uma matéria exposta pelo o portal agropecuário, sobre cultivo do alho e suas principais propriedades, a quantidade de o ácido ascórbico presente no alho é de 31,1 mg 100 $\mathrm{g}^{-1}$.

Os teores de clorofilas diferiram significativamente entre si (Tabela 3) 0 alho alcançou maior resultado na condição de refrigeração com $806,2 \mu \mathrm{g} 100 \mathrm{~g}$-1. Na temperatura ambiente a valor de clorofila estimado foi de 401,0 $\mu \mathrm{g} 100 \mathrm{~g}^{-1}$. Fernandes et al. (2011) ao estudar os bulbilhos de alho identificou que a concentração de clorofilas foram de 680,6 a 700,7 $\mu \mathrm{g} 100 \mathrm{~g}^{-1}$, sendo os resultados expressos no alho refrigerado superior ao citado pelo autor.

Tabela 3. Avaliação dos compostos bioativos do alho (Allium sativum L.).

\begin{tabular}{|c|c|c|c|}
\hline BIOATIVOS & AMBIENTE & REFRIGERADO & CV $(\%)$ \\
\hline Ácido ascórbico $\left(\mathrm{mg} 100 \mathrm{~g}^{-1}\right)$ & $9,5 \pm 1,36 \mathrm{a}$ & $8,6 \pm 0,0 \mathrm{a}$ & 10,56 \\
\hline Clorofilas $\left(\mu \mathrm{g} 100 \mathrm{~g}^{-1}\right)$ & $401,0 \pm 9,0 \mathrm{~b}$ & $806,2 \pm 4,78 \mathrm{a}$ & 1,19 \\
\hline Carotenoides $\left(\mu \mathrm{g} 100 \mathrm{~g}^{-1}\right)$ & $6,37 \pm 1,28 \mathrm{~b}$ & $14,10 \pm 1,46 \mathrm{a}$ & 13,41 \\
\hline Flavonoides $\left(\mathrm{mg} 100 \mathrm{~g}^{-1}\right)$ & $11,1 \pm 0,56 \mathrm{a}$ & $12,9 \pm 2,98 \mathrm{a}$ & 17,81 \\
\hline Antocianinas $\left(\mathrm{mg} 100 \mathrm{~g}^{-1}\right)$ & $4,3 \pm 0,52 \mathrm{a}$ & $5,6 \pm 1,01 \mathrm{a}$ & 16,15 \\
\hline Compostos fenólicos $\left(\mathrm{mg} 100 \mathrm{~g}-1^{-1}\right)$ & $87,8 \pm 4,95 \mathrm{~b}$ & $120,5 \pm 10,05 \mathrm{a}$ & 7,60 \\
\hline
\end{tabular}

Médias seguidas de mesma letra na linha não diferem significativamente pelo teste de Tukey, ao nível de $5 \%$ de probabilidade. CV: Coeficiente de variação.

0 valor de carotenoides do alho apresentou diferença significativa (Tabela 3). Foi observado que o tratamento a temperatura refrigerada foi de $14,1 \mathrm{mg} 100 \mathrm{~g}^{-1}$, sendo maior que o encontrado na 
temperatura ambiente. De acordo com Chitarra e Chitarra (2005) os carotenoides são pigmentos que se tornam visíveis com a degradação da clorofila.

Foi identificado que não houve diferença significativa nos teores de flavonoides e antocianinas dos tratamentos estudados (Tabela 3). Não foi encontrado na literatura resultados que representassem o teor de flavonoides e antocianinas em alho in natura. Porém, segundo o estudo de Mendes (2015) o teor de antocianina em alho condimentado foi de $622 \mu \mathrm{g} \mathrm{mL}-1$.

Nos compostos fenólicos ocorreu uma diferença significativa (Tabela 3). Observou-se que os polifenóis foram de 87,8 mg $100 \mathrm{~g}^{-1}$ na temperatura ambiente e 120,5 mg $100 \mathrm{~g}^{-1}$ na temperatura refrigerada. Esses valores estão acima dos descritos por Queiroz et al. (2009), que ao estudarem o alho descobriram uma quantidade de $8,70 \mathrm{mg} 100 \mathrm{~g}^{-1}$.

Tabela 4. Coeficientes da correlação de Pearson (r) entre os compostos bioativos do alho.

\begin{tabular}{|c|c|c|c|c|c|c|}
\hline BIOATIVOS & AA & CL & CA & FL & AN & CF \\
\hline Ácido ascórbico (AA) & 1,000 & & & & & \\
\hline Clorofila (CL) & $-0,474$ & 1,000 & \multicolumn{5}{|l|}{} \\
\hline Carotenoides (CA) & $-0,364$ & 0,962 & 1,000 & & & \\
\hline Flavonoides (FL) & $-0,179$ & 0,449 & 0,568 & 1,000 & & \\
\hline Antocianinas (AN) & $-0,097$ & 0,712 & 0,825 & 0,859 & 1,000 & \\
\hline Compostos fenólicos (CF) & $-0,422$ & 0,932 & 0,807 & 0,234 & 0,512 & 1,000 \\
\hline
\end{tabular}

Observou-se que houve uma correlação significativa entre os compostos bioativos avaliados (Tabela 4). Os teores de ácido ascórbico se correlacionaram negativamente com a clorofila e compostos fenólicos. Verificou-se uma forte correlação positiva entre a clorofila, carotenoides, antocianinas e compostos fenólicos. Nota-se que não houve correlação entre o ácido ascórbico e os flavonoides.

\section{CONCLUSÃO}

0 alho a temperatura ambiente apresentou valor energético maior que o mantido sob refrigeração. Ambos os tratamentos alcançaram teores de carboidratos e proteína significativos. Os valores de ácido ascórbico, flavonoides e antocianinas foram conservados nas condições em que o alho foi estudado. No entanto, foi constatado que as proporções de clorofila, carotenoides e compostos fenólicos a temperatura ambiente foi maior, indicando que a refrigeração preservou os compostos bioativos do alho.

\section{AGRADECIMENTOS}

Ao Laboratório de Química, Bioquímica e Análise de Alimentos; Grupo de Pesquisa em Ciência, Tecnologia e Engenharia de Alimentos e Unidade Acadêmica de Tecnologia de Alimentos do Campus Pombal.

\section{REFERÊNCIAS}

[1] Anapa, 2014, “Associação Nacional dos Produtores de alho". Disponível em: <https://anapa.com.br/>. Acessado em: 18 de outubro de 2019.

[2] Álvares, V.S. 2006, "Pré-resfriamento, embalagem e hidratação pós-colheita de salsinha". Tese (Doutorado em Fitotecnia) - Universidade Federal de Viçosa, Viçosa, MG, 2006. 161 p.

[3] Apolinário, A.C., Monteiro, M.M.O., Pachú, C.O., Dantas, I.C. 2008, “Allium sativum L. como agente terapêutico para diversas patologias: uma revisão”. Revista de Biologia e Farmácia., Paraíba, Vol. 2, No. 1. pp. 1-6.

[4] Barbosa, J.C., Maldonado Júnior, W. 2015, “AgroEstat - Sistema para Análises Estatísticas de Ensaios Agronômicos". Versão 1.1.0.711. Jaboticabal: Unesp.

[5] Botas, S.J. 2017 "Caracterização química e propriedades bioativas de Allium sativum L. com diferentes proveniências e processamentos”. Dissertação (Farmácia e Química de Produtos Naturais) - Instituto Politécnico de Bragança, pp. 1-61.

[6] Brasil, B. 2011, 2011, "Tabela Brasileira de Composição de Alimentos - Taco 4ª edição revisada e ampliada”. Nepa-Unicamp, 4 ed., pp.16. Disponível em: <http://www.cfn.org.br/wpcontent/uploads/2017/03/Brasil_4_edicao_ampliada_e_revisada.pdf >. Acessado em: 18 de outubro de 2019. 
[7] Chitarra, M.I.F., Chitarra, A.B. Pós-colheita de frutos e hortaliças: fisiologia e manuseio. 2. ed. rev. e ampl. Lavras: UFLA, 2005.

[8] Cunha, A.P., Ribeiro, J.A., Roque, O.R. 2009, "Plantas Aromáticas em Portugal - Caracterização e Utilizações” 2 ed.Faostat. 2014, "Food and Agriculture Organization of the United Nations". Disponível em: <http://www.fao.org/faostat/en/\#data/QC>. Acessado em 18 de outubro de 2019.

[9] Organização das Nações Unidas para a Agricultura e a Alimentação. Disponível em: <http://faostat3.fao.org/faostatgateway/go/to/download/Q/QC/S>. Acesso em: 25 junho 2020.

[10] Fernandes, L.J.C., Villas Bôas, R.L., Backes, C., Lima, C.P., Büll, L.T. 2011. Contribuição das concentrações de nitrogênio em bulbilhos de alho tratados com doses de N em cobertura. Horticultura Brasileira., Vol. 29, No.1, pp. 2631.

[11] Francis, F.J. 1982, "Analysis of anthocyanins. In: Markakis, P. (ed.) anthocyanins as food calors". New York: Academic Press.

[12] Lichtenthaler, H.K. 1987, "Chlorophylls and carotenoids: pigments of photosynthetic biomembranes". In: Packer, L., Douce, R. (Eds.). Methods in Enzymology. London, Vol. 148, pp. 350-352.

[13] Instituto Brasileiro de Geografia e estatística. Pesquisa Mensal de Previsão e Acompanhamento das Safras Agrícolas no Ano Civil. Levantamento Sistemático da Produção Agrícola. Rio de Janeiro Vol. 2, No. 9, pp. 1-85 set. 2014.

[14] Instituto Adolfo Lutz. Normas Analíticas do Instituto Adolfo Lutz. 2008, "Métodos químicos e físicos para análise de alimentos", Vol. 1,4. ed. São Paulo.

[15] Marchiori, V.F. 2014, "Propriedades Funcionais do Alho Allium sativum L.”. Disponível em: < https://www.docsity.com/pt/propriedades-funcionais-do-alho/4871175/>. Acessado em: 18 de outubro de 2019.

[16] Mendes, G.M.1; Rodrigues-das-dores, R.G.1; Campideli, L.C, 2015, “Avaliação do teor de antioxidantes, flavonoides e compostos fenólicos em preparações condimentares" Rev. Bras. Pl. Med., Campinas, Vol.17, No.2, pp.297304.

[17] Novo, F.C. 2018, "Atividade antioxidante do alho Allium sativum L. quando submetido a diferentes processos tecnológicos". Dissertação (Mestrado em Ciências Farmacêuticas) - Universidade Fernando Pessoa, 59 p.

[18] Portal Agropecuário. 2019, “Cultivo de alho Allium sativum e principais propriedades” Disponível em: < https://www.portalagropecuario.com.br/agricultura/agricultura-organica/cultivo-de-alho-allium-sativum-eprincipais-propriedades $>$. Acesso em: 18 de outubro de 2019.

[19] Queiroz, Y.S. 2010, "Efeito do processamento do alho Allium sativum L. sobre os seus compostos bioativos e potencial antioxidante in vitro e in vivo". Tese (Doutorado em nutrição e saúde pública) - Universidade de São Paulo, $161 \mathrm{p}$.

[20] Queiroz, Y.S., Ishimotoa, E.Y., Bastosa, D.H.M., Sampaiob, G.R., Torresa, E.A.F.S.,2009, “Garlic (Allium sativumL.) and ready-to-eat garlic products: In vitroantioxidant activity". Food Chemistry, Vol. 115, pp. 371-374.

[21] Waterhouse, A. 2006, "Folin-ciocalteau micro method for total phenol in wine". American Journal of Enoiogy and Viticulture. 


\section{Capítulo 9}

\section{Avaliação do ruído ocupacional em uma empresa localizada em Campina Grande, Paraíba}

\section{Isis da Silva Rodrigues \\ Yaroslávia Ferreira Paiva \\ Herusca Hellyca Souza de Medeiros \\ Plínio Tércio Medeiros de Azevedo}

Resumo: Esta pesquisa apresenta um estudo realizado em um grupo de trabalhadores com o objetivo de avaliar a exposição ao ruído ocupacional, em uma fábrica de colchões e acessórios na cidade de Campina Grande. Considerando o ruído como uma percepção audível não-desejável, não-agradável e de consequências danosas à saúde é importante que se faça o seu reconhecimento, avaliação, controle e monitoramento no ambiente de trabalho. Os limiares foram medidos através do dosímetro pessoal de ruído DOS-500 Instrutherm. Verificou-se que a maioria dos trabalhadores estão expostos ao nível de ruído que exige nível de ação da empresa. Ressalta-se que as medidas adotadas em relação ao meio ambiente e ao homem são de grande importância para a preservação da integridade física, psicológica e social dos trabalhadores.

Palavras-chave: Ruído. Dosímetro. Trabalhadores. Segurança do trabalho. 


\section{INTRODUÇÃO}

Diversas são as definições de acidente e variam de acordo com o panorama. Conforme dispõe o art. 19 da Lei no 8.213/91, "acidente de trabalho é o que ocorre pelo exercício do trabalho a serviço da empresa ou pelo exercício do trabalho dos segurados referidos no inciso VII do art. 11 desta lei, provocando lesão corporal ou perturbação funcional que cause a morte ou a perda ou redução, permanente ou temporária, da capacidade para o trabalho" (BRASIL, 1991).

A concepção dos acidentes de trabalho apresenta duas vertentes, sendo a primeira de caráter jurídicoinstitucional, sustentando-se na teoria do risco social e fundamenta a operacionalização do seguro de acidente do trabalho. Já, a segunda vertente é a desenvolvida pela engenharia de segurança, que apresenta uma dimensão técnico-científica no controle dos acidentes e constitui a base da teoria do risco profissional.

A Segurança do Trabalho possui a finalidade de buscar soluções que antecedam a ocorrência do acidente, envolver as pessoas nas atividades diárias de forma consistente com uma visão de segurança total, implementar novas técnicas de prevenção e procedimentos, e conscientizar os trabalhadores para que apliquem na prática a teoria, fazendo da segurança um modo de viver (BARSANO; BARBOSA, 2018).

Hoje, a preocupação acústica não é apenas uma questão de condicionamento acústico do ambiente, mas também de controle de ruído e preservação da qualidade ambiental. A questão acústica tornou-se mais importante porque o número de fontes produtoras de ruído são cada vez maiores e suas consequências para o homem são cada vez mais prejudiciais.

O som faz parte do cotidiano das pessoas e geralmente está relacionado com algo agradável, como por exemplo à música. Contudo, na sociedade em que vivemos atualmente, muitos sons podem ser considerados desagradáveis, e conforme a intensidade e irregularidade desses sons, os mesmos são definidos como ruídos.

Desde a ocorrência de uma grande revolução que deu início ao mundo moderno, a chamada Revolução Industrial, a partir do século XVIII e durante o século XIX, o aumento da tecnologia provocou uma crescente utilização de máquinas ruidosas, provocando em contrapartida, riscos para a saúde do trabalhador. Nos últimos cem anos, com a progressiva industrialização e suas manifestações na sociedade, os problemas decorrentes do ruído começaram a ser identificados, tornando-se objeto de constante preocupação pelos pesquisadores, pois se não bastasse o aumento do nível de ruído nas atividades profissionais, o mesmo vem crescendo também nas atividades de lazer.

0 ruído é o terceiro maior agente causador de doenças ocupacionais. Dependendo do tempo de exposição, da intensidade e do tipo de ruído e, ainda, da susceptibilidade individual, a exposição ao ruído pode provocar efeitos temporários ou até permanentes na audição. Contudo, o ruído, mesmo em fraca intensidade, pode provocar alterações no organismo, comprometendo a atividade física, fisiológica e mental do indivíduo (MENEZES; PAULINO, 2004; CUNHA et.al. 2009).

A Organização Mundial da Saúde alerta que um ambiente ruidoso acarreta prejuízos ao desempenho humano e causa danos à saúde geral do indivíduo. Os efeitos observados vão desde fadiga, nervosismo, reações de estresse, ansiedade e falhas de memória até irritabilidade (WHO, 1999).

0 trabalhador deve ter conhecimento e informações sobre os efeitos nocivos do ruído no corpo humano, desta forma, será proporcionada uma maior conscientização da importância da correta utilização de equipamentos de proteção individual e sobre o tempo máximo de exposição ao ruído para prevenção de efeitos danosos à sua audição, prevenção de acidentes de trabalho, para que não tenha prejuízo ao seu desempenho de suas atividades além de alterações físicas, comportamentais e sociais.

A avaliação dos postos de trabalho tem como função identificar ambientes insalubres e encontrar soluções para diminuir esse efeito no trabalho. No caso do ruído a avaliação pode ser realizada com o auxílio de equipamentos que medem a pressão sonora produzida em determinado ambiente. No Brasil as principais metodologias utilizadas, pelas empresas e pelo poder judiciário, são as contidas nas normas NHO01 (FUNDACENTRO, 2001) e NR-15 (BRASIL, 1978).

O objetivo do trabalho é avaliar através de perícia, utilizando o equipamento dosímetro, o ruído que atinge os trabalhadores em uma fábrica de colchões e acessórios. Verificando se está dentro do limite aceitável. 0 efeito danoso do ruído depende do nível de pressão sonora e distribuição do nível de pressão sonora por frequências (espectro sonoro), da duração da exposição, do número de vezes que a exposição se repete por dia, da suscetibilidade individual. 


\section{METODOLOGIA}

0 trabalho foi baseado na pesquisa exploratória. A empresa em que foi realizada a pesquisa fica localizada na cidade de Campina Grande - Paraíba e atua no segmento de colchões, multifuncionais e acessórios. Foram realizadas avaliações objetivas do ruído em vários setores da empresa, durante suas atividades funcionais, sem interferir nas mesmas. A fim de caracterizar fisicamente os níveis sonoros.

O equipamento utilizado foi o dosímetro pessoal de ruído DOS-500 Instrutherm apresentado na Fig. 1, que serve para avaliar a condição sonora do ambiente de trabalho. Por meio deste, a empresa pode ter um controle sobre o ruído e, em caso de necessidade, aplicar ações de prevenção para que os trabalhadores não sofram lesões. 0 princípio da medição é o \%DOSE, ou seja, um parâmetro utilizado para mensurar a exposição ao ruído em determinado período de tempo. 0 valor encontrado é chamado de critério (conforme o manual). 0 equipamento possui um software que permite ao operador uma coleta de dados mais apurada, com isso a comparação e análise dos resultados podem ser feitas por meio de gráficos e de histogramas.

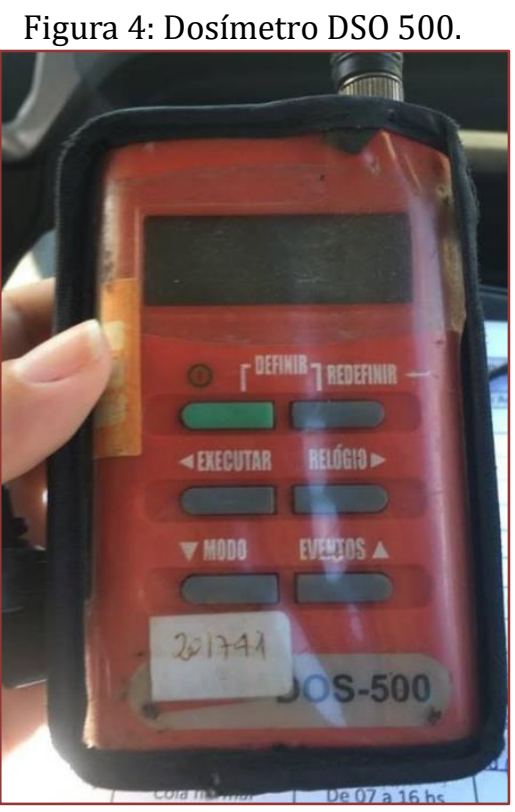

0 equipamento foi colocado em 8 funcionários de acordo com a Tab. 1, onde foram avaliados com o microfone posicionado próximo ao ouvido do trabalhador, para aproximar os resultados obtidos da real situação a qual são expostos. Logo, a coleta de dados foi realizada e os mesmos foram repassados para o computador onde se encontra o software especifico do equipamento.

Tabela 1: Função dos trabalhadores.

\begin{tabular}{|c|c|}
\hline SETOR & FUNÇÃO/LOCAL \\
\hline Flocagem & Auxiliar de espumação (flocador) \\
\hline Espumação & Auxiliar de espumação (moinho) \\
\hline Acabamento & Operador de máquina horizontal \\
\hline Laminação & Operador de máquina (carrosel) \\
\hline Laminação & Operador de máquina vertical \\
\hline Torno & Operador de máquina (torno) \\
\hline Costura & Costureira \\
\hline Pillow top & Auxiliar de produção (pillow top) \\
\hline
\end{tabular}




\section{RESULTADOS E DISCUSSÕES}

Realizou-se a análise da exposição ao ruído de sete funções distintas. Adotando o critério dos grupos heterogêneos, pelo fato dos trabalhadores estarem expostos a ruídos diferentes, dessa forma o resultado obtido será representativo aos demais trabalhadores com a mesma função. Para realizar a medição utilizou-se o método da Dose Diária segundo critérios do Anexo 1 da NR-15, que estabelece os Limites de Tolerância para ruídos contínuos ou intermitentes durante a jornada de trabalho. As medições foram realizadas com base nos procedimentos recomendados pela NHO01 da Fundacentro, e é condizente com os procedimentos metodológicos utilizados na realização de Perícias Judiciais, no que diz respeito ao agente físico ruído. Ambos os métodos foram relacionados para determinar se os ambientes de trabalho são insalubres ou não. A Tabela 2 exibe os valores medidos.

Tabela 2: Valores medidos.

\begin{tabular}{|l|c|}
\hline \multicolumn{1}{|c|}{ FUNÇÃO/LOCAL } & DECIBEIS \\
\hline Auxiliar de espumação (flocador) & 82,2 \\
\hline Auxiliar de espumação (moinho) & 79 \\
\hline Operador de máquina horizontal & 80,9 \\
\hline Operador de máquina (carrosel) & 73,7 \\
\hline Operador de máquina vertical & 66,7 \\
\hline Operador de máquina (torno) & 78,1 \\
\hline Costureira & 79 \\
\hline Auxiliar de produção (pillow top) & 41,1 \\
\hline
\end{tabular}

A Norma Regulamentadora 9 (Programa de Prevenção de Riscos Ambientais) considera nível de ação (NA) o valor acima do qual devem ser iniciadas ações preventivas de forma a minimizar a probabilidade de que as exposições aos agentes ambientais ultrapassem os limites de exposição (ou limites de tolerância). Para o ruído, a dose de 0,5 (dose superior a 50\%), conforme critério estabelecido, corresponde a 80 dB (A). Já a NR 17 (Ergonomia) define como limite de tolerância, para fins de conforto acústico nos locais de trabalho, 65 dB (A), (BRASIL,1978). A Figura 2 evidencia a necessidade de intervenção por parte da empresa.

Figura 2: Valores medidos em decibéis para os trabalhadores expostos.

\begin{tabular}{|c|c|c|c|c|c|c|c|c|}
\hline 90 & 82,2 & 79 & 80,9 & & & 781 & 79 & \\
\hline 80 & & & & & & & & \\
\hline 70 & & & & & & & & \\
\hline 60 & & & & & & & & \\
\hline 50 & & & & & & & & 41,1 \\
\hline 40 & & & & & & & & \\
\hline 30 & & & & & & & & \\
\hline 20 & & & & & & & & \\
\hline 10 & & & & & & & & \\
\hline 0 & & & & & & & & \\
\hline & $\begin{array}{l}\text { Auxiliar de } \\
\text { espumação } \\
\text { (flocador) }\end{array}$ & $\begin{array}{l}\text { Auxiliar de } \\
\text { espumação } \\
\text { (moinho) }\end{array}$ & $\begin{array}{l}\text { Operador } \\
\text { de máquina } \\
\text { horizontal }\end{array}$ & $\begin{array}{l}\text { Operador } \\
\text { de máquina } \\
\text { (carrosel) }\end{array}$ & $\begin{array}{c}\text { Operador } \\
\text { de máquina } \\
\text { vertical }\end{array}$ & $\begin{array}{l}\text { Operador } \\
\text { de máquina } \\
\text { (tomo) }\end{array}$ & Costureira & $\begin{array}{l}\text { Auxiliar de } \\
\text { produção } \\
\text { (pillow top) }\end{array}$ \\
\hline
\end{tabular}

Dessa maneira, podemos observar que nenhum dos trabalhares ultrapassam o limite de tolerância $85 \mathrm{~dB}$ (A) para uma jornada de 8 horas, porém o limite de tolerância para iniciar ações preventivas é de $80 \mathrm{~dB}$ (A) e levando em consideração uma zona de segurança podemos julgar $78 \mathrm{~dB}$ (A), susceptibilidade. Assim, a empresa tem que agir no controle do ruído em alguns setores. Já, de acordo com a NR 17, o ruído deve ser controlado para a função de 7 trabalhadores, pois o limite é $65 \mathrm{~dB}(\mathrm{~A})$ para que o ambiente seja considerado confortável ao trabalhador. (BRASIL, 1978).

Na Figura 3, observa-se que a maioria dos trabalhadores, cerca de 62\%, estão acima do nível de ação e do nível de conforto, ou seja, estão expostos a um ruído ocupacional elevado. Podendo assim, manifestar 
problemas de audição com o tempo e constantemente apresentar problemas como estresse, fadiga, zumbido, cefaleia, ansiedade, entre outros.

Figura 3: Nível de ação.

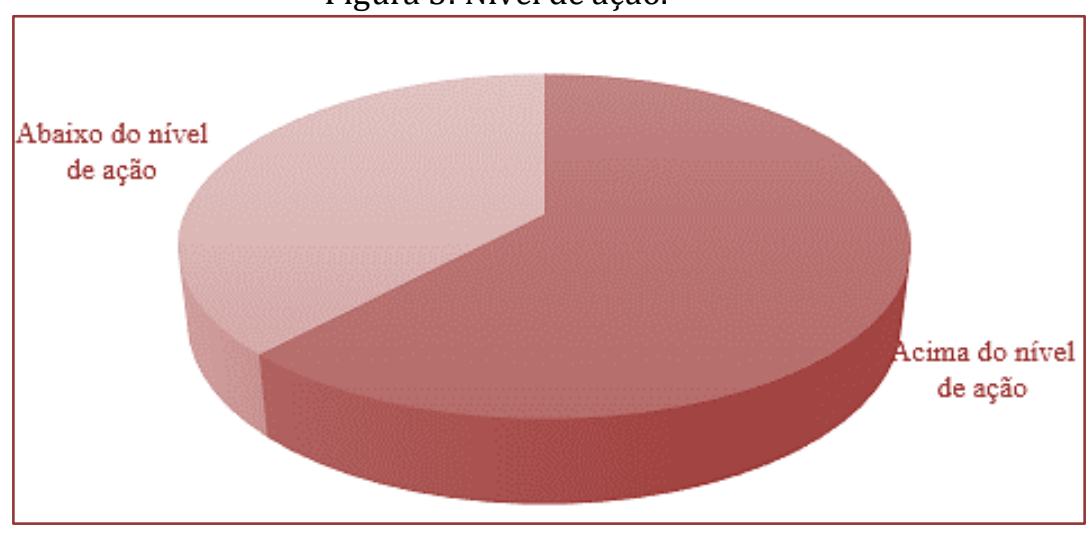

\section{CONCLUSÃO}

As diretrizes, normas e procedimentos técnicos fornecem dados objetivos. Porém, o estudo em questão é de grande subjetividade e complexidade, pois envolve seres humanos com suscetibilidades individuais. No entanto, observa-se que os objetivos propostos para este estudo foram atingidos de maneira satisfatória.

Podemos observar que a empresa já deve trabalhar no controle de ruído ocupacional. As ações tomadas devem ser medidas administrativas, medidas coletivas e por último (e esse último só acontece quando não for possível implantar medidas coletivas anteriores), medidas de controle individual, equipamento de proteção individual (EPI).

Os resultados apontaram que é imprescindível realizar ações para minimizar os níveis de ruídos nas áreas estudadas. Sugere-se algumas medidas simples e urgentes, como: realizar rodízios frequentes nas escalas de trabalho dos funcionários e orientá-los quanto a importância do uso do protetor auricular, esclarecer os efeitos físicos e psicológicos que a exposição pode causar e alterar a arquitetura da área física da unidade.

\section{REFERENCIAS}

[1] BARSANO P. R; BARBOSA R. P. Segurança do Trabalho: guia prático e didático. 2. Ed. São Paulo: Érica, 2018.

[2] BRASIL. Previdência Social. Lei no 8.213 de 24 julho de 1991. Disponível em www. planalto.gov.br/ccivil_03/leis/18213cons.htm, acesso em 12 Ago. 2019.

[3] BRASIL, Norma Regulamentadora № 15, de 08 de junho de 1978. Atividades e operações insalubre. Diário Oficial da República Federativa do Brasil, Brasília.

[4] BRASIL. Ministério do Trabalho. Portaria no 3.214, de 08 de junho de 1978- NR 17. Ergonomia. Diário Oficial da República Federativa do Brasil, Brasília.

[5] CUNHA, J. P. A. R.; DUARTE, M. A. V.; RODRIGUES, J. C. Avaliação dos níveis de vibração e ruído emitidos por um trator agrí́cola em preparo do solo. Revista: Pesq. Agropec. Trop., Goiânia, v. 39, n. 4, p. 348-355, out/dez. 2009.

[6] FUNDACENTRO. NHO 01- Procedimento técnico: Avaliação da exposição ocupacional ao ruído. São Paulo, 2001. $40 \mathrm{p}$.

[7] MENEZES, J. S. R., PAULINO, N. J. A. Efeitos do Ruído no Organismo: Manual de Avaliação e Controle do Ruído. $3^{\mathrm{a}}$ Ed. LTr. p. 62-72. São Paulo. 2004.

[8] WORLD HEALTH ORGANIZATION - WHO. Guidelines for community noise. London, UK, 1999. Disponível em: http//:www.who.int/destore/peh/noise/guidelines2.html. Acesso em: 11 de julho de 2016.

\section{RESPONSABILIDADE AUTORAL}

Os autores são os únicos responsáveis pelo conteúdo deste trabalho. 


\title{
Capítulo 10
}

Principais gargalos do processo produtivo de mel no estado da Paraíba utilizando o método AHP

\author{
Alan Dél Carlos Gomes Chaves \\ Aline Costa Ferreira \\ Herllange Chaves de Brito \\ José Jefferson da Silva Nascimento \\ Rubenia de Oliveira Costa \\ Wilson Luiz dos Santos Filho
}

Resumo: A apicultura produz diversos produtos como mel, pólen, própolis, cera e apitoxina A produção de mel é uma atividade que vem crescendo na Paraíba, devido a sua viabilidade operacional e econômica, mesmo em regiões semiáridas, por propiciar um bom retorno econômico, além de apresentar grande mercado. 0 objetivo da pesquisa foi identificar os principais problemas na produção de mel, permitirá encontrar os gargalos que limitam a produção, os quais interferem na qualidade e comercialização do produto. A metodologia realizada foi levantamentos bibliográfico, entrevistas não estruturadas com um pesquisador da Empresa Estadual de Pesquisa Agropecuária da Paraíba S.A (EMEPA-PB) e o coordenador do Fórum de Apicultura e Meliponicultura Paraibana, e uma entrevista com um técnico de nível superior do setor de Apicultura do Centro de Ciências Agrárias da Universidade Federal da Paraíba (UFPB).Os problemas existentes na cadeia produtiva de mel comprometem a qualidade do produto, ocasionam perdas de produção, diminuição dos lucros e dificuldade de comercialização impossibilitando o setor apícola de atingir novos mercado. Foi possível então analisar cada gargalo bem como mensurar o impacto de cada gargalo no processo produtivo de mel do Estado Paraibano, em que tem-se nestes três gargalos, a falta de manejo das melgueiras, as colônias fracas e a falta de higiene durante o processamento do mel representando mais de $50 \%$ de impacto na produção. Sugere-se então que resolvendo apenas estes três problemas a produção terá um aumento significativo, aumentando assim sua parcela no mercado, diminuindo custos e expandindo o setor agrícola de mel do Estado.

Palavras-chave: Apicultura, Paraíba, Apís, Mellifera, Produção. 


\section{INTRODUÇÃO}

No Brasil existem duas formas de produção de mel: uma é a meliponicultura que consiste na criação das abelhas nativas ou abelhas sem ferrão, as melíponas; a outra forma é a apicultura, que consiste na exploração econômica e racional da abelha do gênero Apis e espécie Mellifera sendo responsável pela maior parte da produção de mel no País (BAYLE, 2013).

A apicultura produz diversos produtos tais como: mel, pólen, própolis, cera e apitoxina. De acordo com Freitas (1998) outro produto produzido pela apicultura que vem se desenvolvendo é o serviço de polinização, que consiste em alugar colmeias para outros produtores a fim de aumentar a produtividade.

A região nordeste apresenta um grande potencial apícola e que o mel produzido nessa região possui uma boa qualidade devido as suas floradas apícolas que são nativas e livres de produtos químicos (SILVA, 2010).

Além das condições climáticas, a tecnologia, os equipamentos e as técnicas contribuem com a produtividade do mel. Vilela (2002) afirma que seguindo a tecnologia recomendada na produção e comercializando o mel de maneira adequada, tem-se uma maior rentabilidade na atividade.

Porém, Freitas (2004) afirma que apesar de existirem inovações tecnológicas de equipamentos e técnicas que contribuem para a melhoria da atividade, a produção e qualidade do mel está associada diretamente ao manejo correto e às condições da flora apícola, adicionado às técnicas de produção e à eficiência na comercialização.

De acordo com Silva (2010) a informalidade no processo produtivo, o mau uso ou a ausência da tecnologia, a falta da casa de mel e o mau gerenciamento da produção são os maiores entraves que interferem nos níveis de produtividade do mel.

A apicultura é uma atividade rentável tanto economicamente quanto socialmente, além de contribuir para a manutenção e preservação dos ecossistemas existentes. A cadeia produtiva da apicultura propicia a geração de inúmeros postos de trabalho, empregos e fluxo de renda, principalmente no ambiente da agricultura familiar, sendo, dessa forma, determinante na melhoria da qualidade de vida e fixação do homem no meio rural (PEREIRA et al., 2003).

O mel é o produto apícola que apresenta maior demanda de mercado, visto que, ele é utilizado em indústrias alimentícias, farmacêuticas e cosméticas, além de apresentar facilidade para a sua comercialização (FREITAS, KHAN e SILVA, 2004).

A produção de mel é uma atividade que vem crescendo na Paraíba, devido a sua viabilidade operacional e econômica, mesmo em regiões semiáridas, por propiciar um bom retorno econômico, além de apresentar grande mercado. Diante do exposto, esta pesquisa é importante porque ao identificar os principais problemas na produção de mel, permitirá encontrar os gargalos que limitam a produção, os quais interferem na qualidade e comercialização do produto.

Diante o exposto, este trabalho busca analisar os principais gargalos do processo produtivo de mel no Estado da Paraíba.

\section{MATERIAIS E MÉTODOS}

O primeiro passo realizado foi fazer um levantamento bibliográfico em artigos, livros e manuais técnicos relacionados, bem como em pesquisas já realizadas sobre o tema em estudo, buscando assim, uma maior compreensão e um melhor entendimento a respeito do tema. E por meio desse levantamento bibliográfico foi construído o referencial teórico.

Em seguida, foram realizadas quatro entrevistas não estruturadas com um pesquisador da Empresa Estadual de Pesquisa Agropecuária da Paraíba S.A (EMEPA-PB) e o coordenador do Fórum de Apicultura e Meliponicultura Paraibana, e uma entrevista com um técnico de nível superior do setor de Apicultura do Centro de Ciências Agrárias da Universidade Federal da Paraíba (UFPB).

Em seguida, com base nas entrevistas realizadas foram listados os gargalos encontrados na produção de mel no estado da Paraíba. A lista com os problemas foi revisada pelos dois entrevistados acima citados para validação dos dados, que resultou em 23 (vinte e três) problemas.

Em seguida, foram feitas as matrizes de julgamentos para os critérios pareados. Após ter feito a matriz, foi realizado entrevista com um especialista na área de apicultura para que o mesmo avaliasse os critérios 
pareados da matriz de julgamentos. Ele respondeu o questionamento dos impactos relativos que cada critério tem no processo produtivo, com base na escala numérica de Saaty, apresentada na Tabela 1.

Desta forma, os critérios foram representados por uma matriz de julgamentos $A_{5 \times 5}$, na qual foram comparados, conforme apresentado no Quadro 2.

Quadro 2 - Matriz de julgamentos

\begin{tabular}{|c|c|c|c|c|c|}
\hline CRITÉRIOS & Instalação & Manutenção & Beneficiamento & Gestão & Logística \\
\hline Instalação & $A_{11}$ & $A_{12}$ & $A_{13}$ & $A_{14}$ & $A_{15}$ \\
\hline Manutenção & $A_{21}$ & $A_{22}$ & $A_{23}$ & $A_{24}$ & $A_{25}$ \\
\hline Beneficiamento & $A_{31}$ & $A_{32}$ & $A_{33}$ & $A_{34}$ & $A_{35}$ \\
\hline Gestão & $A_{41}$ & $A_{42}$ & $A_{43}$ & $A_{44}$ & $A_{45}$ \\
\hline Logística & $A_{51}$ & $A_{52}$ & $A_{53}$ & $A_{54}$ & $A_{55}$ \\
\hline \multirow{2}{*}{ das colunas } & $\sum_{i=1}^{5} A i 1$ & $\sum_{i=1}^{5} A i 2$ & $\sum_{i=1}^{5} A i 3$ & $\sum_{i=1}^{5} A i 4$ & $\sum_{i=1}^{5} A i 5$ \\
\hline
\end{tabular}

Fonte: Autoria própria

Foram feitas mais cinco matrizes de julgamentos, uma para cada critério, de acordo com os problemas agrupados em cada um, ou seja, foram feitas matrizes de julgamento para instalação, manutenção, beneficiamento, gestão e logística. Com relação à identificação de qual problema tem maior impacto no processo produtivo, o especialista avaliou os problemas par a par e para calcular estas matrizes, seguiu-se o mesmo procedimento utilizado na matriz de julgamentos de critério.

Ao se comparar um critério com ele mesmo tem-se o valor de julgamento igual a 1, por exemplo, instalação comparado a instalação o valor de julgamento $A_{11}$ é 1 . Ao comparar instalação a manutenção tem-se o valor de julgamento $A_{12}$ igual a 5 , logo manutenção comparado a instalação o valor de julgamento $A_{21}$ igual a $1 / 5$, pois são valores inversamente proporcional. Após os julgamentos dos critérios fez-se a normalização da matriz de julgamentos.

\begin{tabular}{|c|c|c|c|c|c|c|c|}
\hline \multicolumn{7}{|c|}{ Quadro 3 - Matriz normalizada } \\
\hline CRITÉRIOS & Instalação & \multicolumn{2}{|c|}{ Manutenção } & Beneficiamento & Gestão & Logística & $\begin{array}{c}\text { Autovetor } \\
\text { Normalizado } \\
\text { Média (w) }\end{array}$ \\
\hline Instalação & $\bar{A}_{11}$ & $\bar{A}_{12}$ & $\bar{A}_{13}$ & $\bar{A}_{14}$ & $\bar{A}_{15}$ & $\frac{\sum_{1}^{5} A 1 j}{5}$ \\
\hline Manutenção & $\bar{A}_{21}$ & $\bar{A}_{22}$ & $\bar{A}_{23}$ & $\bar{A}_{24}$ & $\bar{A}_{25}$ & $\frac{\sum_{1}^{5} A 2 j}{5}$ \\
\hline Beneficiamento & $\bar{A}_{31}$ & $\bar{A}_{32}$ & $\bar{A}_{33}$ & $\bar{A}_{34}$ & $\bar{A}_{35}$ & $\frac{\sum_{1}^{5} A 3 j}{5}$ \\
\hline Gestão & $\bar{A}_{41}$ & $\bar{A}_{42}$ & $\bar{A}_{43}$ & $\bar{A}_{44}$ & $\bar{A}_{45}$ & $\frac{\sum_{1}^{5} A 4 j}{5}$ \\
\hline Logística & $\bar{A}_{51}$ & $\bar{A}_{52}$ & $\bar{A}_{53}$ & $\bar{A}_{54}$ & $\bar{A}_{55}$ & $\frac{\sum_{1}^{5} A 5 j}{5}$ \\
\hline
\end{tabular}

Fonte: Autoria própria

A normalização da matriz de julgamentos, conforme se verifica no Quadro 3 foi feita através da divisão de cada elemento $\left(A_{i j}\right)$ pelo somatório da respectiva coluna. Em seguida foi realizado o cálculo do autovetor normalizado $(\mathrm{w})$ obtido por meio das médias das linhas dos elementos da matriz normalizada, ou seja, calculamos o autovalor máximo ( $\lambda$ máx), multiplicando a matriz de julgamentos $A_{5 x 5}$ pelo autovetor (w) e dividindo esse novo vetor encontrado pelo vetor w, conforme apresentado na equação 3.

$$
\lambda \text { máx }=\text { média do vetor } \frac{A w}{w}
$$

Para identificar se houve consistência nas respostas foi calculado o índice de consistência, em que diminuiu n (dimensão da matriz) do autovalor máximo ( $\lambda$ máx) e em seguida dividiu-se por (n-1).

Logo em seguida, foi calculada a razão de consistência, em que se dividiu o índice de consistência pelo índice randômico médio, cujos valores foram apresentados na Tabela 1. Conforme descrito anteriormente, 
para que haja consistência das avaliações pareadas é necessário que a razão de consistência seja menor que 0,1 .

De acordo com as respostas do especialista, a razão de consistência das matrizes em estudo resultou em um valor maior que 0,1 . Neste caso não houve consistência nas respostas e não foi possível continuar com os cálculos do AHP.

Então, foi realizada outra entrevista com um especialista e pesquisador de apicultura para que o mesmo avaliasse os critérios pareados nas matrizes de julgamentos e de acordo com as respostas do mesmo, seguiram-se os cálculos do AHP. Em todas as matrizes calculadas a razão de consistência foi menor que 0,1 o que demonstra que as respostas foram consistentes.

Com base no autovetor normalizado, foram feitas a hierarquização de cada critério e de cada problema. De acordo com os valores do autovetor normalizado foram hierarquizados os problemas e o quanto cada um impacta no processo produtivo.

Para uma hierarquização geral, calculou-se o produto do autovetor normalizado do critério macro pelo autovetor normalizado do critério micro. Por exemplo: o valor do autovetor normalizado do critério macro (instalação) foi multiplicado pelo autovetor normalizado do critério micro (pasto apícola). Ou seja, os valores do autovetor normalizado dos critérios micro foram multiplicados pelo valor do autovetor normalizado do critério macro ao qual estava agrupado.

\section{RESULTADOS E DISCUSSÃO}

Conforme apresentado na tabela 1, é possível perceber de forma geral o impacto de cada gargalo no processo de produção de mel no estado da paraíba. 0 gargalo que tem maior impacto é a falta de manejo das melgueiras (20,33\%), em que segundo pereira et al., (2003) o manejo eficiente das colmeias contribui para o sucesso da atividade, pois é durante o manejo das melgueiras que o apicultor observa a quantidade de alimento disponível, a presença e a qualidade da postura da rainha e o desenvolvimento das crias. Para pereira et al., (2003), essa prática pode evitar muitos problemas, pois por meio do manejo adequado é possível identificar erros e adotar medidas preventivas sem que prejudique a produção de mel.

O segundo são as colônias fracas que geralmente são consequências da falta de alimento disponível no campo, divisão natural de enxames, rainhas velhas e enxames recém-capturados. Além de não produzirem, essas colônias são alvo fácil de pragas e doenças. Para evitar esses problemas, o apicultor deve fortalecer ou unir essas colmeias.

0 terceiro é a falta de higiene durante o processamento do mel, em que é imprescindível que se tenha cuidado com a higiene devido ao contato direto do apicultor com o mel. O sebrae/na (2009) enfatiza que o contato com superfícies sujas, veículos de transporte sujos e equipamentos e máquinas de envase sujos são fontes de contaminação. A falta de higiene dos manipuladores nas diferentes etapas de produção do mel, nas casas de mel e no entreposto pode acarretar em contaminação de origem fecal dos produtos.

O quarto gargalo que mais impacta é a falta de calendário de floradas, a realização desse calendário é extremamente importante, pois, conforme wolff (2008), este calendário possibilita a identificação dos períodos de máxima oferta de alimentos (néctar e pólen) às abelhas e a análise dos momentos mais adequados para o planejamento e a antecipação dos manejos nas colmeias.

O quinto é a falta de assistência técnica aos apicultores, em que a grande maioria dos apicultores não procuram e nem fazem uso de serviços ligados à assistência técnica. Da parcela dos apicultores que procuram essa ajuda, muitos não colocam em prática o que aprendem. 0 sebrae/pb (2006) afirma que essa falta de assistência técnica contribui para o atraso tecnológico e gerencial da apicultura paraibana, além de gerar uma atuação insatisfatória das diversas agencias encarregadas de promover assistência aos produtores rurais, tanto nesta atividade quanto em outras atividades de produção.

O sexto gargalo é o mel verde, em que este é assim caracterizado por ter a retirada de favos da melgueira não maduros, ou seja, os favos ainda não estão operculados. Pereira et al., (2003) afirma que o mel verde apresenta altos índices de umidade o que facilita a proliferação de leveduras, levando-o a fermentar e tornando-se impróprio para o consumo. Por este motivo, o mel verde é considerado um problema, visto que o seu beneficiamento gera perda de produção, pois não pode ser consumido.

O sétimo são as vestimentas inadequadas, pois o seu uso tende a contaminar o produto, além de ser perigoso aos manipuladores que ficam expostos a picadas de abelhas e a acidentes de trabalho. Silva (2005) menciona que as vestimentas devem ser próprias para a atividade apícola (macacão, luvas, botas, 
máscara e chapéu) e as mesmas devem estar limpas, de aparência apresentável e sem cheiro, por que o odor pode comprometer a qualidade do mel. Além disso, as vestimentas adequadas evitam que haja contato do homem com o mel e consequentemente que o mel não seja contaminado.

Tabela 1 - Hierarquização Geral dos Problemas

\begin{tabular}{|l|l|}
\hline Falta do manejo das melgueiras & $20,33 \%$ \\
\hline Colônias fracas & $15,20 \%$ \\
\hline Falta de higiene durante o processo de beneficiamento do mel & $13,73 \%$ \\
\hline Falta de calendário de floradas & $8,77 \%$ \\
\hline Falta de assistência técnica aos apicultores & $4,61 \%$ \\
\hline Mel verde & $4,10 \%$ \\
\hline Vestimentas inadequadas & $3,84 \%$ \\
\hline Falta de cuidado das colmeias durante a entressafra & $3,34 \%$ \\
\hline Má localização do apiário & $3,34 \%$ \\
\hline Falta de alimentação artificial nas colmeias durante a seca & $3,12 \%$ \\
\hline Não realizar a troca de cera & $2,96 \%$ \\
\hline Proximidade do apiário à criação de gado e cavalo & $2,49 \%$ \\
\hline Beneficiamento do mel feito fora da Unidade & $2,35 \%$ \\
\hline Utilização de equipamentos inadequados para beneficiamento do mel & $2,08 \%$ \\
\hline Pasto apícola & $1,82 \%$ \\
\hline Falta de entrepostos a uma distância acessível & $1,84 \%$ \\
\hline Má gestão do negócio & $1,55 \%$ \\
\hline Má utilização de cera nas melgueiras & $1,45 \%$ \\
\hline Fonte de água distante do apiário & $1,21 \%$ \\
\hline Falta de cronograma de colmeia & $0,96 \%$ \\
\hline Baixo nível de tecnologia empregada & $0,47 \%$ \\
\hline Utilização de agrotóxicos em lavoura próxima & $0,26 \%$ \\
\hline Dificuldade de comercialização & $0,19 \%$ \\
\hline & \\
\hline
\end{tabular}

Fonte: Cálculo da Autora

O oitavo é a falta de cuidado das colmeias durante a entressafra, em que souza (2006) afirma que na entressafra são necessários cuidados especiais. Devem-se guardar somente favos novos, distantes uns dos outros (quanto mais distante melhor) e em local bem iluminado e ventilado para que na época de safra as colmeias estejam preparadas para a produção.

o nono é a má localização do apiário, geralmente o apicultor localiza o apiário em região próximo a criação de animais, distante de fonte de água e com pouco pasto apícola o que dificulta o trabalho das abelhas. A localização do apiário é muito importante, pois é o espaço onde estão instaladas as colmeias de abelha, ou seja, deve ser um espaço capaz de dá suporte as abelhas para que estas produzam mel, deve estar próximo ao pasto apícola. Pereira et al., (2003) afirma que a localização do apiário deve ter bastante recursos florais, e deve-se analisar o acesso ao apiário, a topografia e o perímetro de segurança. Além disso, couto \& couto (2006) afirma que o sucesso na criação de abelhas depende, em grande parte, da localização e instalação do apiário, por que as abelhas possuem uma notável capacidade de guardar na memória a exata localização de sua colmeia, para isso elas usam como placas de sinalização, referenciais tais como árvores, construções, pedras e cores que marcam seus voos.

o décimo é a falta de alimentação artificial nas colmeias durante a seca, o que gera morte das abelhas e enfraquecimento das colmeias fracas, pereira et al., (2003) afirma que as abelhas necessitam de reservas de alimento suficientes para atender a sua própria alimentação e das crias em desenvolvimento. Em 
épocas de escassez de néctar e pólen, é comum os apicultores perderem seus enxames que, enfraquecidos em razão da fome, migram à procura de condições melhores. Sebrae/na (2009) informa que para sobreviverem, as abelhas necessitam alimentar-se e atender às exigências do seu organismo, pois a falta de alimentação artificial ocasiona o enfraquecimento dos enxames e por este motivo ocasiona fome e as abelhas abandonam a colmeia.

0 décimo primeiro é a não realização da troca de cera, essa troca é necessária pelo fato de que as células dos quadros de ninhos que recebem a postura da rainha são gradualmente obstruídas pelos dejetos das larvas. Outro efeito do acúmulo de sujeira é a reação defensiva das abelhas que se manifesta na propensão a gerar novos enxames (sebrae/pb, 2006).

0 décimo segundo é a proximidade do apiário à criação de gado e cavalo, isso se dá devido à falta de higienização nos currais tornando assim um ambiente impróprio para entrada de abelhas bem como pelo fato dos animais buscarem como fonte de alimentação as plantas nativas utilizadas próximo ao pasto apícola, comprometendo assim a produção de mel. Além disso, de acordo com o coordenador do fórum de apicultura e meliponicultura da paraíba a apicultura paraibana é em sua maioria uma atividade secundária, ou seja, atrelada a ela o apicultor tem uma atividade principal, que muitas vezes consiste na criação de gado e cavalo.

0 décimo terceiro é o beneficiamento do mel feito fora da unidade, que de acordo com a entrevista feita com o coordenador do fórum de apicultura e meliponicultura paraibana, dennis leon batista, ainda existem muitos apicultores paraibanos que fazem todo o processo de produção de mel dentro da cozinha de sua própria casa, o que compromete a qualidade e a composição química do mel. Visto que não se segue os procedimentos para a produção, que não é feito a higienização correto dos equipamentos, além de não serem utilizados os materiais apícolas, gerando um mel de baixa qualidade ou até impróprio para o consumo.

O décimo quarto é a utilização de equipamentos inadequados para o beneficamento, o sebrae/pb (2006) mostra que o uso de equipamentos e ferramentas específicos da apicultura tem seu emprego necessário e importante para a boa condução dos processos e operações que lhe são peculiares.

0 décimo quinto é o pasto apícola sendo um fator de grande importância na apicultura, pois representa o principal alimento das abelhas. Couto e couto (2006) destaca que a qualidade e quantidade de seu pasto apícola são os principais fatores que limitam a produção num dado local.

O décimo sexto é a falta de entrepostos a uma distância acessível, em algumas cidades do interior da paraíba o entreposto é distante da propriedade apícola o que faz com que, muitas vezes todo o processo produtivo seja feito na unidade de beneficiamento, devido à distância, pois na visão do apicultor isso acarreta em perda de dinheiro e tempo em virtude da necessidade de deslocamento.

O décimo sétimo é a má gestão do negócio, os apicultores, em sua maioria, não fazem planejamento do negócio, controle de produção e controle financeiro. Eles não anotam dados de produção, nem informações gerenciais para que se tenham um maior controle sobre a atividade. 0 sebrae/pb (2006) afirma que o nível de gestão na apicultura paraibana é muito incipiente, tendo um baixo controle de caixa, pois não há controle de custos, cadastro de clientes e acompanhamento de mercado, o que reflete em uma má gestão de negócios.

o décimo oitavo é a má utilização de cera nas melgueiras, segundo o sebrae/pb (2006), é muito baixo o índice de apicultores que fazem a substituição da cera dos ninhos. 0 resultado dessa pesquisa mostra que aproximadamente $57 \%$ dos apicultores deixam de efetuar essa operação elementar, a qual é muito importante para o bom desempenho da colônia.

o décimo nono é a fonte de água distante do apíario, pereira et al., (2003) afirma que a presença de água é fundamental para a manutenção dos enxames, principalmente em regiões de clima quente, uma vez que a água é usada para auxiliar na termorregulação (em casos extremos, uma colmeia pode chegar a consumir 20 litros d'água por semana), portanto deve-se fornecer para as abelhas fonte de água pura a uma distância de, no mínimo, 100 metros, (para que não haja contaminação pelos próprios dejetos das abelhas, uma vez que elas só os liberam fora da colmeia) e no máximo de 500 metros (evitando-se gasto energético acentuado para a sua coleta). Caso o local não disponha de fonte natural (rios, nascentes, etc.), deve-se instalar um bebedouro artificial, tomando-se o cuidado de manter a água sempre limpa. Para isso, deve-se trocá-la frequentemente e lavar o bebedouro com uma escova, evitando foco de contaminação.

o vigésimo é a falta de cronograma de colmeia. 0 cronograma de colmeias permite ao apicultor um maior controle e conhecimento das colmeias, pois todas as atividades que são feitas nas colmeias são anotadas. A 
cada visita à colmeia, o apicultor deve anotar as atividade que realizou na colmeia e qual atividade deverá realizar na próxima visita. Isso garante um maior controle das colmeias. As fichas de anotações não devem ser definitivas, elas podem e devem sofrer modificações para tornar mais fácil a consolidação dos dados, a sua análise e compreensão. A única justificativa da existência de fichas de anotação é gerar informações para a tomada de decisões dos gestores e criar um histórico da atividade, pois cerca de $80 \%$ de um diagnóstico é baseado na história clínica (sebrae, 2007).

O vigésimo primeiro é o baixo nível de tecnologia empregada. 0 sebrae/pb (2006) afirma que na paraíba é frequente o uso de equipamentos em condições precárias e confeccionados de matérias não recomendados para a atividade, o que reflete na baixa eficiência e na qualidade insatisfatória do produto.

0 vigésimo segundo é a utilização de agrotóxicos em lavoura próxima, apícola que na apicultura paraibana tem baixa ocorrência devido a utilização de planta nativa e do pasto apícola.

E o último é a dificuldade de comercialização em que a maior dificuldade de comercialização da produção de mel são os intermediários, pois eles se aproveitam das dificuldades do apicultor em negociar com as empresas processadoras por muitas vezes não terem acesso às empresas ou por não possuírem embalagens adequadas. 0 intermediário compra do apicultor e repassa o produto para as empresas processadoras nas condições recebidas e as mesmas fornecem o padrão comercial para alcançar o consumidor final. Além desse problema, tem a baixa qualidade dos produtos, embalagens inadequadas, dispersão e irregularidade da oferta (deser, 2008).

\section{CONSIDERAÇÕES FINAIS}

O processo produtivo de mel no estado da paraíba gera inúmeros postos de trabalho, renda e lucro aos produtores, proporcionando o desenvolvimento do homem no campo e contribuindo para o equilíbrio do ecossistema e manutenção da diversidade. Os problemas existentes na cadeia produtiva de mel comprometem a qualidade do produto, ocasionam perdas de produção, diminuição dos lucros e dificuldade de comercialização impossibilitando o setor apícola de atingir novos mercado.

Foi possível então analisar cada gargalo bem como mensurar o impacto de cada gargalo no processo produtivo de mel do estado paraibano, em que tem-se nestes três gargalos, a falta de manejo das melgueiras, as colônias fracas e a falta de higiene durante o processamento do mel representando mais de $50 \%$ de impacto na produção. Sugere-se então que resolvendo apenas estes três problemas a produção terá um aumento significativo, aumentodando assim sua parcela no mercado, diminuindo custos e expandindo o setor agrícola de mel do estado.

\section{AGRADECIMENTO}

Agradecemos à CAPES pelo apoio financeiro fornecido para realização deste trabalho através da concessão de bolsa.

\section{REFERÊNCIAS}

[1] BAYLE, E. Estudo da Cadeia Produtiva do Mel no Estado do Pará/ Emmanuel Bayle. Programa de Redução da Pobreza e Gestão dos Recursos Naturais do Pará - PARARURAL, 2013.

[2] COUTO, R. H. N; COUTO, L. Apicultura: manejo e produtos. 3 ed. aboticl: FUNEP, 2006. 191p. DESER Departamento de Estudos Sócio-Econômicos Rurais. Estudo da Cadeia Produtiva do Mel. Curitiba, PR 2008.

[3] FREITAS, B.M. O uso de programas racionais de polinização em áreas agrícolas. Mensagem doce. N.46, p.1620, São Paulo: APACAME, 1998.

[4] FREITAS, D. G. F.; KHAN, A. S. e SILVA, L. M. R. Nível tecnológico e rentabilidade de produção de mel de abelha (Apis mellifera) no Ceará. Rev. Econ. Sociol. Rural vol.42 no.1 Brasília Jan./Mar. 2004.

[5] PEREIRA, F. de M. et al. Produção de mel. Embrapa Meio-Norte, 2003.

[6] SEBRAE - Serviço de Apoio às Micro e Pequenas Empresas. (2007). O que é apicultura? Disponível em: http://www.sebraern.com.br/apicultura. Acesso em setembro de 2014.

[7] SEBRAE/NA - Manual de Segurança e Qualidade para Apicultura. PAS Indústria. Brasília, DF: SEBRAE/NA, 2009.86p. 
[8] SEBRAE/PB - Apicultura paraibana. Serviço Brasileiro de Apoio às Micros e Pequenas Empresas da Paraíba. João Pessoa: SEBRAE/PB, 2006. 69 p.

[9] SILVA, A. F. - Boas apícolas: mel com qualidade/ Armando Ferreira da Silva (org). Natal - SEBRAE/RN, 2005. $21 \mathrm{p}$.

[10] SILVA, EDINILSON AUGUSTO da. Apicultura sustentável: produção e comercialização de mel no sertão sergipano / Edinilson Augusto da Silva. - São Cristóvão, 2010. xix, 153 f. : il. Dissertação (Mestrado em Desenvolvimento e Meio Ambiente) - Núcleo de Pós-Graduação em Desenvolvimento e Meio Ambiente, Universidade Federal de Sergipe, 2010.

[11] SOUZA, Darcet Costa - Org. Apicultura: manual do agente de desenvolvimento rural/ Organizado por Darcet Costa Souza._2. ed. rev._Brasília: Sebrae, 2007. 186 p.; il. 2006.

[12] VILELA, Sérgio Luiz de Oliveira; PEREIRA, Fábia de Melo. Cadeia produtiva do mel no Estado do RN. Natal: SEBRAE/RN, 2002.130p.

[13] WOLFF, L. F. et. al., Flora apícola arbórea nativa na reião serrana de Pelotas para a apicultura sustentável do Rio Grande do Sul/Luís Fernando Wolff... [et. al.] - Pelotas: Embrapa Clima Temperado 2008. 37 p. - (Embrapa Clima Temperado. Documentos, 242).

\section{RESPONSABILIDADE AUTORAL}

Os autores Alan Del Carlos Gomes Chaves, Aline Costa Ferreira, Herllange Chaves de Brito, José Jefferson da Silva Nascimento, Rubenia de Oliveira Costa e Wilson Luiz dos Santos Filhos são os únicos responsáveis pelo conteúdo deste trabalho. 


\section{Capítulo 11}

Avaliação de parâmetros respiratórios em operários de empresas de produção de brita na cidade de Cajazeiras - PB

\section{Jordany Ramalho Silveira Farias \\ Ana Carolina Nóbrega Leite \\ Pablo Antônio Maia de Farias}

Resumo: Introdução: A exposição ocupacional a partículas de material por via inalatória é uma realidade diária para algumas atividades laborais, dentre estas, os trabalhadores de empresas de produção de sílica. Objetivos: identificar a ocorrência de alterações nos parâmetros respiratórios de trabalhadores de quatro empresas produtoras de sílica, na cidade de Cajazeiras/PB. Método: Para análise dos dados foi aplicado um questionário sócio demográfico, os parâmetros ventilatórios e de capacidade pulmonar foram analisados com o auxílio de um ventilômetro, um manovacuômetro e um aparelho de pico de fluxo. Resultados: Foram avaliados 21 trabalhadores que trabalhavam diretamente com a produção de britas. A frequência cardíaca pareceu reduzida nos trabalhadores expostos a britas de tamanho $19(\mathrm{p}=0,04)$ e $22 \mathrm{~mm}(\mathrm{p}=0,043)$, assim como aqueles que trabalhavam com pedra-rocha $(p=0,04)$. Outros parâmetros como volume corrente, frequência respiratória e o volume minuto apareceram mais elevados na população em estudo que a média da população em geral. Conclusão: A atividade laboral pode ter causado alterações respiratórias e cardíacas, no entanto, é possível que as elevações nos parâmetros respiratórios sejam consequência da diminuição da frequência cardíaca. Novos estudos são necessários para se avaliar tal correlação.

Palavras-chave: brita; medicina ocupacional; frequência cardíaca; ventilação; capacidade pulmonar. 


\section{INTRODUÇÃO}

A mineração de agregados para a construção civil resulta em matéria-prima para o crescimento das cidades proporcionando o desenvolvimento urbano e social (TANAKA et al.,2001). Para a preparação deste material que pode ser extraído por pedreiras por meio da seleção de pedras, envolve exposição aos pós liberados no ambiente e frequentemente inalados pelos trabalhadores deste setor.

Dentre as complicações mais comuns da exposição a este tipo de material, podemos citar as pneumoconioses que designam genericamente todas as doenças pulmonares parenquimatosas causadas pela inalação de poeiras independente do processo fisiopatológico envolvido em ambientes de trabalho relacionadas etiologicamente as pneumopatias (CASÉCA et al., 2006). No entanto, as complicações pulmonares por este tipo de exposição pode ir além, chegando a ocorrência de câncer (BORGHI et al., 2004), podendo ser responsável por contribuir de 1,5 a 6 vezes o risco de um silicótico (paciente de silicose) contrair câncer de pulmão (SANTOS, 1988).

A poeira é dividida em três frações: a fração inalável com partículas menores que $100 \mu \mathrm{m}$ (entrada no nariz e boca), fração torácica $<25 \mu \mathrm{m}$ (penetração além da faringe) e fração respirável com partículas menores que $10 \mu \mathrm{m}$ (penetram além dos bronquíolos) (SILVA et al., 2000). As poeiras respiráveis, com diâmetro menor que $10 \mu \mathrm{m}$, têm importância fundamental para a saúde e segurança no trabalho. No Brasil, o número estimado de trabalhadores potencialmente expostos a atividades de risco é superior a seis milhões (RIBEIRO, 2010b).

A sílica ou dióxido de silício é um composto natural formado pelos dois elementos químicos mais abundantes na crosta terrestre, o oxigênio e o silício. Encontrado na natureza nas formas amorfa e cristalina, que quando combinadas com metais e óxidos dão origem a silicatos como talco, feldspato, caulim, mica, entre outros (BRASIL, 2006).

A avaliação da função respiratória é de suma importância no auxílio do diagnóstico das pneumoconioses, consiste em um método de grande importância, pois visa investigar, além das condições da força, o desempenho mecânico dos músculos da respiração, através das variáveis pressão inspiratória máxima (PImáx) e da pressão expiratória máxima (PEmáx) e assim obter dados sobre a força do conjunto dos músculos inspiratórios e expiratórios (CARNEIRO, 2001).

Dentre as medidas utilizadas com frequência para avaliação pulmonar encontramos a capacidade vital e o volume pulmonar. A capacidade vital é um parâmetro correspondente à soma do volume de reserva expiratório, do volume corrente e do volume de reserva inspiratório e corresponde, esta capacidade, cerca de $4.600 \mathrm{~mL}$, é a maior quantidade de ar que uma pessoa pode expelir dos pulmões após tê-los enchidos ao máximo e em seguida expirados completamente. 0 volume corrente é o volume de ar inspirado e expirado em cada ciclo ventilatório normal, no homem jovem médio equivale a cerca de 500Ml (JAYME JUNIOR et al., 2006).

Embora alguns relatos de trabalhos demonstrem a ocorrência de complicações pulmonares em trabalhadores de empresas de produção de britas, estudos que demonstrem se existe algum comprometimento pulmonar com estes trabalhadores sem sinais clássicos de qualquer pneumopatias ainda são escassos.

Em vista do quadro descrito, este trabalho tem o objetivo de verificar se existe comprometimento de parâmetro respiratório em trabalhadores de quatro empresas produtoras de brita na cidade de Cajazeiras/PB.

\section{MATERIAL E MÉTODO}

A população do estudo foi caracterizada por 30 trabalhadores de quatro empresas de produção de brita na cidade de Cajazeiras/PB, dentre estes 21 concordaram em participar da pesquisa, sendo um estudo transversal e descritivo que analisou os parâmetros pulmonares dos trabalhadores, que se expõem aos pós provenientes do preparo dos diferentes tipos de brita. As variáveis estudadas foram: idade, tempo e horas de trabalho nesta atividade, uso de equipamento de proteção individual (EPI) e tipo de pedra produzida.

Além das informações coletadas através do questionário semiestruturado, foram avaliados os parâmetros respiratórios. Um ventilômetro, modelo Ferraris ${ }^{\circledR}$, um clip nasal e um relógio de pulso foram utilizados para avaliar as medidas do volume-minuto, volume corrente e da capacidade vital, mantendo-se o mesmo posicionamento adotado nas medidas da pressão inspiratória máxima (PImáx) e pressão expiratória 
máxima (PEmáx). Para medida da capacidade vital o paciente foi instruído a realizar uma inspiração máxima, tendo suas narinas ocluídas por um clip nasal e então com a boca acoplada ao instrumento, este foi solicitado a realizar uma expiração máxima lenta e não forçada, próxima do volume residual, sendo realizada uma única repetição e o valor registrado no ventilômetro.

Para a coleta do volume-minuto (VM), o paciente com as vias aéreas devidamente ocluída com um clip nasal, foi instruído a responder normalmente, com incursões inspiratórias e expiratórias sem esforços, por um tempo de um minuto marcado em cronômetro.

Para a medida do volume corrente (VC) utilizou-se da seguinte equação: VC = VM / FR, onde a frequência respiratória foi registrada no ventilômetro durante a realização da coleta de volume-minuto (COSTA, 2004).

A força muscular respiratória foi obtido pelas medidas de PImáx e PEmáx, através de um manovacuômetro da marca Wika ${ }^{\circledR}$, com escala operacional em $\mathrm{cmH}_{2} \mathrm{O}$, equipado com um clip nasal, um adaptador de bocais e dois orifícios, um de maior diâmetro (o qual ficará ocluído durante a realização das medidas) e um outro de aproximadamente $2 \mathrm{~mm}$ de diâmetro (GUYTON e HALL, 2006).

Para a medidas da PImáx o paciente foi devidamente posicionado sentando, com suas via aéreas ocluídas pelo clip nasal sendo solicitado a realizar um esforço inspiratório máximo sustentado por no mínimo um segundo, a partir da capacidade residual funcional (CRF).

A medida da PEmáx foi obtida por meio de uma expiração máxima e sustentada por, no mínimo, um segundo, a partir da capacidade pulmonar total (CPT).

A cada sessão de coleta o paciente realizou três manobras para cada uma das pressões (inspiratória e expiratória), com um intervalo de 30 segundos entre cada medida, sendo considerado o resultado de maior valor.

O pico de fluxo expiratório (PFE) (peak flow) é um parâmetro espirométrico medido por meio de aparelhos portáteis, de baixo custo, independente de fonte elétrica, que está diretamente relacionado com a força muscular e volume pulmonar, baseando-se na medida do sopro expiratório (KNUDSON et al, 1976). É frequentemente realizado em clínica pneumológica como procedimento de rotina.

Para a definição do valor padrão para a frequência cardíaca máxima foi utilizada a seguinte equação (SINGH et al, 2006):

$$
\mathrm{FCmax}=208-(0,7 \times \text { idade })
$$

O valor padrão para o pico de fluxo (peak flow) foi analisado de acordo com tabela estabelecida por Knudson et al., 1976.

A Figura 1 representa os movimentos respiratórios durante a ventilação normal em uma pessoa saudável, o pico mais alto indica o volume inspirado de reserva, momento em que a pessoa realiza a máxima inspiração, inflando ao máximo os pulmões. 0 pico de maior depressão representa a máxima expiração e o volume de reserva. Os picos contínuos representam a capacidade respiratória, ou seja, o ritmo normal da respiração formado pela alternância de inspirações e expirações.

Para a análise dos dados foi utilizado o software estatístico SPSS ${ }^{\circledR}$ para Windows ${ }^{\circledR}$, versão 16.0 , onde foram realizadas medidas de correlação bivariada para identificar as possíveis relações entre as variáveis e para as correlações que se mostraram significantes foi realizado o teste $t$ de Student. 0 teste de MannWithney foi utilizado para comparar as médias entres grupos expostos aos diferentes tipos de britas. Para a análise dos dados foi considerado o intervalo de confiança (IC) de 95\% e o valor de p de 0,05.

A pesquisa contou com voluntários que concordaram em participar do estudo assinando o Termo de Consentimento Livre e Esclarecido (TCLE). 0 estudo foi submetido ao Comitê de Ética em Pesquisa da Faculdade Santa Maria e aprovado sob o n 761062011. 
Figura 1 - Diagrama representativo dos movimentos respiratórios durante a ventilação normal e durante a inspiração máxima e a expiração máxima (Adaptado de GUYTON, 2006).

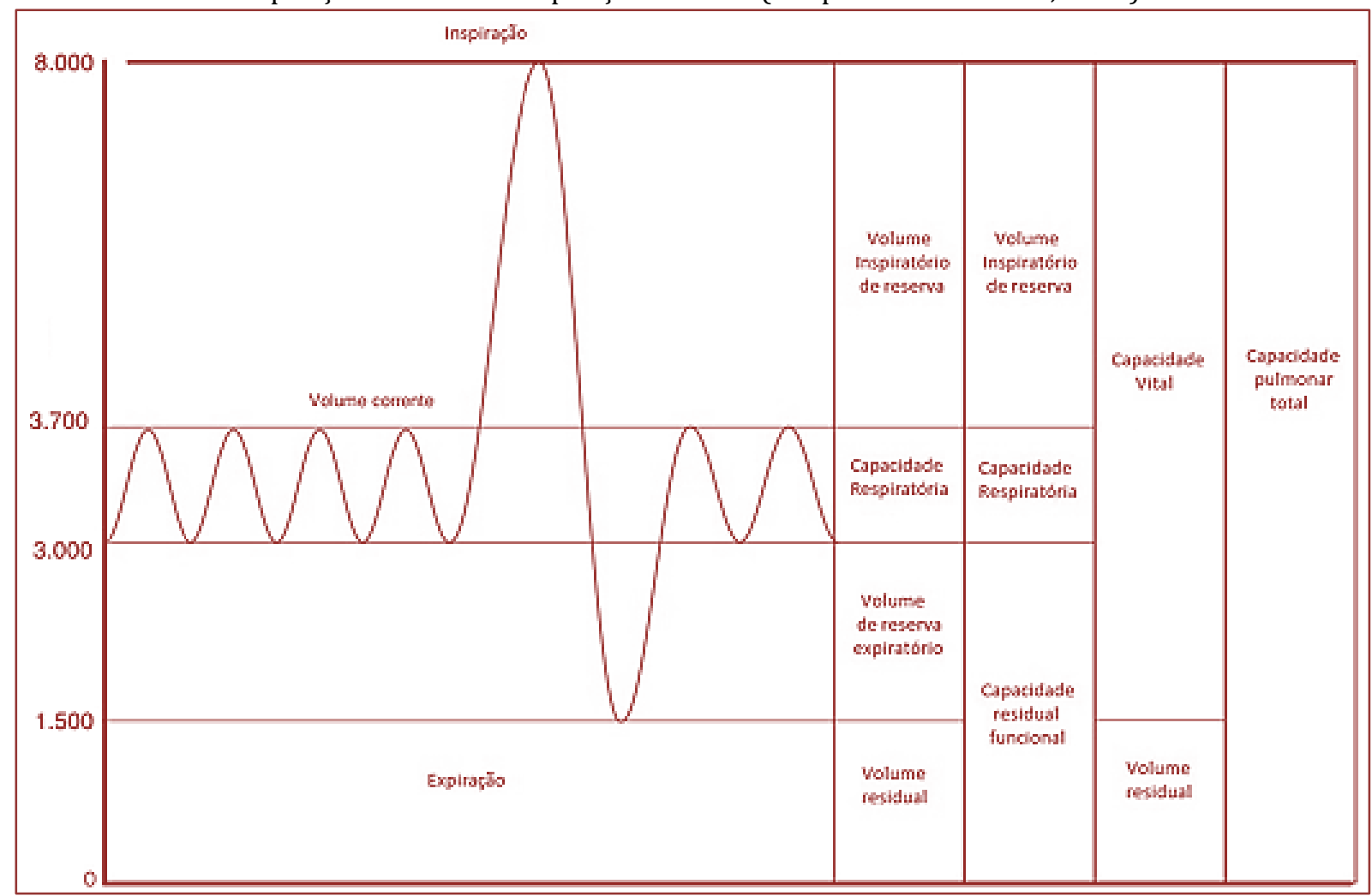

\section{RESULTADOS E DISCUSSÃO}

Nenhuma amostra observou qualquer tipo de doenças crônicas nos trabalhadores das empresas da produção de brita.

Tabela1 - Caracterização da população de estudo.

\begin{tabular}{|l|c|}
\hline Escolaridade & $\begin{array}{c}\text { Ensino Fundamental (66,7\%) } \\
\text { Analfabetos }(9,5 \%)\end{array}$ \\
\hline Tempo de trabalho & $47,6 \%$ \\
\hline Idade & $38,76 \pm 11,24$ \\
\hline Peso & $70 \mathrm{~kg} \pm 9,64$ \\
\hline *IMC - Índice de Massa Corporal & $25,17 \pm 3,00 \mathrm{~kg} / \mathrm{m}^{2}$ \\
\hline Horas de trabalho & $44 \mathrm{~h} \mathrm{semanais}$ \\
\hline *EPI - Equipamento de Proteção Individual & $42,9 \%$ \\
\hline
\end{tabular}

Dentre a população estudada, 66,7\% tinham o ensino fundamental completo, 9,5\% eram analfabetos e $47,6 \%$ exerciam a atividade há mais de um ano. A média das idades foi de 38,76 anos $( \pm 11,24)$, sendo todos do sexo masculino, com peso médio de $70 \mathrm{Kg}( \pm 9,64)$, IMC de $25,17 \mathrm{Kg} / \mathrm{m}^{2}( \pm 3,00)$ e trabalhavam em regime de 44 horas semanais. Embora seja fornecido pela empresa, 42,9\% dos trabalhadores relataram usar raramente os equipamentos de proteção individual (EPI). 
A Tabela 2 mostra as médias dos parâmetros respiratórios analisados no estudo, os resultados comparados com valores padrão e a significância estatística do teste.

Tabela 2 - Diferenças entre os resultados dos parâmetros respiratórios encontrados nos testes e os descritos pela

\begin{tabular}{|c|c|c|c|c|}
\hline Parâmetros & $\begin{array}{l}\text { Média } \pm \text { EPM } \\
\text { Trabalhadores }\end{array}$ & $\begin{array}{l}\text { Média } \pm \text { dp } \\
\text { valores de } \\
\text { frequência } \\
\text { cardíaca - Fc } \\
\text { (bmp) }\end{array}$ & $P$ & Referencia \\
\hline Frequência Cardíaca - FC (bpm) & $77,70 \pm 2,16$ & $180,87 \pm 7,87$ & $<0,001^{*}$ & Tanaka et al., 2001 \\
\hline $\mathrm{SatO}_{2}(\%)$ & $98,19 \pm 0,24$ & $\geq 95 \%$ & - & - \\
\hline Peak Flow - PEF (mL/min) & $488,01 \pm 32,84$ & $667,10 \pm 33,39$ & $<0,0011$ & Knudson, 1976 \\
\hline Volume corrente - VC (mL) & $878,58 \pm 100,82$ & $500 \mathrm{~mL}$ & $<0,001^{2}$ & Guyton, 2006 \\
\hline Volume corrente - VC (mL/Kg) & $12,69 \pm 9,20$ & $6,5(5$ a 8$)$ & $<0,001^{2}$ & Carvalho, 2007 \\
\hline Frequência respiratória - FR (irpm) & $16,95 \pm 1,00$ & 12 & $<0,001^{2}$ & Guyton, 2006 \\
\hline Volume minuto - VM (mL/min) & $15,380 \pm 1361,86$ & 6.000 & $<0,001^{2}$ & Guyton, 2006 \\
\hline Capacidade vital - CV (mL) & $4.067,14 \pm 428,11$ & 4.600 & 0,228 & Guyton, 2006 \\
\hline PImax $\left(\mathrm{cmH}_{2} \mathrm{O}\right)$ & $-94,29 \pm-50,98$ & $-90 a-102$ & - & Azeredo, 2002 \\
\hline PEmax $\left(\mathrm{cmH}_{2} \mathrm{O}\right)$ & $100,48 \pm 29,07$ & 100 a 150 & - & Azeredo, 2002 \\
\hline
\end{tabular}

*bpm: batimentos por minuto **irpm: incursões por minuto. ${ }^{1}$ Teste t pareado, IC $=95 \% ;{ }^{2}$ Teste t one-sample.

Em comparação aos valores padrão esperados para a população de acordo com as referencias utilizadas (Tabela 2), pode ser observado que a população em estudo permaneceu com menor frequência cardíaca e pico de fluxo, em contrapartida foram identificados maiores valores de volume corrente, frequência respiratória e volume minuto. A frequência cardíaca média permaneceu dentro dos padrões da normalidade $(77,70 \pm 2,16)$.

A saturação de oxigênio permaneceu acima de 95\% e os PImax e PEmax permaneceram dentro dos intervalos de referência, não indicando alterações nestes parâmetros.

Dentre os parâmetros respiratórios avaliados (Tabela 2) apenas a capacidade vital (CV) apresentou alguma correlação com britas de tamanho de $12 \mathrm{~mm}$ com um aumento da CV nos trabalhadores expostos a este tipo de pedra, no entanto este resultado parece ter pouca relevância clínica. A frequência cardíaca (FC) apresentou-se de forma diminuída nos trabalhadores que manipulavam pedra-rochas e aumentada nos que manipulavam britas de 19 e $22 \mathrm{~mm}$, os demais parâmetros não se correlacionaram com o tipo de brita produzido.

Com o objetivo de verificar se os tipos de pedras trabalhadas nas empresas causariam algum comprometimento respiratório foi realizada uma análise de diferenças nas médias dos parâmetros entre os expostos e não expostos (Tabela 3). 
O Empoderamento Científico e seus Aspectos Inovadores

Tabela 3 - Média dos parâmetros respiratórios em expostos e não expostos a cada tipo de pedra *bpm: batimentos por minuto **irpm: incursões por minuto.

\begin{tabular}{|c|c|c|c|c|c|c|c|c|}
\hline \multirow{2}{*}{$\begin{array}{l}\text { Parâmetro } \\
\text { respiratório }\end{array}$} & \multicolumn{2}{|c|}{ Pedra-rocha } & \multicolumn{2}{|c|}{ Pedra $12 \mathrm{~mm}$} & \multicolumn{2}{|c|}{ Pedra $19 \mathrm{~mm}$} & \multicolumn{2}{|c|}{ Pedra $22 \mathrm{~mm}$} \\
\hline & Não & Sim & Não & Sim & Não & Sim & Não & Sim \\
\hline \multirow{2}{*}{$\begin{array}{c}\mathrm{FC}(\mathrm{M} \pm \mathrm{dp}) \\
\mathrm{P}\end{array}$} & $\begin{array}{c}79,59 \pm \\
9,75\end{array}$ & $\begin{array}{c}69,50 \pm \\
5,75\end{array}$ & $\begin{array}{c}77,43 \pm \\
11,01\end{array}$ & $\begin{array}{c}78,14 \pm \\
7,88\end{array}$ & $\begin{array}{c}69,50 \pm \\
5,75\end{array}$ & $\begin{array}{c}79,59 \pm \\
9,75\end{array}$ & $\begin{array}{c}73,55 \pm \\
8,58\end{array}$ & $\begin{array}{c}82,20 \pm \\
9,56\end{array}$ \\
\hline & \multicolumn{2}{|c|}{$0,040^{*}$} & \multicolumn{2}{|c|}{0,743} & \multicolumn{2}{|c|}{$0,040^{*}$} & \multicolumn{2}{|c|}{$0,043^{*}$} \\
\hline \multirow{2}{*}{$\begin{array}{c}\mathrm{SatO}_{2}(\mathrm{M} \pm \mathrm{dp}) \\
\mathrm{P}\end{array}$} & $\begin{array}{c}98,12 \pm \\
1,05\end{array}$ & $\begin{array}{c}98,50 \pm \\
1,29\end{array}$ & $\begin{array}{c}98,07 \pm \\
1,14\end{array}$ & $\begin{array}{c}98,43 \pm \\
0,98\end{array}$ & $\begin{array}{c}98,50 \pm \\
1,29\end{array}$ & $\begin{array}{c}98,12 \pm \\
1,05\end{array}$ & $\begin{array}{c}98,18 \pm \\
1,25\end{array}$ & $\begin{array}{c}98,20 \pm \\
0,92\end{array}$ \\
\hline & \multicolumn{2}{|c|}{0,635} & \multicolumn{2}{|c|}{0,488} & \multicolumn{2}{|c|}{0,635} & \multicolumn{2}{|c|}{1} \\
\hline \multirow{2}{*}{$\begin{array}{c}\mathrm{PEF}(\mathrm{M} \pm \mathrm{dp}) \\
\mathrm{P}\end{array}$} & $\begin{array}{c}520,00 \pm \\
134,44\end{array}$ & $\begin{array}{c}352,50 \pm \\
155,86\end{array}$ & $\begin{array}{c}475,00 \pm \\
140,92\end{array}$ & $\begin{array}{c}514,00 \pm \\
176,81\end{array}$ & $\begin{array}{c}352,50 \pm \\
155,86\end{array}$ & $\begin{array}{c}520,00 \pm \\
134,44\end{array}$ & $\begin{array}{c}473,64 \pm \\
147,12\end{array}$ & $\begin{array}{c}504,00 \pm \\
160,43\end{array}$ \\
\hline & \multicolumn{2}{|c|}{0,065} & \multicolumn{2}{|c|}{0,856} & \multicolumn{2}{|c|}{0,065} & \multicolumn{2}{|c|}{1} \\
\hline \multirow{2}{*}{$\begin{array}{c}F R(M \pm d p) \\
P\end{array}$} & $\begin{array}{c}17,35 \pm \\
4,81\end{array}$ & $\begin{array}{c}15,25 \pm \\
3,40\end{array}$ & $\begin{array}{c}16,57 \pm \\
4,42\end{array}$ & $\begin{array}{c}17,71 \pm \\
5,16\end{array}$ & $\begin{array}{c}15,25 \pm \\
3,40\end{array}$ & $\begin{array}{c}17,35 \pm \\
4,81\end{array}$ & $\begin{array}{c}16,55 \pm \\
4,48\end{array}$ & $\begin{array}{c}17,40 \pm \\
4,88\end{array}$ \\
\hline & \multicolumn{2}{|c|}{0,462} & \multicolumn{2}{|c|}{0,743} & \multicolumn{2}{|c|}{0,462} & \multicolumn{2}{|c|}{0,705} \\
\hline \multirow{2}{*}{$\begin{array}{c}\mathrm{VM}(\mathrm{M} \pm \mathrm{dp}) \\
\mathrm{P}\end{array}$} & $\begin{array}{c}16,00 \pm \\
6,61\end{array}$ & $\begin{array}{c}12,75 \pm \\
38,62\end{array}$ & $\begin{array}{c}15,00 \pm \\
5,88\end{array}$ & $\begin{array}{c}16,14 \pm \\
7,34\end{array}$ & $\begin{array}{c}12,75 \pm \\
3,86\end{array}$ & $\begin{array}{c}16,00 \pm \\
6,61\end{array}$ & $\begin{array}{c}15,82 \pm \\
5,58\end{array}$ & $\begin{array}{c}14,90 \pm \\
7,17\end{array}$ \\
\hline & \multicolumn{2}{|c|}{0,362} & \multicolumn{2}{|c|}{0,636} & \multicolumn{2}{|c|}{0,362} & \multicolumn{2}{|c|}{0,863} \\
\hline \multirow{2}{*}{$\begin{array}{c}\mathrm{VC}(\mathrm{M} \pm \mathrm{dp}) \\
\mathrm{P}\end{array}$} & $\begin{array}{c}891,01 \pm \\
511,67\end{array}$ & $\begin{array}{c}825,76 \pm \\
148,71\end{array}$ & $\begin{array}{c}853,96 \pm \\
488,88\end{array}$ & $\begin{array}{c}927,82 \pm \\
435,23\end{array}$ & $\begin{array}{c}825,76 \pm \\
148,71\end{array}$ & $\begin{array}{c}891,01 \pm \\
511,67\end{array}$ & $\begin{array}{c}993,85 \pm \\
450,33\end{array}$ & $\begin{array}{c}751,78 \pm \\
463,59\end{array}$ \\
\hline & \multicolumn{2}{|c|}{0,897} & \multicolumn{2}{|c|}{0,799} & \multicolumn{2}{|c|}{0,897} & \multicolumn{2}{|c|}{0,152} \\
\hline $\begin{array}{c}\mathrm{CV}(\mathrm{M} \pm \mathrm{dp}) \\
\mathrm{P}\end{array}$ & $\begin{array}{c}4334,40 \\
\pm \\
2057,76\end{array}$ & $\begin{array}{c}2931,20 \pm \\
974,97\end{array}$ & $\begin{array}{c}3597,14 \\
\pm \\
2196,10\end{array}$ & $\begin{array}{c}5007,14 \pm \\
913,07\end{array}$ & $\begin{array}{r}2931,25 \pm \\
974,97\end{array}$ & $\begin{array}{c}4334,00 \pm \\
2057,76\end{array}$ & $\begin{array}{r}3537,27 \pm \\
2348,44\end{array}$ & $\begin{array}{c}4650,00 \pm \\
1305,54\end{array}$ \\
\hline & & 03 & & $46^{*}$ & & & & \\
\hline PImax (M $\pm d p)$ & $\begin{array}{c}95,88 \pm \\
53,28\end{array}$ & $\begin{array}{l}87,5 \pm \\
45,74\end{array}$ & $\begin{array}{c}92,86 \pm \\
43,22\end{array}$ & $\begin{array}{c}97,14 \pm \\
67,75\end{array}$ & $\begin{array}{c}87,50 \pm \\
45,74\end{array}$ & $\begin{array}{c}95,88 \pm \\
53,28\end{array}$ & $\begin{array}{c}100,91 \pm \\
44,82\end{array}$ & $\begin{array}{c}87,00 \pm \\
58,51\end{array}$ \\
\hline & & 29 & & & & & & \\
\hline $\operatorname{PEmax}(M \pm d p)$ & $\begin{array}{c}98,24 \pm \\
30,05\end{array}$ & $\begin{array}{c}110,00 \pm \\
25,82\end{array}$ & $\begin{array}{c}107,14 \pm \\
29,92\end{array}$ & $\begin{array}{c}87,14 \pm \\
23,60\end{array}$ & $\begin{array}{c}110,00 \pm \\
25,82\end{array}$ & $\begin{array}{c}98,24 \pm \\
30,05\end{array}$ & $\begin{array}{c}103,64 \pm \\
33,25\end{array}$ & $\begin{array}{c}97,00 \pm \\
24,97\end{array}$ \\
\hline & & 62 & & & & & & \\
\hline
\end{tabular}

${ }^{1}$ Teste t pareado, IC $=95 \%{ }^{2}$ Teste t one-sample.

Com o objetivo de observar se existia alguma correlação entre o tipo de brita produzida e a ocorrência de tosse foi realizado o cálculo da razão de chance (Odds Ratio) (Tabela 4), no entanto não foi verificada qualquer influência do tamanho das pedras e a ocorrência de tosse.

Outras características da população de estudo foram identificadas após análise de correlação Pearson, a qual mostrou que a frequência respiratória apresentou-se de forma reduzida em pessoas mais velhas $(\mathrm{r}=$ $0,550 ; p=0,010)$; a capacidade vital ficou comprometida em pacientes que apresentavam tosse $(r=-0,492$; $p=0,023)$; o hábito de fumar foi mais frequente em trabalhadores mais velhos $(r=0,501 ; p=0,021)$ e nos que tinham jornadas mais longas de trabalho $(r=0,761 ; p=0,000)$. Aqueles que trabalhavam por mais tempo apresentaram maior peso $(r=0,466 ; p=0,033)$ e, consequentemente, maior IMC $(r=0,516 ; p=$ 0,017). 0 uso de EPI não apresentou qualquer correlação com os parâmetros analisados. 
Tabela 4 - Ocorrência de tosse no uso de diferentes tipos de pedras

\begin{tabular}{|c|c|c|c|c|c|}
\hline \multirow{2}{*}{$\begin{array}{l}\text { Tipo de Pedra } \\
\text { Pedra rocha }\end{array}$} & \multicolumn{2}{|c|}{ Tosse } & \multirow{2}{*}{$P$} & \multirow{2}{*}{ OR } & \multirow{2}{*}{ IC (OR;95\%) } \\
\hline & Ausência & Presença & & & \\
\hline Não exposto & 3 & 14 & \multirow{2}{*}{0,228} & \multirow{2}{*}{0,21} & \multirow{2}{*}{$(0,02 ; 2,19)$} \\
\hline Exposto & 2 & 2 & & & \\
\hline \multicolumn{6}{|l|}{$12 \mathrm{~mm}$} \\
\hline Não exposto & 4 & 10 & \multirow{2}{*}{0,624} & \multirow{2}{*}{2,4} & \multirow{2}{*}{$(0,22 ; 26,82)$} \\
\hline Exposto & 1 & 6 & & & \\
\hline \multicolumn{6}{|l|}{$19 \mathrm{~mm}$} \\
\hline Não exposto & 2 & 2 & \multirow{2}{*}{0,228} & \multirow{2}{*}{4,67} & \multirow{2}{*}{$(0,46 ; 47,63)$} \\
\hline Exposto & 3 & 14 & & & \\
\hline \multicolumn{6}{|l|}{$22 \mathrm{~mm}$} \\
\hline Não exposto & 4 & 7 & \multirow{2}{*}{0,311} & \multirow{2}{*}{5,14} & \multirow{2}{*}{$(0,47 ; 56,90)$} \\
\hline Exposto & 1 & 9 & & & \\
\hline
\end{tabular}

*bpm: batimentos por minuto **irpm: incursões por minuto

${ }^{1}$ Teste t pareado, IC $=95 \% ;{ }^{2}$ Teste t one-sample

\section{DISCUSSÃO}

Dentre os parâmetros respiratórios analisados o pico médio de fluxo apareceu reduzido quando comparado a média padrão. Um estudo realizado com 419 trabalhadores demonstrou que, quando expostos à sílica, o pico de fluxo respiratório apareceu reduzido quando comparado ao grupo controle (ALGRANTI, 2001).

Neste estudo foi encontrado um volume corrente aumentado, este fato pode ser consequência de uma maior exigência de esforço ventilatório como medida de proteção para o comprometimento ventilatório evidenciado em outros parâmetros como o Peak Flow e a elevação na frequência respiratória por exemplo. Não foram encontradas publicações que confirmem ou neguem esta suposição.

Os trabalhadores das empresas de fabricação de brita apresentaram algumas alterações relevantes, como por exemplo uma menor frequência cardíaca nos expostos à pedra-rocha, assim como as britas de $19 \mathrm{e}$ $22 \mathrm{~mm}$, no entanto, outros trabalhos não foram encontrados que fornecessem base para a discussão deste parâmetro.

O relato de uso ou não de EPI não apresentou correlação com os parâmetros respiratórios avaliados, este fato pode ser explicado pelo fato de que os trabalhadores usavam o equipamento parte do tempo. É possível que em uma população de maior tamanho este parâmetro seja diferente.

\section{CONCLUSÃO}

Os resultados mostraram que os parâmetros respiratórios não sofreram influência do trabalho em pedreiras, mesmo com o uso limitado dos EPI, no entanto, não foi possível avaliar a função cardíaca que pode ter Embora quase todos os trabalhadores deste ramo, na cidade em que ocorreu o estudo, tenham participado da pesquisa, a amostra pode ser pequena e novos estudos devem ser realizados com finalidade de observar o possível comprometimento da função respiratória nesta população.

\section{REFERÊNCIAS}

[1] ALGRANTI E. Epidemiologia das doenças ocupacionais respiratórias do Brasil. In: Menezes AM. Epidemiologia das doenças respiratórias. Rio de Janeiro, 2001; 1(3):119-43.

[2] BORGHI, E.; SILVA, A.; LORENZO, V. A. P.; OLIVEIRA, C. R. Comportamento da função pulmonar e da força muscular respiratória em paciente submetida à revascularização do miocárdio e a intervenção fisioterapêutica. Revista Brasileira de Terapia Intensiva. 2004; 16.

[3] Brasil. Ministério da Saúde. Secretaria de Atenção à Saúde, Departamento de Ações Programáticas Estratégicas. Pneumoconiose. Brasília: Editora do Ministério da saúde; 2006.

[4] Carneiro, APS. Silicose: perfil de 326 pacientes expostos à sílica atendidos ambulatoriamente, Relatório Técnico. 2001: 15 
[5] CASÉCA, M. B.; ANDRADE, L. B.; BRITTO, M. C. A. Avaliação da função pulmonar em crianças e adolescentes no pré e pós-operatório de correção cirúrgica de valvulopatia reumática. Jornal de Pediatria. Porto alegre, $2006 ; 82$.

[6] COSTA, D. Fisioterapia Respiratória Básica, editora. Atheneu; 2004.p.105

[7] GUYTON, A.C.; HALL, J. E. Tratado de fisiologia médica, editora. Elsevier, 2006.p.475

[8] JAYME, J. A. M.; LOPES, A. J.; JANSEN, J. M.; MELO, P. L. Avaliação das características resistivas do sistema respiratório de indivíduos portadores de silicose pela técnica de oscilações forçadas. Jornal Brasileiro de Pneumologia. 2006; 32 (3): 213-20.

[9] KNUDSON, R. J.; SLATIN, R.C.; LEBOWITZ, M.D. The maximal expiratory flow-volume curve: normal standard, variability and effect of age. The American Review of Respiratory Disease Returns. 1976; 113:587-600.

[10] SANTOS, W. T. Recuperação de áreas mineradoras: um enfoque prevencionista para mineração. Congresso Brasileiro de Geologia. 1988:1983-1988.

[11] SILVA, L. C. C.; RUBIN, A. S.; SILVA, L. M. C. Avaliação funcional pulmonar. Editora. Revinter. $2000 ; 26$.

[12] SINGH, S. K.; CHOWDHARY, G. R.; PUROHIT, G. Assessment of impact $\mathrm{f}$ high particulate concentration on peak expiratory flow rate of lung of sand stone quarry workers. International Journal Environ Research and Public Health. 2006; 3 (4): 355-359.

[13] RIBEIRO, F. S. N. Projeto: vigilância da silicose no Brasil. Relatório de pesquisa. Convenio: $\mathrm{n}^{\circ}$ 1264/2007Ministério da Saúde/ UERJ. 2010b.

[14] TANAKA, H.; MONAHAN, K. D.; SEALS, D. R. Age-predicted maximal heart rate revisited. Journal of the Amer College of Cardiology. 2001; 37 (1): 153-156. 


\section{Capítulo 12}

\section{Incidência de anemia ferropriva em crianças de uma creche municipal na cidade de Piancó - PB}

Victor Vinícius Lins Nunes

Alanna Michely Batista de Morais

Heloisa Farias Gonzaga

Resumo: A anemia ferropriva é o estágio das consequências da deficiência de ferro no organismo onde a falta de ferro faz com que haja diminuição no nível da hemoglobina ou diminuição no número de eritrócitos, tendo em vista que é um elemento essencial para a produção dessas estruturas. 0 ferro é um mineral essencial para a manutenção da saúde do organismo. A carência de ferro decorre do desequilíbrio no balanço entre a utilização pelo organismo e a quantidade de ferro absorvido da dieta, este mineral é indispensável ao crescimento celular e formação de inúmeras enzimas. 0 objetivo deste estudo foi avaliar crianças de uma creche municipal da cidade de Piancó - PB e verificar a incidência de anemias nesse grupo etário, com anamnese do caso para saber possíveis causas dessa doença e os fatores que podem estar ocasionando a deficiência de ferro nestes pacientes, conscientizando os pais sobre a importância do diagnóstico e a prevenção da mesma, através do diagnostico realizado pelo exame de hemograma e dosagem de ferro sérico por método bioquímico. Foram analisadas 11 amostras da qual 07 apresentaram alterações nos níveis de hemoglobina e 03 apresentaram alterações nos índices hematimétricos (HCM, VCM e CHCM), 02 apresentaram um alto grau de anisoscitose, entre neutrofilia e eosinofilia. Estudos afirmam que a doença se define como um processo patológico no qual a concentração de hemoglobina contida nos glóbulos vermelhos, que descreve que a concentração de hemoglobina não possui boa sensibilidade e especificidade para avaliar o estado nutricional do ferro, já que pode estar alterada em diversas outras condições patológicas. 0 diagnóstico precoce e as medidas preventivas são de grande importância para que se possam evitar as consequências causadas pela anemia ferropriva.

Palavras-chave: Anemia. Deficiência. Carência de Ferro. Crescimento Celular. 


\section{INTRODUÇÃO}

Define-se anemia como uma doença em que o paciente apresenta quadro de hipoxia tissular resultante da redução de transporte de oxigênio pelo sangue. Essa redução dessa capacidade é decorrente do número de eritrócitos e/ou da baixa concentração de hemoglobina. Sendo assim, a anemia pode ser gerada de um ou mais dos seguintes fatores: (a) hemorragias e outras formas de perdas sanguíneas; (b) elevada destruição dos eritrócitos; e (c) reduzida produção de eritrócitos (VIEIRA, FERREIRA; 2010).

A anemia nutricional é um modelo onde a concentração de Hemoglobina no sangue está abaixo dos níveis em que são considerados normais para gênero, idade, altitude e estado fisiológico como resultado de um déficit de nutrientes essenciais, seja qual for a causa dessa deficiência. Sob vista epidemiológica, ocorre com mais frequência pela deficiência de ferro, caracterizando a chamada anemia ferropênica ou ferropriva (VIEIRA, FERREIRA; 2010).

A anemia resultante da insuficiência das reservas de ferro, pode gerar prejuízos funcionais ao organismo, como comprometimento da imunidade celular, retardo do desenvolvimento infantil e diminuição da capacidade intelectual. Na infância, três fatores contribuem para a alta prevalência de anemia: elevada velocidade de crescimento; reservas insuficientes de ferro ao nascer, principalmente em prematuros e nascidos com baixo peso e balanço negativo entre a ingestão e perdas do ferro (OLIVEIRA et al., 2013).

De acordo com a natureza multifatorial dessa deficiência, é necessária uma abordagem integrada que mostre os fatores determinantes de sua continuidade e que impedem o controle efetivo desta deficiência. A anemia, considerada um grave problema de saúde, tem origem em um contexto mais amplo, no qual a sua ocorrência está determinada pelas condições socioeconômicas e culturais vigentes, além dos fatores biológicos. Mesmo diante das orientações da tomada de suplementos, muitas vezes não administram na dosagem certa e por tempo suficiente para resultar benefícios nos níveis de hemoglobina (AZEREDO et al., 2013).

De etiologia multifatorial, as causas podem ser absortivas, alimentares, distributivas ou metabólicas, aumento ou perdas das necessidades fisiológicas. Apesar de apresentar grande impacto clínico e ampla distribuição na população em geral, os dados epidemiológicos a respeito das causas da anemia ainda são inconsistentes (SOUZA et al., 2013).

As consequências à saúde das crianças com altas prevalências de anemia, sobretudo ao crescimento e desenvolvimento, tornam a doença um importante problema de saúde pública, com dificuldade de implementar medidas eficazes para o seu controle. Como já foi dito, sua etiologia envolve múltiplos fatores, como ambientais e culturais, socioeconômicos, nutricionais, biológicos e demanda ações que englobem aspectos pertinentes e relevantes no contexto da saúde pública (LEAL et al., 2011).

Diante desse contexto, o objetivo deste estudo foi avaliar crianças de uma creche municipal da cidade de Piancó - PB e verificar a incidência de anemias nesse grupo etário, conscientizando pais e/ou responsáveis sobre a importância do diagnóstico e a prevenção da anemia ferropriva.

\section{METODOLOGIA}

O presente estudo tratou de uma pesquisa Experimental quantitativa na Creche Municipal Cínicia Maria afim de se identificar a Incidência de anemia ferropriva, localizada na cidade de Piancó no Estado da Paraíba.

A população foi formada pelas crianças que frequentam uma creche municipal da cidade de Piancó no estado da Paraíba e a amostragem foi constituída pelas primeiras 11 crianças voluntárias, autorizadas pelos pais/responsáveis, que aceitaram fazer parte da pesquisa, considerando tal amostragem equivalente a $100 \%$ do total proposto.

Como critérios de inclusão dos voluntários na pesquisa foi necessário como pré-requisito, ser de ambos os sexos, estarem devidamente matriculados no ano letivo de 2015 e estarem compreendidos entre uma faixa etária de até 5 anos de idade, além de apresentarem baixas condições socioeconômicas e terem assinado o Termo de Consentimento Livre e Esclarecido - TCLE, enquanto que são utilizados como critérios de exclusão as crianças que não atenderam aos requisitos básicos para a pesquisa.

A coleta de dados se deu com a aplicação de questionários contendo 10 perguntas e realização de flebotomia em veia de fossa cubital nas crianças que aceitaram fazer parte da pesquisa, para obtenção de amostras de sangue e posterior realização de exames hematológicos de Hemograma e dosagens bioquímicas de ferro sérico. 
Inicialmente a coleta dos dados deu-se através de questionário sociocultural que continha de 10 questões relacionadas ao tema que foi aplicado juntamente aos pais ou responsáveis pelas crianças envolvidas na pesquisa. Posteriormente, foram coletados $10 \mathrm{~mL}$ de sangue através de punção venosa da veia de fossa cubital, com auxílio de uma seringa de $10 \mathrm{~mL}$ da marca BD .

Em seguida essa amostra de sangue foi distribuída da seguinte forma: $5 \mathrm{~mL}$ foram transferidos para um tubo contendo o anticoagulante etileno diamino Tetracético (EDTA) que foi homogeneizado para posterior realização do exame de Hemograma em um equipamento semi-automatizado da marca Sysmes®, modelo KX-21 e o restante $5 \mathrm{~mL}$ foram transferidos para um tubo seco sem anticoagulante, este tubo foi colocado no banho-maria da marca centribio ${ }^{\circledR}$ por um período de aproximadamente 20 minutos e em seguida passou por um processo de centrifugação por 10 minutos em uma rotação de $2.500 \mathrm{rpm}$ em uma centrífuga da marca centribio®. Em seguida foi alicotada uma amostra de 250 microlítros da amostra de soro que foi adicionada a $1 \mathrm{~mL}$ do reagente para dosagem de ferro sérico da marca Bioclin $®$, em seguida foi realizada uma homogeneização e o tubo foi deixado em banho maria por dois minutos, após este tempo amostra foi analisada com utilização de um equipamento de bioquímica semi-automatizado da marca Biosystems®, modelo BTS 350 .

Ao final das análises todas as amostras foram descartadas seguindo rigorosamente as normas de biossegurança.

\section{RESULTADOS E DISCUSSÃO}

Foram analisadas 11 amostras de sangue de crianças de uma creche da cidade de Piancó - PB, entre faixa etária até 05 anos de idade e questionário sociocultural aos pais ou responsáveis. Das amostras, 25\% apresentaram compatibilidade com anemia ferropriva.

Figura 1: Incidência de anemia ferropriva em crianças

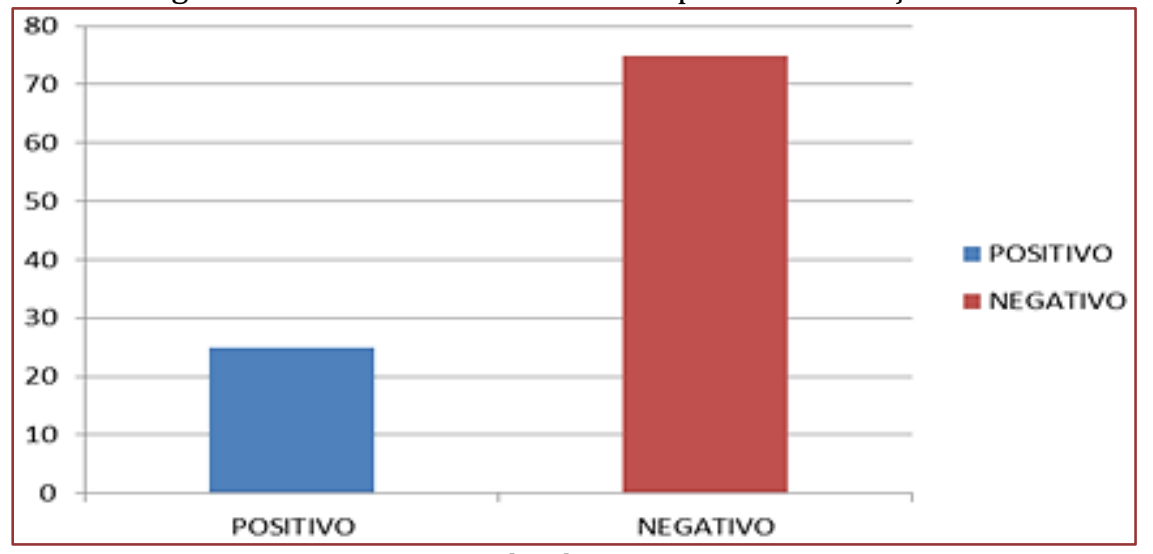

Fonte: Dados da pesquisa

Este estudo vai de encontro ao de Pinheiro et al (2008), que descreve que a análise dos dados por meios estatísticos permitiu observar uma prevalência de 31,73\% de anemia (hemoglobina <11g/dl) na população estudada.

De acordo com os estudos de Jordão et al (2009), o aumento da prevalência da anemia por deficiência de ferro em crianças pode ser decorrente das mudanças nos hábitos alimentares, que acompanham a transição nutricional no país, sendo que na Paraíba, a prevalência aumentou de 19,3\% para 36,4\%.

Foram analisados também os níveis de hemoglobina e índices hematimétricos das crianças no qual encontramos valores inferiores aos referenciais (Tabela 1). 
Tabela 1: Relação de alterações, de acordo com parâmetros adequados a crianças, encontrados nos exames de hemograma.

\begin{tabular}{|l|c|c|c|}
\hline \multirow{2}{*}{ Parâmetros (crianças) } & $\begin{array}{c}\text { Valor de } \\
\text { Referência }\end{array}$ & $\begin{array}{c}\text { Testes } \\
\text { normais }\end{array}$ & Testes alterados \\
\hline Hemoglobina & $12.0-18.0$ & 4 & 7 \\
\hline Hematócrito & $31-50$ & 3 & 8 \\
\hline VCM & $79-99$ & 3 & 8 \\
\hline HCM & $28-36$ & 3 & 8 \\
\hline CHCM & $32-36$ & 4 & 8 \\
\hline R.D.W & $12-15$ & 9 & 2 \\
\hline \multicolumn{4}{|c|}{ Fonte: Dados da Pesquisa }
\end{tabular}

A anemia ferropriva por ser de origem multifatorial, podendo ser absortivas, alimentares, distributivas ou metabólicas, aumento ou perdas das necessidades fisiológicas e estudo assemelha-se com os de Queiroz e Torres (2000) que diz que a doença se define como um processo patológico no qual a concentração de hemoglobina ( $\mathrm{Hb})$, contida nos glóbulos vermelhos, encontra-se baixa de forma anormal, respeitando-se as variações como idade, sexo, infecções crônicas, problemas hereditários sanguíneos, carência de nutrientes essenciais, necessários na formação da hemoglobina.

Corroborando também com Silveira, et al (2008) enfocando em seu estudo que das doenças nutricionais, a anemia é a mais prevalente em todo o mundo, especialmente a que tem por característica a deficiência de ferro, pois trata-se de um problema atual, que preocupa países ricos e pobres, em uma estimativa de que 2,15 bilhões de pessoas, quase $40 \%$ da população do mundo, apresentam níveis baixos de hemoglobina ou carência de ferro.

A figura abaixo mostra as alterações observadas na avaliação da série vermelha, durante a realização dos exames de hemograma das crianças.

Figura 2: Valores normais e alterados encontrados nos hemogramas das crianças avaliadas

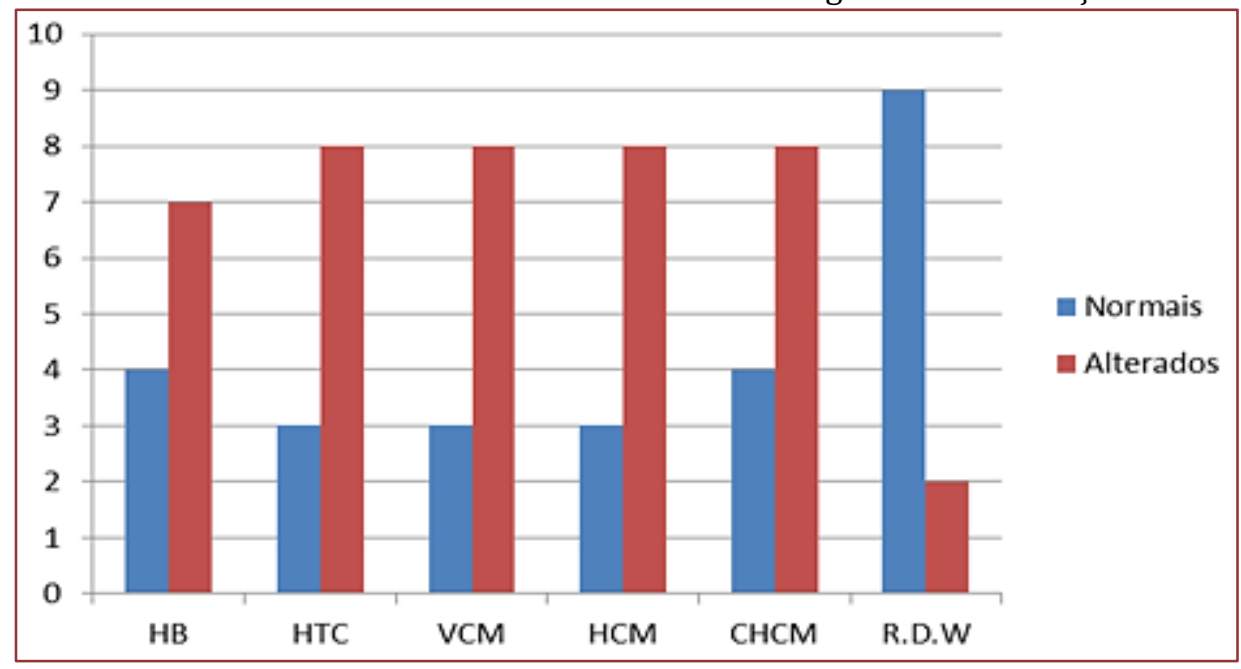

Fonte: Dados da Pesquisa

Neste estudo foram avaliados os índices hematimétricos (VCM, HCM, CHCM e R.D.W) e a ligação dos mesmos com a anemia. Segundo Barbosa et al (2006), o diagnóstico diferencial da anemia poderá ser realizado com exames clínicos e laboratoriais que incluam estes indicadores hematológicos: hemoglobina (HB), hematócrito (HTC) e hemácias (HE) e os indicadores hematimétricos: volume corpuscular médio (VCM), hemoglobina corpuscular média (HCM), concentração de hemoglobina corpuscular média (CHCM) e amplitude de distribuição dos eritrócitos (RDW).

No entanto, a concentração de hemoglobina é, nos dias de hoje, o índice mais utilizado como indicativo de consequências patológicas de anemia, mas segundo, ainda, Barbosa et al (2006), a concentração de HB não possui boa sensibilidade e especificidade para avaliar o estado nutricional do ferro, já que pode estar alterada em diversas outras condições patológicas como por exemplo, processos infecciosos e inflamatórios, hemorragia, desnutrição protéico-calórica, uso de medicamentos e tabagismo. 
O VCM também é um importante índice hematimétrico, onde diagnostica as hemácias em microcíticas, normocíticas e macrocíticas, observando sempre em conjunto com o R.D.W.

Em relação à dosagem de ferro sérico, observou-se que seis resultados, dentre as 11 amostras analisadas, apresentaram-se abaixo dos valores de referência, que está compreendido entre 100 a $250 \mathrm{mg} / \mathrm{dl}$ para recém-nascidos, 40 a 100 para lactentes e 50 a 120 para crianças de até 05 anos de idade. A tabela 2 mostra os resultados encontrados na dosagem de ferro sérico.

Tabela 2: Resultados encontrados nas dosagens de ferro sérico

\begin{tabular}{|c|c|c|}
\hline № de amostras & Resultados Normais & Resultados Alterados \\
\hline 11 & 05 & 06 \\
\hline \multicolumn{3}{|c}{ Fonte: Dados da Pesquisa } \\
\hline \multicolumn{3}{|c|}{}
\end{tabular}

Este estudo tem relação com os de Ferraz et al (2005), onde diz que foi considerada com carência de ferro toda criança de até 5 anos com níveis de hemoglobina < $11 \mathrm{~g} / \mathrm{dl}$. A carência de ferro, conforme as definições adotadas em seu estudo foi encontrada em $35,8 \%$, o que satisfaz a referente pesquisa em que $54,5 \%$ mostra-se positivo em relação a esta carência, desta forma, relatando uma alta prevalência da deficiência de ferro (Figura 3).

Figura 3: Compatibilidade de positividade e negatividade para a anemia ferropriva em relação as crianças da Creche Municipal, equivale a $100 \%$ das amostras utilizadas.

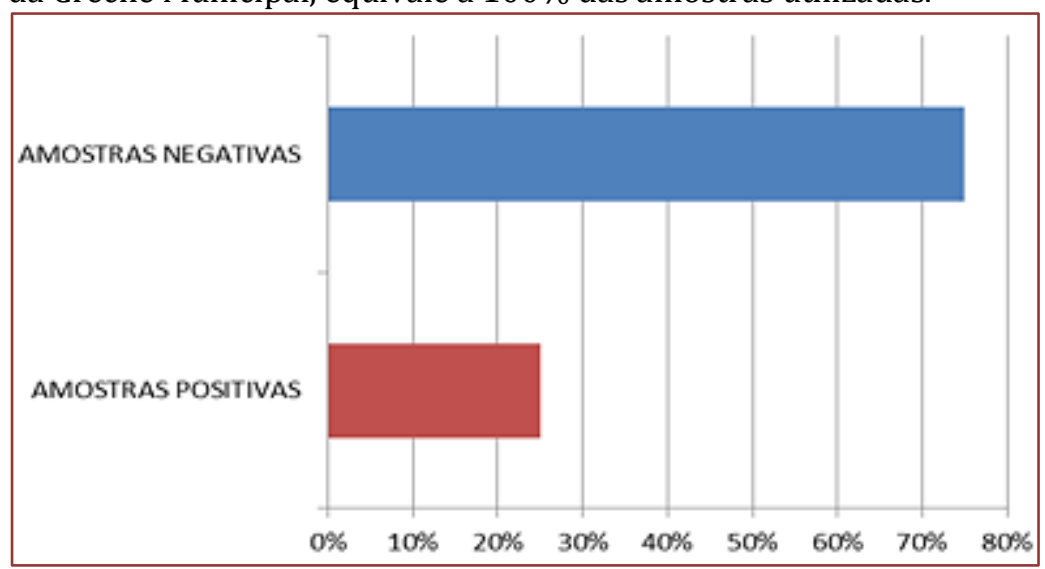

Fonte: Dados da Pesquisa

Apesar das amostras positivas compatíveis para anemia ferropriva ter sido encontrada no grupo de crianças, não se pode afirmar uma alta ou baixa prevalência da doença entre as crianças da creche municipal, devido ao pequeno número de amostras utilizadas na presente pesquisa, independente das baixas condições socioeconômicas das crianças. É importante lembrar que a negatividade para anemia observada, pode estar associada também ao mesmo fator.

\section{CONCLUSÃO}

Independente do resultado encontrado no presente estudo e da pouca quantidade de amostra na realização dos exames, é de extrema importância conscientizar os pais e familiares sobre o diagnostico precoce visando minimizar as consequências da doença, a melhoria da qualidade da alimentação e os cuidados com a criança. 0 exame clínico-laboratorial é um dos parâmetros mais comuns e eficientes na detecção da anemia ferropriva.

Diante da escassez da população referente à prevalência de anemia ferropriva, seria recomendável a replicação e ampliação de estudos dessa natureza, para uma avaliação adequada da magnitude do problema. Considerando também que a anemia é o distúrbio hematológico mais frequente, os profissionais de saúde devem estar sempre atentos para a ocorrência da deficiência de ferro nas crianças, sendo de fundamental importância a utilização de medidas preventivas, como uma dieta rica em ferro, vitamina B12 e ácido fólico. 
O estudo conclui então que se faz necessário e fundamental a implantação de relações socioeducativas, que conscientize a população sobre a anemia e o que pode-se trazer de consequência para a criança, auxiliando a melhorar a qualidade de vida dos alunos da Creche Municipal Cínica Maria e população em geral.

\section{AGRADECIMENTOS}

Agradeço a todos que contribuíram para a realização deste trabalho, de forma direta ou indireta. Aos responsáveis pelo local de estudo, aos pais por aceitarem que seus filhos fizessem parte desta pesquisa, aos funcionários do BIOLAB e em especial a minha Profa . Orientadora, a Msc. Alanna Michelly Batista de Morais, que foi peça fundamental na realização e conclusão deste trabalho, agradeço pelo crescimento profissional, pessoal, intelectual e por confiar na minha capacidade, por estar comigo em todos os momentos de dúvida e de glória. Sou eternamente grato por tudo que fez por mim. Muito obrigado.

\section{REFERÊNCIAS}

[1] AZEREDO, C.M., COTTA, R.M.M., SILVA, L.S., FRANCESCHINI, S.C.C., SANT'ANA, L.F.R., LAMOUNIER, J.A. 2013. "A problemática da adesão na prevenção da anemia ferropriva e suplementação com sais de ferro no município de Viçosa (MG)", Revista Ciência \& Saúde Coletiva, v. 3, pp. 827-836.

[2] JORDÃO, R.E., BERNARDI, J.L.D., FILHO, A.A.B. 2009. "Prevalência de anemia ferropriva no Brasil: uma revisão sistemática", Revista Paul Pediatra, pp. 27(1):90-8.

[3] LEAL, L.P., FILHO, M.B., LIRA, P.I.C., FIGUEIROA, J.N., OSÓRIO, M.M. 2011. "Prevalência da anemia e fatores associados em crianças de seis a 59 meses de Pernambuco”, Revista de Saúde Pública, v. 3, pp. 457-66.

[4] OLIVEIRA, A.P.D.N., PASCOAL, M.N., SANTOS, L.C., PEREIRA, S.C.L., JUSTINO, L.E.H., PETARLI, G.B., KITOKO, P.M. 2013. "Prevalência de anemia e sua associação com aspectos sociodemográficos e antropométricos em crianças de Vitória, Espírito Santo, Brasil”, Ciência \& Saúde Coletiva, v. 11, pp. 3273-3280.

[5] PINHEIRO, F.G.M.B., SANTOS, S.L.D.X., CAGLIARI, M.P.P., PAIVAS, A.A., QUEIROZ, M.S.R., CUNHA, M.A.L., JANEBRO, D.I. 2008. "Avaliação da anemia em crianças da cidade de Campina Grande, Paraíba, Brasil", Revista brasileira de hematologia e hemoterapia. pp. 30(6):457-462.

[6] SILVEIRA, S.V., ALBUQUERQUE, L.C., ROCHA, E.J.M., MARTINS, M.C.V. 2008. "Fatores de risco associados à anemia ferropriva em crianças de 12 a 36 meses de creches públicas em Fortaleza", Revista Pediatria, 9(2): 70-6, jul./dez.

[7] SOUZA, K.J., TABOX, V.F., OLIVEIRA, J.M.C., PIEREZAN, M.R., GIUFFRIDA, R., BRESSA, R.C., BRESSA, J.A.N. 2013. "Perfil epidemiológico da anemia ferropriva no serviço de hematologia de um hospital público, estado de São Paulo, Brasil”, Colloquium Vitae, pp. 18-28, 2013 DOI: 10.5747/ Colloquium vitae, n. 1, v. 1, pp. 18-28.

[8] VIEIRA, R.C., FERREIRA, H.S. 2010. "Prevalência de anemia em crianças brasileiras, segundo diferentes cenários epidemiológicos”, Revista de Nutrição, Campinas, v. 3, pp. 433-444. 


\section{Unidade III}

Bioproduto 


\title{
Capítulo 13
}

\section{Corante natural do pimentão vermelho: Obtenção e caracterização}

\author{
Plínio Tércio Medeiros de Azevedo \\ Yaroslávia Ferreira Paiva \\ Agda Malany Forte de Oliveira \\ Dayanne Kelly Pereira Abreu \\ Alfredina dos Santos Araújo
}

Resumo: 0 pimentão é considerado uma das hortaliças mais importantes em termos de produção e valor comercial, pois além de ser utilizado na sua forma in natura em saladas e em preparações culinárias, também é utilizado na fabricação de corantes naturais, condimentos, temperos, conservas e molhos. Como o uso dos corantes sintéticos levantam uma série de questionamentos com relação ao seu uso e malefícios causados na saúde dos consumidores, objetivou-se extrair o corante natural do pimentão vermelho e caracterizá-lo. Para tanto, o farelo do pimentão vermelho foi obtido através de secagem em estufa com circulação de ar e a partir dele, o corante foi extraído utilizando etanol 95\% (1:6), sendo submetido a redução do solvente através do rotaevaporador à temperatura de $60^{\circ} \mathrm{C}$ por cerca de 2 horas. Após extração, o mesmo e seu farelo foram caracterizados através de análises físico-químicas (acidez (\%), potencial hidrogeniônico $(\mathrm{pH})$, umidade $(\%)$ ), teores de compostos bioativos (flavonóides $(\mathrm{mg} / 100 \mathrm{~g})$, antocianinas $(\mathrm{mg} / 100 \mathrm{~g})$, carotenoides $(\mathrm{mg} / 100 \mathrm{~g})$, clorofila (mg/100g) e compostos fenólicos totais (mg/100g)) e condições microbiológicas (Coliformes à $45^{\circ} \mathrm{C}(\mathrm{NMP} / \mathrm{mL}$ ), Salmonella sp. (ausência/presença), Staphylococcus spp. (UFC/mL) e Contagem total de Bactérias Aeróbias Mesófilas (UFC/mL)). 0 farelo e 0 corante extraído do pimentão vermelho demonstraram um alto teor de compostos bioativos, além de excelentes condições microbiológicas, consequentemente, possibilitando a sua utilização em diversos produtos, nos mais diversos ramos da indústria alimentícia.

Palavras-chave: Capsicum annuum L, aditivos, pigmentos alimentares, compostos bioativos, extração alcoólica. 


\section{INTRODUÇÃO}

As pimentas e pimentões do gênero Capsicum são plantas condimentares, utilizadas pelos índios e por civilizações antigas para tornar os alimentos mais agradáveis ao paladar. Atualmente, além de condimentos também são utilizadas como conservantes em alimentos e são fontes de antioxidantes naturais como a vitamina E, vitamina C e carotenoides (REIFSCHNEIDER, 2000).

Pertencente à família Solanaceae, o pimentão vermelho (Capsicum annuum L.) (GOMES et al., 2014) apresenta a coloração verde-escura que durante os estágios de maturação passa pelas tonalidades amarela e vermelha (BARBOSA-SILVA, 2014). No Brasil e em alguns outros países, o pimentão vermelho é considerado um dos vegetais mais importantes em termos de volume de produção e valor comercial (GOMES et al., 2014).

Além de suas propriedades sensoriais, é uma excelente fonte de compostos bioativos, como os carotenoides (GOMES et al., 2014) que são pigmentos naturais que possuem papel muito importante na fisiologia dos vegetais, conferindo-lhes cor e participando da fotossíntese, conjuntamente com a clorofila (RODRIGUEZ-AMAYA et al., 2004).

Muitos dos carotenóides presentes nos vegetais apresentam atividades de pró-vitamina A e antioxidante. No pimentão o carotenoide predominante é a capsantina (carotenoide existe apenas no gênero Capsicum (JUNG et al., 2015), representando cerca de 50\% dos carotenoides totais, sendo responsável por conferir a coloração avermelhada ao produto (GOMES et al., 2014). Embora a capsantina não possua uma atividade provitamínica A, ela é classificada como um composto funcional devido a sua atividade antioxidante (GÓMEZ-GARCÍA; OCHOA-ALEJO, 2013), conferindo benefícios à saúde humana, atuando como antioxidante e removedor de radicais livres, o que pode reduzir o risco do desenvolvimento de diversos tipos de câncer (MARÍN et al., 2004; NAVARRO et al., 2006).

Além disso, alimentos vermelhos, possuem duas substâncias chamadas de licopeno e antocianina que protegem o coração, estimulam a circulação do sangue, diminuem o risco de alguns tipos de câncer (VARGAS, JIMENEZ, LOPEZ, 2000).

Segundo Casali e Stringheta (1984) outra propriedade importante dos pimentões é sua utilização como corante natural, já que as principais fontes para obtenção desses corantes são as plantas (folhas, flores e frutos) (MENDONÇA, 2011).

A utilização de corantes em alimentos desencadeia uma série de especulações sobre seus benefícios e malefícios à saúde humana (SOUZA et al., 2016). No passado, os corantes artificiais eram os principais agentes de coloração dos produtos industrializados. Nos últimos quinze anos, com base nos resultados de estudos toxicológicos, observa-se uma nova tendência no consumo desses, que vem ocasionando o uso de corantes naturais em substituição aos sintéticos em alimentos industrializados (SOUZA, 2012), pelos mesmos não acarretam lesões à saúde (GOMES, 2012), podendo inclusive possuir outras importantes propriedades, como atividade antioxidante e anti-inflamatória, relevantes tanto para o consumidor, quanto para a indústria, que poderá associar diversas vantagens aos seus produtos (SOUZA, 2012).

Diante do exposto, objetivou-se a obtenção do farelo e do corante natural do pimentão vermelho e sua caracterização.

\section{MATERIAL E MÉTODOS}

\subsection{OBTENÇÃO DA MATÉRIA-PRIMA}

O pimentão vermelho utilizado foi obtido no comércio da cidade de Pombal, Paraíba. Os frutos foram acondicionados em caixas isotérmicas e em seguida transportados para o Laboratório de Microbiologia de Alimentos e para o Laboratório de Química do Centro de Ciências e Tecnologia Agroalimentar (CCTA) da Universidade Federal de Campina Grande (UFCG) em Pombal-PB, onde foram realizados todos os procedimentos e análises que constam nessa pesquisa.

\subsection{OBTENÇÃO DO FARELO}

O fluxograma a seguir (Fig. 1) apresenta todo o procedimento adotado para obtenção do farelo do pimentão vermelho. 
Figura 5. Procedimentos realizados para obtenção do farelo do pimentão vermelho.

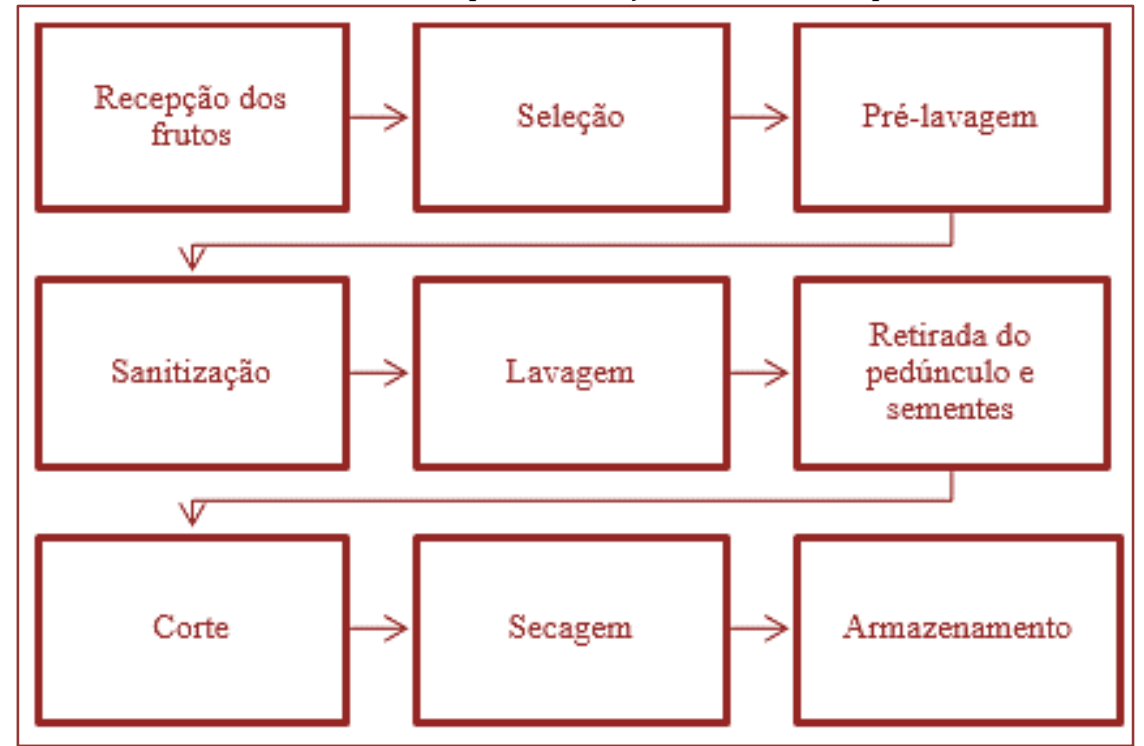

Após a chegada dos pimentões ao laboratório, os frutos foram selecionados de acordo com sua coloração, lavados em água corrente para retirar possíveis sujidades oriundas do campo, em seguida foram sanitizados por imersão com a utilização de hipoclorito de cloro na concentração de $200 \mathrm{ppm}$, por um período de 20 minutos. Posteriormente, foram lavados em água destilada em três repetições para retirar o resíduo do sanitizante. Os frutos seguiram para etapa de beneficiamento, onde inicialmente foi realizada a retirada dos pedúnculos e sementes, em seguida foram cortados em tiras de aproximadamente $2 \mathrm{~cm}$ de largura.

As amostras adquiridas foram submetidas a processos de secagem utilizando estufa microprocessada de circulação de ar a uma temperatura de $60^{\circ} \mathrm{C}$ nas primeiras duas horas e $55^{\circ} \mathrm{C}$ nas últimas 12 horas, conforme metodologia descrita por Spoto (2006).

Após a secagem, os pimentões foram moídos em moinho de facas com 4 lâminas de aço inoxidável e peneira de 10 mesh. 0 farelo produzido foi coletado em potes plásticos previamente esterilizados e armazenados em ambiente escuro e seco até o momento de execução das análises.

\subsection{OBTENÇÃO DO CORANTE}

As extrações foram realizadas na proporção de 1:6 (amostra:solvente) e o solvente utilizado foi o álcool etílico (95\%). As amostras foram homogeneizadas durante uma hora, sendo em seguida, filtradas em funil de Büchner com auxílio de uma bomba à vácuo. Posteriormente, o liquido proveniente da filtração foi submetido a extração por meio do equipamento Rotaevaporador à uma temperatura de $60^{\circ} \mathrm{C}$ por 2 horas. Os extratos obtidos foram coletados em recipientes de vidro envolvidos com papel alumínio para proteger da luz e estocado em refrigerador a uma temperatura de $-5^{\circ} \mathrm{C}$ (TORRES et al., 2002).

Para conseguir o máximo de corante, o álcool etílico recuperado durante a extração foi adicionado novamente na amostra residual para uma nova extração, onde foram submetidos aos mesmos procedimentos descritos anteriormente Silva et al. (2017).

\subsection{CARACTERIZAÇÃO DO FARELO E CORANTE}

\subsubsection{ANÁLISES FÍSICO-QUÍMICAS}

Foram avaliados os seguintes parâmetros: acidez (\%), potencial hidrogeniônico (pH), umidade (\%), sendo para tal utilizadas as metodologias descritas por IAL (2008). 


\subsubsection{COMPOSTOS BIOATIVOS}

Os parâmetros de flavonóides $(\mathrm{mg} / 100 \mathrm{~g})$ e antocianinas $(\mathrm{mg} / 100 \mathrm{~g})$ foram determinados pelo método de Francis (1982), carotenoides $(\mathrm{mg} / 100 \mathrm{~g})$ e clorofila $(\mathrm{mg} / 100 \mathrm{~g})$ utilizando metodologia de Lichthenthaler (1987). 0 conteúdo de compostos fenólicos totais $(\mathrm{mg} / 100 \mathrm{~g})$ foi avaliado de acordo com o método de Folin-Ciocalteu, descrito por Waterhouse (2006).

\subsubsection{ANÁLISE MICROBIOLÓGICA}

Foram submetidos à determinação dos parâmetros de Coliformes à $45^{\circ} \mathrm{C}(\mathrm{NMP} / \mathrm{mL})$, Salmonella sp. (ausência/presença), Staphylococcus spp. (UFC/mL) e Contagem total de Bactérias Aeróbias Mesófilas (UFC/mL) utilizando metodologia descrita por Silva et al. (2010).

\section{RESULTADOS E DISCUSSÃO}

A Tabela 1 apresenta os resultados médios obtidos para os parâmetros avaliados, em relação ao Farelo de Pimentão vermelho e seu corante.

Tabela 1. Parâmetros físico-químicos do farelo do Pimentão vermelho e seu corante.

\begin{tabular}{|l|c|c|}
\multicolumn{1}{|c|}{ Parâmetros } & Farelo & Corante \\
\hline $\mathrm{pH}$ & $5,60 \pm 0,29$ & $4,03 \pm 0,09$ \\
\hline Acidez (\%) & $3,24 \pm 0,02$ & $6,57 \pm 0,28$ \\
\hline Umidade (\%) & $5,82 \pm 0,14$ & $88,49 \pm 0,77$ \\
\hline Flavonóides (mg/100g) & $179,3 \pm 0,15$ & $119,75 \pm 0,31$ \\
\hline Antocianinas (mg/100g) & $17,68 \pm 0,22$ & $13,0 \pm 0,42$ \\
\hline Carotenóides (mg/100g) & $13,20 \pm 0,44$ & $6,46 \pm 0,26$ \\
\hline Clorofilas (mg/100g) & $4,17 \pm 0,50$ & $1,26 \pm 0,39$ \\
\hline Compostos fenólicos (mg/100g) & $2495,68 \pm 0,26$ & $2321,88 \pm 0,33$ \\
\hline
\end{tabular}

Em relação ao parâmetro $\mathrm{pH}$, percebe-se uma redução no corante $(4,03)$ quando comparado ao farelo $(5,60)$. Valores diferentes foram encontrados por Arlindo, Queiroz e Figueiredo (2007), quando obtiveram índices que variaram de 4,82 a 4,88 em pimentões em pó. Tais valores podem ser explicados pela variedade em questão, grau de maturação, entre outros fatores. Quando se trata de corante, os resultados obtidos por Silva (2017) e Paiva et al (2018) corroboram com os da presente pesquisa, onde obtiveram valores de 3,97 e 3,47 respectivamente em corante da pimenta biquinho.

0 valor de acidez obteve uma média de 3,24 para o farelo e 6,57 para o corante, podendo ser explicado pela concentração de ácidos orgânicos carregados pelo solvente utilizado, consequentemente fazendo com que houvesse esse aumento na acidez do corante. Resultados semelhantes ao do farelo foram encontrados em pimentões em pó, com uma acidez que variou de 3,2 a 3,63 Arlindo, Queiroz e Figueiredo (2007). Quanto ao corante, Silva (2017) e Paiva et al (2018) obtiveram uma acidez relativamente menor em $(2,23$ e 3,07, respectivamente) em corantes extraído da pimenta biquinho.

Para o parâmetro de umidade, o farelo apresentou uma média de 5,84 \%, onde já era esperado devido o uso da secagem. 0 corante teve uma média de $88,49 \%$, apresentando um aumento da umidade devido o solvente utilizado para a extração do mesmo.

Elevados teores de flavonoides foram apresentados pelas amostras $(179,3 \mathrm{mg} / 100 \mathrm{~g}$ para o farelo e 119,75 $\mathrm{mg} / 100 \mathrm{~g}$ para o corante), demonstrando que o processo de extração ocorreu de forma eficiente, extraindo o máximo deste componente. Estudos realizados por Silva et al (2017) e Paiva et al (2018) corroboram com os níveis apresentados, onde obtiveram uma média de 183,07 mg/100g para o farelo e 105,38 $\mathrm{mg} / 100 \mathrm{~g}$ para o corante, ambos da pimenta Biquinho.

Para o parâmetro de antocianinas, o presente estudo apresentou valores de 17,68 mg/100g para o farelo e $13 \mathrm{mg} / 100 \mathrm{~g}$ para o corante, estes resultados são relevantes quando comparados a pesquisa realizada por Padilha et al (2014) quando analisou 30 acessos de pimentas in natura do banco ativo da EMBRAPA, onde suas amostras variaram de $0,15 \mathrm{mg} / 100 \mathrm{~g}$ a $4,92 \mathrm{mg} / 100 \mathrm{~g}$, sendo considerados baixos quando comparados ao presente estudo. 
Estudos realizados por Carneiro (2011) corroboram com o presente trabalho, onde variaram de 4,92 $\mathrm{mg} / 100 \mathrm{~g}$ a $17,9 \mathrm{mg} / 100 \mathrm{~g}$ quando analisou o teor de antocianinas em pimenta Cambuci.

Os teores de carotenoides apresentaram um valor médio de $13,20 \mathrm{mg} / 100 \mathrm{~g}$ para o farelo do pimentão vermelho e $6,46 \mathrm{mg} / 100 \mathrm{~g}$ para o corante, este resultado pode ser considerado alto quando comparado ao estudo realizado por Dambros (2014), que obteve médias que variaram de 0,64 a 40,26 mg/100g em frutos de pimenta. Segundo (KALT, 2005), tal variação pode ser explicada pelo genótipo, da espécie, grau de maturação, das condições de cultivo e do armazenamento.

Os teores de clorofila apresentaram uma média de 4,17 e $1,26 \mathrm{mg} / 100 \mathrm{~g}$, para o farelo e corante respectivamente, apresentando resultados já esperado devido a coloração vermelha intensa encontrada no seu último estádio de maturação, porém, foram valores altos quando comparados aos resultados encontrados por Soethe (2013), que obteve no seu estudo teores que variaram de 0,53 a 0,59 $\mathrm{mg} / 100 \mathrm{~g}$ de clorofila em pimentas de moça no final do seu estádio de maturação. Valores inferiores foram encontrados por Silva et al (2017), apresentando um valor médio de 1,5 mg/100g para clorofilas no farelo de pimenta biquinho.

A composição de compostos fenólicos do presente estudo foi considerado alto, podendo ser percebido um alto índice destes componentes, demonstrando o quanto eficiente foi a extração deste componente pelo solvente utilizado, apresentando médias de 2495,68 e 2321,88 EAG/100g para o farelo e corante respectivamente, demonstrando resultados satisfatórios quando comparados ao estudo realizado por Melo et al (2011) que analisaram amostras de pimentas do tipo malagueta, cumari e pimenta de bode, onde apresentaram valores de 1328,28 EAG/100g, 347,12 EAG/100g e 294,00 EAG/100g respectivamente.

Valores semelhantes foram encontrados por Silva et al (2017) quando avaliou a potencialidade da pimenta biquinho como aditivo natural, apresentando um valor médio de 2442, 99 EAG/100g para farelo de pimentas.

0 corante foi submetido a análises de Coliformes à $45^{\circ} \mathrm{C}(\mathrm{NMP} / \mathrm{mL})$, Staphylococcus spp. (UFC $\left./ \mathrm{mL}\right)$, Salmonella sp. (ausência/presença) e Contagem Total de Bactérias Aeróbias Psicotróficas (UFC/mL), onde foi verificado ausência em todos os parâmetros analisados, consequentemente, estando em satisfatórias condições sanitárias para o consumo humano.

\section{CONCLUSÃO}

O farelo e o corante extraído do pimentão vermelho demonstraram um alto teor de compostos bioativos, além de excelentes condições microbiológicas, consequentemente, possibilitando a sua utilização em diversos produtos, nos mais diversos ramos da indústria alimentícia.

\section{AGRADECIMENTOS}

Ao programa CNPq/PIBIC pelo financiamento do projeto de pesquisa, à UFCG pela concessão da bolsa de Iniciação Científica e aos colaboradores pelo apoio durante a execução do trabalho.

\section{REFERÊNCIAS}

[1] ARLINDO, D. M., QUEIROZ, A. D. M., \& FIGUEIREDO, R. D. Armazenamento de pimentão em pó em embalagem de polietileno. Revista Brasileira de Produtos Agroindustriais, v. 9, p. 111-118, 2007.

[2] BARBOSA-SILVA, M. Uso de água residuária, substrato e adubo orgânico na produção e qualidade de pimentão em ambiente protegido. 2014. 78 fls. Dissertação (Mestrado em Engenharia Agricola). Unidade Universitária de Ciências Exatas e Tecnológicas. Universidade Estadual de Goias, Anapolis/GO: 2014.

[3] CARNEIRO, G. G. Elaboração de geleia de pimenta da variedade Cambuci em diferentes estádios de maturação e concentração de sacarose. Dissertação. Mestrado em Engenharia Agrícola. Universidade Federal de Campina Grande. Campina Grande, PB. 2011.

[4] CASALI, V. W. D.; STRINGHETA, P. C. Melhoramento do pimentão e pimenta para fins industriais. Informe Agropecuário, v.10, p. 23-25, 1984.

[5] DAMBROS, J. I. Estabilidade de compostos potencialmente bioativos e alterações de qualidade em frutos e produtos de pimenta (Capsicum spp.). 2014. 113f. Dissertação (Mestrado em Ciência e Tecnologia de 
[7] FRANCIS, F. J. Analysis of anthocyanins in foods. In: Markakis P, Anthocyanins as Food Colors. New York, Academic Press, p. 181-207. 1982.

[8] GOMES, L,M,M. Inclusão de Carotenoides de Pimentão Vermelho em Ciclodextrinas e Avaliação da Sua Estabilidade, Visando Aplicação Em Alimentos. 2012. 108p. 2012. Tese de Doutorado. Dissertação (Mestre em Ciências Aplicadas), Faculdade de Farmácia, Universidade Federal Fluminense, Niterói, 2012.

[9] GOMES, L.M.M.; PETITO, N.; COSTA, V.G.; FALCAO, D.Q.; ARAUJO, K.G.L. Inclusion complexes of red bell pepper pigments with b-cyclodextrin: Preparation, characterisation and application as natural colorant in yogurt. Food Chemistry. v.148. p.428-436. 2014.

[10] GOMEZ-GARCIA, M.R.; OCHOA-ALEJO, N. Biochemistry and molecular biology of carotenoid biosynthesis in Chili Peppers (Capsicum spp.). International Journal of Molecular Science. v.14. n.9. 2013.

[11] INSTITUTO ADOLFO LUTZ. Métodos físico-químicos para análise de alimentos. 4 ed, São Paulo: Instituto Adolfo Lutz, p. 1020, 2008.

[12] JUNG, K.; SONG, B.S.; KIM, M.J.; MOON, B.G.; GO, S.M.; KIM, J.K.; LEE, Y.J.; PARK, J. H. Effect of X-ray, gamma ray, and electron beam irradiation on the hygienic and physicochemical qualities of red pepper powder. Food Science and Technology. p.1-6. 2015.

[13] KALT, W. Effects of production and processing factors on major fruit and vegetable antioxidants. Journal of Food Science, v. 70, n. 1, p. 11-19, 2005.

[14] LICHTENTHALER, H.K. Chlorophylls and carotenoids: pigment photosynthetic biomembranes. Methods in Enzymology, New York v.148, p.362-385, 1987.

[15] MARÍN, A.; FERRERES, F.; TOMÁS-BARBERÁN, F. A.; GIL, M. I. Characterization and quantitation of antioxidant constituents of sweet pepper (Capsicum annuum L.). Journal of Agriculture and Food Chemistry, Davis, v. 52, n. 12, p. 3861-3869, 2004.

[16] MELO, C. M. T.; COSTA, L. A.; BONNAS, D. S.; CHANG, R. Compostos fenólicos e capacidade antioxidante de pimentas Capsicum chinense (bode), Capsicum baccatum variedade praetermissum (cumari) e Capsicum frutescens (malagueta). Enciclopédia Biosfera, Centro Científico Conhecer - Goiânia, vol.7, N.12; 2011.

[17] MENDONÇA, J. N. Identificação e isolamento de corantes naturais produzidos por actinobactérias. 2011. $121 \mathrm{f}$. Dissertação (Mestrado em Ciências) - Faculdade de Filosofia, Ciências e Letras, Universidade de São Paulo. Ribeirão Preto, SP. 2011.

[18] NAVARRO, J.; FLORES, P.; GARRIDO, C.; MARTINEZ, V. Changes in the contents of antioxidant Compounds in pepper fruits at different ripening stages, as affected by salinity. Food Chemistry, London, v. 96, n. 1, p. 66-73, 2006.

[19] PADILHA, H. K. M.; PEREIRA, E. S.; MUNHOZ, P. C.; VIZZOTO, M.; BARBIERI, R. L. Teor de antocianinas em acessos de pimentas. In: III Congresso Brasileiro de Recursos Genéticos. Santos, SP, 2014.

[20] PAIVA, Y. F.; SILVA, E. V.; ALENCAR, F. S. N. M; AZEVEDO, P. T. M; ARAÚJO, A. S. Corante natural extraído da pimenta 'biquinho' (capsicum chinense). ONE, G. M. C.; PORTO, M. L S.; In: Saúde os desafios do mundo contemporâneo 1. ed. João Pessoa: IMEA, 2018. cap. 48, p. 944-962.

[21] REIFSCHNEIDER, F. I. B. Capsicum pimentas e pimentões do Brasil. Brasília: EMPRAPA. Comunicações para Transferência de Tecnologia, 106 p. 2000.

[22] RODRIGUEZ-AMAYA DB, KIMURA M. Harvestplus handbook for Carotenoid analysis. Washington: International Food Policy Research Institute; 2000.

[23] SILVA, E. V. Potencialidades da pimenta biquinho (Capsicum chinense) como aditivo natural. 2017. $170 \mathrm{f}$. Tese (Doutorado) - Curso de Química, Departamento de Química, Universidade Federal da Paraíba, João Pessoa, 2017.

[24] SILVA, E. V.; CONCEIÇÃO, M. M.; CARVALHO FILHO, J. R.; ARAÚJO, A. S.; PAIVA, Y. F.; LOPES, M. F.; MELO, M. A. R. Teor de pigmentos alimentares e capacidade antioxidante de corante natural obtido da pimenta biquinho. Revista de Química Industrial Ano 85 № 754 1o trimestre de 2017 Edição Eletrônica 12, 2017.

[25] SILVA, N. da; JUNQUEIRA, V.; SILVEIRA, N. F. A.; TANIWAKI, M. H.; SANTOS, R. F. S. dos, GOMES, R. A. R. Manual de métodos de análise microbiológica de alimentos e água. 4 edição. São Paulo: Livraria Varela, 614p, 2010.

[26] SOETHE, C. Caracterização físico-química e de compostos funcionais de pimenta dedo-de-moça 'BRS Mari' em função do estádio de maturação e tempo de armazenamento. 2013. 54f. Dissertação. Mestrado em Produção Vegetal. Universidade do Estado de Santa Catarina. 2013.

[27] SOUZA, D. R., DE MIRANDA, J. A., RIBEIRO, K. R., MAPELI, A. M., \& SANTOS, D. D. J. Degradação Fotocatalítica de Corante Alimentício Azorrubina e Monitoramento de Redução de Toxicidade. Orbital-The Electronic Journal of Chemistry, v. 1, n. 1, p. 50-56, 2016. 
[28] SOUZA, R. M. Corantes naturais alimentícios e seus benefícios à saúde. Trabalho de Conclusão do Curso de Graduação em Farmácia, Centro Universitário Estadual da Zona Oeste. Rio de Janeiro, 2012.

[29] SPOTO, M. A, B. R.; OETTERER, M.; REGITANO-D’ARCE, M. A. B. Fundamentos de ciência e tecnologia de alimento. III. Título. Barueri, SP : Manole, 2006.

[30] TORRES, D.E.G.; MANCINI, D.A.P.; TORRES, R.P.; MANCINI- FILHO, J. Antioxidant activity of macambo (Theobroma bicolor L.) extracts. Eur. J. Lipid Sci. Technol., v. 104, p. 278- 281, 2002.

[31] VARGAS, F., JIMENEZ, A. R., PARADE LOPEZ, O.; Natural pigments: carotenoids, anthocyanins, and betalains-characteristics, biosynthesis, processing, and stability; Crit. Rev. Food Scienc Nutri. V. 40, 2000.

[32] WATERHOUSE, A. Folin-ciocalteau micro method for total phenol in wine. American Journal of Enology and Viticulture, p.3-5, 2006.

\section{RESPONSABILIDADE AUTORAL}

Os autores são os únicos responsáveis pelo conteúdo deste trabalho. 


\section{Capítulo 14}

Qualidade físico-química e compostos bioativos no pimentão vermelho

\section{Tatiana Marinho Gadelha \\ Ana Marinho do Nascimento \\ Jéssica Leite da Silva, \\ Charlene Maria Alcântara \\ Larissa Félix Macêdo \\ Franciscleudo Bezerra da Costa}

Resumo: 0 pimentão é uma hortaliça de valor econômico rica em nutrientes. Diante disso, objetivou-se avaliar as características físico-químicas e os compostos bioativos de pimentão vermelho. 0 experimento foi conduzido no Laboratório de Química, Bioquímica e Análise de Alimentos, do Centro de Ciências e Tecnologia Agroalimentar, da Universidade Federal de Campina Grande, Campus de Pombal. Os frutos de pimentões foram selecionados, lavados e sanitizados, cortados, triturados em liquidificador e acondicionados em recipientes plásticos. As características físicas-químicas avaliadas foram atividade de água, pH, concentração de íons hidrogênio, sólidos solúveis, acidez titulável, razão sólidos solúveis e acidez titulável; nos compostos bioativos foram avaliados os teores de ácido ascórbico, carotenoides, flavonoides, antocianinas e compostos fenólicos. Os coeficientes de correlação de Pearson foram determinados entre as características estudadas. A luminosidade do pimentão vermelho apresentou boa aparência, sendo o valor de 14,1. Os resultados expressos para a intensidade de a* $^{*}$ foi de 8,1 e o valor apresentado em $b^{*}$ foi de 9,5. 0 estudo indicou que o pimentão vermelho possui altos teores de fitoquímicos. Houve correlações significativas entre os resultados avaliados. 0 pimentão vermelho é um o fruto rico em ácido ascórbico e compostos fenólicos, sendo o consumo dessa hortaliça importante para inibir a ação dos radicais livres prevenindo doenças.

Palavras-chave: Antioxidante, Capsicum annuum L., polifenóis. 


\section{INTRODUÇÃO}

O pimentão vermelho (Capsicum annuum L) é uma espécie arbustiva, semiperene originária da América Latina, que pertencente à família Solanaceae. É uma planta que apresenta folhas de coloração verde-escura e formato oval-lanceolado (PIMENTEL et al., 2019). A Embrapa é a grande responsável pelo programa de melhoramento do genético Capsicum, atuando no desenvolvimento de populações, linhagens e cultivares com resistência a doenças (BÜTTOW et al., 2010).

O Brasil possui uma grande variabilidade de pimentões que possuem diferentes formatos, tamanhos e cores provenientes da domesticação e do melhoramento genético (SANTOS et al., 2013). São comercializados grupos de pimentões com diferentes tamanhos, formatos e cores, os principais são: cônico, blocky, retangular e quadrado. Entretanto, no comércio brasileiro prevalece o consumo do pimentão cônico, tendo em vista que a sua produção é menos exigente (MATOS et al., 2012).

O pimentão possui um elevado valor econômico e está entre as dez hortaliças de maior cultivo no Brasil, tendo em vista que à localização geográfica e o clima que favorece a produção (FERREIRA et al., 2013; LEME, 2012). É uma hortaliça que produz frutos com variação estacional de oferta e preço o ano todo. Para aprimorar a qualidade e aumentar a produção, grande parte dos produtores tem cultivado o pimentão em ambiente protegido, principalmente nas regiões Sul e Sudeste (OLIVEIRA et al., 2009).

Os pimentões no estádio vermelho são encontrados facilmente no comércio, essa variedade é bem valorizada devido ao aroma e sabor característico que fornecem aos alimentos. As cores dessa hortaliça sofrem modificações, os frutos quando imaturo apresentam a cor verde e após completar a maturação tornam-se vermelhos. A faixa de cores apresentadas de cada variedade do gênero Capsicum está relacionada com a capacidade que os frutos têm em sintetizar os carotenoides e de reter pigmentos de clorofilas (COLLERA-ZUÑIGA et al., 2005).

Os compostos bioativos são nutrientes presentes em frutos que contém ação metabólica específica. Entre esses compostos estão os carotenoides, os fitoesteróis, os flavonoides e os polifenóis (BRASIL, 2013). Esses elementos possuem capacidade antioxidante, propriedade importante para a prevenção de processos degenerativos associados aos radicais livres presentes no organismo (CANUTO et al., 2010). Diante do exposto, objetivou-se determinar as características físico-químicas e os compostos bioativos de pimentão vermelho.

\section{MATERIAL E MÉTODOS}

Foram utilizados pimentões vermelho provenientes do Centro Econômico de Abastecimento Sociedade Anônima (CEASA), localizada na cidade de Patos-PB. Os pimentões foram acondicionados em caixas de papelão e transportados para o Laboratório de Química Bioquímica e Análise de Alimentos da Universidade Federal de Campina Grande, Campus Pombal (Figura 1A).

Figura 1. Fluxograma de obtenção de amostras do pimentão (Capsicum annuum. L) vermelho.

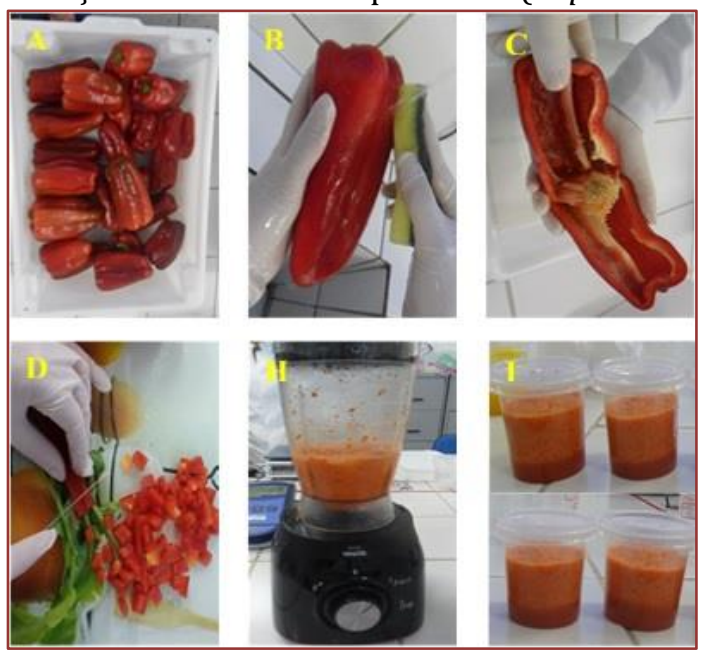


Os mesmos foram lavados em água corrente para retirada de surgidades superficiais (Figura 1B). Logo após, os pimentões foram cortados com facas de aço inoxidável eliminando pedúnculos e sementes (Figura 1C). Para a obtenção dos extratos in natura os pimentões foram cortados (Figura 1D), desintegrados em liquidificador (Figura 1E) e acondicionados em recipientes plásticos, rotulados, envolvidos em papel alumínio e movidos para análises (Figura 1I).

\subsection{ANÁLISE DE COR}

As amostras foram determinadas no sistema CIELAB utilizando-se um colorímetro Konica Minolta, modelo CR 300 Tokyo, foi analisado 5 parâmetros de coloração: luminosidade ( $\mathrm{L}^{*}$ ) eixo principal (preto = 0 ao branco $=100)$, intensidade de $\left(a^{*}\right)$ que corresponde do verde $(-)$ ao vermelho $(+)$, intensidade de $\left(b^{*}\right)$ que corresponde do azul (-) ao amarelo (+), cromaticidade (C) que é a saturação definida pela distância radial do centro do espaço até o ponto da cor e o Ângulo Hue $\left(\mathrm{h}^{\circ}\right)$ que é considerado o atributo qualitativo de cor com as cores definidas tradicionalmente como avermelhada e esverdeada. As leituras dos valores foram feitas em locais diferentes, totalizando 3 leituras por repetição. Após as leituras calculou-se o índice de cor (IC), que indica o grau de variação verde ao amarelo das amostras (FERREIRA; SPRICIGO, 2017).

\subsection{ATIVIDADE DE ÁGUA}

A determinação de atividade de água foi realizada usando hidrômetro de ponto de orvalho AquaLab, decagom, modelo 3T, fabricado por decagon Devices. Foi colocado uma quantidade suficiente para cobrir o fundo da capsula, posteriormente a amostra foi colocada diretamente no equipamento à temperatura de $25^{\circ} \mathrm{C}$, sendo a atividade de água expressa em porcentagem de água livre presente.

\subsection{POTENCIAL HIDROGENIÔNICO}

As amostras foram homogeneizadas e determinadas em potenciômetro digital de bancada, modelo DM-22, conforme as normas Analíticas do Instituto Adolfo Lutz (2008). Os resultados também foram expressos em concentração de íons $\mathrm{H}^{+}$(? $\mathrm{M}$ ).

\subsection{SÓLIDOS SOLÚVEIS}

As amostras foram homogeneizadas e filtradas em camada de algodão, o teor de sólidos solúveis foi determinado em refratômetro digital modelo Reichert AR-200, com compensação automática de temperatura. 0 valor foi expresso em percentagem de sólidos solúveis, conforme as normas Analíticas do Instituto Adolfo Lutz (2008).

\subsection{ACIDEZ TITULÁVEL}

0 teor de acidez foi determinado segundo as normas Analíticas do Instituto Adolfo Lutz (2008). Um grama das amostras foi pesado e transferido para erlenmeyer contendo $49 \mathrm{~mL}$ de água destilada, posteriormente, adicionou-se 2 gotas de fenolftaleína e titulou-se contra a solução de hidróxido de sódio a 0,1 M até pH 8,1. Para o cálculo da acidez foi considerado o fator do ácido equivalente, sendo o resultado foi expresso em percentagem.

\subsection{RATIO}

Os valores do ratio foram obtidos através da divisão dos teores de sólidos solúveis pelos o da acidez titulável.

\section{7 ÁCIDO ASCÓRBICO}

Os teores de ácido ascórbico foram determinados segundo as normas Analíticas do Instituto Adolfo Lutz (2008). Um grama das amostras foi pesado e transferido para erlenmeyer contendo $49 \mathrm{~mL}$ de ácido 
oxálico 0,5\% gelado, posteriormente titulou-se contra a solução de Tillmans: 2,6 Diclorofenol Indofenol (DFI) até o ponto de viragem. Os resultados foram expressos em $\mathrm{mg} 100 \mathrm{~g}^{-1} \mathrm{de}$ ácido ascórbico.

\subsection{CAROTENOIDES}

Foram determinados de acordo com o método de Lichtenthaler (1987). Foram pesados 1,0 g das amostras e maceradas em almofariz com $0,2 \mathrm{~g}$ de carbonato de cálcio e $5 \mathrm{~mL}$ de acetona a $80 \%$. 0 extrato foi transferido para tubos falcon e centrifugados a $10{ }^{\circ} \mathrm{C}$ e $3.000 \mathrm{rpm}$ por 10 minutos. Alíquotas dos sobrenadantes foram colocados em cubeta e as leituras realizadas em espectrofotômetro nas absorbâncias de 470, 646 e $663 \mathrm{~nm}$. Todos os procedimentos foram realizados em ambiente escuro e os resultados expressos em mg $100 \mathrm{~g}^{-1}$.

\subsection{FLAVONOIDES}

Foram quantificados de acordo com o método de Francis (1982). Foram pesados 1,0 g das amostras e maceradas em almofariz com $10 \mathrm{~mL}$ de etanol: HCL. Os extratos foram transferidos para tubos falcon e deixados na geladeira por 24 horas. No dia seguinte, os extratos foram centrifugados a $10{ }^{\circ} \mathrm{C}$ e $3.000 \mathrm{rpm}$ por 10 minutos. Alíquotas dos sobrenadantes foram colocadas em cubeta e as leituras realizadas em espectrofotômetro nas absorbâncias de $374 \mathrm{~nm}$. Todos os procedimentos foram realizados em ambiente escuro e os resultados expressos em mg $100 \mathrm{~g}^{-1}$.

\subsection{ANTOCIANINAS}

Foram pesados 1,0 g das amostras e maceradas em almofariz com $10 \mathrm{~mL}$ de etanol: HCL. Os extratos foram transferidos para tubos falcon e deixados na geladeira por 24 horas. No dia seguinte, os extratos foram centrifugados a $10{ }^{\circ} \mathrm{C}$ e $3.000 \mathrm{rpm}$ por 10 minutos. Alíquotas dos sobrenadantes foram colocadas em cubeta e as leituras realizadas em espectrofotômetro nas absorbâncias $535 \mathrm{~nm}$. Os procedimentos foram determinados conforme método de Francis (1982) e os resultados expressos em mg $100 \mathrm{~g}^{-1}$.

\subsection{COMPOSTOS FENÓLICOS}

A análise foi realizada conforme o método descrito por Waterhouse (2006). Foram pesados 1,0 g das amostras e maceradas em almofariz e diluídas em $50 \mathrm{~mL}$ de água destilada, logo após, foram deixadas em repouso por 30 minutos. Alíquotas dos extratos foram transferidas para tubos de ensaio, onde foram adicionados de água e Folin ciocalteau. As misturas permaneceram em repouso por 5 minutos e logo após, foi adicionado o carbonato de sódio a $20 \%$, seguida de agitação e repouso em banho-maria a $40{ }^{\circ} \mathrm{C}$, por 30 minutos. A curva padrão foi preparada com ácido gálico e as leituras realizadas em espectrofotômetro a $765 \mathrm{~nm}$. Os valores de polifenóis foram expressos em mg $100 \mathrm{~g}^{-1}$.

\subsection{CORRELAÇÃO DE PEARSON}

Os coeficientes de correlação de Pearson foram determinados entre a coloração, características físicoquímica e compostos bioativos a partir do software Microsoft Excel 2013.

\section{RESULTADOS E DISCUSSÃO}

A luminosidade $L^{*}$ do pimentão vermelho apresentou boa aparência, visto que essa coordenada está relacionada com a variação de escuro quanto está próximo a zero e claro quando se aproxima a 100, sendo o valor encontrado de 14,1 "Tab. 1". Brackmann et al. (2005) ao estudarem sobre a indução da cor vermelha em pimentões, indicaram uma luminosidade de 13 a 20, estando o resultado expresso neste trabalho na faixa indicada pelos autores. 
Tabela 1. Coloração de pimentão (Capsicum annuum. L) vermelho

\begin{tabular}{|c|c|}
\hline VARIÁVEIS & MÉDIAS \\
\hline Luminosidade ( $\mathrm{L}^{*}$ ) & $14,1 \pm 1,5$ \\
\hline Intensidade (a*) & $8,1 \pm 1,0$ \\
\hline Intensidade (b*) & $9,5 \pm 1,5$ \\
\hline Cromaticidade (C) & $12,5 \pm 1,7$ \\
\hline Ângulo Hue $\left(\mathrm{H}^{\circ}\right)$ & $49,6 \pm 4,6$ \\
\hline Índice de cor (IC) & $9,3 \pm 1,3$ \\
\hline
\end{tabular}

\pm Desvio padrão das médias

Os resultados expressos para a intensidade de $a^{*}$ foi de 8,1 (Tabela 1). Esse comportamento já era esperado, tendo em vista que os valores de (+a) corresponde cor a vermelha dos frutos. No entanto, o valor apresentado pela na intensidade $b^{*}$ foi de 9,5. Cerqueira-Pereira et al. (2007) ao estudar aplicação de etileno na qualidade pós-colheita de frutos de pimentão, obtiveram as intensidades de 19,63 para a* e 42,21 para b*. Nota-se que os resultados reportados foram maiores que o encontrado nesse trabalho. Segundo os autores, a degradação da clorofila para síntese de pigmentos como carotenoides e antocianinas auxiliam na coloração dos frutos.

As variáveis de coloração mostraram uma correlação significativa entre si (Tabela 2). A luminosidade correlacionou-se negativamente com a intensidade de $b^{*}$, cromaticidade e índice de cor (Tabela 2). Também houve uma forte correlação positiva entre a intensidade de $\mathrm{a}^{*}$, cromaticidade e índice de cor. Foi verificado uma forte correlação negativa entre a intensidade de $b^{*}$ e a cromaticidade. 0 ângulo Hue se correlacionou negativamente com o índice de cor.

Tabela 2. Coeficientes de correlação de Pearson (r) entre as variáveis de coloração

\begin{tabular}{|c|c|c|c|c|c|c|}
\hline Variáveis & $\mathrm{L}$ & $\mathrm{a}^{*}$ & $\mathrm{~b}^{*}$ & \multicolumn{1}{c|}{$\mathrm{C}$} & $\mathrm{H}^{\circ}$ & $\mathrm{IC}$ \\
\hline Luminosidade (L) & 1,000 & & & & & \\
\hline Intensidade (a*) & $-0,983$ & 1,000 & & & & \\
\hline Intensidade (b*) & $-0,490$ & 0,502 & 1,000 & & & \\
\hline Cromaticidade (C) & $-0,808$ & 0,813 & 0,909 & 1,000 & & \\
\hline Ângulo Hue (h ${ }^{\circ}$ ) & 0,350 & $-0,337$ & 0,641 & 0,263 & 1,000 & \\
\hline Índice de cor (IC) & $-0,833$ & 0,829 & $-0,062$ & 0,360 & $-0,804$ & 1,000 \\
\hline
\end{tabular}

Atividade de água no pimentão vermelho foi de 1,0 (Tabela 3). No estudo de Alves et al. (2015) sobre as isotermas de dessorção de pimentão o teor de água foi de 0,6 e 0,9, respectivamente. Segundo Alves et al. (2014) a atividade de água indica a perecibilidade do pimentão vermelho, ou seja, o elevado teor da atividade de água é propício para o desenvolvimento de micro-organismos e reações químicas.

Tabela 3. Avaliação das características físico-químicas de pimentão (Capsicum annuum. L) vermelho

\begin{tabular}{|c|c|}
\hline Características & Médias \\
\hline Atividade de água (adimensional) & $1,0 \pm 0,1$ \\
\hline Sólidos solúveis (\%) & $6,6 \pm 0,1$ \\
\hline Potencial hidrogênio (adimensional) & $4,9 \pm 0,1$ \\
\hline Concentração de Ílons $(\mu \mathrm{M})$ & $11,4 \pm 0,7$ \\
\hline Acidez titulável (\%) & $0,3 \pm 0,1$ \\
\hline Razão (adimensional) & $19,4 \pm 1,8$ \\
\hline
\end{tabular}

0 teor de sólidos solúveis do pimentão vermelho foi de 6,6\% (Tabela 3), valor próximo aos descrito por Cerqueira-Pereira et al. (2007), que ao estudarem sobre a qualidade pós-colheita de frutos de pimentão encontraram 6,50\%. 0 valor de $\mathrm{pH}$ obtido no pimentão vermelho foi de 4,9, entretanto, a concentração de íons $\mathrm{H}^{+}$foi $11,4 \mu \mathrm{M}$. Os resultados de $\mathrm{pH}$ descritos por Cerqueira-Pereira et al. (2007) foi de 4,69. A acidez estimada foi de 0,3\% sendo inferior ao valor exposto por Machado et al. (2018). Já o resultado obtido na razão foi de 19,4 sendo menor que a descrita no trabalho de Ferreira et al. (2013).

Houve correlação significativa entre as características físico-químicas avaliadas (Tabela 4). Observou-se correlação negativa entre atividade de água, $\mathrm{pH}$ e a razão, por outro lado, a concentração de $\mathrm{H}^{+}$ 
correlacionou-se positivamente. Houve forte correlação negativa entre o pH e a concentração de $\mathrm{H}^{+}$, sendo os resultados obtidos inversamente proporcionais. A acidez titulável correlacionou-se fortemente com a razão.

Tabela 4. Coeficientes da correlação de Pearson (r) entre as características físico-químicas

\begin{tabular}{|l|c|c|c|c|c|c|}
\multicolumn{1}{|c|}{ Características } & WA & SS & $\mathrm{pH}$ & $\mathrm{H}^{+}$ & $\mathrm{AT}$ & SS/AT \\
\hline Atividade de água (WA) & 1,000 & & & & & \\
\hline Sólidos solúveis (SS) & 0,000 & 1,000 & & & & \\
\hline Potencial hidrogênio (pH) & $-0,988$ & 0,040 & 1,000 & & & \\
\hline Concentração de Íons (H+) & 0,987 & $-0,027$ & $-1,000$ & 1,000 & & \\
\hline Acidez titulável (AT) & 0,524 & 0,404 & $-0,561$ & 0,570 & 1,000 & \\
\hline Razão (SS/AT) & $-0,538$ & $-0,337$ & 0,579 & $-0,587$ & $-0,997$ & 1,000 \\
\hline
\end{tabular}

0 ácido ascórbico destacado no pimentão vermelho foi de 113,8 mg $100 \mathrm{~g}^{-1}$ (Tabela 5), isso indica que o pimentão vermelho possui elevados teores de vitamina C. No trabalho Maciel et al. (2019) ao estudar sobre diferentes variedades de pimentão encontrou valores de $118,79 \mathrm{mg} 100 \mathrm{~g}^{-1}$. Nota-se que os resultados encontrados na literatura foram próximos ao deste trabalho.

Tabela 5. Avaliação dos compostos bioativos de pimentão (Capsicum annuum. L) vermelho

\begin{tabular}{|c|c|}
\hline Características & Médias \\
\hline Ácido ascórbico (mg $100 \mathrm{~g}^{-1}$ ) & $113,8 \pm 3,9$ \\
\hline Carotenoides (mg $100 \mathrm{~g}^{-1}$ ) & $0,5 \pm 0,1$ \\
\hline Flavonoides (mg $100 \mathrm{~g}^{-1}$ ) & $6,7 \pm 0,6$ \\
\hline Antocianinas (mg $100 \mathrm{~g}^{-1}$ ) & $1,5 \pm 0,1$ \\
\hline Compostos fenólicos (mg $\left.100 \mathrm{~g}^{-1}\right)$ & $156,3 \pm 2,5$ \\
\hline
\end{tabular}

\pm Desvio padrão das médias

Os carotenoides estimados no pimentão vermelho foram de 0,5 mg $100 \mathrm{~g}^{-1}$ (Tabela 5). De acordo com Maciel et al. (2019) o teor de carotenoides do pimentão vermelho foi de 77,23 $\mu \mathrm{g} 100 \mathrm{~g}^{-1}$, que corresponde a $0,8 \mathrm{mg} 100 \mathrm{~g}^{-1}$, sendo o resultado reportado pelo autor próximo ao encontrado nesta pesquisa. As antocianinas no pimentão vermelho obtiveram valor de 1,5 mg $100 \mathrm{~g}^{-1}$ (Tabela 5). Esses valores foram abaixo dos descritos por Maciel et al. (2019) que ao avaliarem os fitoquímicos em diferentes variedades de pimentão, encontrarem valores de 3,11 mg $100 \mathrm{~g}^{-1}$.

0 teor de compostos fenólicos foi 156,3 mg $100 \mathrm{~g}^{-1}$ (Tabela 5), valor idêntico ao descrito por Maciel et al. (2019) que ao estudar os bioativos em diferentes variedades de pimentão encontrou 156, $3 \mathrm{mg} 100 \mathrm{~g}^{-1} .0$ resultado indicado sugere que o pimentão vermelho possui alto teor de compostos fenólicos, sendo uma qualidade visto que essas características indicam capacidade antioxidante (MACHADO et al., 2017).

Tabela 6. Coeficientes da correlação de Pearson (r) dos compostos bioativos

\begin{tabular}{|l|c|c|c|c|c|}
\multicolumn{1}{c}{ CARACTERÍSTICAS } & AA & CA & FL & AN & CF \\
\hline Ácido ascórbico (AA) & 1,000 & & & & \\
\hline Carotenoides (CA) & 0,265 & 1,000 & & & \\
\hline Flavonoides (FL) & $-0,793$ & $-0,450$ & 1,000 & & \\
\hline Antocianinas (AN) & 0,865 & 0,188 & $-0,888$ & 1,000 & \\
\hline Compostos fenólicos (CF) & 0,944 & 0,168 & $-0,777$ & 0,952 & 1,000 \\
\hline
\end{tabular}

Os compostos bioativos apresentaram correlação significativa (Tabela 6). Os teores de ácido ascórbico se correlacionaram positivamente com as antocianinas e compostos fenólicos, entretanto, foi observado que o ácido ascórbico se correlacionou negativamente com os flavonoides. Verificou-se uma correlação negativa entre os carotenoides e os flavonoides. Houve forte correlação negativa entre flavonoides, antocianinas e compostos fenólicos. 


\section{CONCLUSÃO}

O pimentão vermelho manteve as características físicas-químicas e bioativas adequadas para os frutos, uma vez que ele é rico em ácido ascórbico e compostos fenólicos, indicando que o consumo dessa hortaliça poderá auxiliar na inibição da ação dos radicais livres e auxiliar na prevenção de doenças.

\section{AGRADECIMENTOS}

Ao Laboratório de Química, Bioquímica e Análise de Alimentos; Grupo de Pesquisa em Ciência, Tecnologia e Engenharia de Alimentos; Unidade Acadêmica de Tecnologia de Alimentos, Campus Pombal

\section{REFERÊNCIAS}

[1] Brackmann, A., Giehl, R.F.H., Sestari, I., Steffens, C.A., Heldwein. A.B. 2005, "Indução da cor vermelha em pimentões 'vidi' com etileno e luminosidade". Revista da Faculdade de Zootecnia Veterinária e Agronomia., Vol.12, No. 1, pp. 53-62.

[2] Alves, T.P., Fóz, H.D., Nicoleti, J.F., 2015, “Isotermas de dessorção de pimentão verde e energia envolvida no processo". Braz. J. Food Technol., Vol. 18, No. 2, pp. 137-145.

[3] Esse e congresso

[4] Alves, T.P., Fóz, H.D., Nicoleti, J.F., 2014, "Isotermas de dessorção de pimentão verde e energia envolvida no processo". XX Congresso brasileiro de engenharia química.

[5] Bernardo, D.B.F., Lopes, M.N., Lucena, M.L., Lopes, W.E., Chinelate, G.C.B., Medeiros, E.V. 2018, “Caracterização física e físico-química de frutos de pimentão com diferentes colorações comerciais". Revista Brasileira de Agrotecnologia., Vol. 8, No. 2, pp. 07-12.

[6] Büttow, M.V., Barbieri, R.L., Neitzke, R.S., Heide, G., Carvalho, F.I.F. 2010, “Diversidade genética entre acessos de pimentas e pimentões da Embrapa Clima Temperado”. Ciência Rural., Vol. 40, No. 6, pp. 1264-1269.

[7] Brasil. "Agência Nacional de Vigilância Sanitária”. 2013. Guia para Comprovação da Segurança de Alimentos e Ingredientes. Brasília, 45p.

[8] Canuto, G.A.B., Xavier, A.A.O., Neves, L.C., Benassi, M.D.T. 2010, “Caracterização físico-química de polpas de frutos da Amazônia e sua correlação com a atividade antiradical livre". Revista Brasileira de Fruticultura, Jaboticabal., Vol. 32, No. 4, pp. 1196-1205.

[9] Cerqueira-Pereira, E.C., Pereira, M.A., Mello, S.C., Jacomino, A.P., Trevisan, M.J., Dias, C.T.S. 2007, "Efeito da aplicação de etileno na qualidade pós-colheita de frutos de pimentão vermelhos e amarelos". Horticultura Brasileira., Vol. 25, No. 4, pp. 590-593.

[10] Collera-Zuniga, O., Jimenez, F.G., Gordillo, R.M. 2005, “Comparative study of carotenoid composition in three mexican varieties of Capsicum annuum L.” Food Chemistry., Vol. 90, No. 1, pp. 109-114.

[11] Ferreira, M.D., Spricigo, P.C. 2017. “Colorimetria - Princípios e Aplicações na Agricultura”. In: Ferreira, M.D. Ed. técnico. Instrumentação pós-colheita em frutas e hortaliças, São Carlos: Embrapa Instrumentação, pp. 209-220.

[12] Ferreira, L.L.; Oliveira, F.S., Almeida, A.E.S., Lima, R.K.B., Loiola, A.T., Santos, E.C., Porto, V.C.N. 2013, "Caracterização físico-química de frutos de pimentão em diferentes acessos mercadológico". Revista Agropecuária Científica do Semiárido., Vol. 9, No. 1, pp. 99-103.

[13] Francis, F.J. Analysis of anthocyanins. In: Markakis, P. (ed.) anthocyanins as food calors. New York: Academic Press, 1982.

[14] Hojo, E.T. D., Cardoso, A. D., Hojo, R. H., Vilas Boas, E. V. de B., Alvarenga, M. A R. 2007, "Uso de películas de fécula de mandioca e pvc na conservação pós-colheita de pimentão”. Ciênc. agrotec., Vol. 31, No. 1, pp. 184-190.

[15] Instituto Adolfo Lutz. Normas Analíticas do Instituto Adolfo Lutz. 2008, "Métodos químicos e físicos para análise de alimentos", Vol. 1, 4. ed. São Paulo.

[16] Lichtenthaler, H.K. 1987, "Chlorophylls and carotenoids: pigments of photosynthetic biomembranes". In: Packer, L., Douce, R. (Eds.). Methods in Enzymology., Vol. 148, pp. 350-352.

[17] Leme, S.C. 2012, "Qualidade pós-colheita de pimentões produzidos em sistema orgânico". Tese (Doutorado) Universidade Federal de Lavras. Fevereiro de 2012.

[18] Maciel, M.I.S., Mélo, E.A., Lima, V.L.A., Musser, R.S., Lima, D.E. da. S., Silva, M.V. 2019. Disponível em. < http://www.abhorticultura.com.br/biblioteca/arquivos/Download/Biblioteca/olfi4009.pdf>. Acesso em: 18 de outubro de 2019. 
[19] Matos, F.A.P., Banci, C.N., Gontijo G.M., Dias, G.M. Saiba como cultivar hortaliças para colher bons negócios. Sebrae, Brasília, 2012.

[20] Machado, A.R., Aquino, I.C., Tiecher, A., Ribeiro, G., Ribeiro, P.F.A. 2017, "Caracterização físico-química e antioxidante de diferentes variedades de pimentão". Agrarian Academy, Centro Científico Conhecer, Goiânia., Vol.4, No. 8, pp. 83-92.

[21] Oliveira, C.D., Braz, L.T., Santos, J M., Banzatto, D.A., Oliveira, P.R. 2009, "Resistência de pimentas a nematóides de galha e compatibilidade enxerto/porta-enxerto entre híbridos de pimentão e pimentas". Horticultura brasileira., Vol. 27, No. 4, pp. 520-526.

[22] Pimentel, F., Pinto, F.T., Schmitt, L. 2019, “Pimentão". Disponível em: <http://www.ufrgs.br/afeira/materiasprimas/hortalicas/pimentao/caracteristicas $>$. Acessado em: 18 outubro de 2019.

[23] Santos, P.S., Moura, F.M., Neto, J.G., Silva, F.S., Lima, A.M.S., Costa, I.J.N., Melo, R.A. 2013, "Produtividade precoce de linhagens e cultivares de pimentão em cultivo protegido”. XIII Jornada Ensino, Pesquisa e Extensão.

[24] Vilas Boas, R.M., Siqueira, H.H., Leme, S. C., Lima, L.C. de O., Alves, T.C. 2012, “Conservação de pimentão verde minimamente processado acondicionado em diferentes embalagens plásticas". Pesq. Agropec. Trop., Vol. 42, No. 1, pp. 34-39.

[25] Waterhouse, A. 2006, "Folin-ciocalteau micro method for total phenol in wine”. American Journal of Enoiogy and Viticulture. 


\section{Capítulo 15}

\section{Características físico-químicas e compostos bioativos do pimentão amarelo}

\section{Ana Marinho do Nascimento}

Jéssica Leite da Silva

Tatiana Marinho Gadelha

Charlene Maria Alcântara

\section{Larissa Félix Macêdo}

\section{Franciscleudo Bezerra da Costa}

Resumo: 0 pimentão tem frutos ricos em fitoquímicos, presentes na maioria das hortaliças. Diante disso, objetivou-se determinar as características físico-químicas e os compostos bioativos no pimentão amarelo. 0 experimento foi conduzido no Laboratório de Química, Bioquímica e Análise de Alimentos, do Centro de Ciências e Tecnologia Agroalimentar, da Universidade Federal de Campina Grande, Campus de Pombal. Os frutos de pimentões foram selecionados, lavados e sanitizados, cortados, triturados em liquidificador e acondicionados em recipientes plásticos. As características físicasquímicas avaliadas foram atividade de água, $\mathrm{pH}$, concentração de íons hidrogênio, sólidos solúveis, acidez titulável, razão sólidos solúveis e acidez titulável; nos compostos bioativos foram avaliados os teores de ácido ascórbico, carotenoides, flavonoides, antocianinas e compostos fenólicos. Os coeficientes de correlação de Pearson foram determinados entre as características estudadas. Foi verificado que a luminosidade indicou aparência escurecida com 14,8. A intensidade de $b^{*}$ foi de 18,3 sendo mais expressivo que o 2,4 de $a^{*}$, comportamento correspondente da cor amarela dos frutos. 0 estudo indicou que o pimentão amarelo é rico em compostos bioativos. Houve correlações significativas entre os resultados obtidos. 0 pimentão amarelo apresentou alto teor de ácido ascórbico e compostos fenólicos, isso sugere que o fruto possui propriedades funcionais que pode auxiliar na manutenção da saúde.

Palavras-chave: Capsicum annuum L., fotoquímicos, hortaliças, saúde. 


\section{INTRODUÇÃO}

O pimentão (Capsicum annuum L.) é uma espécie originaria da América Latina que pertence à família Solanaceae, é uma planta com características arbustivas, semiperene, folhas de coloração verde-escura e formato oval-lanceolado. Seus frutos são do tipo baga e apresentam diversos formatos e coloração, podendo ser classificados em grupos de acordo com sua forma, classes conforme o comprimento longitudinal e subclasses de acordo com o seu comprimento transversal (PIMENTEL, 2019; EMBRAPA, 1999). 0 pimentão amarelo é uma hortaliça muito procurada pelos consumidores devido a sua cor, aroma e sabor. Nos tecidos dessa hortaliça encontram-se os carotenoides, pigmento natural que fornece ações benéficas à saúde (MARÍN et al., 2004; NAVARRO et al., 2006).

A cor dos pimentões é um dos principais fatores que influência na escolha do consumidor, através dessa caraterística os clientes fazem a avaliação de qualidade baseado na aparência geral do produto, isso ocorre, devido a relação direta que existe entre a cor e o sabor dos alimentos (BISCHOFF et al., 2012). A modificação nas colorações dos frutos é marcada pela alteração da cor verde para a cor específica de cada espécie. A clorofila e os carotenoides são os pigmentos responsáveis pelas mudanças de cores ocorridas, seja ela amarela, laranja, vermelha ou roxo (BRAMLEY, 2002). As modificações de cor dos pimentões iniciam-se 39 dias após sua frutificação, ou seja, 10 dias antes do fruto obter seu tamanho final (SERRANO et al., 2010).

As características físico-químicas podem ser influenciadas pela coloração do pimentão, desta forma, a variação da coloração desta espécie pode determinar mudanças em outros parâmetros, tais como a acidez total e pH, modificando as características sensoriais do alimento, assim como, a concentração nos teores dos compostos bioativos (MACHADO et al., 2017).

Os compostos bioativos conhecidos também como fitoquímicos, são componentes químicos e bioquímicos que estão presentes em grande parte dos frutos e hortaliças. Desta forma, esses elementos desempenham amplas atividades biológicas no organismo humano trazendo diversos benefícios para a saúde. Isto porque, os compostos com capacidade antioxidante encontrados nos frutos, são importantes na prevenção de processos degenerativos associados aos radicais livres presentes no organismo (HORST; LAJOLO, 2019; CANUTO et al., 2010; NASCIMENTO et al., 2017). Diante do exposto, objetivou-se determinar as características físico-químicas e os compostos bioativos de pimentão amarelo.

\section{MATERIAL E MÉTODOS}

Foram utilizados pimentões amarelo (Capsicum annuum L.) provenientes do Centro Econômico de Abastecimento Sociedade Anônima (CEASA), localizada na cidade de Patos-PB. Os pimentões foram acondicionados em caixas de papelão e transportados para o Laboratório de Química Bioquímica e Análise de Alimentos da Universidade Federal de Campina Grande, Campus Pombal (Figura 1A).

Figura 1. Fluxograma de obtenção de amostras do pimentão (Capsicum annuum. L) amarelo.

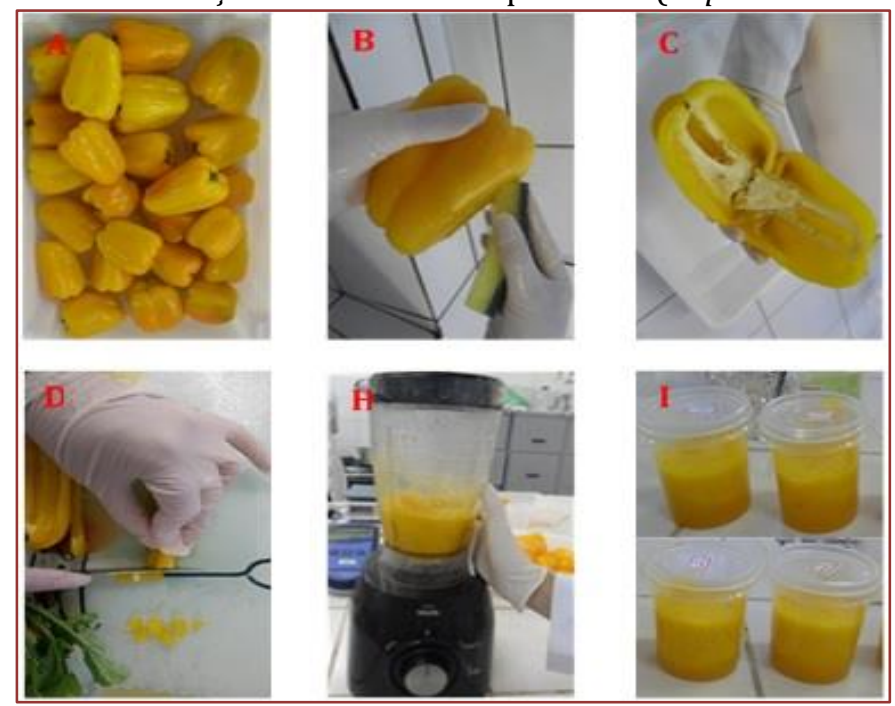


Os mesmos foram lavados em água corrente para retirada de sujidades superficiais (Figura 1B). Logo após, os pimentões foram cortados com facas de aço inoxidável eliminando pedúnculos e sementes (Figura 1C). Para a obtenção dos extratos in natura os pimentões foram cortados (Figura 1D), desintegrados em liquidificador (Figura 1E) e acondicionados em recipientes plásticos, rotulados, envolvidos em papel alumínio e movidos para análises (Figura 1I).

\subsection{ANÁLISE DE COR}

As amostras foram determinadas no sistema CIELAB utilizando-se um colorímetro Konica Minolta, modelo CR 300 Tokyo, foi analisado 5 parâmetros de coloração: luminosidade ( $L^{*}$ ) eixo principal (preto $=0$ ao branco $=100)$, intensidade de $\left(a^{*}\right)$ que corresponde do verde $(-)$ ao vermelho $(+)$, intensidade de $\left(b^{*}\right)$ que corresponde do azul (-) ao amarelo (+), cromaticidade (C) que é a saturação definida pela distância radial do centro do espaço até o ponto da cor e o Ângulo Hue $\left(\mathrm{h}^{\circ}\right)$ que é considerado o atributo qualitativo de cor com as cores definidas tradicionalmente como avermelhada e esverdeada. As leituras dos valores foram feitas em locais diferentes, totalizando 3 leituras por repetição. Após as leituras calculou-se o índice de cor (IC), que indica o grau de variação verde ao amarelo das amostras (FERREIRA; SPRICIGO, 2017).

\subsection{ATIVIDADE DE ÁGUA}

A determinação de atividade de água foi realizada usando hidrômetro de ponto de orvalho AquaLab, decagom, modelo 3T, fabricado por decagon Devices. Foi colocado uma quantidade suficiente para cobrir o fundo da capsula, posteriormente a amostra foi colocada diretamente no equipamento à temperatura de $25^{\circ} \mathrm{C}$, sendo a atividade de água expressa em porcentagem de água livre presente.

\subsection{POTENCIAL HIDROGENIÔNICO}

As amostras foram homogeneizadas e determinadas em potenciômetro digital de bancada, modelo DM-22, conforme as normas analíticas do Instituto Adolfo Lutz (2008). Os resultados também foram expressos em concentração de íons $\mathrm{H}^{+}$(?M).

\subsection{SÓLIDOS SOLÚVEIS}

As amostras foram homogeneizadas e filtradas em camada de algodão, o teor de sólidos solúveis foi determinado em refratômetro digital modelo Reichert AR-200, com compensação automática de temperatura. 0 valor foi expresso em percentagem de sólidos solúveis, seguindo as normas analíticas do Instituto Adolfo Lutz (2008).

\subsection{ACIDEZ TITULÁVEL}

0 teor de acidez foi determinado segundo as normas analíticas do Instituto Adolfo Lutz (2008). Um grama das amostras foi pesado e transferido para erlenmeyer contendo $49 \mathrm{~mL}$ de água destilada, posteriormente, adicionou-se 2 gotas de fenolftaleína e titulou-se contra a solução de hidróxido de sódio a 0,1 M até pH 8,1. Para o cálculo da acidez foi considerado o fator do ácido equivalente, sendo o resultado foi expresso em percentagem.

\subsection{RATIO}

Os valores do ratio foi obtido pela divisão dos teores de sólidos solúveis pelos os da acidez titulável.

\section{7 ÁCIDO ASCÓRBICO}

Os teores de ácido ascórbico foram determinados segundo as normas analíticas do Instituto Adolfo Lutz (2008). Um grama das amostras foi pesado e transferido para erlenmeyer contendo $49 \mathrm{~mL}$ de ácido oxálico 0,5\% gelado, posteriormente titulou-se contra a solução de Tillmans: 2,6 Diclorofenol Indofenol (DFI) até o ponto de viragem. Os resultados foram expressos em mg 100 g-1 de ácido ascórbico. 


\subsection{CAROTENOIDES}

Foram determinados de acordo com o método de Lichtenthaler (1987). Foram pesados 1,0 g das amostras e maceradas em almofariz com $0,2 \mathrm{~g}$ de carbonato de cálcio e $5 \mathrm{~mL}$ de acetona a $80 \%$. 0 extrato foi transferido para tubos falcon e centrifugados a $10{ }^{\circ} \mathrm{C}$ e $3.000 \mathrm{rpm}$ por 10 minutos. Alíquotas dos sobrenadantes foram colocados em cubeta e as leituras realizadas em espectrofotômetro nas absorbâncias de 470, 646 e $663 \mathrm{~nm}$. Todos os procedimentos foram realizados em ambiente escuro e os resultados expressos em mg $100 \mathrm{~g}-1$.

\subsection{FLAVONOIDES}

Foram quantificados de acordo com o método de Francis (1982). Foram pesados 1,0 g das amostras e maceradas em almofariz com $10 \mathrm{~mL}$ de etanol: HCL. Os extratos foram transferidos para tubos falcon e deixados na geladeira por 24 horas. No dia seguinte, os extratos foram centrifugados a $10{ }^{\circ} \mathrm{C}$ e $3.000 \mathrm{rpm}$ por 10 minutos. Alíquotas dos sobrenadantes foram colocadas em cubeta e as leituras realizadas em espectrofotômetro nas absorbâncias de $374 \mathrm{~nm}$. Todos os procedimentos foram realizados em ambiente escuro e os resultados expressos em mg $100 \mathrm{~g}^{-1}$.

\subsection{ANTOCIANINAS}

Foram pesados 1,0 g das amostras e maceradas em almofariz com $10 \mathrm{~mL}$ de etanol: HCL. Os extratos foram transferidos para tubos falcon e deixados na geladeira por 24 horas. No dia seguinte, os extratos foram centrifugados a $10^{\circ} \mathrm{C}$ e $3.000 \mathrm{rpm}$ por 10 minutos. Alíquotas dos sobrenadantes foram colocadas em cubeta e as leituras realizadas em espectrofotômetro nas absorbâncias $535 \mathrm{~nm}$. Os procedimentos foram determinados conforme método de Francis (1982) e os resultados expressos em mg $100 \mathrm{~g}^{-1}$.

\subsection{COMPOSTOS FENÓLICOS}

A análise foi realizada conforme o método descrito por Waterhouse (2006). Foram pesados 1,0 g das amostras e maceradas em almofariz e diluídas em $50 \mathrm{~mL}$ de água destilada, logo após, foram deixadas em repouso por 30 minutos. Alíquotas dos extratos foram transferidas para tubos de ensaio, onde foram adicionados de água e Folin ciocalteau. As misturas permaneceram em repouso por 5 minutos e logo após, foi adicionado o carbonato de sódio a $20 \%$, seguida de agitação e repouso em banho-maria a $40{ }^{\circ} \mathrm{C}$, por 30 minutos. A curva padrão foi preparada com ácido gálico e as leituras realizadas em espectrofotômetro a $765 \mathrm{~nm}$. Os valores de polifenóis foram expressos em mg 100 g-1.

\subsection{CORRELAÇÃO DE PEARSON}

Os coeficientes de correlação de Pearson foram determinados entre a coloração, características físicoquímica e compostos bioativos a partir do software Microsoft Excel 2013.

\section{RESULTADOS E DISCUSSÃO}

A luminosidade $\mathrm{L}^{*}$ do pimentão amarelo foi de 14,8 (Tabela 1). 0 resultado apresentado foi considerado baixo se comparado aos estudos expostos por Vilas Boas et al. (2012) e Hojo et al. (2007), sendo em média de 37,7. Assim, pode-se dizer que os frutos de pimentão obtiveram aparência escurecida, visto que a luminosidade está relacionada com a variação 0 a 100, sendo que os valores próximos de 0 considerados escuros e os que se aproximam de 100 mais claros. 


Tabela 1. Coloração de pimentão (Capsicum annuum. L) amarelo
\begin{tabular}{|l|l|}
\hline VARIÁVEIS & MÉDIAS \\
\hline Luminosidade & $14,8 \pm 1,7$ \\
\hline Intensidade $\left(\mathrm{a}^{*}\right)$ & $2,4 \pm 0,8$ \\
\hline Intensidade $\left(\mathrm{b}^{*}\right)$ & $18,1 \pm 2,2$ \\
\hline Cromaticidade $(\mathrm{C})$ & $18,2 \pm 2,3$ \\
\hline Ângulo Hue $\left(\mathrm{H}^{\circ}\right)$ & $82,2 \pm 2,5$ \\
\hline Índice de cor (IC) & $1,7 \pm 0,6$ \\
\hline \multicolumn{2}{|c}{ \pm Desvio padrão das médias }
\end{tabular}

0 valor da intensidade de $\mathrm{a}^{*}$ foi de 2,4 (Tabela 1 ), resultado inferior se comparado a estudos citados. No entanto, a intensidade de $b^{*}$ obteve um valor de 18,2. Esse comportamento já era esperado, tendo em vista que a coordenada (+b) corresponde a cor amarela. Os trabalhos de Vilas Boas et al. (2012) e Hojo et al. (2007) constataram que a perda da coloração verde em pimentões armazenados, provoca uma variação na coordenada a* podendo alterar entre valores positivos e negativos. Por outro lado, quando se observa os valores positivos na coordenada b* percebe-se que a coloração amarela do pimentão prevaleceu.

Observou-se luminosidade positivamente correlacionada com a intensidade de $b^{*}$ e a cromaticidade (Tabela 2). Houve forte correlação positiva entre a intensidade de $a^{*}$, com a intensidade de $b^{*}$, cromaticidade e o índice de cor. Foi verificado uma forte correlação negativa entre a intensidade de $b^{*} \mathrm{e}$ ao ângulo hue. A cromaticidade se correlacionou negativamente com o ângulo hue e positivamente com o índice de cor. As variáveis de coloração mostraram uma correlação significativa entre si.

Tabela 2. Coeficientes de correlação de Pearson (r) entre as variáveis de coloração

\begin{tabular}{|l|c|c|c|c|c|c|}
\hline \multicolumn{1}{|c|}{ VARIÁVEIS } & $\mathrm{L}$ & $\mathrm{a}^{*}$ & $\mathrm{~b}$ & $\mathrm{C}$ & $\mathrm{H}^{\circ}$ & $\mathrm{IC}$ \\
\hline Luminosidade $\left(\mathrm{L}^{*}\right)$ & 1,000 & & & & & \\
\hline Intensidade $\left(\mathrm{a}^{*}\right)$ & 0,227 & 1,000 & & & & \\
\hline Intensidade $\left(\mathrm{b}^{*}\right)$ & 0,746 & 0,759 & 1,000 & & & \\
\hline Cromaticidade $(\mathrm{C})$ & 0,730 & 0,775 & 1,000 & 1,000 & & \\
\hline Ângulo Hue $\left(\mathrm{h}^{\circ}\right)$ & $-0,012$ & $-0,955$ & $-0,586$ & $-0,606$ & 1,000 & \\
\hline Índice de cor (IC) & $-0,186$ & 0,911 & 0,431 & 0,454 & $-0,959$ & 1,000 \\
\hline
\end{tabular}

Os valores expressos indicam que o pimentão amarelo possui um baixo $\mathrm{pH}$, que consequentemente aumentou concentração de íons $\mathrm{H}^{+}$, a acidez permitiu encontrar uma razão entre os sólidos solúveis com a acidez expressiva, indicando que o fruto possui sabor agradável (Tabela 3). Os teores de sólidos solúveis encontram-se próximos aos resultados reportados por Bernardo et al. (2018), no entanto, a acidez titulável e o ratio apresentam valores superiores.

Tabela 3. Avaliação das características físico-químicas de pimentão (Capsicum annuum. L) amarelo

\begin{tabular}{|l|c|}
\hline \multicolumn{1}{|c|}{ CARACTERÍSTICAS } & MÉDIAS \\
\hline Atividade de água (adimensional) & $1,0 \pm 0,1$ \\
\hline Sólidos solúveis (\%) & $7,2 \pm 0,2$ \\
\hline Potencial hidrogênio (adimensional) & $4,7 \pm 0,2$ \\
\hline Concentração de Íons $(\mu \mathrm{M})$ & $23,2 \pm 0,2$ \\
\hline Acidez titulável (\%) & $0,3 \pm 0,1$ \\
\hline Ratio (adimensional) & $22,8 \pm 0,1$ \\
\hline
\end{tabular}

\pm Desvio padrão das médias

A atividade de água foi negativamente correlacionada com a concentração de íons $\mathrm{H}^{+}$(Tabela 4). No $\mathrm{pH}$ houve uma fraca correlação negativa com o ratio, entretanto, o $\mathrm{pH}$ se correlacionou positivamente com a acidez titulável. A concentração de íons hidrogênio apresentou forte correlação negativa com o pH e o ratio. Observou-se que o $\mathrm{pH}$ e a concentração de íons hidrogênio foram inversamente proporcionais. Acidez titulável foi correlacionada positivamente com o ratio. Percebe-se que houve alta correlação entre os teores de sólidos solúveis e o ratio. Nota-se que os características físico-químicas obtiverem correlação significativa entre si, independentemente de ser positiva ou negativa. 
Tabela 4. Coeficientes da correlação de Pearson (r) entre as características físico-químicas

\begin{tabular}{|l|c|c|c|c|c|c|}
\multicolumn{1}{c}{ CARACTERÍSTICAS } & WA & SS & $\mathrm{pH}$ & $\mathrm{H}^{+}$ & AT & Ratio \\
\hline Atividade de água (WA) & 1,000 & & & & & \\
\hline Sólidos solúveis (SS) & $-0,498$ & 1,000 & & & & \\
\hline Potencial hidrogênio (pH) & 0,778 & $-0,202$ & 1,000 & & & \\
\hline Concentração de Íons (H+) & $-0,802$ & $-0,261$ & $-0,997$ & 1,000 & & \\
\hline Acidez titulável (AT) & 0,319 & 0,382 & 0,469 & $-0,477$ & 1,000 & \\
\hline Ratio & $-0,461$ & $-0,164$ & $-0,549$ & 0,572 & $-0,974$ & 1,000 \\
\hline
\end{tabular}

0 teor de ácido ascórbico do pimentão amarelo foi de 189,7 mg $100 \mathrm{~g}^{-1}$ (Tabela 5), indicando que o pimentão amarelo possui alta concentração de vitamina C. No trabalho de Leme (2012) ao estudar os teores de ácido ascórbico em diferentes variedades de pimentão, foi encontrado valores de 57,17 a 69,64 $\mathrm{mg} 100 \mathrm{~g}^{-1}$. Nota-se que os resultados encontrados na literatura foram inferiores ao deste trabalho.

Tabela 5. Avaliação dos compostos bioativos de pimentão (Capsicum annuum. L) amarelo

\begin{tabular}{|c|c|}
\hline CARACTERÍSTICAS & MÉDIAS \\
\hline Ácido ascórbico (mg $100 \mathrm{~g}^{-1}$ ) & $188,9 \pm 11,3$ \\
\hline Carotenoides (mg $100 \mathrm{~g}^{-1}$ ) & $0,7 \pm 0,1$ \\
\hline Flavonoides $\left(\mathrm{mg} 100 \mathrm{~g}^{-1}\right)$ & $5,6 \pm 0,7$ \\
\hline Antocianinas (mg $100 \mathrm{~g}^{-1}$ ) & $0,6 \pm 0,2$ \\
\hline Compostos fenólicos (mg $\left.100 \mathrm{~g}^{-1}\right)$ & $191,3 \pm 2,3$ \\
\hline
\end{tabular}

\pm Desvio padrão das médias

Os valores de carotenoides estimados do pimentão amarelo foram de 0,7 mg $100 \mathrm{~g}^{-1}$ (Tabela 5). No estudo de Nachtigall et al. (2007) ao quantificar a luteína em hortaliças, informou que o teor de carotenoides totais em pimentão foi de $0,51 \mathrm{mg} 100 \mathrm{~g}^{-1}$. Os teores de flavonoides do pimentão amarelo foram de 5,6 mg $100 \mathrm{~g}^{-1}$ (Tabela 5). Maciel et al. (2019) avaliando os bioativos em diferentes variedades de pimentão, informou que o teor de flavonoides de pimentão amarelo foi de $8,4 \mathrm{mg} 100 \mathrm{~g}^{-1}$, respectivamente. Nota-se que os teores de flavonoides encontrado nesta pesquisa está de acordo com os valores citados na literatura.

As antocianinas no pimentão amarelo obtiveram valor de 0,6 mg $100 \mathrm{~g}^{-1}$ (Tabela 5). Maciel et al. (2019) ao estudar os bioativos em diferentes variedades de pimentão, informou que os teores de antocianinas apresentado em pimentão amarelo foi de $0,16 \mathrm{mg} 100 \mathrm{~g}^{-1}$, valor inferior ao encontrado neste trabalho.

Os compostos fenólicos apresentaram valores de 191,3 mg $100 \mathrm{~g}^{-1}$ (Tabela 5). Na pesquisa de Leme (2012) sobre a qualidade pós-colheita em diferentes variedades de pimentão, foi encontrado de 89,59 a 137,04 mg $100 \mathrm{~g}^{-1}$ de compostos fenólicos. Os resultados observados indicam que o pimentão amarelo possui altos teores de ácido ascórbico e compostos fenólicos. De acordo com Machado et al. (2017) essas características indicam que os pimentões amarelos possuem capacidade antioxidante.

Tabela 6. Coeficientes da correlação de Pearson (r) dos compostos bioativos

\begin{tabular}{|l|c|c|c|c|c|}
\multicolumn{1}{c}{ CARACTERÍSTICAS } & AA & CA & FL & AN & CF \\
\hline Ácido ascórbico (AA) & 1,000 & & & & \\
\hline Carotenoides (CA) & 0,184 & 1,000 & & & \\
\hline Flavonoides (FL) & $-0,065$ & 0,710 & 1,000 & & \\
\hline Antocianinas (AN) & 0,703 & 0,780 & 0,358 & 1,000 & \\
\hline Compostos fenólicos & $-0,653$ & 0,179 & $-0,178$ & $-0,126$ & 1,000 \\
\hline
\end{tabular}

Observou-se que houve uma correlação significativa entre os compostos bioativos (Tabela 6). Os teores de ácido ascórbico se correlacionaram positivamente com as antocianinas e negativamente com os compostos fenólicos. Verificou-se uma forte correlação positiva entre os carotenoides, flavonoides e antocianinas. Nota-se que houve uma baixa correlação entre os compostos fenólicos, flavonoides e antocianinas. 


\section{CONCLUSÃO}

O pimentão amarelo apresentou características físicas-químicas adequadas, sugerindo que o fruto possui qualidade. Os teores de ácido ascórbico e compostos fenólicos indicam que o pimentão amarelo tem propriedades funcionais que auxiliam na manutenção da saúde.

\section{AGRADECIMENTOS}

Ao Laboratório de Química, Bioquímica e Análise de Alimentos; Grupo de Pesquisa em Ciência, Tecnologia e Engenharia de Alimentos, Unidade Acadêmica de Tecnologia de Alimentos, Campus Pombal

\section{REFERÊNCIAS}

[1] Bernardo, D.B.F., Lopes, M.N., Lucena, M.L., Lopes, W., Chinelate, G.C.B., Medeiros, E.V. 2018, “Caracterização física e físico-química de frutos de pimentão com diferentes colorações comerciais". Revista Brasileira de Agrotecnologia., Vol. 8, No. 2, pp. 07-12.

[2] Bischoff, T.Z., Schoeninger, V., Prado, N.V., Pramiu, P.V., Coelho, S.R.M. 2012, "Qualidade e aparência do tomate embalado com biofilme comestível e filme de pvc". Cultivando o Saber, Cascavel., Vol. 5, No. 4, pp. 1-7.

[3] Bramley, P.M. 2002, "Regulation of carotenoid formation during tomato fruit ripening and development". Journal of Experimental Botany., Vol. 53, p. 2107-2113.

[4] Canuto, G.A.B., Xavier, A.A.O., Neves, L.C., Benassi, M.D.T. 2010, “Caracterização físico-química de polpas de frutos da Amazônia e sua correlação com a atividade Anti-Radical livre". Revista Brasileira de Fruticultura, Jaboticabal., Vol.32, No.4, pp.1196-1205.

[5] Embrapa, 1999. Disponível em:<http://www.ceasacampinas.com.br/mercado_hortifruti/ documentos/classificacao_hortalicas.pdf >. Acessado em: 18 de outubro de 2019

[6] Francis, F.J. 1982, “Analysis of anthocyanins. In: Markakis, P. (ed.) anthocyanins as food calors”. New York: Academic Press.

[7] Ferreira, M.D., Spricigo, P.C. 2017. “Colorimetria - Princípios e Aplicações na Agricultura”. In: Ferreira, M.D. Ed. técnico. Instrumentação pós-colheita em frutas e hortaliças, São Carlos: Embrapa Instrumentação, pp. 209-220.

[8] Hojo, E.T.D., Cardoso, A.D., Hojo, R.H., Vilas Boa, S. E.V.B., Alvarenga, M.A.R. 2007, “Uso de películas de fécula de mandioca e pvc na conservação pós-colheita de pimentão”. Ciênc. Agrotec., Lavras, Vol. 31, No. 1, pp. 184-190.

[9] Horst, M.A., Lajolo, F.M. 2019, "Biodisponibilidade de compostos bioativos de alimentos". Disponível em: < https://nutrisaude14.files.wordpress.com/2014/09/biodisponibilidade-1.pdf> acessado em: 18 de outubro de 2019.

[10] Instituto Adolfo Lutz. Normas Analíticas do Instituto Adolfo Lutz. 2008, "Métodos químicos e físicos para análise de alimentos", Vol. 1, 4. ed. São Paulo.

[11] Leme, S.C. 2012, "Qualidade pós-colheita de pimentões produzidos em sistema orgânico". 117 f. Tese (Doutorado em Ciência dos Alimentos), Universidade Federal de Lavras, Minas Gerais.

[12] Lichtenthaler, H.K. 1987, "Chlorophylls and carotenoids: pigments of photosynthetic biomembranes". In: Packer, L., Douce, R. (Eds.). Methods in Enzymology., London. Vol. 148, pp. 350-352.

[13] Machado, A.R., Aquino, I.C., Tiecher, A., Ribeiro, G., Ribeiro, P.F.A. 2017, "Caracterização físico-química e antioxidante de diferentes variedades de pimentão". Agrarian Academy, Centro Científico Conhecer, Goiânia, Vol.4, No. 8, pp. 83-92.

[14] Maciel, M.I.S., Mélo, E.A., Lima, V.L.A., Musser, R.S., Lima, D.E. da. S., Silva, M.V. 2019. Disponível em. < http://www.abhorticultura.com.br/biblioteca/arquivos/Download/Biblioteca/olfi4009.pdf>. Acesso em: 18 de outubro de 2019.

[15] Marín, A., Ferreres, F., Tomás-Barberán, F. A., Gil, M. I. 2004, "Characterization and quantitation of antioxidant constituents of sweet pepper (Capsicum annuum L.)". Journal of Agriculture and Food Chemistry, Davis., Vol. 52, No. 12, pp. 3861-3869.

[16] Nachtigall, A.M., Stringheta, P.C., Fidelis, P.C., Nachtigall, F.M. 2007, "Determinação do teor de luteína em hortaliças". B. Ceppa, Curitiba., Vol. 25, No. 2, pp. 181-192.

[17] Nascimento, A.M., Costa, F.B., Silva, J.L., Araújo, C.R., Formiga, A.S., 2017, “Compostos bioativos do pimentão verde in natura e desidratado". Revista verde de agroecologia e desenvolvimento sustentável, Vol. 12, No.3, pp. 552555. 
[18] Navarro, J., Flores, P., Garrido, C., Martinez, V. 2006, "Changes in the contents of antioxidant compounds in pepper fruits at different ripening stages, as affected by salinity". Food Chemistry., Vol. 96, No. 1, pp. 66-73.

[19] Oliveira, C.D, Braz, L.T; Santos, J.M, Banzatto, D.A, Oliveira, P.R. 2009, "Resistência de pimentas a nematóides de galha e compatibilidade enxerto/porta-enxerto entre híbridos de pimentão e pimentas". Horticultura Brasileira., Vol. 27, No. 4, pp. 520-526.

[20] Pimentel, F., Pinto, F.T., Schmitt, L. 2019, "Pimentão". Disponível em: <http://www.ufrgs.br/afeira/materiasprimas/hortalicas/pimentao/caracteristicas>. Acesso em: 18 outubro de 2019.

[21] Souza, S.G. 2017, "Produtividade e qualidade de pimentão amarelo sob diferentes níveis de depleção de água no substrato". Dissertação (Mestrado em Agronomia), Universidade Federal do Vale do São Francisco, pp. 1-98.

[22] Scivittaro, W.B., Melo, A.M.T., Tavares, M., Azevedo Filho, J.A., Carvalho, C.R.L., Ramos, M.T.B. 1999, "Caracterização de híbridos de pimentão em cultivo protegido". Horticultura Brasileira., Vol. 17, No. 2, pp. 147-150.

[23] Serrano, M., Zapata, P. J., Castillo, S., Guillén, F., Martínezromero, D., Valero, D. 2010, “Antioxidant and nutritive constituents during sweet pepper development and ripening are enhanced by nitrophenolate treatments". Food Chemistry., Vol. 118, No. 3, pp. 497-503.

[24] Waterhouse, A. 2006, "Folin-ciocalteau micro method for total phenol in wine". American Journal of Enoiogy and Viticulture.

[25] Vilas Boas, R.M., Siqueira, H.H., Leme, S.C., Lima, L C.O., Alves, T.C., 2012, “Conservação de pimentão verde minimamente processado acondicionado em diferentes embalagens plásticas”. Pesq. Agropec. Trop., Vol. 42, No. 1, pp. 34-39. 


\section{Capítulo 16}

Qualidade físico-química de Cladódios jovens de palma minimamente processados

\section{Larissa Félix Macêdo}

Ana Marinho do Nascimento

Jéssica Leite da Silva

Tatiana Marinho Gadelha

\section{Charlene Maria Alcântara}

\section{Franciscleudo Bezerra da Costa}

Resumo: 0 broto de palma surge como uma hortaliça alternativa para o consumo humano. Desse modo, objetivou-se estudar a qualidade físico-química dos cladódios jovens da palma 'Orelha de Elefante Mexicana' minimamente processados. O experimento foi realizado no Laboratório de Química, Bioquímica e Análise de Alimentos do Centro de Ciências e Tecnologia Agroalimentar da Universidade Federal de Campina Grande, Campus Pombal, PB. Foram utilizados cladódios jovens de palma "Orelha de Elefante Mexicana" entre 12-16 cm de comprimento. Os cladódios foram submetidos as etapas de processamento sendo elas: lavagem, sanitização, enxágue, retirada dos espinhos, corte em processador e embalagem que foram armazenados por $48 \mathrm{~h}$ em temperatura controlada $\left(22 \pm 2{ }^{\circ} \mathrm{C}\right) . \quad \mathrm{O} \quad \mathrm{pH}$ dos cladódios jovens minimamente processados apresentou um aumento de 3,9 para 4,3. A acidez titulável diminuiu com o avanço do tempo de armazenamento, passando de 1,3 para $0,6 \%$. Os sólidos solúveis reduziram de 5,2 para 4,3\%. Houve um acréscimo dos açúcares de 2,0 para 2,3 g 100 g-1. As clorofilas aumentaram para 1,4 mg 100 g-1. 0 ácido ascórbico aumentou de 5,2 para $5,8 \mathrm{mg} 100 \mathrm{~g}$-1. 0 armazenamento influenciou nas características físico-químicas analisadas, mas, os cladódios jovens da palma "Orelha de Elefante Mexicana" minimamente processados ainda configuram um produto de possível inserção na alimentação humana e agregação de valor para os pequenos produtores dessa cultura.

Palavras-chave: Ácido ascórbico, consumo humano, Opuntia ssp. 


\section{INTRODUÇÃO}

A palma é uma cactácea de grande relevância mundial que vem sendo cultivada em diversas regiões semiáridas do mundo, seu crescimento ocorre de forma acentuada indicando a sua importância para a alimentação humana, visto que apresenta-se como uma boa fonte de nutrientes, possuindo sabor bastante palatável e alta digestibilidade (LIRA; SANTOS et al., 2006; SAMPAIO et al., 2005).

A palma "Orelha de Elefante Mexicana" (Opuntia stricta Haw), exprime desenvolvimento horizontal, dispõe de abundantes frações de matéria seca e possui pêlos. No sertão paraibano, as palmas "Gigante" e "Redonda" (Opuntia fícus-indica (L.) Mill.) e "Miúda" (Nopalea cochenilifera (L.) Salm Dyck) tem sido substituídas pela "Orelha de Elefante Mexicana", em consequência a sua elevada resistência a doenças, estiagem e a sua produtividade (FORMIGA, 2016).

Embora, ainda seja pouco utilizado na alimentação humana, o cladódio jovem de palma se apresenta como boa fonte de nutrientes. Ele é suculento, constituído principalmente de água e carboidratos, incluindo fibras, proteínas e minerais. Contêm ainda valores consideráveis de fitoquímicos com propriedades antioxidantes quando comparado a outras hortaliças (FARIAS, 2013). Para dieta humana, a palma tem sido utilizada em preparações culinárias, sendo os cladódios denominados de verduras e os frutos consumos in natura ou processado (MOURA et al., 2009; REINOLDS; ARIAS, 2017). Os cladódios têm sido investigados para o tratamento de gastrite, hiperglicemia, aterosclerose, diabetes e hipertrofia prostática (ENNOURI et al., 2006).

A execução de estudos favorece a agregação de valores a essas espécies, que exprimem potencial como alternativa alimentar e fonte de renda complementar para agricultores de todo o mundo (ASSUNÇÃO; SOUZA et al., 2008). Com isso, objetivou-se avaliar as características físico-químicas de cladódios jovem de palma "Orelha de Elefante Mexicana" minimamente processados, durante o período de armazenamento de 48 horas.

\section{MATERIAL E MÉTODOS}

\subsection{MATERIAL VEGETAL}

Foram utilizados cladódios de palma da espécie "Orelha de Elefante Mexicana" Opuntia tuna (L.) Mill de ordem primária articulados ao cladódio mãe e secundária articulados ao cladódio primário entre 12-16 $\mathrm{cm}$ de comprimento. Os mesmos foram colhidos manualmente no início da manhã das 6:50 às 7:30 h, com aparência fresca e cor característica evitando-se os danificados. Logo após foram conduzidos até o Laboratório de Química, Bioquímica e Análise de Alimentos do Centro de Ciências e Tecnologia Agroalimentar da Universidade Federal de Campina Grande, Campus Pombal.

\subsection{PROCESSAMENTO MÍNIMO DOS CLADÓDIOS}

Os cladódios foram acondicionados em bandejas plásticas previamente sanitizadas e identificadas, sendo novamente selecionados visualmente quanto à ausência de injúrias de modo a obter amostras uniformes e com qualidade. Na higienização os cladódios foram lavados em água corrente para remover resíduos aderidos na superfície (Figura 1A), logo após foram submetidas à sanitização em solução 200 ppm (dicloroisocianurato de sódio dihidratado) por 10 minutos, seguido de enxágue em solução de 5 ppm (dicloroisocianurato de sódio dihidratado) por 10 minutos (Figura 1B). Logo após foi realizado o corte manualmente com auxílio de lâminas de aço inoxidável, retirando-se os espinhos e as bordas dos cladódios (Figura 1C). 
Figura 1. Fluxograma do processamento de cladódios de palma orelha de elefante.

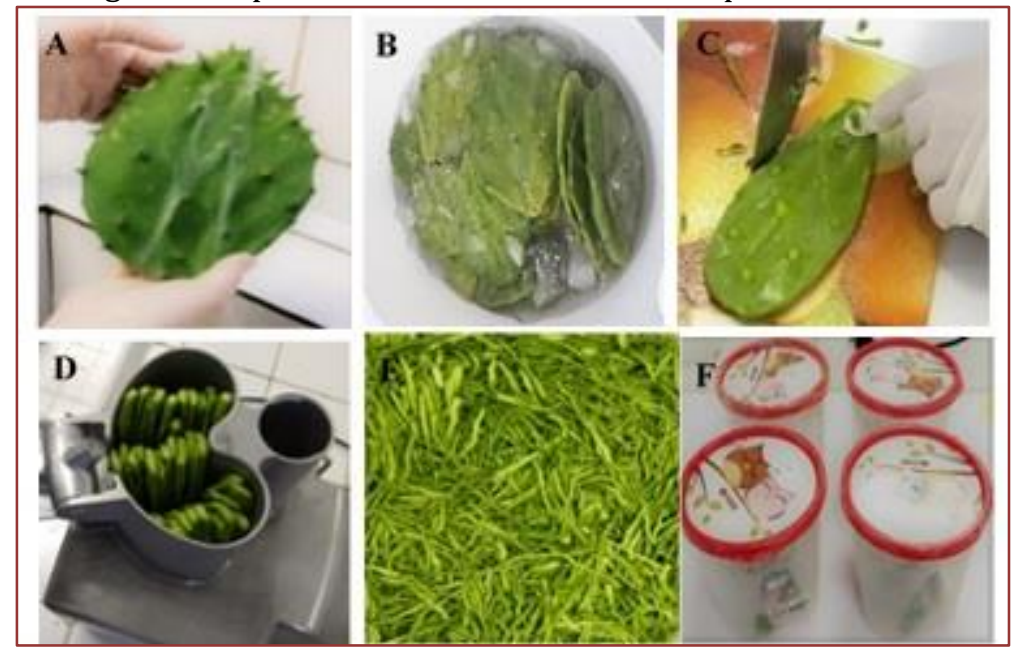

Os cladódios foram fatiados em processador mecânico de hortaliças (Robot Coupe CL 50 Ultra) em lâmina de $2 \mathrm{~mm}$ espessura, sendo colocados em sentido longitudinal para a obtenção de cortes transversais (Figura 1D), seguido de seleção para retirada de fatias desuniformes (Figura 1E). As amostras foram acondicionadas em recipientes plásticos de 1,6 litros e armazenadas por $48 \mathrm{~h}$ em temperatura controlada $\left(22 \pm 2^{\circ} \mathrm{C}\right)$ (Figura $\left.1 \mathrm{~F}\right)$.

\subsection{DELINEAMENTO}

0 delineamento esperimental utilizado foi o inteiramente casualizado, com três tratamentos representando os tempos de armazenamento $(0,24$ e 48$)$.

\subsection{ANÁLISES REALIZADAS}

\subsubsection{POTENCIAL HIDROGENIÔNICO}

As amostras foram homogeneizadas e o $\mathrm{pH}$ determinado em potenciômetro digital de bancada (modelo DM-22). 0 procedimento foi realizado conforme as normas do Instituto Adolfo Lutz (2008).

\subsubsection{ACIDEZ TITULÁVEL}

Foi pesado 3,0 g da amostra, homogeneizado em $47 \mathrm{~mL}$ de água destilada. A solução foi titulada com $\mathrm{NaOH}$ $0,1 \mathrm{~N}$ até atingir o ponto de viragem do indicador fenoftaleína, confirmado pela faixa de $\mathrm{pH}$ do indicador de 8,2. A acidez titulável foi expressa como porcentagem de ácido abundante na palma equivalente à quantidade de $\mathrm{NaOH} 0,1 \mathrm{~N}$ gasto na titulação. 0 procedimento foi realizado segundo as normas analíticas do Instituto Adolfo Lutz (2008).

\subsubsection{SÓLIDOS SOLÚVEIS}

O suco celular foi extraído a partir de cladódio de palma minimamente processados triturados com auxílio de um microprocessador (RI7632 650W - Arno) e o suco filtrado em duas camadas de algodão, utilizando um refratômetro digital (Megabrix BZW45) com compensação automática de temperatura. A análise foi efetuada de acordo com as normas apresentadas pelo Instituto Adolfo Lutz (2008). 


\subsubsection{AÇÚCARES SOLÚVEIS}

Foram estimados como descrito por Yemm e Willis (1954) com adaptações. Cerca de 2,0 g da amostra foi macerado em $3 \mathrm{~mL}$ de água destilada e completado o volume para $75 \mathrm{~mL}$, o extrato filtrado em papel filtro e uma alíquota de $15 \mu \mathrm{L}$ do extrato diluído mais $985 \mu \mathrm{L}$ de água destilada e $2000 \mu \mathrm{L}$ de Antrona foram utilizados para reação em água fervente, por 10 minutos, seguido de resfriamento, em água com gelo, até temperatura ambiente. As leituras foram realizadas a $620 \mathrm{~nm}$, em spectrum SP-1105.

\subsubsection{CLOROFILAS}

Foram determinados de acordo com o método de Lichtenthaler (1987). Pesou-se 1,0 g da amostra colocou-se em almofariz com 0,2 g de carbonato de cálcio e $3 \mathrm{~mL}$ de acetona a $80 \%$, macerou-se e transferiu-se o extrato para um tubo falcon completando-se o volume para $5 \mathrm{~mL}$. Logo após, centrifugouse por 10 minutos a $10{ }^{\circ} \mathrm{C}$ e $3000 \mathrm{rpm}$. Tomou-se uma alíquota numa cubeta e fez-se as leituras em espectrofotômetro nas absorbâncias de 470, 646 e 663 nm, em spectrum SP-1105.

\subsection{6 ÁCIDO ASCÓRBICO}

Foi pesado 3,0 g da amostra triturada, completado o volume para $47 \mathrm{~mL}$ com ácido oxálico $0,5 \%$ e titulado contra a solução de Tillmans (2,6 diclorofenol indofenol $0,2 \%)$ até o ponto de viragem conforme descrito pelo Instituto Adolfo Lutz (2008).

\subsection{ANÁLISE ESTATÍSTICA}

A comparação entre os tratamentos foi realizada pela análise de variância anova, utilizando o teste de Tukey com um nível de $5 \%$ de probabilidade. Os dados foram analisados por meio do software AgroEstat@ (SILVA; AZEVEDO, 2016).

\section{RESULTADOS E DISCUSSÃO}

Verificou-se que o valor de $\mathrm{pH}$ apresentou diferença significativa entre os tempos de armazenamento (Figura 2). Nota-se que o $\mathrm{pH}$ dos cladódios jovens minimamente processados apresentou um aumento de 3,9 para 4,3, indicando redução da acidez com o armazenamento. Podendo estar associado ao consumo dos ácidos orgânicos pelo processo respiratório (ALVES et al. 2010), o que provavelmente ocorreu durante o armazenamento. Pereira et al., 2013, analisando o processamento mínimo em brotos de palma da variedade "Gigante" obteve valores semelhantes ao deste trabalho, que variaram em torno de 4,4.

Figura 2. Potencial hidrogeniônico em cladódios jovens de palma minimamente processados.

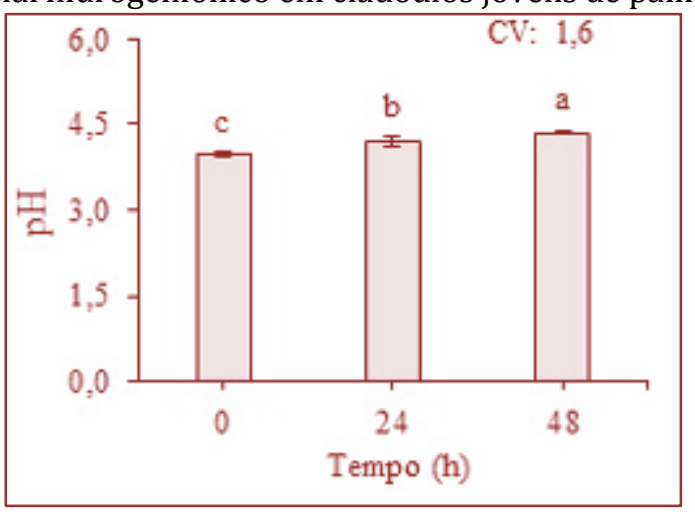

Houve diferença significativa na acidez titulável entre os tempos de análise (Figura 3). Verificou-se uma diminuição dos valores de acidez com o avanço do tempo de armazenamento, passando de 1,3 para 0,6\% nos cladódios jovens com $48 \mathrm{~h}$ de armazenamento, corroborando com a reposta do pH (Figura 2). 
Conforme Alves et al. (2010), a proporção de ácidos orgânicos tende a diminuição durante o processo de oxidação dos ácidos no ciclo dos ácidos tricarboxilícos.

Figura 3. Acidez titulável em cladódios jovens de palma minimamente processados.

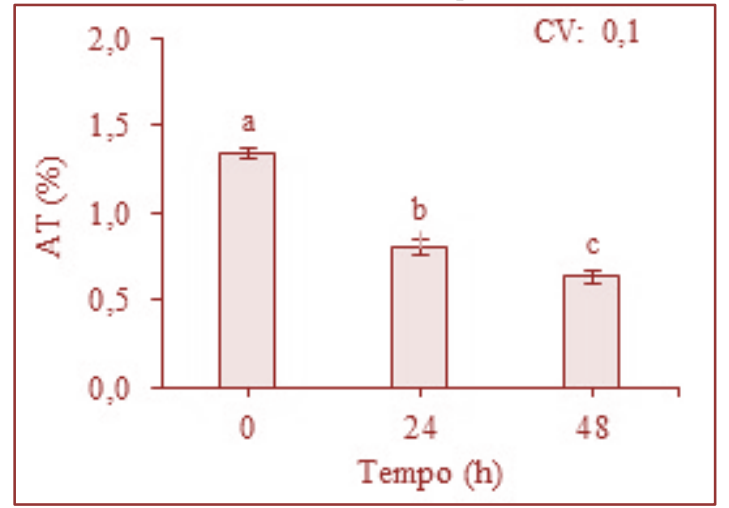

Os teores de sólidos solúveis apresentaram diferença significativa entre os tempos de armazenamento (Figura. 4). Os sólidos solúveis diminuíram até o tempo de $24 \mathrm{~h}$, seguido de um pequeno aumento no tempo de 48 h, mas no geral, os valores diminuíram de 5,2 para 4,3\%. 0 conteúdo de sólidos solúveis é empregado como um parâmetro indireto do teor de açúcares, visto que seu valor pode ser elevado conforme estes vão se depositando no vegetal. Contudo, a palma apresenta baixa quantidade de açúcares, indicando que a quantidade de sólidos solúveis não equivale ao conteúdo exato destes, estando associado a vitaminas, fenólicos, pectinas, ácidos orgânicos e diversas substâncias também estarem dissolvidas no conteúdo celular (CHITARRA; CHITARRA, 2005).

Figura 4. Sólidos solúveis em cladódios jovens de palma minimamente processados.

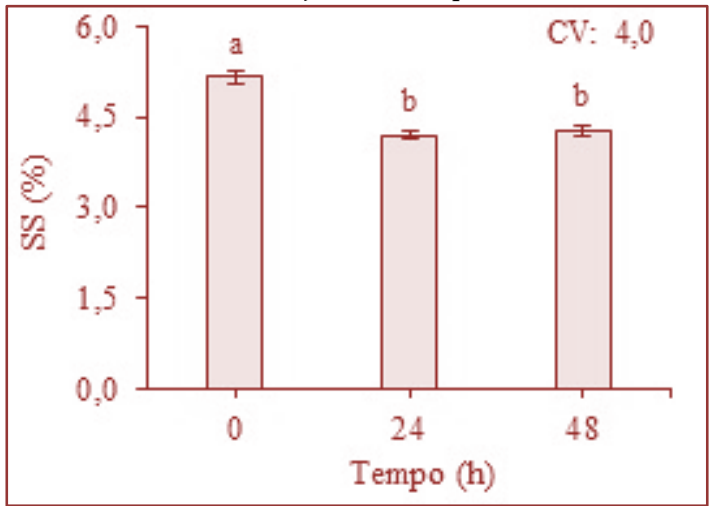

Nos açúcares solúveis foram verificados diferença significativa com o tempo de armazenamento (Figura 5). Foi observado um acréscimo dos açúcares com o avanço das $48 \mathrm{~h}$, aumentando de 2,0 a 2,3 g $100 \mathrm{~g}^{-1}$. Conforme Ayadi et al. (2009), a Opuntia fícus-indica F. Amyloceae apresenta 2,49\% de açúcares solúveis (base seca) valor próximo ao encontrado nessa pesquisa. De acordo com Souza Filho (2014), a palma forrageira apresenta alto teor de polissacarídeos, tanto celulose, que consiste de um biopolímero de moléculas de glicose, quanto hemicelulose que se apresenta como um polímero heterogêneo formado por cadeias curtas lineares e ramificadas de açúcares, tais como D-xilose, D-galactose, D-manose e Darabinose. Porém o seu alto teor de lignina pode favorecer a existência de uma barreira maior que impeça a hidrólise destes polissacarídeos em açúcares fermentescíveis. 
Figura 5. Açúcares solúveis em cladódios jovens de palma minimamente processados.

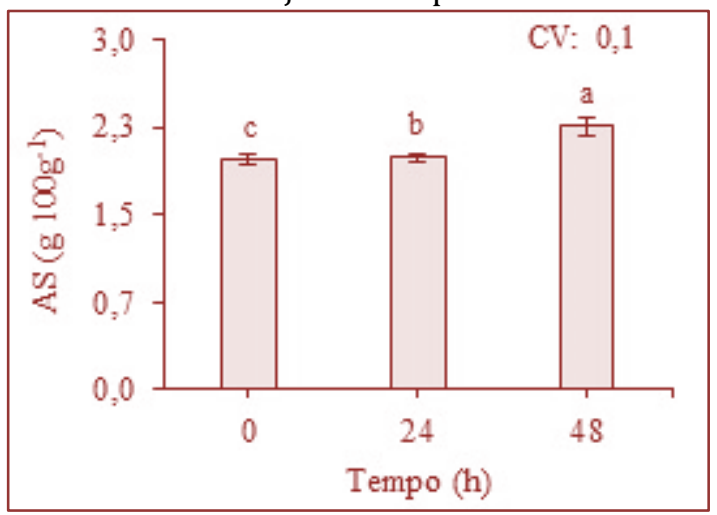

A proporção de clorofila total nos cladódios jovens de palma minimamente processados diferiu estatisticamente entre os tempos de armazenamento (Figura 6). Os valores aumentaram de 0,8 para 1,4 mg $100 \mathrm{~g}^{-1}$. A literatura presume uma redução exponencial da clorofila durante o armazenamento (MORAWICKI et al., 1999; STEET; TONG, 1996). Ainda assim, o resultado obtido foi um aumento na concentração da clorofila com o armazenamento. Em conformidade com Berset; Caniaux (1983), isso pode ter acontecido por interferência de outros pigmentos constituídos durante o período de armazenamento, desde que apresentem absorção nos comprimentos de onda utilizados para o cálculo dos pigmentos clorofílicos, o que é permitido pelas limitações da espectrofotometria.

Figura 6. Clorofila total em cladódios jovens de palma minimamente processados.

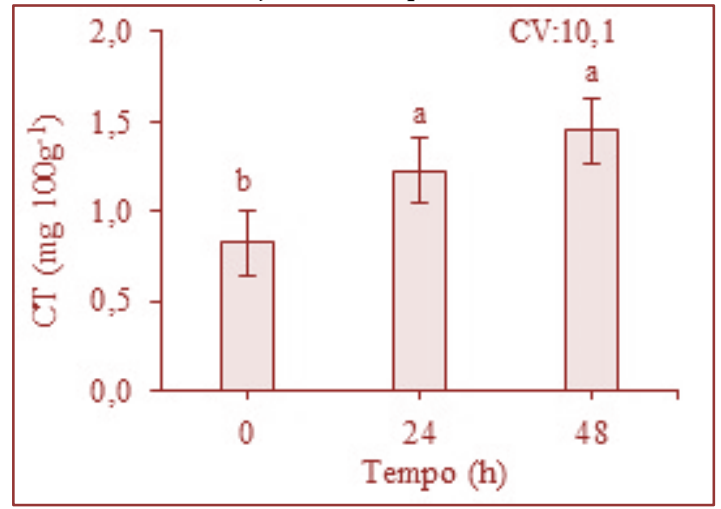

Os teores de ácido ascórbico diferiram entre os tempos de armazenamento, sendo observado aumento de 5,2 para 5,8 mg $100 \mathrm{~g}^{-1}$ (Figura 7). Nunes (2011) encontrou teores de ácido ascórbico em brotos de palma (Opuntia fícus-indica), em torno de $11,02 \mathrm{mg} 100 \mathrm{~g}^{-1}$, diferindo dos resultados encontrados no presente trabalho, o que pode ser atribuído a alterações pelo método de determinação, pelo processamento, armazenamento e ainda por condições de cultivo, conforme afirma Farias (2013). 
Figura 7. Ácido ascórbico em cladódios jovens de palma minimamente processados.

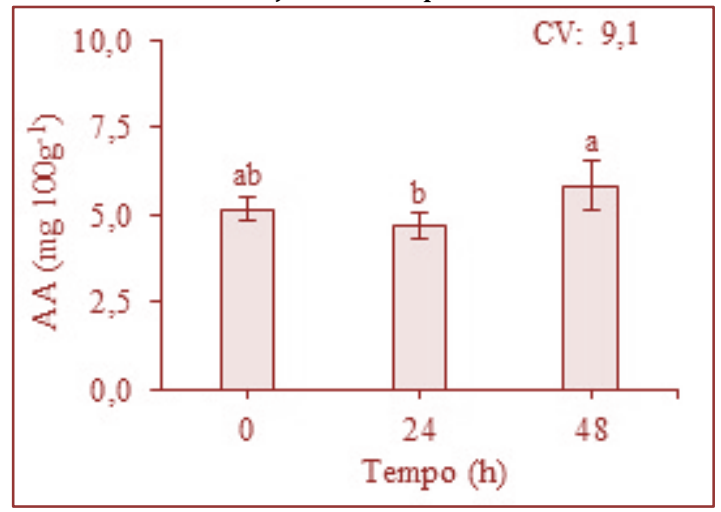

\section{CONCLUSÃO}

As características físico-químicas dos cladódios jovens da palma "Orelha de Elefante Mexicana" minimamente processados foram influenciadas pelo armazenamento, mesmo assim, constituem uma alternativa viável ao consumo humano, além de uma possibilidade de geração de renda aos produtores dessa cultura.

\section{AGRADECIMENTOS}

A Universidade Federal de Campina Grande; Centro de Ciência e Tecnologias Agroalimentar; Laboratório de Química, Bioquímica e Análise de Alimentos; Grupo de Pesquisa em Ciência, Tecnologia e Engenharia de Alimentos e Unidade Acadêmica de Tecnologia de Alimentos, Campus Pombal.

\section{REFERÊNCIAS}

[1] Alves, J.A, Boas, E.V.B., Boas, B.M.V. 2010, "Qualidade de produto minimamente processado à base de abóbora, cenoura, chuchu e mandioquinha-salsa", Ciência e Tecnologia de Alimentos, Campinas, Vol. 30, No. 3, pp. 625634.

[2] Assunção, M.A., S.A.C.M., Gamarra-Rojas, G., Guerra, N.B. 2008, "Fruto de palma (Opuntia fícus-indica L.) Miller, Cactaceae]: morfologia, composição química, fisiologia índices de colheita e fisiologia pós-colheita", Revista Iberoamericana de Tecnología Postcosecha, Hermosillo, México, Vol. 9, No. 1, pp. 16-25.

[3] Ayadi, M.A., Abdelmaksoud, W., Ennouri, M., Attia, H. 2009, "Cladodes from Opuntia ficus indica as a source of dietary fiber: Effect on dough characteristics and cake making”, Industrial crops and products, Vol. 30, No.1, pp. 40-47.

[4] Berset, C., Caniaux, P. 1983, "Relationship between color evaluation and chlorophyllian pigment contente in frif parsley leaves". Journal of Food Science, Vol.48, pp. 1854-1857.

[5] Chitarra, M.I.F., Chitarra, A.B. 2005, “Pós Colheita de Frutas e Hortaliças: Fisiologia e Manuseio”, 2a Edição, Lavras- MG: UFLA.

[6] Ennouri, M., Fetoui, H., Bourret, E., Zeghal, N., Attia, G., Fadhel, H. 2006, "Evaluation of some biological parameters of Opuntia ficus indica". 2. Influence of seed supplemented diet on rats. Bioresource technology, Vol. 97, No. 16, pp. 2136-2140.

[7] Farias, V.F.S. 2013, "Avaliação do desenvolvimento, qualidade e capacidade antioxidante em brotos de palma (opuntia sp.) para o consumo humano", Dissertação (Mestrado em Sistemas Agroindustriais), Universidade Federal de Campina Grande, Pombal-PB.

[8] Formiga, A.D.S. 2016, "Atividade de polifenoloxidase e peroxidase em diferentes estádios de maturação de brotos de palma", Monografia (Graduação em Engenharia de Alimentos), Universidade Federal de Campina Grande, Pombal, PB.

[9] Instituto Adolfo Lutz, 2008, "Normas Analíticas do Instituto Adolfo Lutz-Métodos químicos e físicos para análise de alimentos", Vol. 1, 4. Ed, São Paulo.

[10] Lichtenthaler, H.K., 1987, “Chlorophylls and carotenoids: pigments of photosynthetic biomembranes", Methods in Enzymology, London, Vol. 148, pp. 350-352. 
[11] Lira, M.A., Santos, M.V.F., Cunha, M. V., Mello, A.C.L., Farias, I., Santos, D.C., 2006, “A Palma Forrageira na Pecuária do Semi-árido", Alternativas Alimentares para Ruminantes, Aracaju: Embrapa Tabuleiros Costeiros, Vol. 1, pp. 17-33.

[12] Moura, L.B., Rocha, E.M.F., Sousa, E.M., Magalhães, S. F., Holanda Neto, J.P. 2009, "Elaboração de produtos alimentícios à base de palma (Opuntia fícus indica) e do seu fruto". Revista Verde de Agroecologia e Desenvolvimento Sustentável, Vol. 4, pp. 146-161.

[13] Morawicki, R.O., Schmalko, M.E., Kanzig, R.G., 1999, “Chlorophyll Stability in yerba maté leaves in controlled atmospheres", Brazilian archives of biology and technology, Vol.42, No. 1, pp. 85-90.

[14] Nunes, C.S. 2011, "Usos e aplicações da palma forrageira como uma grande fonte de economia para o semiárido nordestino", Revista Verde de Agroecologia e Desenvolvimento Sustentável, Mossoró, Vol. 6, No. 1, pp.5866.

[15] Pereira, E.M., Costa, F.B., Albuquerque, J.R.T., Rocha, T.C., Costa, R.T.R.V. 2013, “Qualidade pós-colheita e processamento mínimo de brotos de palma Opuntia ficus-indica Mill". Revista Verde de agroecologia e Desenvolvimento Sustentável, Mossoró-RN, Vol. 8, No. 3, pp. 229-234.

[16] Reinolds, S.G., Arias, E. 2004, “General background on opuntia". Disponível em: <http://www.fao.org/DOCREP/005/2808E/y2808e04.htm. >Acesso em: 20 de outubro de 2019.

[17] Sampaio, E.V.S., Menezes, R.S.C., Salcedo, I., 2005, "Produtividade de palma em propriedades rurais", A palma no Nordeste do Brasil: conhecimento atual e novas perspectivas de uso. Recife, pp. 129-141.

[18] Silva, F.A.S., Azevedo, C.A.V. 2016, "The Assistat Software Version 7.7 and its use in the analysis of experimental data", African Journal of Agricultural Research, Vol. 11, No.39, pp.3733-3740.

[19] Souza Filho, P.F. 2014, "Palma forrageira (Opuntia ficus indica e Napolea cochenilifera) como matéria-prima para produção de etanol celulósico e enzimas celulolíticas”, Dissertação (Mestrado em Engenharia Química), Centro de Tecnologia, Universidade Federal do Rio Grande do Norte, Natal.

[20] Steet, J.A., Tong, C.H. 1996, "Degradation kinetics of green color and chlorophylls in peas by colorimetry and HPLC", Jounal of Food Science, Vol. 61, No.5, pp. 924-931.

[21] Yemm, E.W., Willis, A.J., 1954, "The estimation of carbohydrates in plant extracts by anthrone". The Biochemical Journal, Vol. 57, pp. 508-514. 


\section{Capitulo 17}

\section{Corante natural do pimentão vermelho aplicado em gelados comestíveis}

\section{Yaroslávia Ferreira Paiva \\ Plínio Tércio Medeiros de Azevedo \\ Dayanne Kelly Pereira Abreu \\ Agda Malany Forte de Oliveira \\ Alfredina dos Santos Araújo}

Resumo: 0 pimentão é considerado uma das hortaliças mais importantes em termos de produção e valor comercial, pois além de ser utilizado na sua forma in natura em saladas e em preparações culinárias, também é utilizado na fabricação de corantes naturais, condimentos, temperos, conservas e molhos. Como o uso dos corantes sintéticos levantam uma série de questionamentos com relação ao seu uso e malefícios causados na saúde dos consumidores, objetivou-se extrair corantes do pimentão vermelho com diferentes solventes e adiciona-los em gelados comestíveis. Para tanto, a partir do farelo do pimentão vermelho, foram extraídos dois tipos de corante, onde o alcoólico foi extraído utilizando o etanol (1:6) e o hidroalcoólico utilizando 30\% de água deionizada e $70 \%$ de etanol (1:6). Os corantes obtidos foram adicionados às formulações de dois tipos de gelados comestíveis (picolé e dindim), na proporção de 0,5\%, 1\% e $2 \%$ de cada corante separadamente e uma amostra sem adição de corante, obtendo assim sete formulações por tipo de gelado. As quatorze amostras foram posteriormente caracterizadas através de análises físico-químicas e condições microbiológicas. Ao avaliar a maioria dos parâmetros, pode-se concluir que o corante foi adicionado de forma eficaz, se comportando como um aditivo nos gelados comestíveis, não apresentando diferença significativa na maioria dos parâmetros analisados.

Palavras-chave: Capsicum annuum L., aditivos, pigmentos alimentares. 


\section{INTRODUÇÃO}

Pertencente à família das Solanáceas, o pimentão vermelho (Capsicum Annuum L.) (GOMES et al., 2014) apresenta a cor verde nos primeiros estádios de maturação e com o passar do tempo passa para as tonalidades amarelo e vermelho (BARBOSA-SILVA, 2014). No Brasil e em outros países, é considerado como uma das hortaliças mais importantes em termo de volume de produção e valor comercial (GOMES et al., 2014).

A maioria dos frutos do pimentão são consumidos in natura, sendo possíveis outras utilizações, como no caso do pimentão vermelho que tem ganhado importância na indústria alimentícia devido a sua alta carga de pigmentos naturais, conferindo cor aos produtos adicionados como sopas e produtos cárneos (REIFSCHNEIDER, 2000; GOMES 2012).

A indústria de alimentos utiliza a adição de corantes com o intuito de conferir, intensificar ou restaurar a cor dos produtos (BRASIL, 1997). Levando em consideração que a aceitação de um alimento pelo consumidor usa comumente da visão para descobrir fatores sensoriais como a cor para sentirem-se atraídas ou inibidas com relação a compra de determinado produto, já que não podem provar o mesmo antes da compra. (ROCHA \& REED, 2014)

O uso de corantes sintéticos é um dos mais questionáveis avanços no ramo alimentício, já que seu uso é apenas questões de hábitos alimentares, não adicionando nenhuma vantagem nutricional para o produto (PRADO \& GODOY, 2009). Além disso, nos últimos anos tem se falado dos malefícios que foram descobertos em estudos toxicológicos, onde a utilização de diversos corantes artificiais tem sido proibidos na indústria alimentícia, consequentemente, uma nova tendência tem sido notada nas indústrias em relação à substituição do corante artificial pelo corante natural nos alimentos (SOUZA, 2012).

Gelados comestíveis são produtos alimentícios obtidos a partir de uma emulsão de gorduras e proteínas, com ou sem adição de outros ingredientes e substâncias, ou de uma mistura de água, açúcares e outros ingredientes e substâncias que tenham sido submetidas ao congelamento (BRASIL, 1999). Segundo a Mintel (2018) espera-se que o mercado desses produtos brasileiros atinja até 2020 mais de $80 \%$ de crescimento em relação aos anos antecedentes. Sendo assim, torna-se um excelente meio para substituição dos corantes artificiais normalmente utilizados, pelo corante natural extraído do pimentão vermelho.

Diante do exposto, objetivou-se obter corantes extraídos de forma alcoólica e hidroalcoólica do pimentão vermelho e utilizá-los como corante em formulações de gelados comestíveis, além de avaliar a qualidade desses produtos através de análises físico-químicas e microbiológicas.

\section{MATERIAL E MÉTODOS}

\subsection{OBTENÇÃO DA MATÉRIA-PRIMA}

O pimentão vermelho utilizado foi obtido no comércio da cidade de Pombal, Paraíba. Os frutos foram acondicionados em caixas isotérmicas e em seguida transportados para o Laboratório de Microbiologia de Alimentos e para o Laboratório de Química do Centro de Ciências e Tecnologia Agroalimentar (CCTA) da Universidade Federal de Campina Grande (UFCG) em Pombal-PB, onde foram realizados todos os procedimentos e análises que constam nessa pesquisa.

\subsection{OBTENÇÃO DO FARELO}

Após a chegada dos pimentões ao laboratório, os frutos foram selecionados de acordo com sua coloração, lavados em água corrente para retirar possíveis sujidades oriundas do campo, em seguida foram sanitizados por imersão com a utilização de hipoclorito de cloro na concentração de $200 \mathrm{ppm}$, por um período de 20 minutos. Posteriormente, foram lavados em água destilada em três repetições para retirar o resíduo do sanitizante. Os frutos seguiram para etapa de beneficiamento, onde inicialmente foi realizada a retirada dos pedúnculos e sementes, em seguida foram cortados em tiras de aproximadamente $2 \mathrm{~cm}$ de largura.

As amostras adquiridas foram submetidas a processos de secagem utilizando estufa microprocessada de circulação de ar a uma temperatura de $60^{\circ} \mathrm{C}$ nas primeiras duas horas e $55^{\circ} \mathrm{C}$ nas últimas 12 horas, conforme metodologia descrita por Spoto (2006).

Após a secagem, os pimentões foram moídos em moinho de facas com 4 lâminas de aço inoxidável e peneira de 10 mesh. 0 farelo produzido foi coletado em potes plásticos previamente esterilizados e armazenados em ambiente escuro e seco até o momento de execução das análises. 


\subsection{OBTENÇÃO DOS CORANTES}

As extrações foram realizadas na proporção de 1:6 (amostra:solvente) e os solventes utilizados foram o álcool etílico (95\%) para os extratos alcoólicos, água deionizada para os extratos aquosos, $70 \%$ de álcool etílico e $30 \%$ de água deionizada para os extratos hidroalcoólicos, seguindo esta ordem de polaridade para a extração. As amostras foram homogeneizadas durante uma hora, sendo em seguida, filtradas em funil de Büchner com auxílio de uma bomba à vácuo. Posteriormente, o liquido proveniente da filtração foi submetido a extração por meio do equipamento Rotaevaporador à uma temperatura de $60^{\circ} \mathrm{C}$ por 2 horas. Os extratos obtidos foram coletados em recipientes de vidro envolvidos com papel alumínio para proteger da luz e estocado em refrigerador a uma temperatura de $-5^{\circ} \mathrm{C}$ (TORRES et al., 2002).

Para conseguir o máximo de corante, o álcool etílico recuperado durante a extração foi adicionado novamente na amostra residual para uma nova extração, onde foram submetidos aos mesmos procedimentos descritos anteriormente Silva et al. (2017).

\subsection{ELABORAÇÃO DOS GELADOS COMESTÍVEIS}

Os produtos foram elaborados no laboratório de análise sensorial da Universidade Federal de Campina Grande, campus Pombal - PB. Os ingredientes utilizados na elaboração foram adquiridos no comércio local da cidade de Pombal - PB. Foram elaboradas sete formulações de cada tipo de gelado comestível (picolé e dindim), sendo uma amostra controle, sem adição de corante (P0 (picolé), D0 (dindim)), três amostras com adição de 0,5\%, 1\% e 2\% do corante alcoólico (PA1, PA2 e PA3 (picolé), DA1, DA2 e DA3 (dindim)) e as demais com adição de 0,5\%, 1\% e 2\% do corante hidroalcoólico (PH1, PH2 e PH3 (picolé), DH1, DH2 e DH3 (dindim)).

Os ingredientes utilizados para elaboração do picolé foram: leite integral UHT (67\%), açúcar cristal (13\%), leite em pó integral (6\%), creme de leite (13\%), liga neutra (0,5\%), saborizante $(0,5 \%)$.

Para a produção dos dindins os ingredientes utilizados foram: leite integral UHT (75\%), leite condensado (24\%) e saborizante $(1 \%)$.

Para elaboração de ambos os produtos (picolés e dindins), todos os ingredientes foram pesados em balança analítica, em seguida foram misturados e submetidos à pasteurização a $65^{\circ} \mathrm{C}$ por 30 minutos com agitação constante e resfriados até atingir $4^{\circ} \mathrm{C}$, sendo posteriormente adicionados os corantes e as misturas foram acondicionadas nas suas respectivas embalagens.

\subsection{CARACTERIZAÇÃO DOS GELADOS COMESTÍVEIS}

\subsubsection{ANÁLISES FÍSICO-QUÍMICAS}

Foram avaliados os seguintes parâmetros: acidez (\%), potencial hidrogeniônico (pH), umidade (\%), cinzas (resíduo mineral fixo) (\%), sólidos solúveis (ํㅡrix), açucares redutores (\% lactose) e açucares não redutores (\% sacarose) conforme metodologias descritas pelo IAL (2008).

\subsubsection{ANÁLISE MICROBIOLÓGICA}

Os produtos foram caracterizados microbiologicamente pelos parâmetros de Coliformes à $45^{\circ} \mathrm{C}$ (NMP/mL), Staphylococcus spp. (UFC/mL), Salmonella sp. (ausência/presença) e Contagem Total de Bactérias Aeróbias Psicotróficas (UFC/mL) utilizando metodologia descrita por Silva et al. (2010).

\subsection{ANÁLISE ESTATÍSTICA}

O delineamento experimental adotado foi o de blocos inteiramente casualizados. Os resultados serão analisados através da comparação das médias utilizando-se o teste de Tukey, com significância estatística ao nível de $5 \%$ de probabilidade. A correlação dos dados foi realizada por meio do software Sisvar (FERREIRA, 2014).

\section{RESULTADOS E DISCUSSÃO}

Os gelados comestíveis produzidos foram submetidos às análises de Coliformes à $45^{\circ} \mathrm{C}(\mathrm{NMP} / \mathrm{mL})$, Staphylococcus spp. (UFC/mL), Salmonella sp. (ausência/presença) e Contagem Total de Bactérias Aeróbias Psicotróficas (UFC/mL), onde foi verificado ausência em todos os parâmetros analisados, consequentemente, estando em satisfatórias condições sanitárias para o consumo humano. 
A Tabela 1 apresenta os resultados obtidos para as análises físico-químicas dos picolés com e sem adição de corantes, e a Tab 2, mostra os resultados para os dindins elaborados.

Tabela 1. Parâmetros físico-químicos do picolé com adição do corante natural do pimentão.

\begin{tabular}{|l|c|c|c|c|c|c|c|}
\hline \multicolumn{1}{|c|}{ Parâmetro } & P0 & PA1 & PA2 & PA3 & PH1 & PH2 & PH3 \\
\hline pH & $6,53 \pm 0,01^{\mathrm{a}}$ & $6,52 \pm 0,01^{\mathrm{a}}$ & $6,17 \pm 0,0^{\mathrm{a}}$ & $6,44 \pm 0^{\mathrm{a}}$ & $6,53 \pm 0,01^{\mathrm{a}}$ & $6,50 \pm 0^{\mathrm{a}}$ & $6,43 \pm 0,02^{\mathrm{a}}$ \\
\hline Acidez (\%) & $2,31 \pm 0,01^{\mathrm{a}}$ & $2,20 \pm 0,1^{\mathrm{ab}}$ & $2,05 \pm 0,08^{\mathrm{b}}$ & $2,17 \pm 0,01^{\mathrm{ab}}$ & $2,16 \pm 0,02^{\mathrm{ab}}$ & $2,56 \pm 0,01^{\mathrm{c}}$ & $2,71 \pm 0,01^{\mathrm{c}}$ \\
\hline Umidade (\%) & $28,01 \pm 0,7^{\mathrm{a}}$ & $30,08 \pm 0,5^{\mathrm{b}}$ & $30,38 \pm 0,5^{\mathrm{b}}$ & $29,44 \pm 0,5^{\mathrm{ab}}$ & $29,46 \pm 0,02^{\mathrm{ab}}$ & $30,83 \pm 0,8^{\mathrm{b}}$ & $33,23 \pm 0,5^{\mathrm{c}}$ \\
\hline Cinzas (\%) & $0,92 \pm 0,01^{\mathrm{a}}$ & $1,24 \pm 0,05^{\mathrm{b}}$ & $1,09 \pm 0,1^{\mathrm{ab}}$ & $1,21 \pm 0,03^{\mathrm{b}}$ & $0,92 \pm 0,01^{\mathrm{a}}$ & $0,99 \pm 0,01^{\mathrm{b}}$ & $1,08 \pm 0^{\mathrm{ab}}$ \\
\hline SST (음ix) & $33,10 \pm 0,5^{\mathrm{a}}$ & $38,53 \pm 0,8^{\mathrm{b}}$ & $34,06 \pm 0,8^{\mathrm{a}}$ & $32,80 \pm 0,9^{\mathrm{a}}$ & $33,56 \pm 0,2^{\mathrm{a}}$ & $33,76 \pm 0,3^{\mathrm{a}}$ & $33,13 \pm 0,2^{\mathrm{a}}$ \\
\hline ARL (\%) & $3,88 \pm 0,07^{\mathrm{a}}$ & $3,86 \pm 0,08^{\mathrm{a}}$ & $3,71 \pm 0,1^{\mathrm{a}}$ & $3,76 \pm 0,03^{\mathrm{a}}$ & $3,92 \pm 0,4^{\mathrm{a}}$ & $3,67 \pm 0,1^{\mathrm{a}}$ & $3,82 \pm 0,3^{\mathrm{a}}$ \\
\hline ANRS (\%) & $12,27 \pm 0,2^{\mathrm{ab}}$ & $10,11 \pm 0,6^{\mathrm{abc}}$ & $10,49 \pm 0,8^{\mathrm{abc}}$ & $13,11 \pm 0,9^{\mathrm{b}}$ & $9,06 \pm 0,07^{\mathrm{ab}}$ & $10,13 \pm 0,6^{\mathrm{abc}}$ & $8,27 \pm 0,2^{\mathrm{c}}$ \\
\hline Proteínas (\%) & $1,44 \pm 0,07^{\mathrm{a}}$ & $1,36 \pm 0,1^{\mathrm{a}}$ & $1,17 \pm 0,1^{\mathrm{a}}$ & $1,54 \pm 0,01^{\mathrm{a}}$ & $1,30 \pm 0,07^{\mathrm{a}}$ & $1,28 \pm 0,05^{\mathrm{a}}$ & $1,39 \pm 0,2^{\mathrm{a}}$ \\
\hline
\end{tabular}

Tabela 2. Parâmetros físico-químicos do dindim com adição do corante natural do pimentão.

\begin{tabular}{|l|c|c|c|c|c|c|c|}
\hline \multicolumn{1}{|c}{ Parâmetro } & D0 & DA1 & DA2 & DA3 & DH1 & DH2 & DH3 \\
\hline pH & $6,41 \pm 0,02^{\mathrm{a}}$ & $6,39 \pm 0,03^{\mathrm{a}}$ & $6,46 \pm 0,01^{\mathrm{a}}$ & $6,41 \pm 0,06^{\mathrm{a}}$ & $6,39 \pm 0,02^{\mathrm{a}}$ & $6,46 \pm 0,02^{\mathrm{a}}$ & $6,39 \pm 0,00^{\mathrm{a}}$ \\
\hline Acidez (\%) & $2,12 \pm 0,04^{\mathrm{a}}$ & $2,08 \pm 0,10^{\mathrm{a}}$ & $2,17 \pm 0,02^{\mathrm{a}}$ & $2,67 \pm 0,02^{\mathrm{a}}$ & $2,72 \pm 0,10^{\mathrm{a}}$ & $2,38 \pm 0,00^{\mathrm{a}}$ & $2,71 \pm 0,00^{\mathrm{a}}$ \\
\hline Umidade (\%) & $27,34 \pm 0,70^{\mathrm{ab}}$ & $27,34 \pm 0,60^{\mathrm{ab}}$ & $26,84 \pm 0,70^{\mathrm{ac}}$ & $28,46 \pm 0,50^{\mathrm{b}}$ & $25,56 \pm 0,40^{\mathrm{c}}$ & $22,74 \pm 0,40^{\mathrm{d}}$ & $19,91 \pm 0,30^{\mathrm{e}}$ \\
\hline Cinzas (\%) & $0,98 \pm 0,04^{\mathrm{ab}}$ & $1,06 \pm 0,01^{\mathrm{b}}$ & $0,89 \pm 0,06^{\mathrm{ac}}$ & $0,73 \pm 0,03^{\mathrm{a}}$ & $0,92 \pm 0,04^{\mathrm{abc}}$ & $0,80 \pm 0,02^{\mathrm{cb}}$ & $1,02 \pm 0,04^{\mathrm{ab}}$ \\
\hline SST (-Brix) & $30,20 \pm 0,20^{\mathrm{ab}}$ & $29,53 \pm 0,05^{\mathrm{a}}$ & $33,03 \pm 1,07^{\mathrm{c}}$ & $29,66 \pm 0,10^{\mathrm{a}}$ & $30,03 \pm 0,40^{\mathrm{ab}}$ & $30,96 \pm 1,00^{\mathrm{ab}}$ & $31,53 \pm 0,7 \mathrm{bc}^{\mathrm{bc}}$ \\
\hline ARL (\%) & $3,74 \pm 0,10^{\mathrm{a}}$ & $3,83 \pm 0,04^{\mathrm{a}}$ & $4,26 \pm 0,01^{\mathrm{a}}$ & $3,90 \pm 0,70^{\mathrm{a}}$ & $4,02 \pm 0,10^{\mathrm{a}}$ & $4,40 \pm 0,03^{\mathrm{a}}$ & $4,54 \pm 0,05^{\mathrm{a}}$ \\
\hline ANRS (\%) & $12,29 \pm 0,30^{\mathrm{a}}$ & $10,14 \pm 0,80^{\mathrm{ab}}$ & $9,97 \pm 0,60^{\mathrm{b}}$ & $10,57 \pm 0,30^{\mathrm{ab}}$ & $10,57 \pm 0,30^{\mathrm{ab}}$ & $11,20 \pm 0,50^{\mathrm{ab}}$ & $9,01 \pm 0,13^{\mathrm{b}}$ \\
\hline Proteínas (\%) & $0,82 \pm 0,07^{\mathrm{a}}$ & $0,73 \pm 0,02^{\mathrm{a}}$ & $0,77 \pm 0,12^{\mathrm{a}}$ & $0,84 \pm 0,04^{\mathrm{a}}$ & $0,76 \pm 0,11^{\mathrm{a}}$ & $0,64 \pm 0,23^{\mathrm{a}}$ & $0,77 \pm 0,01^{\mathrm{a}}$ \\
\hline
\end{tabular}

É possível observar que tanto para os picolés quanto para os dindins elaborados, os resultados expressos nas Tabelas 3 e 4 mostram que o $\mathrm{pH}$ dos produtos não diferiu estatisticamente em todas as formulações, onde os resultados dos picolés com e sem adição de corante, variariam de 6,17 a 6,53 (Tabela 1) e dos dindis estavam entre 6,39 e 6,46 (Tabela 2). Pazianotti et. al. (2010), encontrou resultados semelhantes quando avaliou sorvetes artesanais e industrializados comercializados na região de Arapongas-PR, variando de 6,38 a 6,45 .

A determinação da acidez em produtos com alto teor de leite é uma das medidas mais usadas no controle desse tipo matéria-prima pela indústria de derivados do leite (BRASIL, 1997). Houve diferença significativa entre os picolés avaliados, e uma variação de 2,05 a 2,71 para os resultados de acidez encontrados, onde a amostra PH3 apresentou a maior porcentagem. Nota-se que nos produtos adicionados de corante extraído de forma hidroalcóolica, houve aumento da porcentagem de acidez titulável de forma gradativa, onde quanto maior o teor do corante, maior a acidez. 0 mesmo aconteceu com os teores de umidade encontrados nos picolés adicionados desse tipo de corante.

Em contrapartida, os dindins elaborados com e sem adição de corantes, não diferiram estaticamente entre si, com variação de 2,08 a 2,72 .

Houve variação de 28,01 a 30,83 (Tabela 1) para os valores de umidade encontrados nos picolés, e de 19,91 a 28,46 (Tabela 2) para os dindins elaborados, em que as amostras diferiram estatisticamente entre si em relação a ambos os produtos. Em comparação com outras pesquisas (MORZELLE et. al., 2012; MONTEIRO et. al., 2015), os valores de umidade para esses tipos de gelado comestível podem ser considerados relativamente baixos. Segundo Soler e Veiga (2001), quanto maior a umidade, menor a concentração de sólidos, entretanto, os sólidos são desejados, pois atuam melhorando a textura e a cremosidade do produto elaborado.

Os valores encontrados para cinzas (\%) dos picolés e dos dindins, diferiram estatisticamente entre si e nota-se que a adição de corantes proporcionou aumento gradativo do teor de cinzas nas amostras analisadas de picolés. Contudo, ambos os produtos apresentam valores semelhantes em relação a este parâmetro, variando de 0,92 a 1,24 nos picolés e de 0,73 a 1,06 nos dindins. Estes resultados condizem com os de Lamounier et. al. (2015), quando avaliou diferentes formulações de sorvetes enriquecidos com 
farinha da casca da jabuticaba. Tais valores são justificados, pois segundo Sousa e outros autores (2010), os gelados comestíveis são ricos em diversos sais minerais (cálcio, sódio, potássio, magnésio, etc.) devido a presença do leite, amido, e demais ingredientes.

O açúcar é considerado um ingrediente importante na formulação de sorvetes, devido ao seu efeito sobre sabor, elevando assim a aceitação do produto, além disso, possui o papel de aumentar o teor de sólidos e viscosidade podendo torná-lo mais cremoso.

A Tabela 1 detalha que para os picolés avaliados, com exceção da amostra PA1, os picolés elaborados com e sem adição de corantes não diferiram estatisticamente entre si com relação aos sólidos solúveis totais. Por outro lado, a Tabela 2 expressa os valores obtidos para os dindins elaborados, onde as amostras com e sem adição de corantes diferiram estatisticamente entre si, com uma variação de 29,53 a 31,53. No entanto, ambos os produtos estão de acordo com a legislação brasileira, onde os gelados comestíveis devem atender os valores mínimos de $28 \%$ de sólidos totais (BRASIL, 1999). Os SST representam os compostos que são solúveis em água, assim Pazianotti et. al. (2010) encontrou valores próximos, que

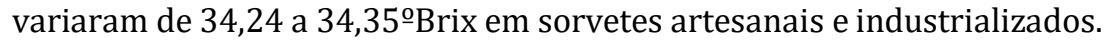

Além de influenciar no sabor, os açucares também são responsáveis pela fixação de compostos aromáticos. É importante lembrar que a lactose presente nos gelados comestíveis pode se cristalizar durante o armazenamento devido a quantidade de sólidos da mistura, temperatura de armazenamento e da quantidade de estabilizantes (COELHO; ROCHA, 2005). Os valores encontrados para açucares redutores em lactose variaram de 3,67 a 3,92 nos picolés (Tabela 1) e de 3,4 a 4,54 nos dindins, não havendo diferença significativa entre as diferentes amostras analisadas para os dois tipos de produtos, logo, não houve influência dos corantes adicionados para este parâmetro.

Em relação aos açucares não redutores em sacarose, nota-se que as amostras diferiram entre si tanto nos picolés, quanto nos dindins, onde observa-se que os resultados obtidos foram de 8, 27 para a PH3 e 13,11 para PA3 (Tabela 1) e de 9,01 para a DH3 e 12,29 para a D0. Entretanto, não é possível afirmar que a adição de corantes influenciou nos resultados obtidos, visto que tais variações não são gradativas.

As proteínas têm grande importância na qualidade dos gelados comestíveis, pois influencia no batimento, emulsificação e melhoram a estrutura (SILVEIRA et al., 2009). Podem contribuir também nas propriedades funcionais, como a interação com outros estabilizantes, estabilização da uma emulsão depois da homogeneização, contribuição para a formação da estrutura do gelado e capacidade de retenção de água, que melhora viscosidade da mistura, assim como para o aumento do tempo de derretimento do sorvete e para redução de formação do gelo (SOUZA, 2010).

Os teores de proteínas encontrados para os picolés avaliados (1,17 a 1,54 - Tabela 1) são maiores em comparação com os dindins avaliados (0,64 a 0,84 - Tabela 2), no entanto a adição de corantes não influenciou nos resultados de ambos os produtos, visto que não houve diferença estatística entre nenhuma das formulações elaboradas. Fassio et al. (2009), ao avaliarem picolés a base de soro de leite, obtiveram resultados semelhantes ao presente estudo, variando de 1,04 a 1,26\% em 3 amostras. Por outro lado, Andrighetto e Gomes (2003) encontraram resultados superiores (2,41 a 2,50 \%) quando avaliou picolés com ácido acidófilo, em 3 amostras diferentes.

\section{CONCLUSÃO}

Ao avaliar as análises realizadas, pode-se concluir que o corante foi adicionado de forma eficaz, se comportando como um aditivo natural nos gelados comestíveis, pois não existiu diferença significativa na maioria dos parâmetros analisados, não modificando sua composição química, apenas conferindo cor ao mesmo.

\section{AGRADECIMENTOS}

Ao programa CNPq/PIBIC pelo financiamento do projeto de pesquisa, à UFCG pela concessão da bolsa de Iniciação Científica e aos colaboradores pelo apoio durante a execução do trabalho.

\section{REFERÊNCIAS}

[1] ANDRIGHETTO, C.; GOMES, M. I. F. V. Produção de picolés utilizando leite acidófilo. Braz. J. Food Technol, v. 6, n. 2, p. 267-271, 2003.

[2] BARBOSA-SILVA, M. Uso de água residuária, substrato e adubo orgânico na produção e qualidade de pimentão em ambiente protegido. 2014. 78 fls. Dissertação (Mestrado em Engenharia Agricola). Unidade Universitária de Ciências Exatas e Tecnológicas. Universidade Estadual de Goias, Anapolis/GO: 2014. 
[3] BRASIL, Agência Nacional de Vigilância Sanitária. Portaria n 379, de 26 de abril de 1999. Regulamento técnico $\mathrm{r}$ eferente a gelados comestíveis, preparados, pós para o preparo e bases para gelados comestíveis. Diário Oficial da União, Brasília, DF, 29 abr 1999.

[4] BRASIL. Ministério da Agricultura Pecuária e Abastecimento - MAPA. Portaria n.o 368 de 04/09/97. Regulamento Técnico sobre as Condições higiênico sanitárias e de Boas Práticas de Fabricação para Estabelecimentos Produtores/Industrializadores de Alimentos. Diário Oficial da União, Brasília, 1997.

[5] COELHO, D. T.; ROCHA, J. A. A. Práticas do processamento de produtos de origem animal. Viçosa: UFV, 2005. $64 \mathrm{p}$.

[6] FASSIO, L. D. O., TÉRAN-ORTIZ, G. P., ARAÚJO, R., \& MENDONÇA, A. Caracterização sensorial e físico-química de gelados comestíveis a base de soro de leite adicionado de polpas de frutos do cerrado. II Semana de Ciência e Tecnologia e II Jornada Científica, Universidade Federal de Minas Gerais, Bambuí, 2009.

[7] FERREIRA, D. F. Sisvar: a Guide for its Bootstrap procedures in multiple comparisons. Ciênc. agrotec. [online]. 2014, vol.38, n.2, pp.109-112. ISSN 1413-7054.

[8] GOMES, L,M,M. Inclusão de Carotenoides de Pimentão Vermelho em Ciclodextrinas e Avaliação da Sua Estabilidade, Visando Aplicação Em Alimentos. 2012. 108p. 2012. Tese de Doutorado. Dissertação (Mestre em Ciências Aplicadas), Faculdade de Farmácia, Universidade Federal Fluminense, Niterói, 2012.

[9] GOMES, L.M.M.; PETITO, N.; COSTA, V.G.; FALCAO, D.Q.; ARAUJO, K.G.L. Inclusion complexes of red bell pepper pigments with b-cyclodextrin: Preparation, characterisation and application as natural colorant in yogurt. Food Chemistry. v.148. p.428-436. 2014.

[10] INSTITUTO ADOLFO LUTZ. Métodos físico-químicos para análise de alimentos. 4 ed, São Paulo: Instituto Adolfo Lutz, p. 1020, 2008

[11] LAMOUNIER, M. L., DAS CHAGAS ANDRADE, F., DE MENDONÇA, C. D., \& MAGALHÃES, M. L. Desenvolvimento e caracterização de diferentes formulações de sorvetes enriquecidos com farinha da casca da jabuticaba (Myrciaria cauliflora). Revista do Instituto de Laticínios Cândido Tostes, v. 70, n. 2, p. 93-104, 2015.

[12] MINTEL. Disponível em http://store.mintel.com/sorvetes-brasil-junho-2016. Acessado em :25 de abril 2018.

[13] MORZElle, M. C., LAMOUNIER, M. L., SOUZA, E. C., SALGADO, J. M., \& DE BARROS VILAS-BOAS, E. $\mathrm{V}$. Caracterização físico-química e sensorial de sorvetes à base de frutos do cerrado. Revista do Instituto de Laticínios Cândido Tostes, v. 67, n. 387, p. 70-78, 2012.

[14] PAZIANOTTI, L., BOSSO, A. A., CARDOSO, S., DE REZENDE COSTA, M., \& SIVIERI, K. Características microbiológicas e físico-químicas de sorvetes artesanais e industriais comercializados na região de ArapongasPR. Revista do Instituto de Laticínios Cândido Tostes, v. 65, n. 377, p. 15-20, 2010.

[15] PRADO, M. A., \& GODOY, H. T. Corantes artificiais em alimentos. Alimentos e Nutrição Araraquara, v. 14, n. 2 , 2009.

[16] REIFSCHNEIDER, F. I. B. Capsicum pimentas e pimentões do Brasil. Brasília: EMPRAPA. Comunicações para Transferência de Tecnologia, 106 p. 2000.

[17] MONTEIRO, R. C. R; VELOSO, C. R., DE SOUSA NERES, L., JÚNIOR, J. D. B. L., PACHECO, E. A., SATO, S. T. A.; RIBEIRO, I. R. Desenvolvimento e avaliação da qualidade de sorvete de iogurte Esimbiótico, de leite de búfala enriquecido com polpa de açaí (Euterpe Oleracea mart.). Nucleus, v. 12, n. 2, p. 237-244, 2015.

[18] ROCHA, D. S.; REED, E. Pigmentos naturais em alimentos e sua importância para a saúde. Estudos, Goiânia, v. 41, n. 1, p. 76-85, jan./mar. 2014

[19] SILVA, E. V.; CONCEIÇÃO, M. M.; CARVALHO FILHO, J. R.; ARAÚJO, A. S.; PAIVA, Y. F.; LOPES, M. F.; MELO, M. A. R. Teor de pigmentos alimentares e capacidade antioxidante de corante natural obtido da pimenta biquinho. Revista de Química Industrial Ano 85 № 754 1ํo trimestre de 2017 Edição Eletrônica 12.

[20] SILVA, N. da; JUNQUEIRA, V.; SILVEIRA, N. F. A.; TANIWAKI, M. H.; SANTOS, R. F. S. dos, GOMES, R. A. R. Manual de métodos de análise microbiológica de alimentos e água. 4 edição. São Paulo: Livraria Varela, 614p, 2010.

[21] SILVEIRA, H. G.; QUEIROZ, N. A. S.; NETA, R. S. P.; RODRIGUES, M. C. P.; COSTA, J. M. C. Avaliação da Qualidade físico-química e microbiológica de sorvetes do tipo tapioca. Revista Ciência Agronômica, Fortaleza, v. 40, n 01, p. 6065. 2009.

[22] SIlveirA, H. G.; QUEIROZ, N. A. S.; NETA, R. S. P.; RODRIGUES, M. C. P.; COSTA, J. M. C. Avaliaçã o da Qu alidade físico-química e mi crobiológica de sorvetes do tipo tapioca. Revista Ciência Agronômica, Fortaleza, v. 40, n 01, p. 60-65. 2009.

[23] SOLER, M. P.; VEIGA, P. G. Sorvetes. Campinas: ITAL; CIAL, 2001. 68 p. (Especial, 1).

[24] SOUZA, J. C. B. Sorvete: composição, processamento e viabilidade da adição de probiótico. Alimentos e Nutrição, v. 21, n. 1, p. 153-163, 2010. 
[25] SOUZA, R. M. Corantes naturais alimentícios e seus benefícios à saúde. Trabalho de Conclusão do Curso de Graduação em Farmácia, Centro Universitário Estadual da Zona Oeste. Rio de Janeiro, 2012.

[26] SPOTO, M. A, B. R.; OETTERER, M.; REGITANO-D’ARCE, M. A. B. Fundamentos de ciência e tecnologia de alimento. III. Título. Barueri, SP : Manole, 2006.

[27] TORRES, D.E.G.; MANCINI, D.A.P.; TORRES, R.P.; MANCINI- FILHO, J. Antioxidant activity of macambo (Theobroma bicolor L.) extracts. Eur. J. Lipid Sci. Technol., v. 104, p. 278- 281, 2002.

\section{RESPONSABILIDADE AUTORAL}

Os autores são os únicos responsáveis pelo conteúdo deste trabalho. 


\section{Capítulo 18}

Coloração de frutos de Juazeiro armazenados sob temperatura controlada

\section{Jéssica Leite da Silval}

Ana Marinho do Nascimento

Tatiana Marinho Gadelha

\section{Larissa Félix Macêdo}

\section{Charlene Maria de Alcântara}

Franciscleudo Bezerra da Costa

Resumo: 0 juazeiro (Ziziphus joazeiro Mart.) é uma árvore comum e importante para a Caatinga, produz frutos que são empregados, em especial, na alimentação animal, mas que apresentam potencial ao consumo humano, não sendo utilizados para esse fim devido à escassez de informações sobre sua qualidade e estabilidade dos frutos ao armazenamento. Dessa forma, objetivou-se avaliar parâmetros de coloração de frutos de juazeiro armazenados sob temperatura controlada. Os frutos maduros foram colhidos de plantas localizadas na Universidade Federal de Campina Grande, campus Pombal/PB. Após a seleção, classificação, remoção de sujidades, retirada do pedúnculo e embalagem, os frutos foram submetidos ao armazenamento em temperatura ambiente controlada $\left(25,0 \pm 1,0{ }^{\circ} \mathrm{C}\right.$ e $34,0 \pm 1,0 \%$ UR), durante 4 dias. Em todos os dias de armazenamento, realizaram-se análise de parâmetros de coloração (luminosidade - $\mathrm{L}^{*}$, coordenadas a* $\mathrm{e}$ $\mathrm{b}^{*}$, cromaticidade, ângulo Hue e índice de cor). 0 armazenamento influenciou nas características de luminosidade, coordenada a*, ângulo Hue e índice de cor dos frutos de juazeiro, as demais características não foram afetadas em grandes proporções pelo armazenamento sob temperatura ambiente controlada, assim, o armazenamento foi eficiente para manter a coloração dos frutos no período de armazenamento estudado.

Palavras-chave: Ziziphus joazeiro Mart, conservação, aparência. 


\section{INTRODUÇÃO}

A Caatinga é conhecida como um ambiente homogêneo e pobre em biodiversidade, mas na verdade, grande parte do patrimônio biológico dessa região não é observada em nenhum outro lugar do mundo, senão, no Nordeste do Brasil (SILVA et al., 2003). Ocupa uma área que corresponde a 9,92 \% da área total do Brasil, que compreende a $844.453 \mathrm{~km}^{2}$ (IBGE, 2004), possui vegetação bem heterogênea composta de espécies vegetais endêmicas, em sua maioria de porte arbustivo e arbóreo, as quais possuem estratégias de adaptação às condições extremas de clima e solo, como é o caso das regiões semiáridas (SILVA et al., 2003).

O representante mais notável do bioma Caatinga é o Ziziphus joazeiro Mart,, conhecido popularmente como juazeiro ou laranjeira-do-vaqueiro (LORENZI; MATOS, 2002). 0 juazeiro é uma planta importante para a região semiárida do Nordeste, a qual serve de alimento para animais durante a escassez de chuvas, mantendo-se sempre verde durante todo o ano. A árvore pode alcançar até $10 \mathrm{~m}$ de altura, possui copa grande, proporcionando boa sombra, e suas sementes apresentam dormência devido à alta resistência do endocarpo (MENDES, 1996; LORENZI, 2002).

o Ziziphus joazeiro Mart. produz frutos de sabor adocicado, ricos em vitamina $\mathrm{C}$ e em compostos fenólicos, que são basicamente consumidos na forma in natura, sendo definidos como drupas oblongas e ásperas, com polpa carnosa e relativamente fina (LORENZI et al., 2006; SILVA, 2015). Embora apresente grande utilidade e potencial econômico, a sua exploração limita-se ao extrativismo, sendo necessários conhecimentos para contribuir na sua domesticação e cultivo (ALVES et al., 2008). Como também se faz indispensáveis estudos de seus frutos a fim de avaliar sua qualidade na tentativa de inseri-lo ao consumo humano.

Pesquisas sobre a caracterização física do fruto proporcionam importantes subsídios relativos ao manuseio e acondicionamento, e para programas de melhoramento genético das espécies e, em fase mais avançada de exploração comercial. Bem como na agroindústria, auxiliam no dimensionamento de máquinas e equipamentos, contribuindo para o uso adequado e a aplicação de métodos tecnológicos ao seu aproveitamento (OLIVEIRA et al., 2009). As características físicas dos frutos referentes à aparência externa, tamanho, forma e coloração da casca, entre outros, constituem atributos de qualidade à comercialização e utilização da polpa na elaboração de produtos industrializados (LIRA JÚNIOR et al., 2005).

Assim sendo, objetivou-se avaliar o efeito do armazenamento a temperatura ambiente controlada a partir dos parâmetros de coloração dos frutos de juazeiro colhidos no estádio de maturação maduro.

\section{MATERIAL E MÉTODOS}

\subsection{OBTENÇÃO DO MATERIAL VEGETAL}

Foram utilizados frutos de juazeiro (Ziziphus joazeiro Mart.), provenientes de plantas localizadas no Centro de Ciências e Tecnologia Agroalimentar (CCTA) da Universidade Federal de Campina Grande (UFCG), situado no município de Pombal - PB caracterizado pelas coordenadas geográficas de 648'16" de latitude S e 37049'15" de longitude W, a uma altitude de 175 m. De acordo com a classificação de Köppen, o clima predominante na região é do tipo BSh, ou seja, semiárido quente, com precipitação anual de 750 mm (FARIAS, 2013).

\subsection{PROCEDIMENTO EXPERIMENTAL}

0 procedimento experimental foi executado conforme fluxograma ilustrado na Fig. 1. As etapas do procedimento experimental são descritas a seguir. 
Figura 1. Fluxograma de execução do procedimento experimental.

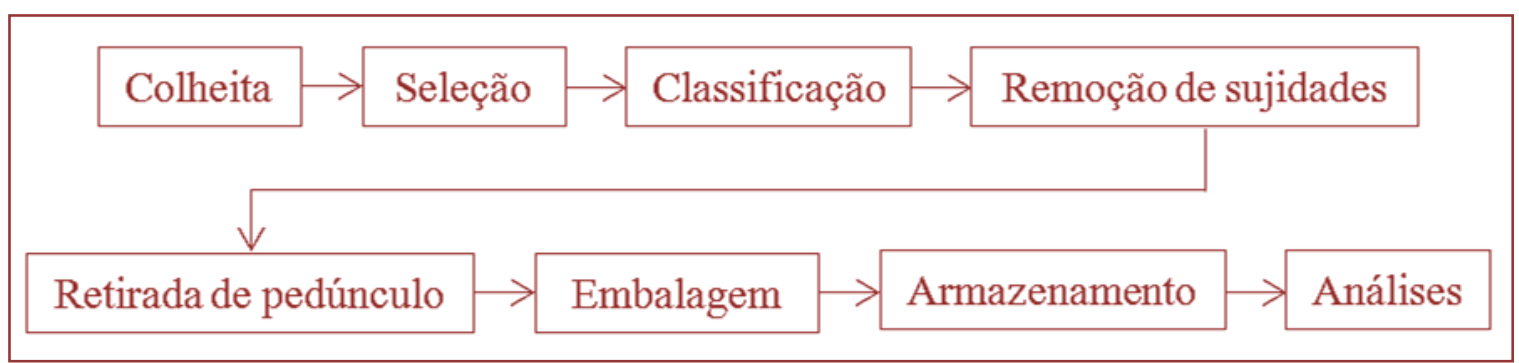

\subsubsection{COLHEITA}

Os frutos foram colhidos manualmente no início da manhã, das 7:00 às 9:00 h, acondicionados em sacos de polietileno, e transportados ao laboratório de Química, Bioquímica e Análise de Alimentos do CCTA.

\subsubsection{SELEÇÃO}

Os frutos foram selecionados visualmente quanto à ausência de injúrias, de modo a obter amostras uniformes e com qualidade.

\subsubsection{CLASSIFICAÇÃO}

Os frutos utilizados neste estudo foram os classificados como estádio de maturação IV, segundo classificação definida por Silva (2015). Os frutos deste estádio de maturação apresentam a casca totalmente amarela (Fig. 2), sendo considerado totalmente maduro.

Figura 2. Frutos de juazeiro classificados no estádio de maturação IV.

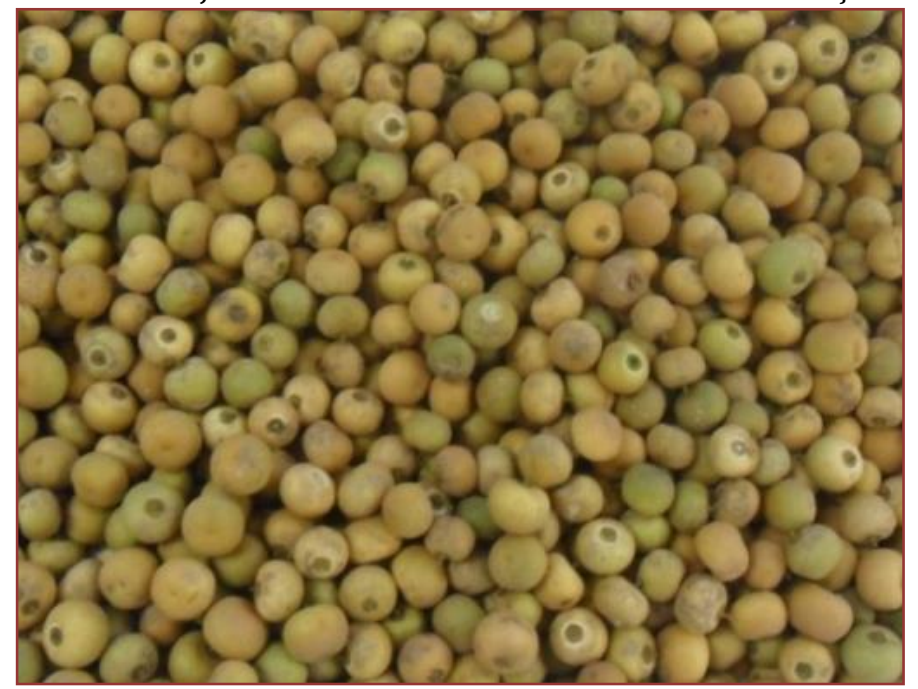

A escolha deste estádio de maturação em específico foi decorrente do mesmo apresentar características satisfatórias, viabilidade de consumo e de industrialização, em estudo realizado por Silva (2015), no qual o mesmo se mostrou com maiores valores de massa fresca, rendimento de polpa, sólidos solúveis e compostos fenólicos. 


\subsubsection{REMOÇÃO DE SUJIDADES}

A higienização não foi realizada em água corrente, nem sanitização, pois os frutos de juazeiro apresentam elevada taxa metabólica e, o contato com água, intensifica os processos de senescência, como foi relatado por Silva (2015), em que os estádios de maturação mais avançados (III, IV e V) não mostraram-se aptos à realização das análises durante o armazenamento proposto na pesquisa (6 dias). Foi realizada a remoção das sujidades aparentes com auxílio de papel toalha.

\subsubsection{RETIRADA DE PEDÚNCULO}

A remoção do pedúnculo dos frutos foi realizada manualmente com auxílio de faca.

\subsubsection{EMBALAGEM}

Os frutos foram embalados em bandejas de poliestireno expandido envolvidas por filme de PVC $12 \mu \mathrm{m}$, cada bandeja contendo $100 \mathrm{~g}$ de frutos. Foram elaboradas cinco bandejas para cada dia de armazenamento.

\subsubsection{ARMAZENAMENTO}

As bandejas foram dispostas sob bancada (Fig. 3) e mantidas sob temperatura ambiente controlada por meio de ar condicionado $\left(25,0 \pm 1,0^{\circ} \mathrm{C}\right.$ e $34,0 \pm 1,0 \%$ UR $)$ por quadro dias.

Figura 3. Armazenamento de frutos do juazeiro sob temperatura ambiente controlada.

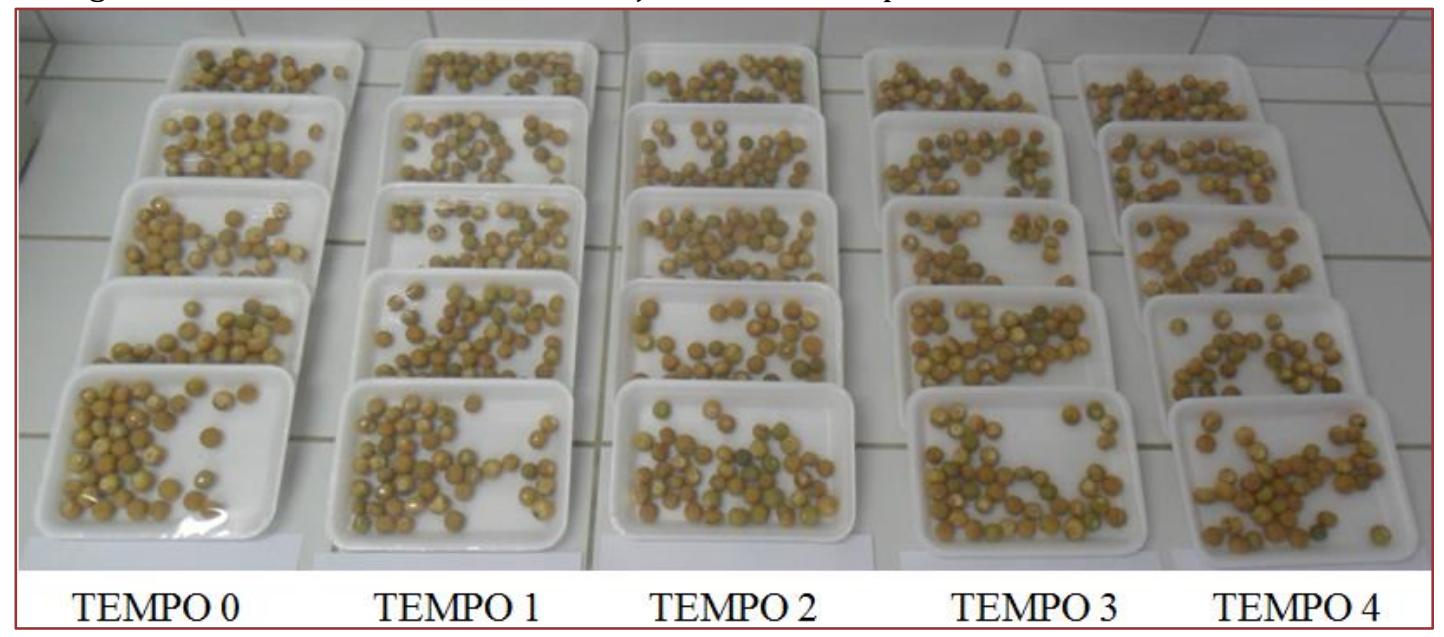

\subsubsection{ANÁLISES}

Foram realizadas análises de coloração em todos os dias de armazenamento, sendo que, logo no dia 0 de armazenamento foram realizadas as análises, configurando cinco tempos de análises (0, 1, 2, 3 e 4 dias).

\subsection{DELINEAMENTO EXPERIMENTAL}

0 delineamento experimental utilizado foi o inteiramente casualizado, em que foi considerado como tratamento os dias de armazenamento $(0,1,2,3$ e 4), com 5 repetições (bandejas) de $100 \mathrm{~g}$ de frutos.

\subsection{ANÁLISES DE COLORAÇÃO}

Para as análises foram considerados 10 frutos de cada bandeja, a fim de obter uma amostragem mais representativa, totalizando 50 repetições para cada dia de armazenamento. 
A cor dos frutos foi determinada no sistema CIELAB utilizando-se um colorímetro Konica Minolta (modelo CR 300 Tokyo), sendo analisados 5 parâmetros de coloração: luminosidade - L*, coordenada a* e b*, cromaticidade e ângulo Hue (MINOLTA, 1998).

- Luminosidade - $\mathrm{L}^{*}$ : relaciona-se com a aparência da amostra, numa escala de variável de $0=$ preta a 100 = branca;

- Coordenada $\mathrm{a}^{*}$ : representa a intensidade da cor verde e vermelha, onde $-\mathrm{a}^{*}=$ verde $\mathrm{e}+\mathrm{a}^{*}=$ vermelha;

- Coordenada b*, representa a intensidade da cor azul e amarela, sendo - b $^{*}=$ azul e + b $^{*}=$ amarela;

- Cromaticidade: destaca o grau de pureza de uma cor, quanto mais próximo de 0 (zero), mais impura é cor;

- Ângulo Hue: destaca a tonalidade, sendo o ângulo $0^{\circ}=$ vermelha, $90^{\circ}=$ amarela, $180^{\circ}=$ verde e $270^{\circ}=$ azul.

0 índice de cor que indica a variação de cor entre verde/amarelo das amostras foi calculado de acordo com a equação abaixo, proposta por Camelo e Gomes (2004).

$$
\mathrm{IC}=\frac{200 \mathrm{a}^{*}}{\mathrm{~L}^{*} \sqrt{\left(\mathrm{a}^{*}\right)^{2}+\left(\mathrm{b}^{*}\right)^{2}}}
$$

Onde:

$$
\begin{aligned}
& \mathrm{L}^{*}=\text { luminosidade; } \\
& \mathrm{a}^{*}=\text { variação de cor entre verde e vermelho; } \\
& \mathrm{b}^{*}=\text { variação de cor entre azul e amarelo. }
\end{aligned}
$$

\subsection{ANÁLISE ESTATIÍSTICA}

Os dados obtidos foram submetidos à análise de variância, quando detectado efeito significativo para o teste $\mathrm{F}$ foi aplicado o teste de Tukey ao nível de $5 \%$ de probabilidade. Os dados foram analisados por meio do software Assistat versão 7.7 beta (SILVA; AZEVEDO, 2016).

Os coeficientes de correlação de Pearson entre os parâmetros de coloração durante o armazenamento foram determinados por meio do software Microsoft Office Excel versão 2007.

\section{RESULTADOS E DISCUSSÃO}

A Fig. 4A ilustra os valores de luminosidade de frutos de juazeiro durante o armazenamento, foi constatado pequenas variações na luminosidade dos frutos, e os valores variaram de 62,29 a 58,91, foi observado tendência à redução durante o armazenamento, demonstrando que os frutos se tornam um pouco mais opacos com o armazenamento.

0 parâmetro luminosidade está relacionado à aparência de fruto, indicando o quão o fruto varia de preto (0) e branco (100), então pode-se dizer que os frutos de juazeiro apresentaram boa aparência, já que os valores foram próximos a 60, o que os torna com coloração mais clara do que escura. 
Figura 4. Luminosidade (A), coordenada $a^{*}(B)$ e b* (C), cromaticidade (D), ângulo Hue (E) e índice de cor (F) de frutos de juazeiro armazenados sob temperatura ambiente controlada.

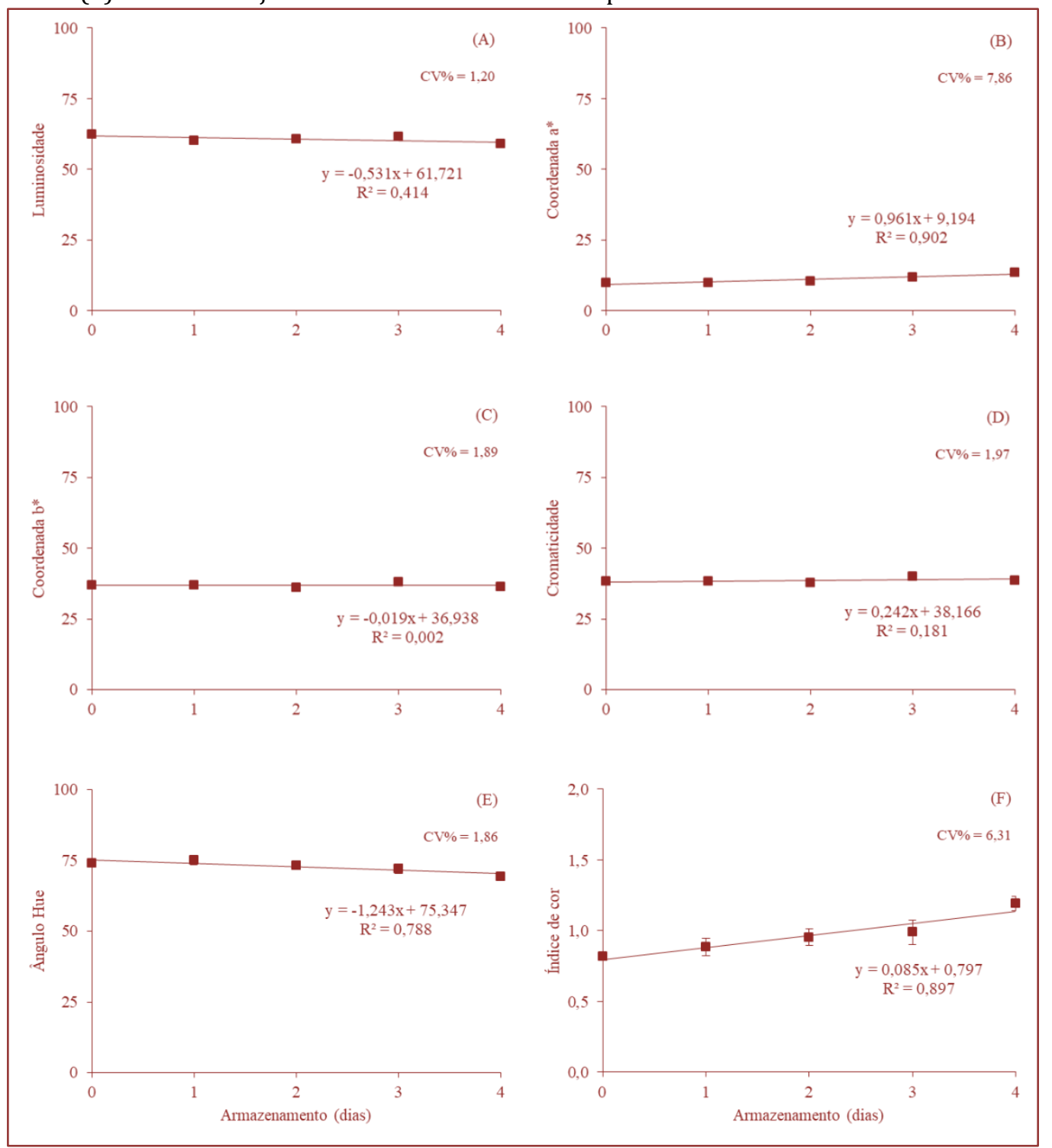

Foi constatado aumento na coordenada $\mathrm{a}^{*}$ durante o armazenamento de frutos de juazeiro, aumentando de 9,76 a 13,71 (Fig. 4B). Os valores de a* variam entre vermelho a verde, onde (+a*) corresponde a cor vermelha e $\left(-\mathrm{a}^{*}\right)$ a cor verde. Assim, percebe-se uma tendência à cor vermelha, que pode ser atribuído ao avançar da maturação dos frutos durante o armazenamento, tornando-os com coloração amarronzada.

A coordenada $b^{*}$ em frutos de juazeiro sofreu pequenas variações durante o armazenamento (Fig. 4C) variando de 37,04 a 36,31. Esse parâmetro está relacionado a coloração amarela (+b*) e azul (-b*), assim percebe-se que a coloração amarela prevaleceu durante o armazenamento sem grandes variações.

A Fig. 4D demonstra os valores obtidos para a cromaticidade de frutos de juazeiro. Assim como o parâmetro luminosidade e coordenada b*, não houve grandes variações da cromaticidade durante o período de armazenamento, variando apenas de 38,40 a 38,70. Com os valores alcançados, observa-se que a pureza ou intensidade de cor permaneceu praticamente constante durante o armazenamento.

Os resultados obtidos para o ângulo Hue demonstraram ligeira redução durante o armazenamento (Fig. $4 \mathrm{E}$ ), variando de 74,13 a 69,43. O ângulo Hue define a tonalidade da cor, sendo $0^{\circ}$ (vermelho), 90ㅜㅡ. (amarelo), $180^{\circ}$ (verde) e $270^{\circ}$ (azul). Assim, percebe-se que os frutos de juazeiro permaneceram durante todo o armazenamento próximo ao ângulo de cor que corresponde à coloração amarela. 
A evolução no índice de cor de frutos de juazeiro está evidenciada na Fig. 4F. Percebe-se um aumento continuo durante todo o período de armazenamento dos frutos, aumentando de 0,82 a 1,19.

Os resultados obtidos concordam com a coordenada b* e com o ângulo Hue, que mostraram que os frutos permaneceram durante todo o armazenamento na coloração amarela, já que o índice de cor varia de -20 a +20; quanto mais negativo, mais verde e quanto mais positivo, mais alaranjado está o fruto. Valores próximos a zero representam a cor amarela.

A coordenada $\mathrm{a}^{*}$ apresentou forte correlação positiva com o índice de cor, decorrente do comportamento similar (aumento) durante o armazenamento (Tab. 1). Essa resposta pode esta relacionada ao fato que a elevação de ambas as características promovem a coloração amarelada/alaranjada.

Tabela 1. Coeficientes de correlação de Pearson (r) dos parâmetros de coloração de frutos de juazeiro (Ziziphus joazeiro Mart.) armazenados sob temperatura ambiente controlada.

\begin{tabular}{|c|c|c|c|c|c|}
\hline Características & $\mathrm{L}$ & $a^{*}$ & $b^{*}$ & C & $\mathrm{h}^{\circ}$ \\
\hline$a^{*}$ & $-0,514^{*}$ & -- & -- & -- & -- \\
\hline $\mathrm{b}^{*}$ & $0,530^{*}$ & $0,034^{\mathrm{ns}}$ & -- & -- & -- \\
\hline $\mathrm{C}$ & $0,246^{\text {ns }}$ & $0,463^{*}$ & $0,895^{*}$ & -- & -- \\
\hline $\mathrm{h}^{\circ}$ & $0,525^{*}$ & $-0,912^{*}$ & $0,178^{\mathrm{ns}}$ & $-0,245^{\text {ns }}$ & -- \\
\hline Índice de cor & $-0,718^{*}$ & 0,933* & $-0,226^{\text {ns }}$ & $0,202^{\text {ns }}$ & $-0,873^{*}$ \\
\hline
\end{tabular}

*significativo ao nível de 5\% de probabilidade; ns não significativo.

Foi verificada forte correlação negativa entre a coordenada $a^{*}$ e ângulo Hue, consequente do comportamento oposto observado, enquanto a coordenada $a^{*}$ aumentou durante o armazenamento, o ângulo Hue apresentou ligeiro decréscimo. Foi observada correlação positiva entre a coordenada $b^{*}$ e a cromaticidade, resultado do modo como se mantiveram no armazenamento, ambas sem grandes variações.

O ângulo Hue apresentou forte correlação negativa com o índice de cor. Que também pode ser explicado pelo comportamento apresentado durante o armazenamento, onde, o ângulo Hue e índice de cor apresentaram comportamentos diferentes (enquanto o ângulo Hue diminuiu, o índice de cor aumentou). Os demais parâmetros de coloração não apresentaram correlação significativa entre si.

\section{CONCLUSÃO}

A luminosidade, coordenada $\mathrm{a}^{*}$, ângulo Hue e índice de cor dos frutos de juazeiro foram levemente afetados pelo armazenamento sob temperatura ambiente controlada, as demais características não foram influenciados em grandes proporções pelo armazenamento avaliado. Dessa forma, o armazenamento sob temperatura ambiente controlada mostrou-se eficiente na manutenção da coloração dos frutos de juazeiro no período de tempo avaliado (4 dias).

\section{AGRADECIMENTOS}

Aos colegas do Grupo de Pesquisa em Ciência e Tecnologia de Alimentos (GPCTEA) da Universidade Federal de Campina Grande (UFCG), Campus Pombal.

\section{REFERÊNCIAS}

[1] Alves, E.U., Braga Júnior, J.M., Bruno, R.L.A., Oliveira, A.P., Cardoso, E.A., Alves, A.U., Alves, A.U., Silva, K.B., 2008, "Métodos para quebra de dormência de unidades de dispersão de Zizyphus joazeiro Mart. (RHAMANACEAE)", Revista Árvore, Vol. 31, No. 3, pp. 407-415.

[2] Camelo, A.F.L., Gomes, P.A., 2004, “Comparison of color indexes for tomato ripenings", Horticultura Brasileira, Vol. 22, No. 3, pp.534-537. 
[3] Farias, V.F.S., 2013, "Avaliação do desenvolvimento, qualidade e capacidade antioxidante em brotos de palma (Opuntia sp.) para o consumo humano", Dissertação - Mestrado em Sistemas Agroindustriais, Universidade Federal de Campina Grande, pp. 78.

[4] IBGE, 2004, "Mapa Biomas de e Vegetação", http://www.ibge.gov.br/home/presidencia/noticias/21052004biomashtml.shtm, Acesso em: 22/12/2018.

[5] Lira Júnior, J.S., Musser, R.S., Melo, E.A., Maciel, M.I.S., Lederman, I.E., Santos V.F.,2005, “Caracterização física e físico-química de frutos de cajá-umbu (Spondias spp.)", Ciência e Tecnologia de Alimentos, Vol. 25, No. 4, pp. 757 761.

[6] Lorenzi, H., 2002, "Árvores brasileiras: manual de identificação e cultivo de plantas arbóreas nativas do Brasil”, Nova Odessa, Ed. 2, pp. 368.

[7] Lorenzi, H., Bacher, L., Lacerda, M.E., Sartori, S., 2006, "Frutas Brasileiras e Exóticas Cultivadas (de consumo in natura)", Nova Odessa, Ed. 1, pp. 640.

[8] Lorenzi, H., Matos, F.J.A, 2002, “Plantas medicinais no Brasil: nativas e exóticas”, Nova Odessa, Ed. 1, pp. 512.

[9] Mendes, B.V., 1996, "Juazeiro (Zizyphus joazeiro Mart.): símbolo da resistência das plantas das caatingas", Fundação Vingt-Un Rosado/ ETFERN-UNED, Coleção Mossoroense, 168, pp. 24.

[10] Minolta, 1998, "Precise color communication - color control from perception to instrumentation", Minolta Co., Ltd., pp.59.

[11] Oliveira, M.E.B., Guerra, N.B., Maia, A.H.N., Alves, R.E., Xavier, D.S., Matos, N.M.S., 2009, “Caracterização física de frutos do pequizeiro nativos da chapada do Araripe", Revista Brasileira de Fruticultura, Vol. 31, No. 4, pp. 11961201.

[12] Silva, F.A.S., Azevedo, C.A.V, 2016, "The Assistat Software Version 7.7 and its use in the analysis of experimental data", African Journal of Agricultural Research, Vol. 11, No.39, pp.3733-3740.

[13] Silva, J.L., 2015, "Qualidade e armazenamento de frutos de juazeiro (Ziziphus joazeiro Mart.) sob temperatura ambiente, Monografia - Graduação em Engenharia de Alimentos, Universidade Federal de Campina Grande, pp. 75.

[14] Silva, J.M.C., Tabarelli, M., Fonseca, M.T., Lins, L.V., 2003, "Biodiversidade da caatinga: áreas e ações prioritárias para a conservação", Ministério do meio Ambiente: Universidade Federal de Pernambuco, pp. 17-91.

\section{RESPONSABILIDADE AUTORAL}

Os autores são os únicos responsáveis pelo conteúdo deste trabalho 


\section{ÍNDICE REMISSIVO}

\section{A}

Acidentes, 48

Ácido ascórbico, 96, 97, 136, 139, 144, 147, 150, 153, 156

Aditivos, 127, 158

Ajustes, $31,61,80,84,85,86,87,88$

Alliaceae, 92

Anemia, 120

Antioxidante, 134

Aparência, 62, 108, 134, 137, 142, 143, 145, 148, 151, $165,166,169$

Apicultura, 104, 105, 110, 111

Apís, 104

\section{B}

Bifásico, 67, 69, 78

Brita, 5, 13, 112, 113, 115, 116, 117, 118

Bulbilhos, 92, 93, 96, 98

\section{C}

Capacidade pulmonar, 112, 114

Capsicum annuum, 127, 128, 132, 134, 135, 138, 139, $140,142,143,146,147,148,158$

Características físicas e químicas, 57, 58, 64, 65

Carboidratos, 92, 93, 94, 96, 97, 151

Carência de Ferro, 120

CFD, 5, 45, 48, 49, 56, 69

Cinética de secagem, 58, 61, 62, 80

Compostos bioativos, 5, 7, 13, 14, 92, 93, 95, 96, 97, 98, $127,128,131,134,135,137,139,142,143,145,147$, 148

Conservação, 36, 48, 50, 63, 70, 80, 81, 93, 140, 148, 165,172

Consumo humano, 131, 150, 156, 160, 165, 166, 172

Crescimento Celular, 120

\section{D}

Deficiência, 120

Dispersão, 36, 67, 68, 69, 110, 171

Dosímetro, 99, 101

\section{E}

Eficiência do Processo, 23

Energia Solar, 23, 34

Extração alcoólica, 127

\section{$\mathbf{F}$}

Fosfato, 16

Fotoquímicos, 142

Frequência cardíaca, 112, 114, 116, 118

\section{G}

Granulometria, 16

\section{H}

Hortaliças, 89, 98, 127, 135, 140, 141, 142, 143, 147, $148,151,152,158,159$

\section{M}

Medicina ocupacional, 112

Meio ambiente, 50, 67, 68, 99

Mellifera, 104, 105

Misturador interno, 35

Modelos matemáticos, 31, 57, 58, 60, 61, 62, 80, 81, 83

$\mathbf{0}$

Opuntia ssp, 150

\section{$\mathbf{P}$}

Paraíba, 6, 8, 9, 11, 13, 33, 36, 81, 97, 99, 101, 104, 105, $111,121,122,125,128,132,159$

Partícula, 16

Pigmentos alimentares, 127, 132, 158, 163

Polifenóis, 95, 97, 134, 135, 137, 145

Polímeros, 35, 36, 37, 38, 39

Poluentes, 67, 68, 79

Processamento, 35, 37, 45, 82, 151

Produção, 10, 26, 33, 34, 65, 98, 104, 110, 132, 162

Produto farináceo, 57,64

$\mathbf{R}$

Rendimento Térmico, 23

Ruído, 99, 103

\section{S}

Saúde, 68, 78, 92, 93, 98, 99, 100, 113, 118, 120, 121, $124,127,128,133,142,143,148,158,163,164$ Secador solar, 23, 34

secagem, 5, 6, 7, 11, 12, 20, 23, 24, 25, 26, 27, 28, 29, 30, $31,32,33,34,57,58,59,60,61,62,63,64,65,66$, $80,81,82,83,84,85,86,87,88,89,90,127,129$, 130,159

Secagem, 23, 34, 58, 66, 89

Segurança do trabalho, 99

Simulação Numérica, 48

Sorgo, 5, 57, 58, 59, 60, 61, 62, 63, 64, 65, 66

\section{$\mathbf{T}$}

Teor de água, 30, 57, 58, 59, 60, 61, 62, 63, 64, 65, 80, $81,83,138$

Trabalhadores, 99, 116

\section{V}

Velocidade, 18, 20, 31, 37, 51, 67, 68, 70, 71, 72, 73, 74, $75,76,77,78,80,81,82,84,93,121$

Ventilação, 27, 112, 114, 115

\section{$\mathbf{Z}$}

Ziziphus joazeiro Mart, 165, 166, 171, 172 


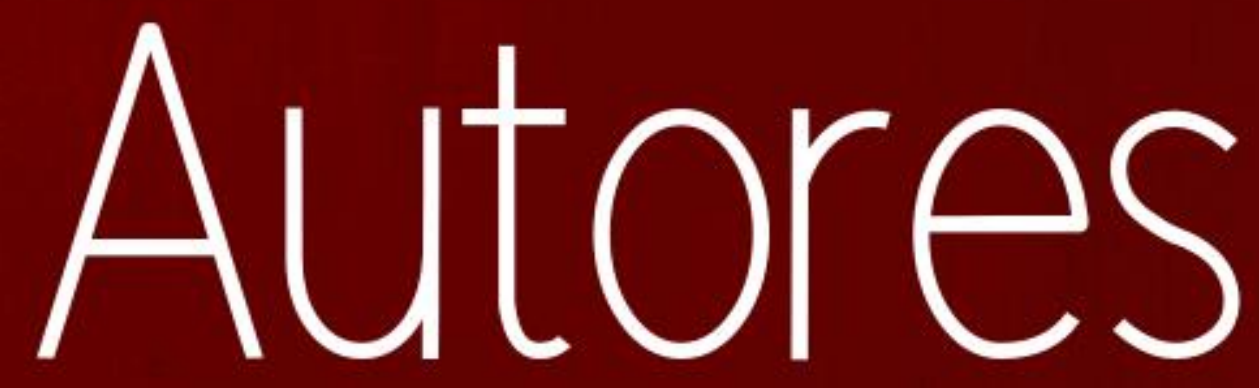




\section{ADRIANO DE SOUSA CABRAL}

Possui Graduação em Engenharia Mecânica pela Universidade Federal de Campina Grande. Pós-graduação em Administração de Empresas pela Fundação Getúlio Vargas - FGV. Mestrado em Engenharia Mecânica pela Universidade Federal de Campina Grande e atualmente é aluno de doutorado do Programa de Pós-graduação em Engenharia de Processos também pela UFCG.

\section{AGDA MALANY FORTE DE OLIVEIRA}

Agrônoma, formada no Centro de Ciências e Tecnologia agroalimentar (CCTA), da Universidade Federal de Campina Grande (UFCG), campus Pombal. Foi monitora bolsista da disciplina de Sistemática Vegetal e monitora voluntária da disciplina Nutrição Mineral de Plantas. Foi aluna pesquisadora da empresa $\mathrm{CNPq}$, atuando nas Linhas de Pesquisa de Tecnologia pós-colheita e processamento de produtos vegetais, com ênfase no uso de recobrimentos comestíveis em frutos e hortaliças. Atualmente é mestranda no programa de pós-graduação em Horticultura tropicalUFCG, bolsista CAPES, atuando na linha de pesquisa de fisiologia vegetal de plantas.

\section{ALAN DÉL CARLOS GOMES CHAVES}

Doutorando em Engenharia de Processos - UFCG, Campus Campina Grande/PB, Mestre em Sistemas Agroindustriais-UFCG, Campus Pombal-PB, 2014,1, Dissertação intitulado: Caracterização das águas subterrâneas usadas na irrigação de hortaliças em comunidades rurais no município de Pombal-PB. Especialista em Educação Ambiental e Sustentabilidade-UFCG, campus de Patos-PB. Graduação em LICENCIATURA PLENA EM GEOGRAFIA - Faculdades Integradas de Patos (2006). Graduando do curso de Engenharia Ambiental-UFCG, Pombal/PB. Membro da equipe editorial da Revista Verde de Agroecologia e Desenvolvimento Sustentável - ISSN 1981 - 8203. Grupo de Pesquisa Membro da equipe editorial da Revista Verde de Agroecologia e Informativo Técnico do Semiárido- ISSN 2317 - 305x. Grupo de Pesquisa Membro da comissão editorial da Revista Brasileira de Gestão Ambiental ISSN 2317 - 3122. Tem experiência na área de Engenharia Sanitária, com ênfase em Engenharia Ambiental, atuando principalmente nos seguintes temas: meio ambiente, saneamento básico, políticas públicas, Educação Ambiental e impactos ambientais.

\section{ALANNA MICHELY BATISTA DE MORAIS}

Mestre em Ciências Animais pela Universidade Federal de Campina Grande UFCG (2016), Especialista em Citologia Clínica pelas Faculdades Integradas de Patos - FIP (2012), Graduada em Biomedicina pelas Faculdades Integradas de Patos - FIP (2010). Atualmente e Coordenadora e Responsável Técnica do Laboratório Escola de Análises Clínicas BIOLAB da UNIFIP e Docente dos cursos de Graduação (Biomedicina e Medicina) e Pós-graduação (Biomedicina e Enfermagem) Lato Senso da Instituição. Tem experiência em educação Médica e no uso de Metodologias ativas no processo ensino aprendizagem e nas áreas de Hematologia, Imunologia, Bioquímica, Parasitologia, Uroanálises e Citologia Clínica. 


\section{ALINE COSTA FERREIRA}

Possui graduação em Engenharia Agrícola pela Universidade Federal de Campina Grande (2007), Especialista em Desenvolvimento Sustentável para o Semiárido Brasileiro, Especialista em Gestão da Agroindústria Sucroalcooleira, Mestre em Irrigação e Drenagem pela UFCG (2009) e Doutora em Irrigação e Drenagem pela UFCG, Professora das disciplinas de Fotogrametria e Desenho técnico do Centro de Ciências e Tecnologia Agroalimentar/CCTA da Universidade Federal de Campina Grande/UFCG. Experiência na área de Engenharia Agrícola, com ênfase em Engenharia Agrícola, atuando principalmente nos seguintes temas: Desenho Técnico, Sensoriamento Remoto, Geoprocessamento, Conservação do Solo e da Água, Manejo Integrado de Bacias, Desenvolvimento Sustentável, Barragem Subterrânea, Reuso de Águas, Fitorremediação, Irrigação e Drenagem, Técnicas Alternativas de Drenagem e etc.

\section{ALFREDINA DOS SANTOS ARAÚJO}

Possui graduação em Química Industrial pela Universidade Estadual da Paraíba (2000), Mestrado em Engenharia Química pela Universidade Federal da Paraíba (2002) e Doutorado em Engenharia de Processos pela Universidade Federal de Campina Grande (2006), É Professora Associada III da Universidade Federal de Campina Grande do Centro de Ciências e Tecnologia Agroalimentar. Exerce atualmente a função de Diretora do Centro Vocacional Tecnológico de Pombal PB. Coordenou a Pós-graduação em Sistemas Agroindustriais nível Acadêmico e Profissional. Atualmente Coordena a Pós-graduação em Sistemas Agroindustriais nível Acadêmico. Atua principalmente nos seguintes temas: Ciências Agrárias, Microbiologia de Alimentos, Caracterização e Análise de alimentos, Mel, Bovinocultura leiteira e derivados produzidos pela Agricultura Familiar.

\section{ANA PAULA MOISÉS DE SOUSA}

Graduação em Licenciatura em Ciências Biológicas pela Universidade Federal de Campina Grande (2013) e mestrado em Ciências Naturais e Biotecnologia pela Universidade Federal de Campina Grande (2016). Atualmente, é aluna de doutorado no Programa de Pós-Graduação em Engenharia Agrícola. Tem experiência em iniciação à docência como monitora bolsista em genética geral. Participou de projetos de pesquisa na área de Biologia Molecular e Biotecnologia atuando nos seguintes temas: bioprospecção de genes, interação molecular planta-patógeno, fermentação semissólida, enriquecimento proteico e tecnologia de alimentos.

\section{ANA REGINA NASCIMENTO CAMPOS}

Possui graduação em Química Industrial pela Universidade Estadual da Paraíba (2000), mestrado em Engenharia Química pela Universidade Federal de Campina Grande (2003) e doutorado em Engenharia de Processos pela Universidade Federal de Campina Grande (2008). Professora Associada da Universidade Federal de Campina Grande (UFCG/CCT/UAEQ). Tem experiência na área de Engenharia Química, com ênfase em Fermentação Semissólida, atuando principalmente nos seguintes temas: fermentação semi-sólida, enriquecimento proteico, produtos farináceos. 


\section{ANTONIO DANIEL BURITI DE MACEDO}

Graduação em Licenciatura em Química pela Universidade Federal de Campina Grande (2016) e mestrado em Ciências Naturais e Biotecnologia pela Universidade Federal de Campina Grande (2018). Atualmente, é aluno de doutorado no Programa de Pós Graduação em Engenharia de Processos pela Universidade Federal de Campina Grande. Participou de projetos de pesquisa na área de Química e Biotecnologia atuando nos seguintes temas: fermentação semissólida, enriquecimento proteico e tecnologia de alimentos.

\section{ARNALDO BEZERRA LOPES DE ALMEIDA}

Possui graduação em Engenharia de Minas pela UFPE (2004), Mestrado em Engenharia de Minas pela UFCG e pós-graduação em Gestão Pública pelo Instituto Federal de Educação, Ciência e Tecnologia de Pernambuco (IFPE). Academicamente tem experiência na área de tratamento de minérios, com ênfase em concentração mineral atuando principalmente nos seguintes temas: flotação de minérios, tratamento mineral, shear flocculation e profissionalmente tem experiência em lavra de minas, atuando principalmente no controle das operações unitárias (perfuração, desmonte de rochas, transporte e britagem) de extração de minérios em mina a céu aberto. Atualmente é servidor público estatutário da Agência Nacional de Mineração, Gerência Operacional da Paraíba, onde atua basicamente com as premissas da legislação mineral especificamente no que se refere a fiscalização e outorga da atividade mineral.

\section{BONIEK EVANGELISTA LEITE}

Possui graduação em Química industrial pela Universidade Estadual da Paraíba (2009) e mestrado em Engenharia Mecânica na Universidade Federal de Campina Grande (2012) e doutorado em Engenharia de Processos na Universidade Federal de Campina Grande (2016), atualmente é pesquisador de Pós Doutorado no programa de pósgraduação em Engenharia de Processos na Universidade Federal de Campina Grande, tendo experiência nas áreas de mecânica dos fluidos, transferência de calor e massa, fluidodinâmica computacional e computação de alto desempenho, atuando principalmente nos seguintes temas: simulação computacional de escoamentos multifásicos no setor petrolífero, analise numérica de fenômenos de combustão interna e implementação de Cluster Beowulf.

\section{CHARLENE MARIA ALCANTARA}

Graduanda do curso de Engenharia de Alimentos pela Universidade Federal de Campina Grande,

Campus Pombal/PB.

\section{DAYANE KELLY PERREIRA ABREU}

Engenheira de Alimentos pela Universidade Federal de Campina Grande, Campus de Pombal. CREA-PB: 161754013-7. Atuou como voluntária e pesquisadora no Centro Vocacional Tecnológico (CVT). Tem experiência na área de Ciência e Tecnologia de Alimentos, com ênfase em Microbiologia de Alimentos, Análises Físico-Químicas e Sensoriais e Rotulagem de Alimentos. Na graduação, foi monitora voluntária da disciplina Microbiologia Geral durante os períodos 2017.1 e 2017.2 e 
atuou como bolsista no Programa Institucional de Bolsas de Iniciação em Desenvolvimento Tecnológico e Inovação (PIBITI) 2016/2017 e como e voluntária em outros projetos de pesquisa e extensão. Atualmente, cursando MBA em Engenharia de Produção pelo Instituto Pró Saber.

\section{ELIAS NUNES FILHO}

Técnico em Mineração do Instituto Federal de Educação do Rio Grande do Norte IFRN/Campus Avançado Parelhas, Parelhas, RN.

\section{EMMANUEL FABIANO MARQUES DA SILVA}

Possui graduação em Agronomia pela Universidade Federal da Paraíba (2004). Mestrado em Engenharia Agrícola pela Universidade Federal de Campina Grande (2010). Experiência na área de Agronomia, com ênfase em extensão rural, tecnologia de aplicação, mecanização agrícola e pastagem, incluindo controle de ervas daninhas. Experiência na área de Engenharia Agrícola com ênfase em processamento e secagem de produtos agrícolas.

\section{FABIANY BENTO DA SILVA}

Graduanda em Engenharia Química pela Universidade Federal de Campina Grande.

\section{FAGNO DALLINO ROLIM}

Doutorando em Engenharia de Processos, pelo Centro de Ciências e Tecnologia - CCT, da Universidade Federal de Campina Grande - Campus de Campina Grande/PB (2019). Linha de Pesquisa: Processos Térmicos e de Separação. Mestre em Sistemas Agroindustriais, pelo Centro de Ciências e Tecnologia Agroalimentar - CCTA, da Universidade Federal de Campina Grande - Campus de Pombal/PB (2018). Linha de Pesquisa: Gestão e Tecnologia Ambiental. Especialista em Metodologias do Ensino Superior, pelo Instituto Superior de Educação Vale do Salgado (2008). Especialista em Gestão Estratégica de Negócios, pela Universidade Federal de Campina Grande (2006). Possui Graduação em Administração, pelo Centro Universitário de João Pessoa - UNIPÊ (2001), CRA-PB N³950. Atualmente é Servidor Público Federal, sendo Administrador da Universidade Federal de Campina Grande, lotado no Centro de Formação de Professores, Campus de Cajazeiras/PB, desde maio de 2010. Foi Professor Universitário do Curso de Administração da Faculdade Santa Maria em Cajazeiras/PB (2010 - 2017) e Professor Universitário do Curso de Administração e Ciências Contábeis da Faculdade Vale do Salgado em Icó/CE(2005 - 2009). Experiência em Administração, com ênfase em Gestão de Processos e Sistemas, Planejamento Estratégico, Teorias Organizacionais, Gestão da Qualidade, Gestão de Frota, Manutenção e Serviços, Conformidade de Registros de Gestão, Gestão de Patrimônio, Recursos Hídricos, entre outras. 


\section{FRANCISCLEUDO BEZERRA DA COSTA}

Engenheiro Agrônomo pela Universidade Federal Rural do Semi-Árido (2003), mestrado (2004), doutorado (2009) e pós-doutorado (2010) em Fisiologia Vegetal pela Universidade Federal de Viçosa. Professor Associado I; Coordenador Administrativo da Unidade Acadêmica de Tecnologia de Alimentos (UATA) de 20122017 e Vice-diretor pro-tempore do Centro de Ciência e Tecnologia Agroalimentar (CCTA) em 2017, da Universidade Federal de Campina Grande (UFCG), professor permanente no Programa de Pós-Graduação em Sistemas Agroindustriais e do Programa de Pós- Graduação em Horticultura Tropical do CCTA, coordenador do laboratório de Química, Bioquímica e Análises de Alimentos do CCTA, foi coordenador geral dos laboratórios do CCTA/UFCG (2010-2013). Editor de área da Revista Caatinga (UFERSA). Atua na área de Fisiologia pós-colheita de órgãos perecíveis: produção vegetal, qualidade pós-colheita, processamento mínimo e tecnologia de conservação de alimentos.

\section{HELOISA FARIAS GONZAGA}

Possui graduação em Radiologia pela Faculdade Maurício de Nassau - Campina Grande (2017). Pós-Graduanda em Oncologia pela Faculdade Única de Ipatinga. Atualmente é professora e supervisora pedagógica do Instituto Tecnológico da Paraíba - ITEC. Tem experiência na área de Biofísica, com ênfase em Radiologia e Fotobiologia.

\section{HERLLANGE CHAVES DE BRITO}

Graduada em Arquitetura e Urbanismo pela Universidade Federal da Paraíba (2005), Mestre em Engenharia Urbana e Ambiental pela Universidade Federal da Paraíba (2012) e Especialista em Light Design - Projetos Luminotécnico pela Universidade Castelo Branco-RJ (2008). Professora da Universidade Federal de Campina Grande (UFCG) - Campus Pombal (2016). Foi professora substituta da Universidade de Federal da Paraíba - UFPB (2007-2009), Professora Assistente do Centro Universitário de João Pessoa -UNJPE (2007-2013) e Professora Substituta do IFPB-CG (2013-2015). De 2005 até 2015 atuou como Sócia Diretora da empresa Arquitetura Criativa.

\section{HERUSCA HELLYCA SOUZA DE MEDEIROS}

Possui Graduação em Engenharia de Petróleo, pela Universidade Federal de Campina Grande. Experiência na área de Fluidodinâmica Computacional: realizou Estagio Integrado no Laboratório Computacional de Térmica e Fluido, localizado na Universidade Federal de Campina Grande, no Departamento de Engenharia Mecânica. Pós-graduanda em Engenharia de Segurança do Trabalho, pela Inovar Cursos. Já lecionou para o curso Técnico de Segurança do trabalho, no Instituto Educacional Particular Brasileiro. 


\section{ÍTALO DE ANDRADE GOMES}

Bacharel em Engenharia Mecânica pela Universidade Federal da Paraíba - UFPB. Especialista em Engenharia de Segurança do Trabalho, título obtido no Instituto de Educação Superior da Paraíba - IESP. Mestre em Engenharia Mecânica pelo Programa de Pós-Graduação em Engenharia Mecânica da Universidade Federal de Campina Grande - UFCG. Doutorando do Programa de Pós-Graduação em Engenharia de Processos pela Universidade Federal de Campina Grande - UFCG. Assistente administrativo da Universidade Estadual da Paraíba - UEPB. Perito judicial em reclamações trabalhistas de insalubridade e periculosidade - TRT PB.

\section{JOÃO MARCOS DOMINGUES BOTELHO}

Graduando em Engenharia Mecânica pela Universidade Federal de Campina Grande.

\section{JONAS FERNANDO DE SOUZA FERNANDES}

Técnico em Agroindústria pela Universidade Federal da Paraíba Campus III, onde também cursou o ensino médio integralmente (Bananeiras-PB, 2013). Graduado em Engenharia Mecânica pela Faculdade UNINASSAU (2018). Mestrando em Engenharia Mecânica na Universidade Federal de Campina Grande na área de Termofluidos onde vem desenvolvendo trabalhos com ênfase em energia solar térmica e transferência de calor e massa.

\section{JOSÉ JEFFERSON DA SILVA NASCIMENTO}

Possui graduação em Engenharia Mecânica pela Universidade Federal da Paraíba (1988), mestrado em Engenharia Mecânica pela Universidade Federal da Paraíba (1995) e doutorado em Engenharia Mecânica pela Universidade Federal da Paraíba (2002), também com formação em geração solar fotovoltaica: projeto, legislação e instalação. Atualmente é Professor Titular da Universidade Federal de Campina Grande e também docente e orientador de Doutorado no Programa de PósGraduação em Engenharia de Processos. Tem experiência na área de engenharia de matérias e metalúrgica, com ênfase em cerâmicos, atuando principalmente nos seguintes temas: secagem, experimental, cerâmica, simulação, fluidodinâmica.

\section{JOSIVANDA PALMEIRA GOMES}

Possui graduação em Engenharia Agrícola pela Universidade Federal da Paraíba (1989), mestrado em Engenharia Agrícola pela Universidade Federal da Paraíba (1992) e doutorado em Engenharia de Alimentos pela Universidade Estadual de Campinas (1999). Atualmente é professor titular da Universidade Federal de Campina Grande, Editora Associada da Revista Brasileira de Engenharia Agrícola, Coordenadora do Programa de Pós-Graduação da Unidade Acadêmica de Engenharia Agrícola do CTRN/UFCG, participante do Comitê de Ética da UFCG e do Comitê Assessor das Ciências Agrárias no CNPq. Tem experiência na área de Engenharia Agrícola, com ênfase em Processamento e Armazenamento de Produtos Agrícolas, atuando principalmente nos seguintes temas: secagem, armazenamento, atividade de água, pós-colheita e modelos matemáticos. 


\section{LARISSA FÉLIX MACÊDO}

Graduanda em Agronomia pela Universidade Federal de Campina Grande - UFCG. Bolsista no Programa Institucional de Bolsas de Iniciação Científica - PIBIC, CNPq desde 2019. Integrante do Grupo de pesquisa em Ciência, Tecnologia e Engenharia de Alimentos (GPCTEA).

\section{LÍGIA MARA GONZAGA}

Engenheira de Minas, pela Universidade Federal de Campina Grande - UFCG e Mestre em Engenharia Metalúrgica e de Materiais pela Universidade Federal do Rio de Janeiro-UFRJ. Atualmente professora do Instituto Federal do Rio Grande do Norte Campos de Parelhas. Trabalhou como pesquisadora do Programa de Desenvolvimento Tecnológico e Industrial no Centro de Tecnologia Mineral (CETEM) desenvolvendo projetos de pesquisa e desenvolvimento tecnológico nas áreas de Separação Magnética, Flotação e operações unitárias aplicadas no beneficiamento de minerais portadores de terras Raras, doutorado em andamento em Engenharia de processos pela Universidade Federal de Campina Grande - UFCG.

\section{MANUEL JOSÉ ANDRADE ROMERO}

Engenheiro Metalúrgico formado pela UNIVERSIDAD INTRUSTRIAL DE SANTANDER (2004), Mestre em Engenharia Metalúrgica UNIVERSIDAD INTRUSTRIAL DE SANTANDER (2008), Doutor em Engenharia Metalúrgica e de Materiais pela UNIVERSIDADE FEDERAL DO RIO DE JANEIRO- UFRJ/COPPE (Bolsista de doutorado CNPq no projeto de desenvolvimento de barreiras para a difusão do hidrogênio nos materiais metálicos ferrosos). Profissional com

capacidade cientifica, tecnológica e humanística para conduzir projetos de novas tecnologias suportadas no desenvolvimento e inovação científica, responsável, forte capacidade analítica e habilidades de comunicação verbal e escrita.

\section{MARCELLA MAYARA COSTA ARAÚJO ARAGÃO}

Graduada em Engenharia de Petróleo pela Universidade Federal de Campina Grande (2014), mestrado em Exploração Petrolífera e Mineral pela Universidade Federal de Campina Grande (2017), pós-graduação em Engenharia de Segurança do trabalho pela Faculdade Integrada de Patos (2016). Atualmente aluna de Doutorado em Engenharia de Processos pela Universidade Federal de Campina Grande, estudando dispersão de poluentes num sistema água - ar utilizando a fluidodinâmica computacional.

\section{MARCELO BEZERRA GRILO}

Possui Doutorado, Mestrado e Graduação em Engenharia Mecânica pela Universidade Federal da Paraíba (UFPB). Especialização em Matemática na PUC/MG. Iniciou o doutorado na área de Planejamento Energético no Programa de Pós-Graduação em Engenharia Elétrica em Campina Grande (COPELE), cursou disciplinas na USP (IEE/USP), fez estágio doutoral na França (INPT/TOULOUSE), defendeu a tese na UFPB. Tem experiência profissional como Engenheiro. Trabalhou no Grupo Votorantim e na Mercedes-Benz do Brasil. Foi professor universitário em várias instituições: PUC-MG (Vale do Aço), POLI-UPE e UFPE (Recife), UFAL (Maceió), atualmente é professor na Universidade Federal de Campina Grande UFCG. Consultor e perito especial na área automotiva/veicular. Trabalha com pesquisa 
na área de Aproveitamento de Energia, com ênfase em: energia solar, combustíveis e motores de combustão interna.

\section{MARIA DE SOUZA LEITE FILHA}

Possui graduação em Matemática pela Universidade Federal de Campina Grande (2010) e mestrado em Matemática pela Universidade de Brasília (2012). Atualmente é professora assistente da Universidade Federal de Campina Grande no Campus de Pombal/PB e aluna do Programa de Pós- Graduação em Engenharia de Processos pela Universidade Federal de Campina Grande.

\section{PABLO ANTONIO MAIA DE FARIAS}

Graduação em Farmácia pela Universidade Federal do Ceará (2000), mestrado em Ciências Farmacêuticas pela Universidade Federal do Ceará (2006) e doutorado em Desenvolvimento e Inovação Tecnológica de Medicamentos pela Universidade Federal do Ceará (2016). Avaliador do Banco de Avaliadores do Sistema Nacional de Avaliação da Educação Superior - BASis (MEC/INEP). Atualmente é farmacêutico - Secretaria de Saúde do Estado do Ceará e coordenador geral da pósgraduação "Lato Sensu" na Unileão. Tem experiência na área de Educação, com ênfase em Educação, atuando principalmente nos seguintes temas: atenção farmacêutica, uso de medicamentos, boas práticas, farmacoterapia, farmacologia e toxicologia.

\section{PLÍNIO TÉRCIO MEDEIROS DE AZEVEDO}

Engenheiro de Alimentos pela Universidade Federal de Campina Grande. Atualmente Mestrando em Sistemas Agroindustriais (UFCG) e Pós-graduando em Gestão e Engenharia de Produção (UCAM). Foi monitor de Microbiologia Geral, Microbiologia de Alimentos e Tecnologia de Materiais e Embalagens para Alimentos, além de bolsista de projeto de pesquisa PIBIC (CNPQ). Possui experiência na área de Ciência e Tecnologia de Alimentos, com ênfase em Microbiologia de Alimentos, Aditivos e Tecnologia de Embalagens.

\section{RAQUEL MARQUES DOS SANTOS}

Possui graduação em Engenharia de pesca pela Universidade do Estado da Bahia (UNEB) (2012), atuando principalmente nos seguintes temas: alimento, tilápia, reservatório, criação, reprodução, pesquisa, tanque-rede, universo dos ambientes aquáticos e raceways. Possui mestrado em Engenharia química pela Universidade Federal de Pernambuco (UFPE), atuando principalmente na área dos polímeros, aproveitamento de resíduos sólidos derivados de pescados na incorporação de polímeros, caracterização e aditivação de polímeros, concluiu a seguinte pesquisa: Avaliação da Estabilidade de Filmes de PVC aditivado com Quitosana. Possui Doutorado em Engenharia de Processos na Universidade Federal de Campina Grande (UFCG), atuando nas áreas de processamento, modelagem, simulação e caracterização de polímeros com a seguinte pesquisa: Preparação e Propriedades de blendas de PET Pós-consumo/PEAD Compatibilizados com PE-g- MA Extensor de Cadeia Epoxídico. Atualmente cursa o sexto período em Licenciatura em química na Universidade Estadual da Paraíba (UEPB). 


\section{RENATO ALEXANDRE COSTA DE SANTANA}

Possui graduação em Química Industrial pela Universidade Estadual da Paraíba (2000), graduação em Licenciatura Plena em Química pela Universidade Estadual da Paraíba (2006), mestrado em Engenharia Química pela Universidade Federal de Campina Grande (2003) e doutorado em Engenharia de Processos pela Universidade Federal de Campina Grande (2007). Atualmente é professor Adjunto da Universidade Federal de Campina Grande. Tem experiência na obtenção e caracterização de revestimentos metálicos contendo molibdênio e tungstênio com os metais do grupo do ferro obtidos pelo processo de eletrodeposição. Possui experiência no estudo de corrosão de ligas com memória de forma e de biomateriais. Tem experiência na obtenção e caracterização de revestimentos obtidos pelo processo de soldagem. O pesquisador participa como membro permanente do Programa de Pós-Graduação em Engenharia Mecânica da Universidade Federal de Campina Grande. Desenvolve pesquisa na obtenção de produtos agroindústrias sustentáveis pelo processo de secagem e pelo processo do enriquecimento proteico de cactáceas, frutas e vegetais.

\section{RUBENIA DE OLIVEIRA COSTA}

Graduada em Administração pela Universidade Federal da Paraíba (2015). Mestre em Sistemas Agroindustriais pela Universidade Federal de Campina Grande (2016). Doutoranda em Engenharia de Processos pela Universidade Federal de Campina Grande. Atualmente é Professora da Unidade Acadêmica de Ciências Contábeis da Universidade Federal de Campina Grande. Possui experiência nas áreas de administração e economia, com ênfase em administração da produção e operações, economia rural, economia, empreendedorismo e sustentabilidade.

\section{SEVERINO RODRIGUES DE FARIAS NETO}

Graduado em Engenharia Química pela Universidade Federal da Paraíba (1988), mestrado em Engenharia Química pela Universidade Federal da Paraíba (1992) e doutorado em Engenharia de Processos pela Universidade de Nantes (1997). Atualmente é Professor de Magistério Superior da Classe E - Titular da Universidade Federal de Campina Grande. Tem experiência na área de Engenharia Química, com ênfase em Operações de Separação e Mistura, atuando principalmente nos seguintes temas: fluidodinâmica computacional, escoamentos multifásicos (separação água/óleo - gás/sólido; transporte de gás/óleo e água/óleo; escoamento em meios porosos - membranas cerâmicas e reservatórios petrolíferos; entre outros).

\section{TATIANA MARINHO GADELHA}

Graduada em Ciências Biológicas pela Universidade Federal de Campina Grande (UFCG) - Campus Cajazeiras.

\section{VICTOR VINICIUS LINS NUNES}

Biomédico formado pelas Faculdades Integradas de Patos - FIP. Especialista em Microbiologia Clínica pelas Faculdades Integradas de Patos - FIP. Professor no Instituto Tecnológico da Paraíba (ITEC Mais) - Unidade Patos/PB. 


\section{WILSON LUIZ DOS SANTOS FILHO}

Doutorando em Engenharia de Processos pela Universidade Federal de Campina Grande, Mestre em Matemática pelo PROFMAT (2015), Especialista em Ensino de Matemática pela FURNE/UNIPÊ (2014) e possui graduação em Licenciatura em Ciências Exatas pela Universidade de São Paulo (2003), com Habilitação em Matemática. Atua como professor de Matemática no Instituto Federal de Educação, Ciência e Tecnologia da Paraíba (IFPB). Foi professor das redes Privada e Estadual de Ensino da Paraíba e da rede Estadual de Ensino de São Paulo, nas cidades de Campina Grande e São Carlos. Foi professor de Raciocínio Lógico e Matemática Financeira em cursos preparatórios para Concursos Públicos. Foi professor no curso de Física Teórica e Experimental EXPERIMENTU.

\section{YÊDA MEDEIROS BASTOS DE ALMEIDA}

Possui graduação em Engenharia Química pela Universidade Federal de Pernambuco (1986), mestrado em Engenharia Química pela Universidade Estadual de Campinas (1991) e doutorado em Química de Materiais - Universite de Montpellier II (Scien. et Tech Du Languedoc), França (1996). Professora Titular do Departamento de Engenharia Química, pesquisadora com experiência na área de Engenharia Química, com ênfase em Polímeros, atuando principalmente nos seguintes temas: degradação e estabilização de polímeros, polímeros biodegradáveis, modificação de polímeros, blendas poliméricas, reciclagem de polímeros, biodiesel e biocorrosão. 


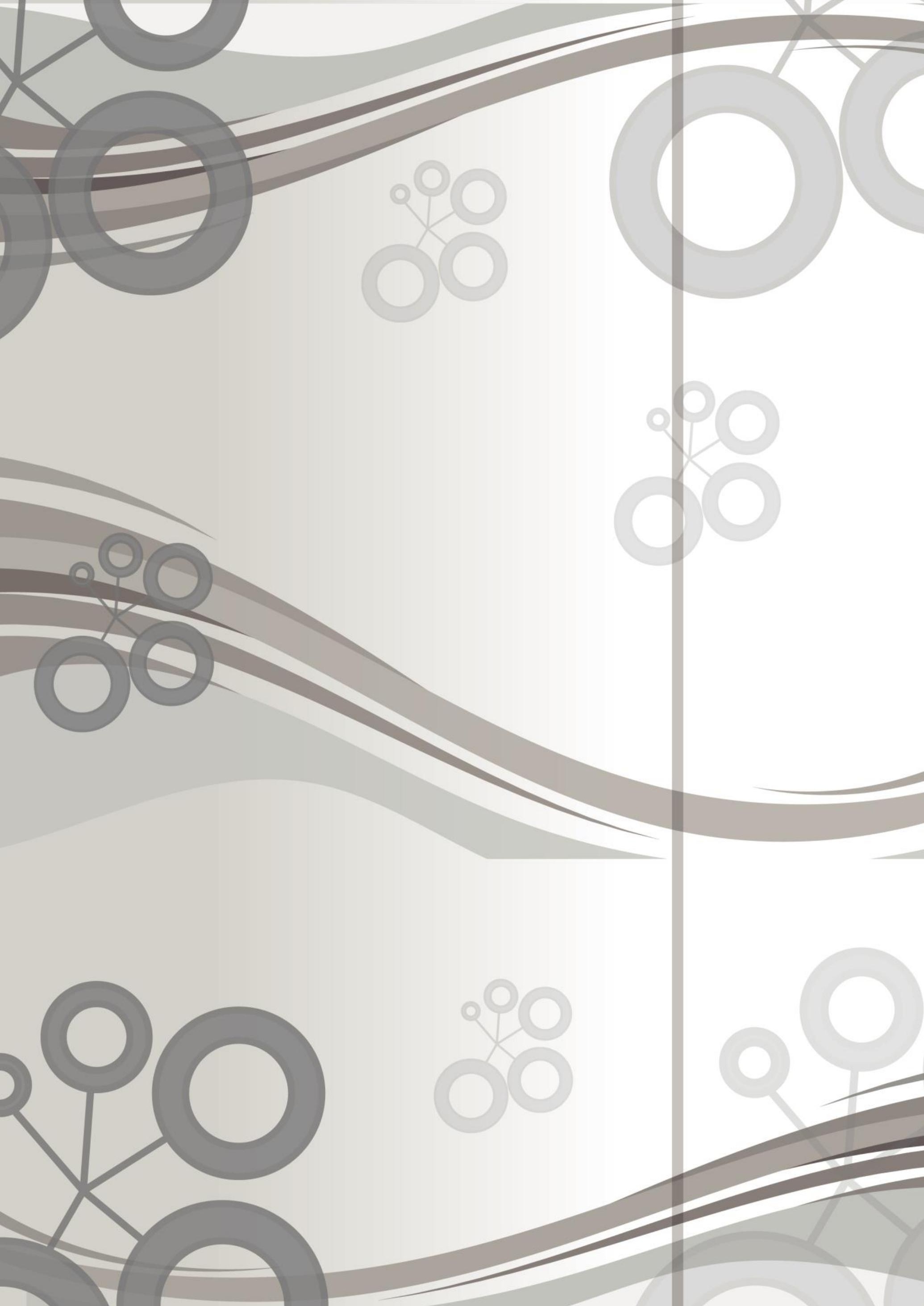

